ÉCOLE DE TECHNOLOGIE SUPÉRIEURE UNIVERSITÉ DU QUÉBEC

THESIS PRESENTED TO

ÉCOLE DE TECHNOLOGIE SUPÉRIEURE

IN PARTIAL FULFILLMENT OF THE REQUIREMENTS FOR

A MASTER'S DEGREE ENGINEERING

M. Eng.

BY

Hossein HAMEDANIANPOUR

EFFECT OF TOOL WEAR ON QUALITY OF CARBON FIBER REINFORCED POLYMER LAMINATE DURING EDGE TRIMMING

MONTREAL, OCTOBER $16^{\mathrm{TH}}, 2013$

(C) Copyright 2013 reserved by Hossein Hamedanianpour 
(C) Copyright reserved

It is forbidden to reproduce, save or share the content of this document either in whole or in parts. The reader who wishes to print or save this document on any media must first get the permission of the author. 
BOARD OF EXAMINERS THESIS M. ENG

THIS THESIS HAS BEEN EVALUATED

BY THE FOLLOWING BOARD OF EXAMINERS

Mr. Jean François Chatelain, Thesis Supervisor

Department of Mechanical Engineering at École de technologie supérieure

Mr. Victor Songmene, President of the Board of Examiners

Department of Mechanical Engineering at École de technologie supérieure

Mr. Marek Balazinski Member of the jury

Department of Mechanical Engineering at École Polytechnique de Montréal

THIS THESIS WAS PRENSENTED AND DEFENDED

IN THE PRESENCE OF A BOARD OF EXAMINERS AND PUBLIC

SEPTEMBER $18^{\mathrm{TH}}, 2013$

AT ÉCOLE DE TECHNOLOGIE SUPÉRIEURE 



\section{ACKNOWLEDGMENT}

I would like to thank my research director, Professor Jean-François Chatelain for his support, guidance and financial support that helped me to stay focused on this work. Also I would like to thank Réjean Roy who helped me to perform machining process at Centre Technologique en Aérospatiale (CTA). In addition, my acknowledge goes to Sébastien Bérubé who proposed the best operational condition ranges for similar tool and composite materials.

The experiments were carried out at CTA. Moreover, this work was funded by the Consortium for Research and Innovation in Aerospace in Québec (CRIAQ) and its partners, the Natural Sciences and Engineering Research Council of Canada (NSERC), MITACS, Bombardier Aerospace, Avior Integrated Products, Delastek and AV\&R Vision \& Robotics. I also acknowledge the committee members, Prof. Victor Songmene, president of the board of examiners and Prof. Marek Balazinski, member of the jury for taking time to review my work. Finally I would like to thank my parents and especially, my wife, Marjan for giving me the emotional support. 



\title{
EFFECT OF TOOL WEAR ON QUALITY OF CARBON FIBER REINFORCED POLYMER LAMINATE DURING EDGE TRIMMING
}

\author{
Hossein HAMEDANIANPOUR
}

\section{RÉSUMÉ}

Les matériaux Composites, en particulier les polymères renforcés de fibres de carbone sont largement utilisés dans l'industrie de haute technologie, notamment l'aérospatiale, l'automobile et l'énergie éolienne. En général, lorsque ces matériaux sont fabriquées aux formes et dimensions près des cotes «near net shape ", des opérations de parachèvement telles le détourage, le fraisage et le perçage sont utilisées pour éliminer la matière en excès et pour assurer les requis pour l'assemblage final des composantes. La qualité de ces opérations de finition ainsi que leur coût sont donc critiques dans le processus manufacturier. La présente recherche étudie l'effet de l'usure des outils de coupe sur la qualité produite en détourage de stratifiés composites haute performance en fibres de carbone-époxy (CFRP) utilisés dans l'industrie aérospatiale. Les paramètres de qualité évalués dans cette recherche constituent la rugosité de surface ainsi que l'intégrité du matériau obtenue suite à la coupe (fibres non coupées, arrachement de fibres, délaminage et endommagent thermique de la matrice). Ces types de défaut sont reconnus comme altérant la performance mécanique des stratifiés. Dans cette étude, un outil en carbure revêtu de diamant (CVD) ayant un diamètre de $3 / 8$ pouce et six flutes a été utilisé pour le détourage de stratifiés de 24 plis avec séquence d'empilement offrant des propriétés quasi-isotropes. Les vitesses de coupe considérées dans l'étude sont de 200, 300 et $400 \mathrm{~m}$ / min alors que les vitesses d'avance sont de 0.3048, 0.3556 et $0.4064 \mathrm{~mm} / \mathrm{tr}$. L'évaluation de la qualité des surfaces obtenues a été effectuée à l'aide d'un microscope électronique à balayage (MEB) ainsi que d'un profilomètre tactile. Les résultats montrent que les défauts de surface augmentent avec l'usure des outils. Les moins bons états d'intégrité de matériel, où on retrouve fissures de la matrice, arrachement de fibres et cavités ont été observés pour les plis orientés à $-45^{\circ}$ degrés. Pour le fini de surface, il a été observé qu'une augmentation de l'usure des outils diminue la rugosité de surface. En ce qui concerne l'usure des outils, un taux plus bas a été observé à des valeurs plus faibles d'avance et des 
VIII

vitesses de coupe plus élevées, tandis qu'un taux plus élevé d'usure d'outil a été observé aux valeurs intermédiaires des plages d'avance et de vitesse de coupe testées.

Mots-clés: Composite, CFRP, Détourage, Usure des outils, Qualité de surface 


\title{
EFFECT OF TOOL WEAR ON QUALITY OF CARBON FIBER REINFORCED POLYMER LAMINATE DURING EDGE TRIMMING
}

\author{
Hossein HAMEDANIANPOUR
}

\begin{abstract}
Polymer matrix composites, especially carbon fiber reinforced polymers (CFRPs) are vastly used in different high technology industries, including aerospace, automotive and wind energy. Normally, when CFRPs are cured to near net shape, finishing operations such as trimming, milling or drilling are used to remove excess materials. The quality of these finishing operations is highly essential at the level of final assembly. The present study aims to study the effect of cutting tool wear on the resulting quality for the trimming process of high performance CFRP laminates, in the aerospace field. In terms of quality parameters, the study focuses on surface roughness and material integrity damages (uncut fibers, fiber pullout, delamination or thermal damage of the matrix), which could jeopardize the mechanical performance of the components. In this study, a 3/8 inch diameter CVD diamond coated carbide tool with six flutes was used to trim 24-ply carbon fiber laminates. Cutting speeds ranging from $200 \mathrm{~m} / \mathrm{min}$ to $400 \mathrm{~m} / \mathrm{min}$ and feed rates ranging from $0.3048 \mathrm{~mm} / \mathrm{rev}$ to $0.4064 \mathrm{~mm} / \mathrm{rev}$ were used in the experiments. The results obtained using a scanning electron microscope (SEM) showed increasing defect rates with an increase in tool wear. The worst surface integrity, including matrix cracking, fiber pull-out and empty holes, was also observed for plies oriented at $-45^{\circ}$ degrees. For the surface finish, it was observed that an increase in tool wear resulted in a decrease in surface roughness. Regarding tool wear, a lower rate was observed at lower feed rates and higher cutting speeds, while a higher tool wear rate was observed at intermediate values of our feed rate and cutting speed ranges.
\end{abstract}

Keywords: Composite, CFRP, Trimming, Tool wear, Surface quality 



\section{TABLE OF CONTENTS}

INTRODUCTION

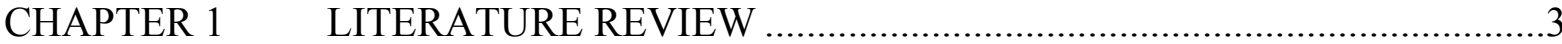

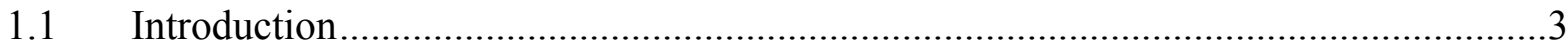

1.2 Mechanical properties of CFRPs .........................................................................

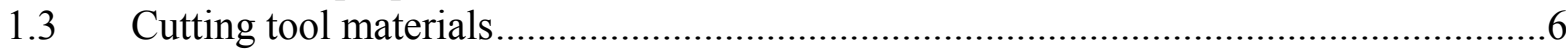

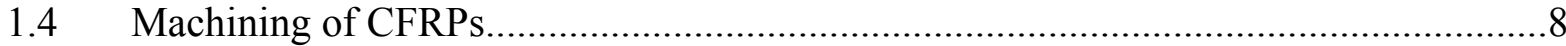

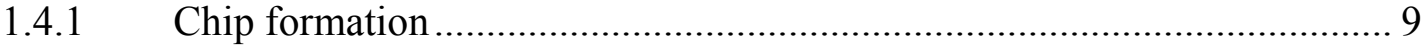

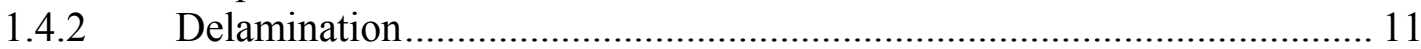

1.4.3 Surface quality and surface damage ............................................... 15

1.4.4 Effect of trimming operation on the mechanical properties ..................... 19

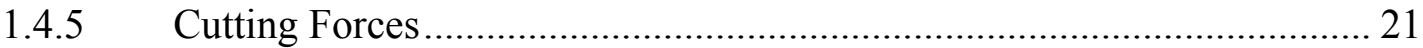

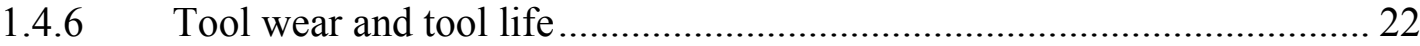

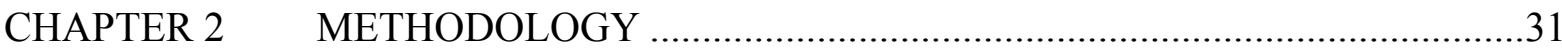

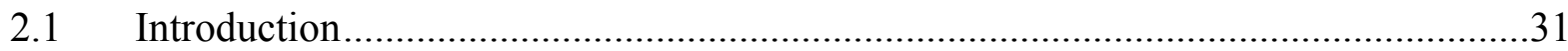

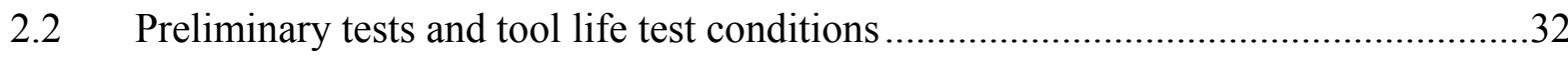

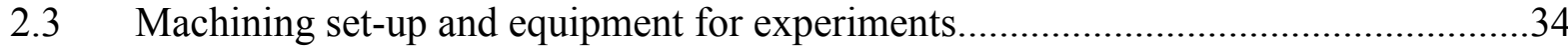

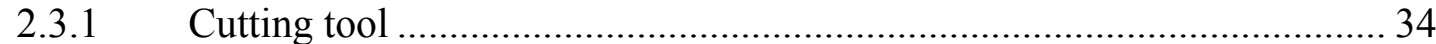

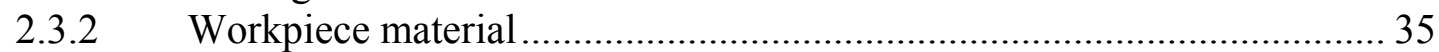

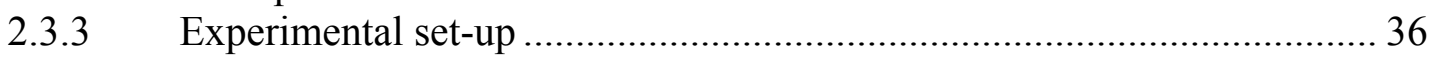

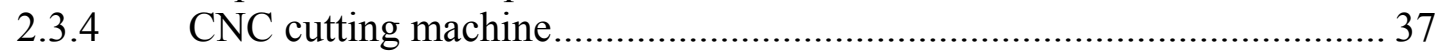

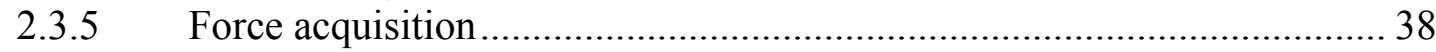

2.4 Measurement set-up and equipment for quality evaluation ..................................40

2.4.1 Roughness measurement............................................................... 40

2.4.2 Tool wear measurement .................................................................... 43

2.4.3 Surface integrity evaluation ........................................................ 45

CHAPTER 3 STUDY AND MODELING OF MACHINING

PARAMETERS EFFECT ON CUTTING FORCES

AND SURFACE ROUGHNESS (PRELIMINARY TESTS) ..................49

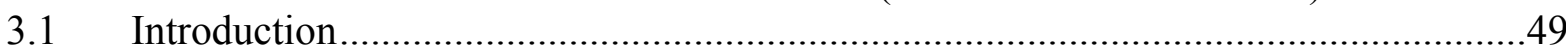

3.2 Influence of cutting parameters on Fx (Normal force) ..........................................51

3.3 Influence of cutting parameters on Fy (Feed force) ...........................................53

3.4 Influence of cutting parameters on Fz (Axial force) ................................................55

3.5 Influence of cutting parameters on Ft (Total force) ...............................................57

3.6 Influence of cutting parameters on $\mathrm{Ra}$ (Surface roughness) ...................................59

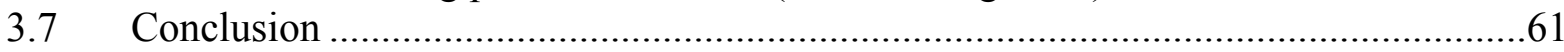

$\begin{array}{ll}\text { CHAPTER } 4 & \text { TOOL WEAR EFFECT ON QUALITY OF } \\ & \text { TRIMMED LAMINATES } \ldots \ldots \ldots \ldots \ldots \ldots \ldots \ldots \ldots \ldots \ldots \ldots \ldots \ldots \ldots \ldots \ldots \ldots \ldots \ldots \ldots \ldots \ldots \ldots \ldots \ldots \ldots \ldots \ldots \ldots \ldots \ldots \ldots \ldots \ldots\end{array}$

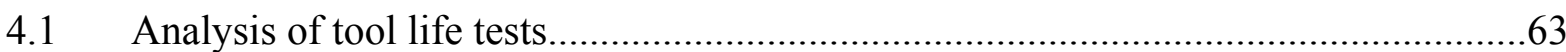

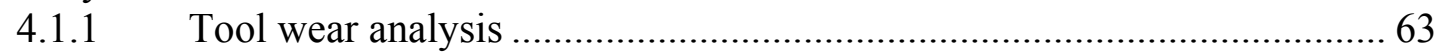


4.1.2 Effect of fiber orientation on tool wear profile ................................... 71

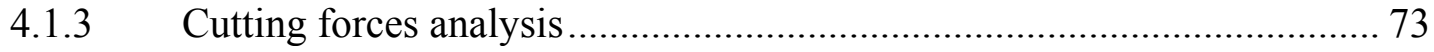

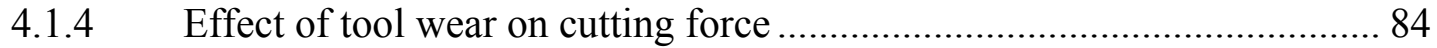

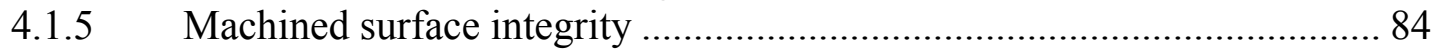

4.1.6 Excessive tool wear and material integrity ......................................... 91

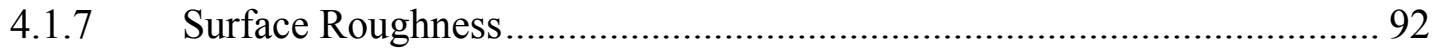

4.1.8 Effect of tool wear on roughness ................................................. 100

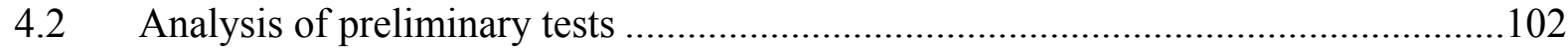

4.2.1 Effect of cutting conditions on cutting forces durin

g trimming using new tool ............................................................. 102

4.2.2 Effect of cutting conditions on surface roughness during

trimming using new tool ......................................................... 103

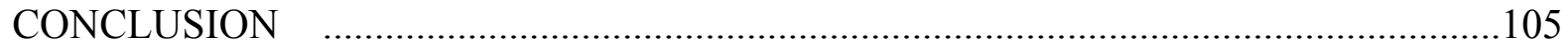

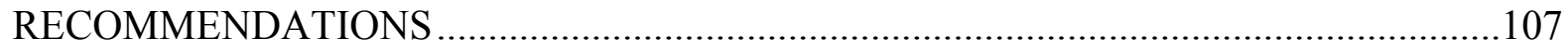

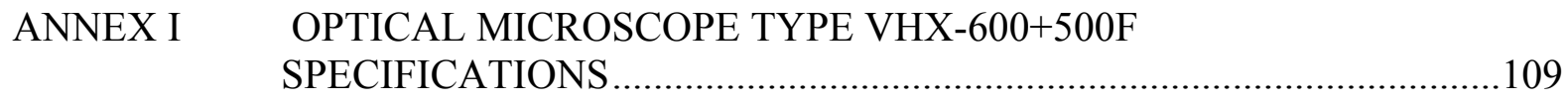

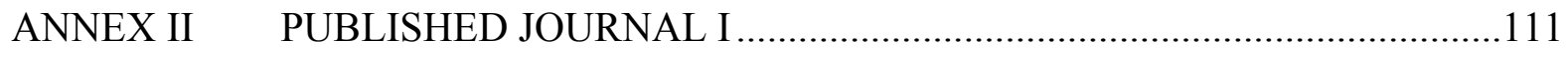

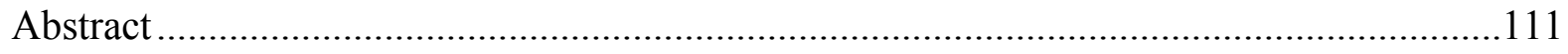

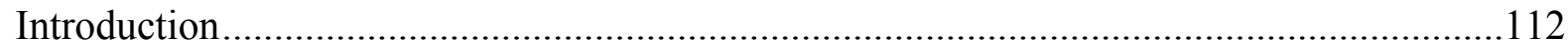

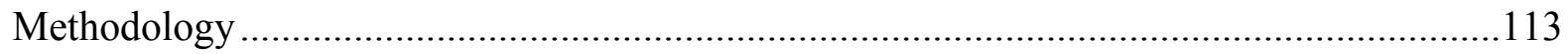

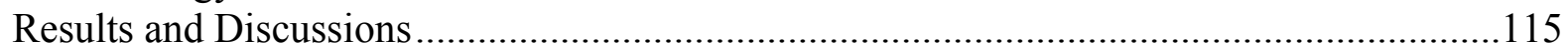

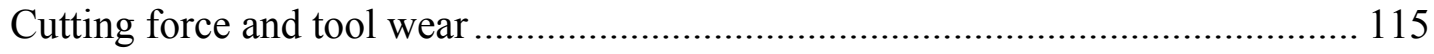

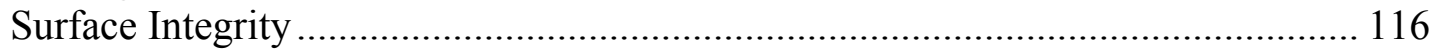

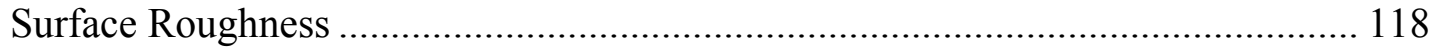

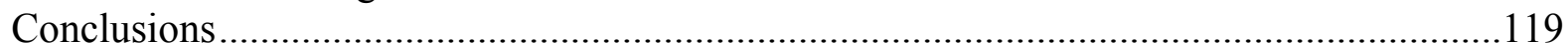

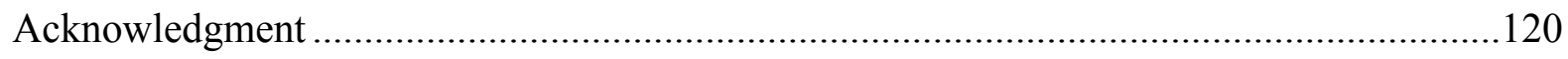

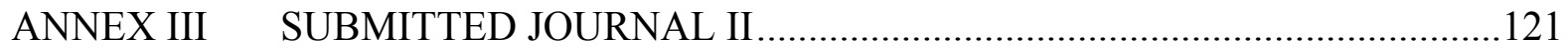

LIST OF BIBLIOGRAPHICAL REFERENCES ......................................................139 


\section{LIST OF TABLES}

Table 2.1

Table 2.2

Table 2.3

Table 2.4

Table 2.5

Table 2.6

Table 3.1

Table 3.2

Table 3.3

Table 3.4

Table 3.5

Table 3.6

Table 3.7

Table 3.8

Table 4.1

Table 4.2

Table 4.3

Table 4.4

Table 4.5
Cutting conditions of preliminary tests. 33

Parameters of tool life experiments .34

Cutting tool specifications .34

CNC machine specifications..... .38

Parameters of roughness measurement. .43

Scanning electron microscope specifications . .47

Independent variables .50

Dependent variables .50

Values of cutting forces and $\mathrm{Ra}$ as a function of the cutting parameters. .50

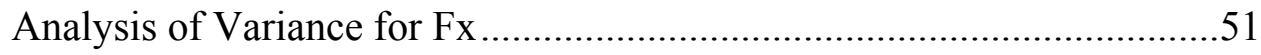

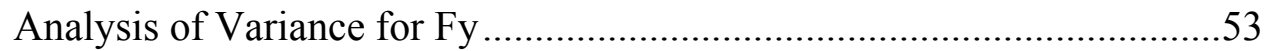

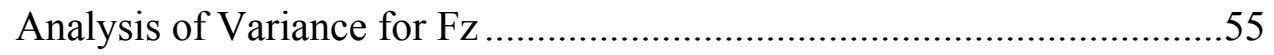

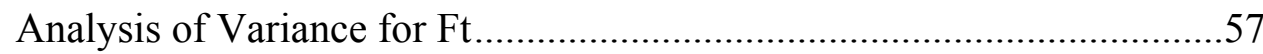

Analysis of Variance for Ra......

Average tool wear, tool wear of teeth, maximum VBmax and their related cutting lengths during Test 1

(Feed: $1524 \mathrm{~mm} / \mathrm{min}$, Speed: $400 \mathrm{~m} / \mathrm{min}$ ).

Average tool wear, tool wear of teeth, maximum

VBmax and their related cutting lengths during Test 2

(Feed: $2794 \mathrm{~mm} / \mathrm{min}$, Speed: $300 \mathrm{~m} / \mathrm{min}$ ) .65

Average tool wear, tool wear of teeth, maximum VBmax and their related cutting lengths during Test 3 (Feed: $4064 \mathrm{~mm} / \mathrm{min}$, Speed: $200 \mathrm{~m} / \mathrm{min}$ ) .66

Average cutting forces and their related cutting lengths in Test 1 .75 Average cutting forces and their related cutting lengths in Test 2 . .76 
XIV

Table 4.6 Average cutting forces and their related cutting lengths in Test $3 \ldots \ldots . . . . .77$

Table 4.7 Average roughness $\mathrm{Ra}, \mathrm{Rt}, \mathrm{Rv}$ and their related..................................94

Table 4.8 Average roughness Ra, Rt, Rv and their related ................................95

Table 4.9 Average roughness Ra, Rt, Rv and their related...................................96

Table 4.10 Total cutting forces for different cutting ........................................103

Table 4.11 Roughness for different cutting speeds .........................................104 


\section{LIST OF FIGURES}

Page

Figure 1.1

Longitudinal strength/ultimate.......................................................4

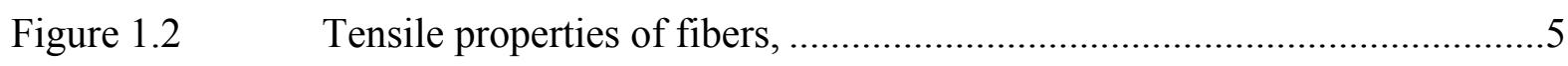

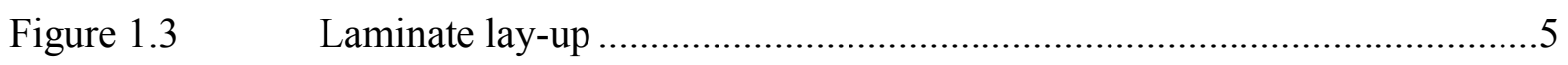

Figure $1.4 \quad$ Up milling and down milling modes ..............................................8

Figure $1.5 \quad$ Chip formation modes of CFRP ….............................................. 10

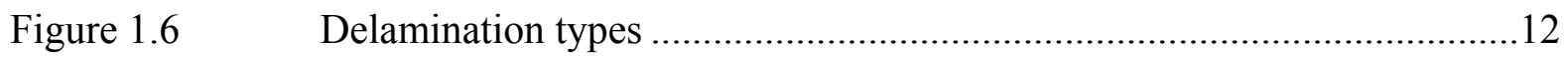

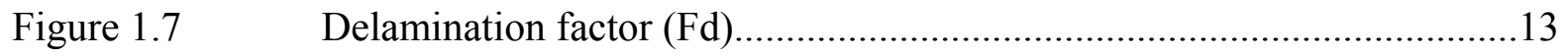

Figure $1.8 \quad$ Effect of type of operation on surface quality ...................................14

Figure 1.9 Longitudinal and transverse directions of surface roughness measurement ............................................................................... 16

Figure 1.10 Variation of surface roughness with fiber orientation at .........................19

Figure $1.11 \quad$ Effect of cutting tool material on ....................................................20

Figure $1.12 \quad$ Effect of cutting speed on failure ........................................................20

Figure 1.13 Effect of cutting speed on tool wear in turning of CFRPs.......................23

Figure $1.14 \quad$ Effect of tool wear on delamination of .............................................24

Figure $1.15 \quad$ Tool wear diagram for the $6 \%$ Co micrograin ....................................25

Figure 1.16 Milling tool (a) Z14-12 and (b) Z14-11 ........................................26

Figure $1.17 \quad$ (a) The machined laminates using new tool; (b) ...................................26

Figure $1.18 \quad$ Machining in a) the room temperature (RT) ....................................27

Figure 2.1 Cutting process in each tool life test ..................................................32

Figure 2.2 Experimental a) short cut set-up and b) long cut set-up ..........................32

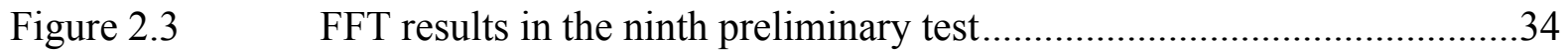

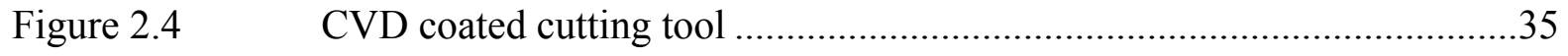


Figure 2.5 Stacking sequence of CFRP laminate …........................................

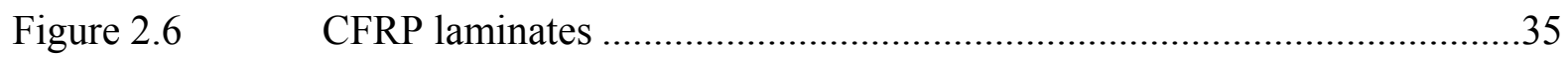

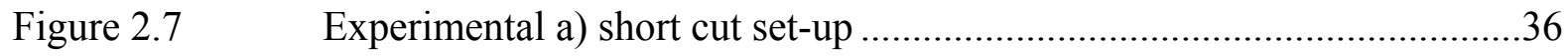

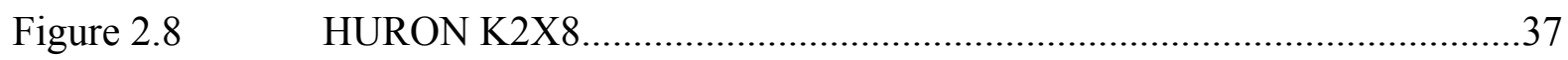

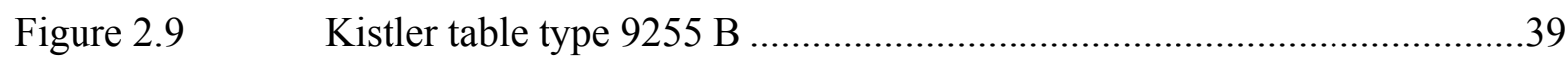

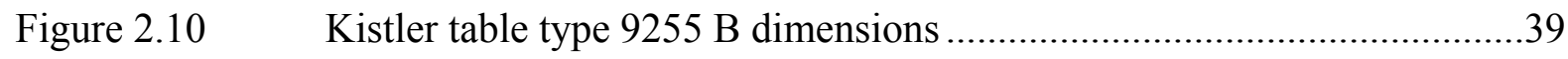

Figure 2.11 Comparison of 2 plies for 3 samples at different cutting conditions ..................................................................... 41

Figure 2.12 Profilometer Mitutoyo type SJ 400 SURFPAK .....................................42

Figure $2.13 \quad$ Longitudinal and transverse .......................................................42

Figure 2.14 Tool holder including cutting tool mounted ........................................44

Figure 2.15 Measurement of tool wear (VBmax) ............................................44

Figure 2.16 Optical microscope type Keyence ................................................45

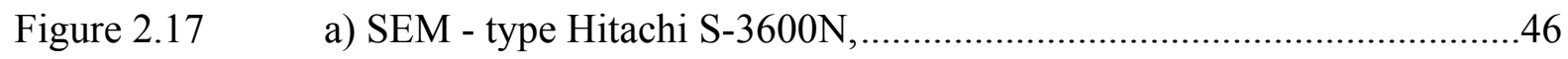

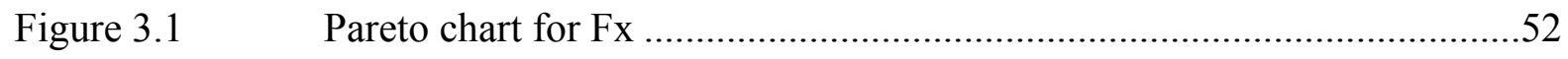

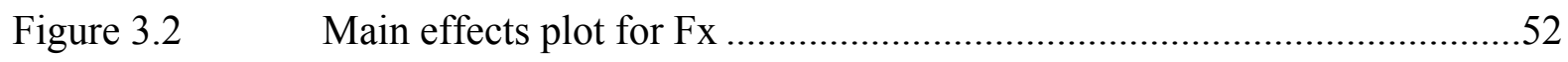

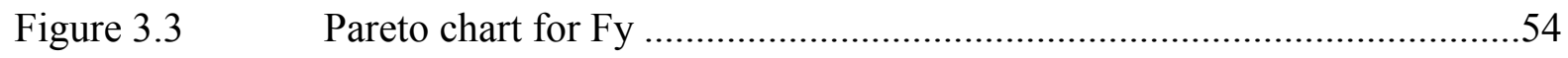

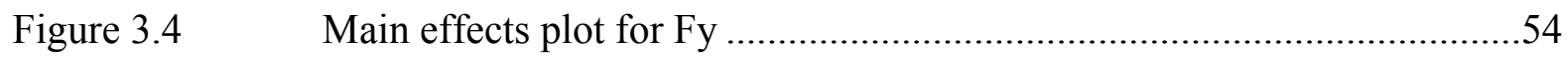

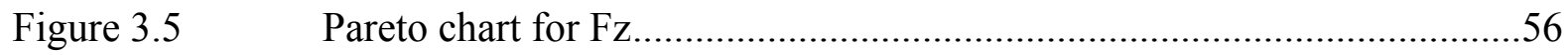

Figure $3.6 \quad$ Main effects plot for Fz..............................................................56

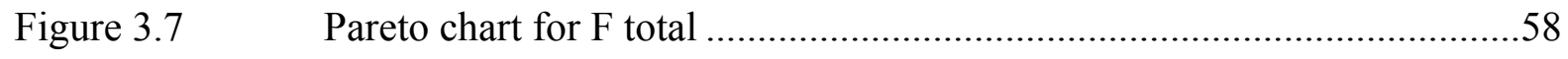

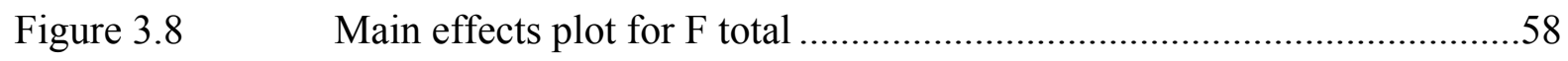

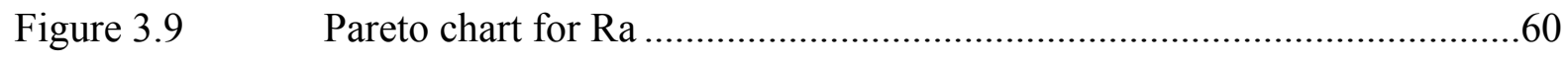

Figure $3.10 \quad$ Main effects plot for Ra .............................................................60 
Figure 4.1

Figure 4.2

Figure 4.3

Figure 4.4

Figure 4.5

Figure 4.6

Figure 4.7

Figure 4.8

Figure 4.9

Figure 4.10

Figure 4.11

Figure 4.12

Figure 4.13

Figure 4.14

Figure 4.15

Figure 4.16

Figure 4.17

Figure 4.18

Figure 4.19

Figure 4.20

Figure 4.21
Tool wear at a) 0, b) 4, c) 9, d) 15.8 , e) 27.2 and f) 28.2 meters of cut for Tooth \#5 in Test 1 (Feed: $1524 \mathrm{~mm} / \mathrm{min}$, Speed: $400 \mathrm{~m} / \mathrm{min}$ ) .67

Tool wear at a) 0, b) 4, c) 9, d) 12, e) 14 and f) 15 meters of cut for .68

Tool wear at a) 0, b) 4, c) 9, d) 14, e) 19 and f) 20 meters of cut for .69

Average tool wear as a function of cutting length for Test $1-3 \ldots \ldots \ldots \ldots \ldots . . .70$

Maximum VBmax as a function of cutting length for Test 1-3. 71 Effect of fiber orientation on tool wear for:

a) Test 1 (Feed: $1524 \mathrm{~mm} / \mathrm{min}$, Speed: $400 \mathrm{~m} / \mathrm{min}$ ),

b) Test 2 (Feed: $2794 \mathrm{~mm} / \mathrm{min}$, Speed: $300 \mathrm{~m} / \mathrm{min}$ ), .72

One tool cutting revolution for new six teeth .74

Tool engagement process for new six teeth ..........................................74

Average forces in $\mathrm{x}, \mathrm{y}$ and $\mathrm{z}$ directions and average total ......................78

Average forces in $\mathrm{x}, \mathrm{y}$ and $\mathrm{z}$ directions and average total ......................79

Average forces in $\mathrm{x}, \mathrm{y}$ and $\mathrm{z}$ directions and average total ......................79

Average normal forces as a function of cutting length in Test $1-3 \ldots \ldots \ldots . . . .80$

Average feed forces as a function of cutting length in Test 1-3 ..............80

Average axial forces as a function of cutting length in Test $1-3$.............81

Average total forces as a function of cutting length in Test $1-3$..............81

Recorded forces in $\mathrm{x}-, \mathrm{y}$ - and $\mathrm{z}$-directions using new and worn tools .......82

Recorded forces in $\mathrm{x}-, \mathrm{y}$ - and $\mathrm{z}$-directions using new and worn tools .......83

Recorded forces in $\mathrm{x}-, \mathrm{y}$ - and $\mathrm{z}$-directions using new and worn tools .......83

Total cutting forces as a function of tool wear in Test 1-3 .84

a) New tool, b) Worn tool $(14100 \mathrm{~mm})$ in Test 2 ................................86

Trimmed surface after 14.1 meters of cutting length in

a) Test 1 (Feed: $1524 \mathrm{~mm} / \mathrm{min}$, Speed: $400 \mathrm{~m} / \mathrm{min}$ ),

b) Test 2 (Feed: $2794 \mathrm{~mm} / \mathrm{min}$, Speed: $300 \mathrm{~m} / \mathrm{min}$ ), .87 
Figure 4.22 SEM micrographs of trimmed surface after a) 0.1, b) 4.1, c) 9.1, d) 15.9 ,

Figure 4.23 SEM micrographs of Trimmed surface after a) 0.1, b) 4.1,

c) 9.1, d) 14.1

Figure 4.24 SEM micrographs of trimmed surface after a) 0.1, b) 4.1, c) 9.1 , d) 14.1 , . .90

Figure $4.25 \quad$ a) Smoke from burnt matrix, b) Burnt matrix in Test 2 ...........................91

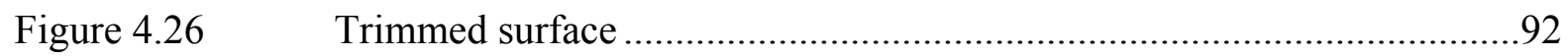

Figure 4.27 The machined surfaces of two coupons ..................................................93

Figure 4.28 Surface roughness a) Rt and Rv, b) Ra as..............................................97

Figure 4.29 Surface roughness a) Rt and $\mathrm{Rv}, \mathrm{b}$ ) $\mathrm{Ra}$ as a function.................................98

Figure 4.30 Surface roughness a) Rt and $\mathrm{Rv}, \mathrm{b}$ ) $\mathrm{Ra}$ as a function of ...........................99

Figure 4.31 Surface roughness, Ra as a function of cutting in Test 1-3 …................100

Figure 4.32 Effect of Tool Wear on Roughness in Test 1........................................101

Figure 4.33 Effect of Tool Wear on Roughness in Test 2.......................................101

Figure 4.34 Effect of Tool Wear on Roughness in Test 3........................................102

Figure 4.35 Effect of cutting speed and feed rate on average cutting .......................103

Figure 4.36 Effect of cutting speed and feed rate on................................................104 


\section{LIST OF ABREVIATIONS}

$\begin{array}{ll}\text { CFRP } & \text { Carbon Fiber Reinforced Polymer } \\ \text { FRP } & \text { Fiber Reinforced Polymer } \\ \text { GFRP } & \text { Glass Fiber Reinforced Polymer } \\ \text { MMC } & \text { Metal Matrix Composite } \\ \text { CMS } & \text { Ceramic Matrix Composite } \\ \text { PMC } & \text { Polymer Matrix Composite } \\ \text { CVD } & \text { Chemical Vapor Deposition } \\ \text { PVD } & \text { Physical Vapor Deposition } \\ \text { CBN } & \text { Cubic Boron Nitride } \\ \text { WC } & \text { Tungsten Carbide } \\ \text { PCBN } & \text { Polycrystalline Cubic Boron Nitride } \\ \text { CCD } & \text { Charge Coupled Device } \\ \text { FFT } & \text { Fast Fourier Transform } \\ \text { SEM } & \text { Scanning Electron Microscope } \\ \text { ANOVA } & \text { Analysis of Variance }\end{array}$





\section{LIST OF SYMBOLS}

$\begin{array}{ll}\text { Fx } & \text { Cutting Force in X-Direction } \\ \text { Fy } & \text { Cutting Force in Y-Direction } \\ \mathrm{Fz} & \text { Cutting Force in Z-Direction } \\ \mathrm{Ft} & \text { Total cutting force } \\ \mathrm{Fd} & \text { Delamination Factor } \\ \mathrm{Ra} & \text { Arithmetic Average } \\ \mathrm{Rv} & \text { Maximum Valley Depth } \\ \mathrm{Rt} & \text { Maximum Height Profile } \\ \mathrm{Rp} & \text { Maximum Peak Height } \\ \mathrm{Ry} & \text { Maximum Peak } \\ \mathrm{Rz} & \text { Ten-Point Mean } \\ \mathrm{Rq} & \text { Root Mean Squared } \\ \mathrm{Vbmax} & \text { Maximum Flank Wear } \\ \mathrm{Ga} & \text { Grey Scale Value }\end{array}$





\section{INTRODUCTION}

The present research aims to study the effect of tool wear on the surface quality of machined laminates following routing of CFRP. A composite is a material composed of two or more materials that make it stronger and stiffer than the individual components used separately. Its components are reinforcement and matrix. The matrix has many important functions, including keeping the fibers in the proper orientation and protecting the fibers from abrasion and environment such as cold, heat, moisture. The reinforcement controls strength and stiffness of a composite. In most cases, the reinforcement is stronger than the matrix, meaning that fibers undergo the primary load and the matrix distributes the applied load. In general, reinforcement materials are carbon fiber, glass, boron and ceramic. Matrix materials are metal, ceramic and polymer. Based on matrix material, the composites are categorized into three groups: metal matrix composite (MMC), ceramic matrix composite (CMS) and polymer matrix composite (PMC) (Campbell, 2010).

This study focuses on the polymer matrix composites especially the carbon fiber reinforced plastic composites (CFRPs). They are used massively in aerospace, automotive, wind energy and other high-technology industries since the fiber reinforced polymer composites have lots of advantages including high fatigue strength, high specific strength, high specific modulus, corrosion resistance and also lighter weight that allows us energy saving. The composites are

produced near-net shape; they withstand finishing operations to meet the dimensional requirements for assembly process. The finishing operations are such as trimming, drilling and turning in which the trimming is a major machining operation for CFRPs in aerospace industries while they encounter many machine surface problems such as matrix cracking, fiber fracture, fiber pull-out and interlaminar delamination due to their inhomogeneous nature. Surface quality has great effect on machined components which are coming in contact with each other for final assembly. So, it becomes important to evaluate and study the machined surface and its behavior. Quality of the machined surface can be evaluated by the surface integrity, surface roughness and delamination depth.

Tool condition plays an important role in surface quality. The tool may continue to cut the 
composite and tool life may not be finished while quality of machining can't meet the standard thresholds for edge delamination depth and surface roughness. To verify the tool condition, tool wear should be inspected and measured. In general, tool wear has different types such as flank wear, nose wear, fracture or chipping, etc. The combination of all tool wear types control tool life criterion. In this research, the effects of tool wear on surface integrity, surface roughness and other surface damages are studied. This work has two objectives, the first objective is to study the effect of tool wear on laminate quality and the second objective is to analysis the effect of cutting conditions on cutting forces, tool life, surface integrity and surface roughness. This thesis is organized into four chapters. Chapter one presents the literature review related to the mechanical properties of CFRPs, as well as the machining/ trimming of CFRP. Chapter two describes the methodology including the experimental setup, and the machining parameters and the measurement equipment used in this study. Chapter three presents the study and modeling of machining parameters effect on cutting forces and surface roughness (preliminary tests). Finally, chapter four presents tool wear effect on quality of trimmed laminates. 


\section{CHAPTER 1}

\section{LITERATURE REVIEW}

\section{$1.1 \quad$ Introduction}

Carbon fiber reinforced plastic composites (CFRPs) are high demand in different industries, especially aerospace industries. They are vastly used in fuselage, wing and empennage assemblies. They have higher physical and mechanical properties relative to weight over conventional materials. Moreover they provide stronger and stiffer structures which allow us to manufacture more fuel efficient and environmentally friendly airplanes. When CFRP are normally cured to near-net-shape, machining processes such as trimming, milling or drilling are used to remove excess material in order to meet the dimensional requirements for assembly process. Previous studies have shown that machining of CFRPs is different from machining conventional metals and their alloys. Moreover, the finished surface of the carbon fiber composites is rougher than metals. This difference is due to the heterogeneity and anisotropy of CFRP composite materials. Machining of CFRP is associated with different types of damages including, matrix cracking, fiber fracture, fiber pull-out and interlaminar delamination. Little research has been carried out in this field compared to metals and their alloys.

\subsection{Mechanical properties of CFRPs}

CFRPs are distinguished by excellent properties such as high fatigue, corrosion resistance, light weight, high specific stiffness and strength. These mechanical properties have increased the applications of CFRPs in aerospace over the last decades. Composites materials aren't isotropic. Their mechanical properties vary with direction within the material. The elastic modules are different in each direction meaning that $\mathrm{E}^{\circ}, \mathrm{E} 45^{\circ}, \mathrm{E} 90^{\circ}$ are not the same in carbon fiber reinforced composite material. Figure 1.1 represents the main role of the fibers in determining strength and stiffness of the composite material. When loads are parallel to the fibers orientation $\left(0^{\circ}\right)$, the ply is much stronger and stiffer than when loads are 
perpendicular $\left(90^{\circ}\right)$ to the fiber orientation. There is a significant decrease in strength and stiffness due to only a few degrees of misalignment from $0^{\circ}$. (Campbell, 2010)

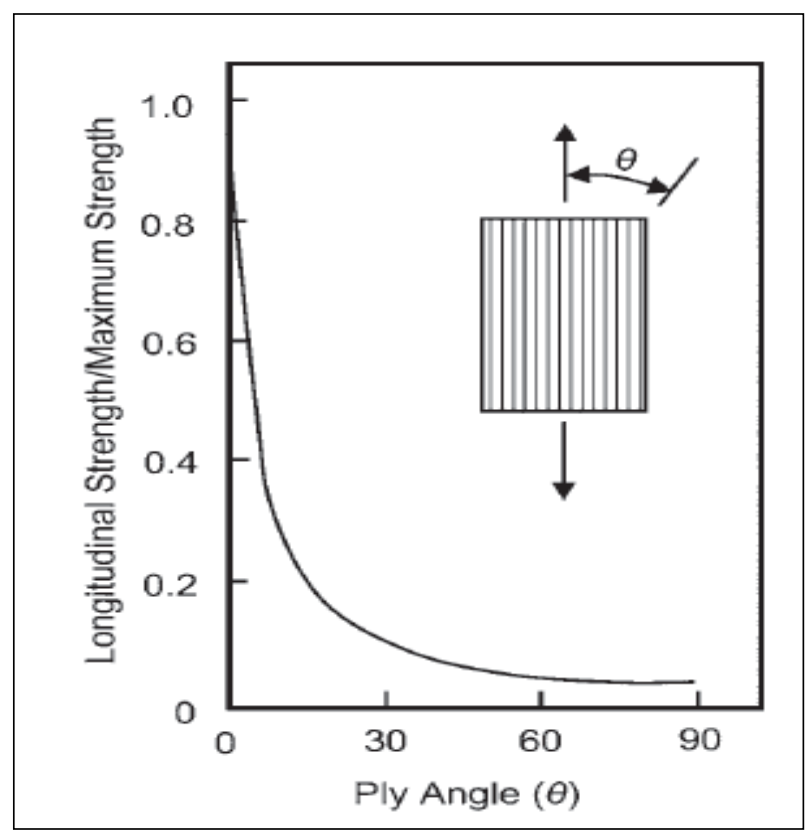

Figure 1.1 Longitudinal strength/ultimate strength as function of ply angle Drawn from Campbell (2010, p. 10)

The longitudinal tension and compression loads are supported by the fibers, while the matrix protects fibers from buckling in compression and distributes the loads between them in tension. In addition, the matrix undergoes the primary interlaminar shears. In order to clarify the roles of fibers, matrix and composite in terms of mechanical property, their tensile properties are compared in Figure 1.2. Mostly, continuous-fiber composites are laminated in the directions that increase the strength in applied load direction; for example $\left(0^{\circ}\right)$ lamina is strong in the $0^{\circ}$ direction while it is too weak in the $90^{\circ}$ direction because in this condition the applied load is only supported by the weaker polymeric matrix. 


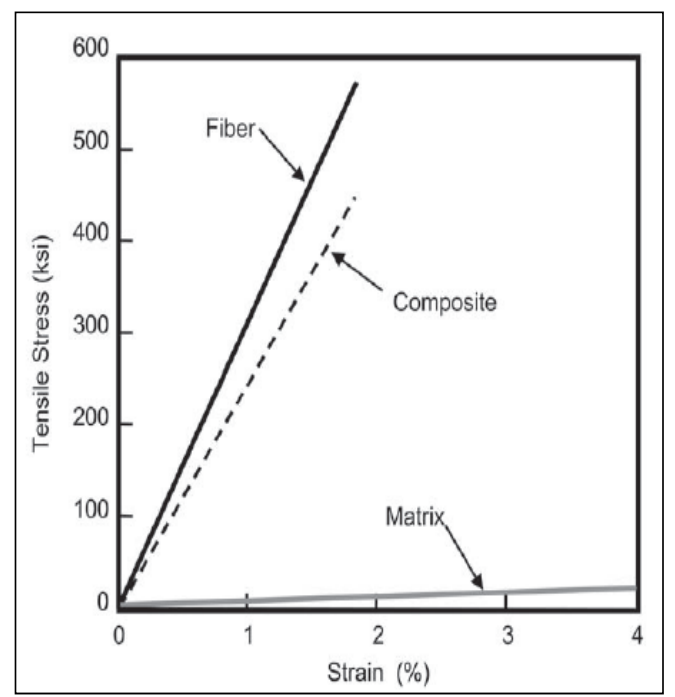

Figure 1.2 Tensile properties of fibers, matrix and composite material Drawn from Campbell (2010, p. 8)

If CFRPs are stacked in various angles, the lay-up type is called a laminate. A laminate is manufactured by polymer matrix and stacking a number of laminas to a desired thickness. Figure 1.3 represents the laminate lay-up.

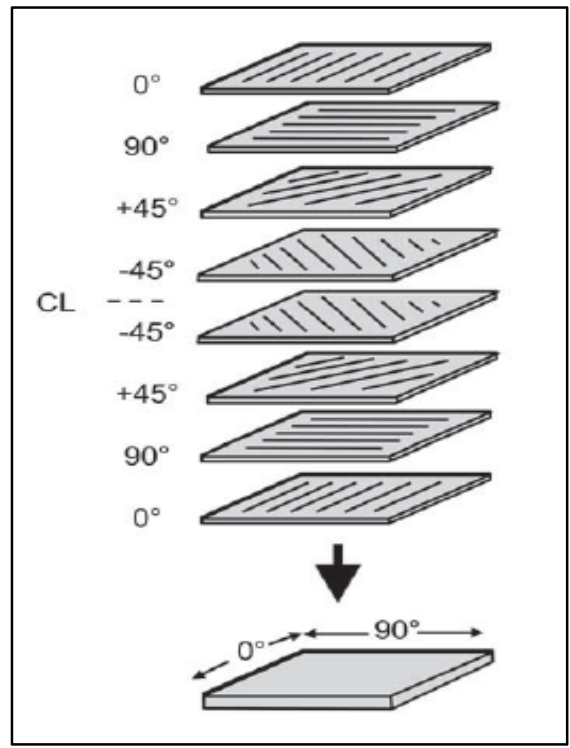

Figure 1.3 Laminate lay-up

Drawn from Campbell (2010, p. 7) 


\subsection{Cutting tool materials}

The chip formation mechanism is different in machining of CFRPs and metals because the compression shearing or fracture of the fiber reinforcement and matrix occur in machining of CFRPs while the plastic deformation take place in cutting of metals. The chip formation mechanism requires a sharp tool with a large positive rake angle. Hardness and toughness of the cutting tool are necessary to overcome the abrasiveness of the fibers and the loads which are produced during fracture of fibers. There are limited ranges of tool materials which satisfy these conditions. Normally, with an increase in hardness, the toughness decreases and vice versa. According to Sheikh-Ahmad (2009), the cutting tool materials are categorized in various types as listed in following paragraphs:

- Cemented tungsten carbides

Cemented tungsten carbides are composed of hard carbide particles (WC) and metallic binder material cemented together. High hardness and toughness are the main properties of submicron carbides to make them suitable for machining of composites. In machining with this tool material, the cutting forces are low and the most common form of wear is abrasion due to inhomogeneous nature of composite materials. Moreover; in this case, the fluctuated cutting forces could increase the chipping of the cutting tool.

- Coated carbides

In order to improve tool wear resistance of cemented carbide tool, the hard ceramic coatings are used. The coatings are mostly formed by two methods; first method is chemical vapor deposition (CVD). In this method, single layer and multilayer coatings of $\mathrm{TiC}, \mathrm{TiN}, \mathrm{TiCN}$, and A12O3 are used at high temperature. The second method is physical vapor deposition (PVD) is carried out at low temperature. PVD coatings have the advantages such as finer microstructures, higher toughness at high temperatures and they are utilized in case of high cutting forces. In machining of composites, using coated carbides doesn't improve considerably the wear resistance, tool life and edge chipping. 


\section{- Ceramics}

Ceramic tools are composed of sintered alumina (A12O3) at high temperatures and pressures. Low toughness and chipping are most common problems in ceramic tools when the loads are heavy or interrupted; they tend to fail by chipping. In addition, it is difficult to produce them with sharp edges.

- Polycrystalline diamond

Polycrystalline diamond tool has good thermal conductivity, low friction coefficient, high tool life and it produces the good surface finish however it has some disadvantages such as cutting tool size limit, fracture susceptibility and cost of production. Polycrystalline diamond is composed of compacted PCDs and small amounts of metallic binder, such as cobalt at high

temperature and pressure. Applications of this tool are in machining of abrasive materials, interrupted and rough machining. It was found that this material tool generates less delamination when the cutting tool has low tool wear.

- Polycrystalline cubic boron nitride

Polycrystalline cubic boron nitride (PCBN) tools are composed of a sintered mixture of CBN crystals and metallic or ceramic binder such as $\mathrm{TiC}$ and $\mathrm{TiN}$. The major form of tool wear is microchipping so, these tools are not useful for cutting of inhomogeneous materials or the interrupted cutting.

- Diamond coated carbides

Low-pressure diamond synthesis produced by CVD allows processing of diamond as a tool coating. This coating leads to a great tool life improvement in machining of abrasive materials such as carbon fiber composites. The failure mode of diamond-coated carbides is associated with uniform wear of the diamond film and film delamination. 


\subsection{Machining of CFRPs}

There are different types of machining methods for fiber composite materials. The machining operations are categorized in two divisions: conventional and non-conventional. Turning, milling and drilling are conventional methods. Laser cutting, electric discharge machining, ultrasonic and water jet machining are non-conventional methods while they have some disadvantages such as low rate production, heat affected zone and high price. So due to these shortcomings, still conventional machining is a main economical method utilized in industry (Wang, 1993).

There are two types of milling mode; one is up milling mode, the other one is down milling mode. In up milling, at first, the chip thickness has zero value and then increases with the rotation of the tool. The feed direction and the cutting tool rotation are in the opposite direction. In contrast, in case of down milling, the chip thickness decreases with the rotation of the tool to zero value. In this case, the feed direction and cutting tool rotation are in the same direction. Figure 1.4 shows up milling and down milling modes. When the cutting machine has high rigidity, in peripheral down milling, the cutting forces tend to keep the workpiece on cutting machine and decrease the cutting vibration but in terms of cutting forces and surface finish, Bérubé (2012) showed that up milling mode generates less cutting forces and surface roughness during trimming of CFRP composites.

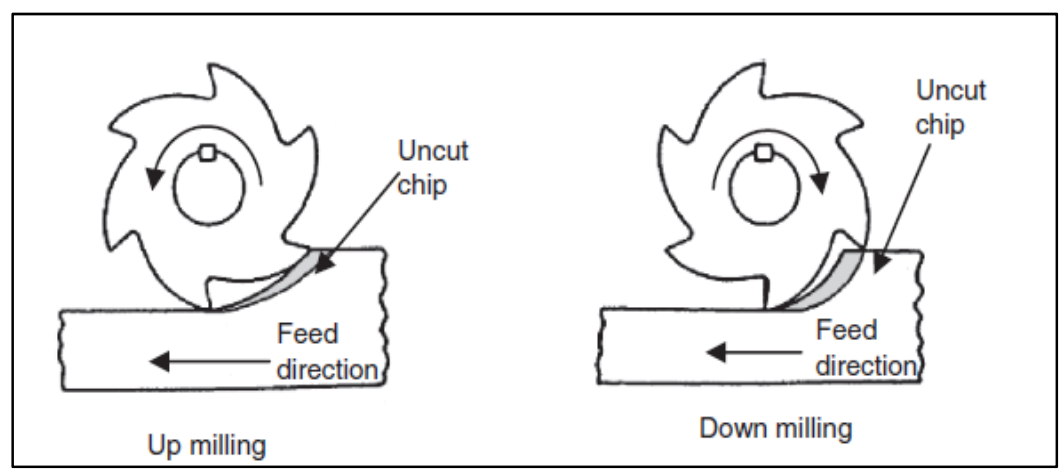

Figure 1.4 Up milling and down milling modes Drawn from Sheikh-Ahmad (2009, p. 44) 


\subsubsection{Chip formation}

The mechanism of chip formation in orthogonal machining of unidirectional CFRPs was investigated by several researchers. Koplev et al. (1983) was one of the first researchers who studied CFRP orthogonal cutting. He pointed out that chip formation was strongly affected by fiber orientation, and occurred during a series of successive ruptures. He also concluded that surface quality and the delamination factor were strongly influenced by cutting forces and the tool geometry.

Wang et al. (1995) classified chip formation process during machining of carbon fiber plastic composites in five types based on the fiber orientation and cutting edge rake angle (Figure 1.5). When fiber orientation $(\theta)$ is $0^{\circ}$ and the cutting tool has positive rake angle, as the tool feeds into the workpiece, the layer slides up the rake face, resulting in bending of layer. Bending-induced fracture starts perpendicular to the fiber direction. The cutting forces alternates with the repeated cycles of delamination and fracture. Moreover, this process forms the small distinct chip segment by mechanism of rupture. The fiber buckling type of chip takes place when fiber orientation is zero and rake angle is negative. The fiber undergoes compression or buckling and finally, this compression causes the fracture of fibers in a direction perpendicular to their lengths. This fracture forms small discontinuous chips.

When $0^{\circ}<\theta<90^{\circ}$, the chip type depends on the amount of interlaminar shear that occurs as the chip segment slides up the tool rake face. It forms a ribbon shape with some curl by mechanism of deformation. With an increase in the fiber orientation, continuous chip size decreases, and by approaching to $90^{\circ}$, the interlaminar shear increases. It leads to the fracture of the chip segments along the fiber-matrix interface and it forms discontinuous chips. When the fiber orientation is between $105^{\circ}$ and $150^{\circ}$ with positive rake angle, the compressive stress causes the crack of the fibers and matrix and it forms discontinuous chip by mechanism of shearing. In this case, the several damages occur including delamination, intralaminar shear along fiber-matrix interface and out-of-plane displacement. 


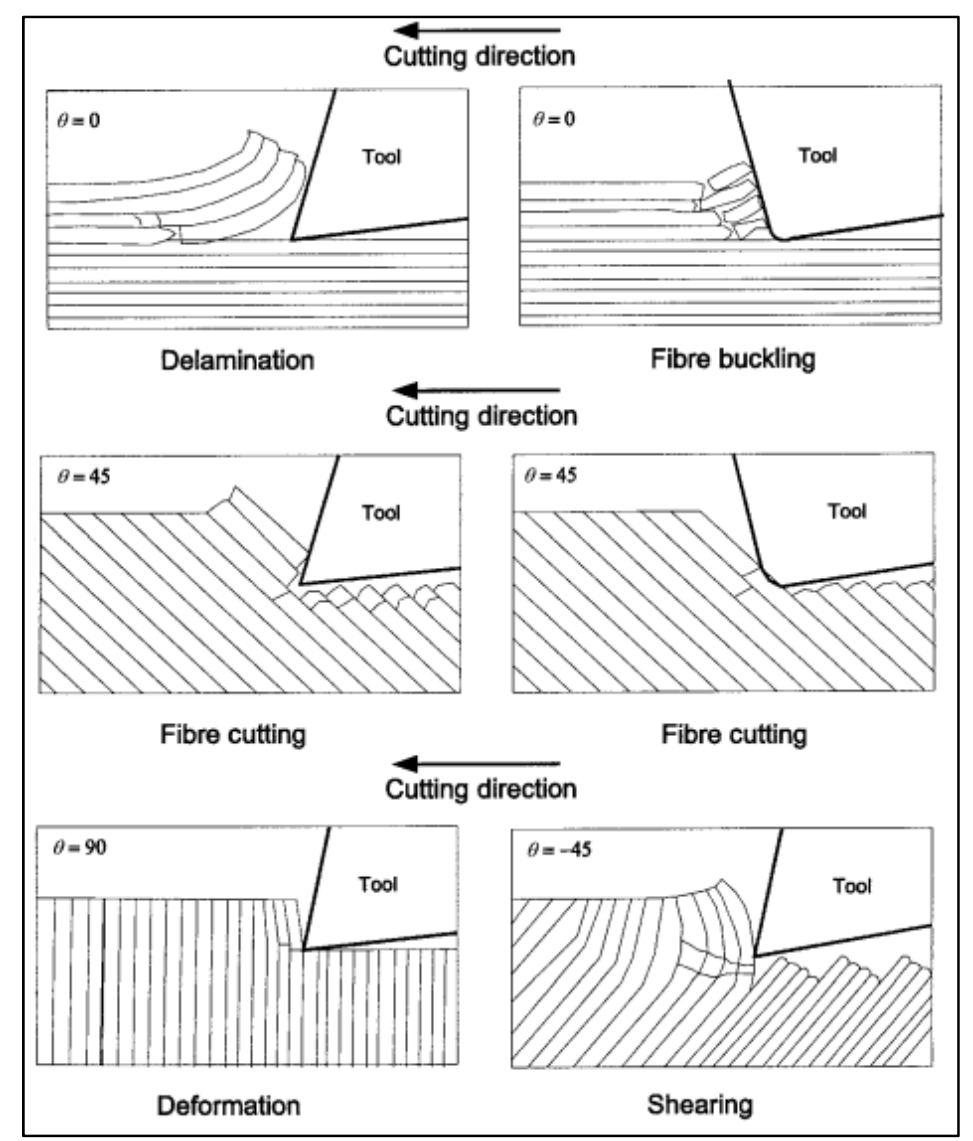

Figure 1.5 Chip formation modes of CFRP Drawn from Gordon (2003, p. 41)

Arola et al. (1996) studied chip formation process during orthogonal trimming of graphite/epoxy composite using PCD end mill. They concluded that chip formation firstly depended on the fiber orientation, and secondly, is affected by tool geometry and cutting conditions. They found that at $0^{\circ}$ fibre orientations, chip formation involved failure along the fibre-matrix interface through bending and fracture perpendicular to the fibre orientation. Up to $75^{\circ}$, the chip formation involved compressive shear at the cutting tool nose. For more than $90^{\circ}$, chip formation included out-of-plane shear with compressive loading, resulting in the intralaminar deformation. They also showed that an increase in the rake angle of the cutting tool insert decreased the period of fracture during chip formation, which resulted in a smaller discontinuous chip and a higher machined surface quality. 
Wang et al. (2003) carried out an experimental investigation during the orthogonal cutting of unidirectional FRPs. They found that fibre orientation $\theta$ was a main factor that affected the surface integrity of a machined component. The $90^{\circ}$ was a critical angle, meaning that more than $90^{\circ}$, an intense subsurface damage occurred. In case of $\theta \leq 90^{\circ}$, they observed three distinct deformation zones including chipping, pressing and bouncing. In case of $\theta>90^{\circ}$, fibre-bending during machining was observed considerably. In addition, they found that the rake angle of a cutting tool lightly influenced the surface roughness. In the studied range, a better surface obtained when rake angle was between $0^{\circ}$ and $20^{\circ}$.

Lasri et al. (2009) studied the modelling of chip separation in machining unidirectional FRP composites using the stiffness degradation concept. They showed that chip formation took place in several modes of failure such as fiber-matrix debonding, fiber breaking and matrix cracking. Fiber-matrix debonding was the first failure mode progressed in composite structure during machining and the fiber breaking was the last failure mode that took place in the chip formation process. This debonding started close to the cutting tool edge and continued with the matrix cracking and finally the fiber breaking occurred in the chip formation process. They also proposed the predicted cutting force models in which the trend of the predicted cutting forces with Hachin criterion was so close to the experimental results. In all criteria, the predicted and experimental thrust forces didn't follow the same trend. In all fiber orientations, the subsurface damage such as matrix cracking, fiber-matrix debonding and predicted Hoffman damage started close to the tool edge and continued in directions parallel and perpendicular to the fiber inside the composite. The minimum sub-surface damage in fiber-matrix interface occurred at $30^{\circ}$ degree fiber orientation. Moreover, an increase in fiber orientation more than $45^{\circ}$ degree led to the intense sub-surface damage in matrix and fiber-matrix interface.

\subsubsection{Delamination}

The most important type of edge surface damages during trimming of CFRP is delamination or the ply separation. This damage is caused by the absence of support from the adjacent 
plies during trimming. So the delamination is usually found on the top and the bottom of the surface plies. Colligan et al. (1992) categorized delamination types as following:

Type I: The surface areas where ply fibers are missing;

Type II: The uncut fibers overhung from the trimmed edge;

Type III: The loose fibers partially attached to the trimmed surface edge;

Type I/II: A combination of both Type I, and Type II delamination.

All four types of delamination are shown in Figure 1.6.

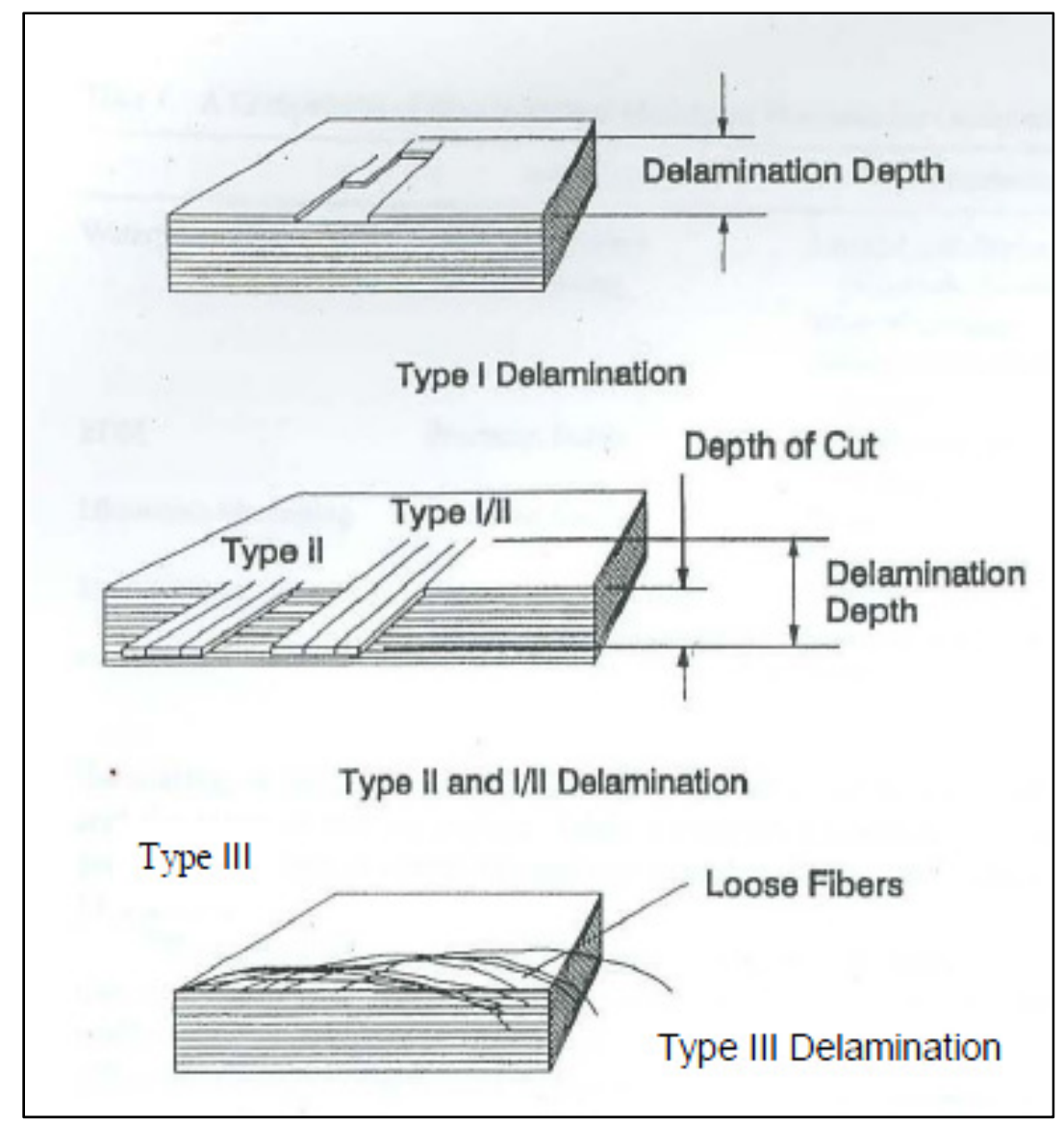

Figure 1.6 Delamination types

Drawn from Colligan et al. (1994, p. 280)

Davim et al. (2005) studied the damage and dimensional precision during milling carbon fiber-reinforced plastics using design experiments. They used two-flute and six-flute tools to 
cut the CFRPs. They concluded that the delamination factor increased slightly with the feed rate for two-flute and six-flute end mills. For the six-flute end mill, the delamination factor increased with an increase in the cutting speed. The two-flute end mill produced less damage on the CFRP composite material than the six-flute end mill; meaning that the delamination factor $(\mathrm{Fd})$ was smaller for two-flute end mill. They also showed that the surface roughness (Ra) increased with feed rate and decreased with cutting speed. Feed rate was the machining parameter that showed the highest statistical and physical effects on the surface roughness and the delamination factor for both end mills. Figure 1.7 shows the feed direction and the delamination factor $(\mathrm{Fd})$ in their experiments.

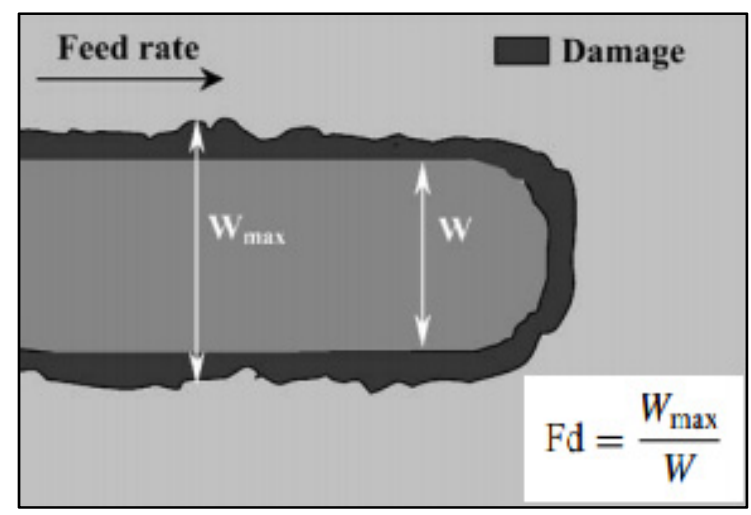

Figure 1.7 Delamination factor $(\mathrm{Fd})$ Drawn from Davim et al. (2005, p. 165)

Janardhan et al. (2006) studied the edge trimming of CFRP laminates. They found that the machining quality including average delamination and roughness in up milling is much better than in down milling using PCD flute cutter, as shown in Figure 1.8. The fact was that in down milling, the matrix and fibers were collected inside the flutes of the cutting tool and consequently the cutting tool produced the rough surface with associated damages. 


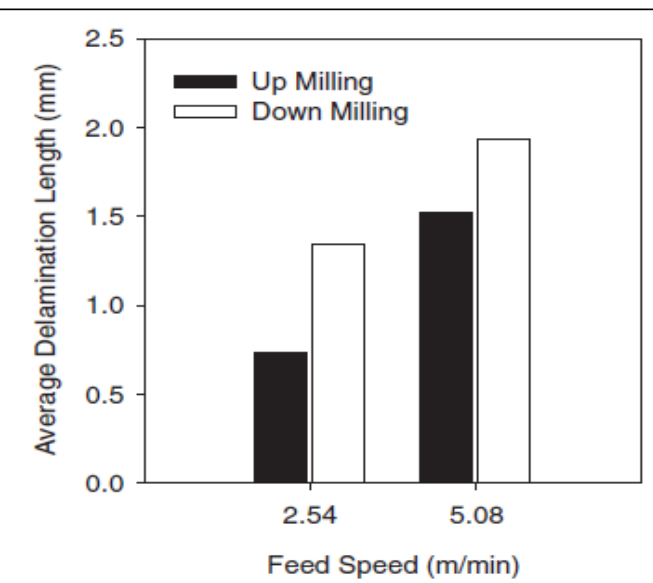

(a)

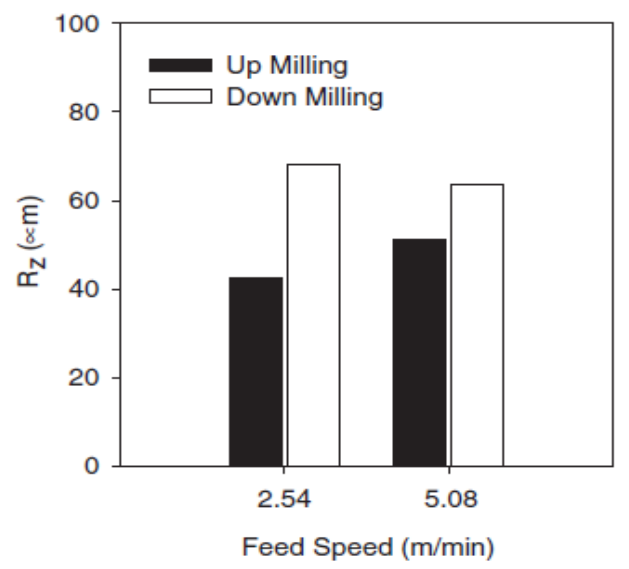

(b)

Figure 1.8 Effect of type of operation on surface quality Drawn from Janardhan et al., (2006, p. 805)

Hintze et al. (2011) studied the occurrence and propagation of delamination during the contour milling of unidirectional CFRPs using PCD tools. They found that delamination was greatly dependent on the fibre orientation and the tool sharpness. It was shown that two mechanisms could describe delamination: occurrence and propagation. They found out that the occurrence of delamination and fibre pull-out during the milling mostly depended on tool wear and the fibre cutting angle $\theta$ on the top laminate layers. In case of using a worn tool, there was also a preferred fibre cutting angle range which led to no delamination and no fibre pull-out $\left(0^{\circ}<\theta<90^{\circ}\right)$. They found that between $90^{\circ}$ and $180^{\circ}$, the most delamination and fibre pull-out occurred. They also showed that delamination propagated from the critical cutting angle range to the component edge, produced the fibres were primarily cut at a cutting angle of $90^{\circ}<\theta<180^{\circ}$ and at the component edge with a cutting angle of $0^{\circ}<\theta<90^{\circ}$.

Sheikh-Ahmad et al. (2012) also studied the machining damage during trimming of CFRP. They found that delamination took placed mainly in the surface plies, and was mostly of types I /II and I. Average delamination depth increased with an increase in feed rate and decreased with an increase in cutting speed. They also showed that the surface roughness in the longitudinal direction increased with an increase in feed rate and decreased with an 
increase in cutting speed. Surface roughness in the transverse direction didn't have clear trends and was mostly higher than that in the longitudinal direction. The best trimmed surface quality, in terms of surface roughness and delamination depth was obtained using low feed rate.

\subsubsection{Surface quality and surface damage}

Surface quality includes surface roughness and surface integrity. The surface quality depends on the tool geometry, dynamics of the machining process, cutting conditions (cutting speed and feed rate), workpiece material characteristics, fiber type, fiber orientation, matrix type and work piece/machine rigidities. In case of rigidity, proper clamping is so important in machining of CFRPs because it affects directly on surface roughness and it reduces vibration. Surface integrity is related to the physical and chemical conditions of the surface layer after machining including fiber pullout, fiber breakage, delamination, matrix removal, burning and decomposition. The reliability of machined components depends on quality of surface finish, so it is essential to qualify and quantify the surface finish. There are different (2D) profile roughness parameters to evaluate the surface roughness such as arithmetic average height, $\mathrm{Ra}$, peak to valley height, Rt, peak to mean height, Rp, mean to valley height, Rv, or tenpoint average height, Rz. All these methods represent a little composite surface characteristic, so the visual inspection is often associated with these types of measurement because the visual inspection reveals surface qualities such as fiber pullout, matrix smearing and delamination. In case of comparison of profile roughness parameters, $\mathrm{Ra}$ and $\mathrm{Rq}$ are the least sensitive to surface topography changes with fiber orientation while Ry and Rz are most sensitive in FRPs (Ramulu et al. 1999).

There are two major methods to measure edge surface roughness: one is longitudinal, the other one is transversal as shown in Figure 1.9. Sheikh-Ahmad et al. (2012) found that the surface roughness in the transverse direction was mostly higher than that in the longitudinal direction and showed no clear trends with cutting parameters (cutting speed and feed rate). 


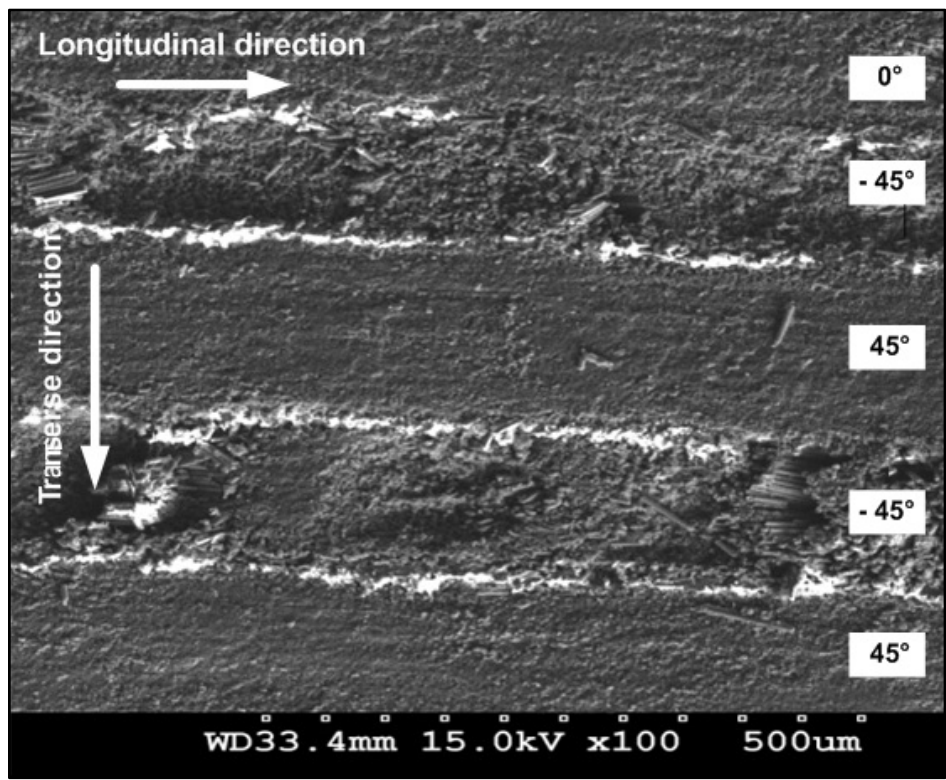

Figure 1.9 Longitudinal and transverse directions of surface roughness measurement

Palanikumar (2007) modeled and analysed the surface roughness during turning of GFRPs using the response surface methodology. Analysis of variance (ANOVA) was also used to verify the validity of the model. He developed a mathematical model for surface roughness in order to correlate the important cutting parameters during machining of GFRP composites. He evaluated that his technique was economical to obtain the effects of different parameters in a systematic manner however its validity of the procedure was generally limited to the range of factors considered for the experimentation. The four input variables used in his study were cutting speed, fiber orientation angle, depth of cut and feed rate. He also pointed out that the surface roughness decreased with an increase in cutting speed. In addition, it increased with an increase of feed rate. It also increased with an increase in fibre orientation angle. Moreover it decreased with an increase in depth of cut.

Sarma et al. (2009) studied the surface roughness of the machined surfaces of GFRP at the different cutting conditions using digital image processing. The GFRP pipes were turned in lathe using PCD tool. During turning, the machined surface images were captured using a Charge Coupled Device (CCD) camera. For all the images average, grey scale value (Ga) were calculated. The average grey scale values and surface roughness $(\mathrm{Ra})$ values were correlated and a relation was found between them. In addition, a second order quadratic 
model was proposed to predict surface roughness. The obtained grey scale values were in good correlation with the measured surface roughness values. The effects of cutting speed, feed rate, depth of cut and fiber orientation angle on surface roughness were also studied. It was found that feed rate affected surface roughness, followed by cutting speed and fiber orientation angle. Depth of cut had no effect on the surface roughness of machined GFRP composites.

Rajasekaran et al. (2010) verified the effect of machining parameters on surface roughness during turning of CFRP. Turning operation was carried out using carbide cutting. A fuzzy rule based model was proposed to predict surface roughness of the machined component. It was shown that there was a good correlation between the obtained surface roughness from the experiments and the fuzzy rule based model. In addition, based on experimental results, It was found that feed rate was a cutting parameter which played a main role affecting the surface roughness, meaning that with an increase in feed rate, surface roughness increased while with an increase in cutting speed, the surface roughness decreased.

El-Hofy et al. (2011) studied the factors which affected workpiece surface integrity during trimming of CFRP. The studied factors were the different trimming parameters, tool materials (WC \& PCD) and cutting environment (chilled air \& dry) on the surface roughness and surface integrity of machined CFRP laminates using a fractional factorial Taguchi experiment. They used scanning electron micrographs and 3D topographic maps to inspect the effect of fibre orientation with respect to the trimming direction. By using chilled air, thermal damage (burning \& resin melt) on trimmed surfaces was minimized. They also found that use of PCD tools increased considerably productivity compared to coated WC. Moreover, burning of the CFRP resin was seen in some of the experiments, mostly when using dry condition and low feed rates. Wavy surfaces were seen at $45^{\circ}$ orientated plies while those at the $-45^{\circ}$ and $90^{\circ}$ orientated plies, there were matrix cracking and fibre pull out due to high cutting forces and softening of the resin. The best quality of surface was found on plies where the fibres were parallel to the feed direction $\left(0^{\circ}\right)$. 
Pecat et al. (2012) studied the effect of milling process parameters on the surface integrity of CFRP. The studied workpiece materials were the unidirectional CFRPs. The cutting conditions such as cutting speed, fiber orientation were different. The examination of crosssectional micrographs represented that the depth of sub-surface damages was considerably dependent on the fiber orientation of the CFRP material. In addition, it was found that higher cutting speeds led to fiber bending in the sub-surface of the machined surfaces. In terms of fiber orientation, a smooth surface was seen for milling in $0^{\circ}$ and $+45^{\circ}$ while under $-45^{\circ}$ and $90^{\circ}$, the micrograph showed severe damage in the form of cracks.

Bérubé (2012) evaluated the performance of cutting tools during trimming operation of CFRP composites. He found that the PCD tool comprised of two flutes had the most appropriate tool for trimming operations of CFRPs. For this cutting tool, he proposed that the use of a rotational speed of $13400 \mathrm{rpm}$, about $400 \mathrm{~m} / \mathrm{min}$ with a feed rate of 0.005 inch per tooth. Under these conditions, $\mathrm{Ra}$ values varied between $0.7 \mu \mathrm{m}$ and $3.1 \mu \mathrm{m}$, with an average of $1.4 \mu \mathrm{m}$. Rt values varied between $11 \mu \mathrm{m}$ and $39 \mu \mathrm{m}$, with an average of $20 \mu \mathrm{m}$. For the effect of the fiber orientation on the criteria $\mathrm{Ra}$ and Rt, at 0 degrees, he obtained average 0.8 $\mu \mathrm{m} \mathrm{Ra}$ and $5.13 \mu \mathrm{m}$ Rt. For a fiber orientation at $-45^{\circ}$ degree, he obtained an average $2.7 \mu \mathrm{m}$ Ra and average $31 \mu \mathrm{m} \mathrm{Rt}$.

Chatelain et al. (2012) studied the effect of ply orientation on roughness for the trimming process of quasi-isotropic aerospace CFRP laminates. They found that the fiber angle was an important parameter affecting the roughness profile, regardless of the cutting conditions. Each ply orientation had its own "typical" roughness profile. The surface roughness across the laminate was measured for different fiber orientations $\left(0^{\circ}, 45^{\circ}, 90^{\circ}\right.$ and $\left.-45^{\circ}\right)$ of the CFRP laminate using longitudinal method. The $-45^{\circ}$ ply orientation showed the worst surface roughness. Moreover, it was shown that low feed rates led to better surface finish. Furthermore, the cutting speed effect was not as significant as the feed rate effect on surface roughness while a higher cutting speed led to better surface finishes in most cases. Figure 1.10 shows the variation of surface roughness with fiber orientation at the different cutting conditions. 


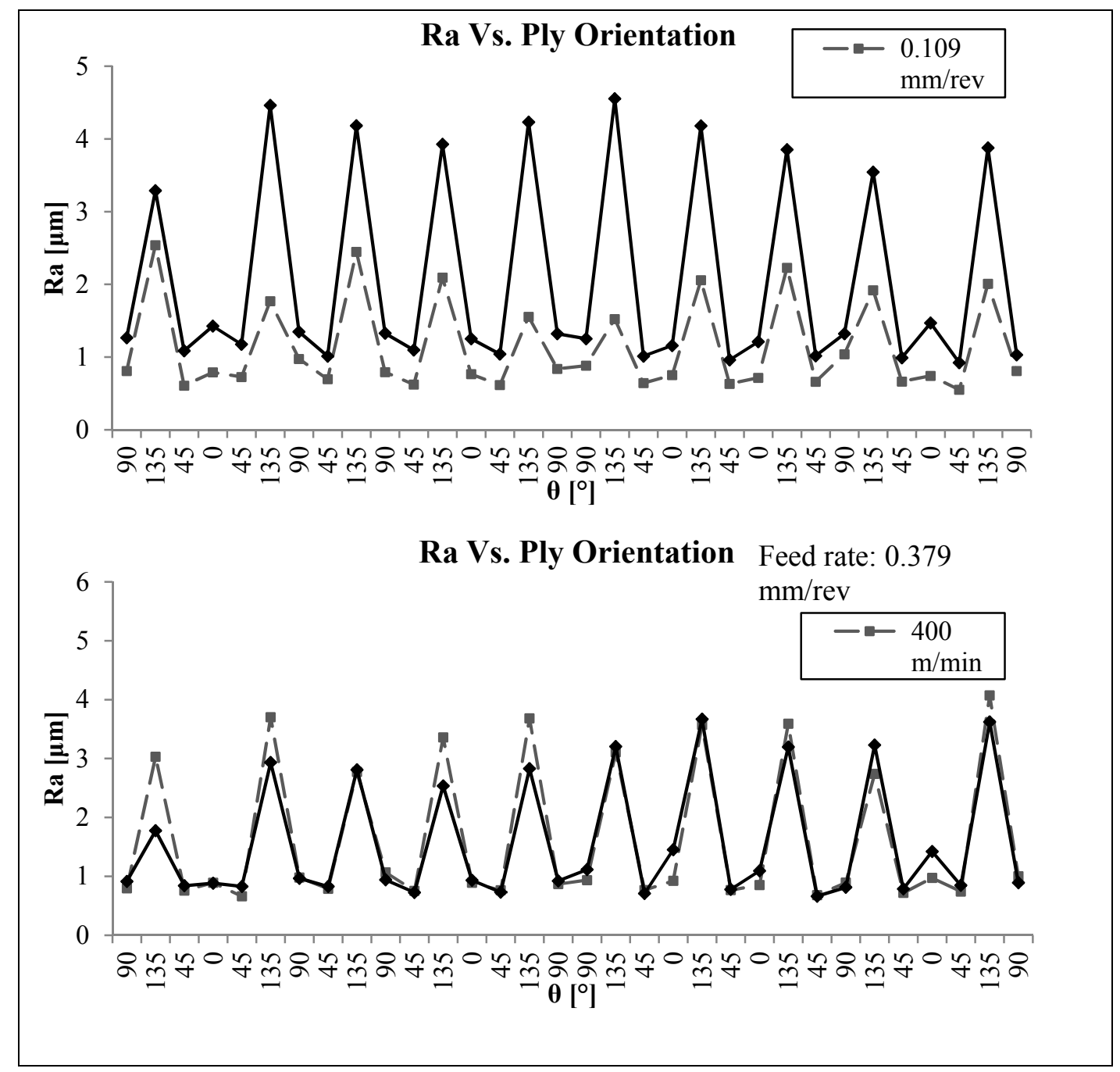

Figure 1.10 Variation of surface roughness with fiber orientation at different feed rate and cutting speed

Drawn from Chatelain et al. (2012, p. 1210)

\subsubsection{Effect of trimming operation on the mechanical properties}

Guéan (1994) carried out tensile tests for the trimmed glass epoxy coupons. He compared two trimmed coupons machined using the cutting machining parameters with the different cutting tool materials. One coupon was trimmed using PCD tool and the other one was machined using diamond grain coated tool. He showed that the second coupon was stronger than the first one. He concluded that tool material could affect the mechanical properties of machined coupons as shown in Figure 1.11. 


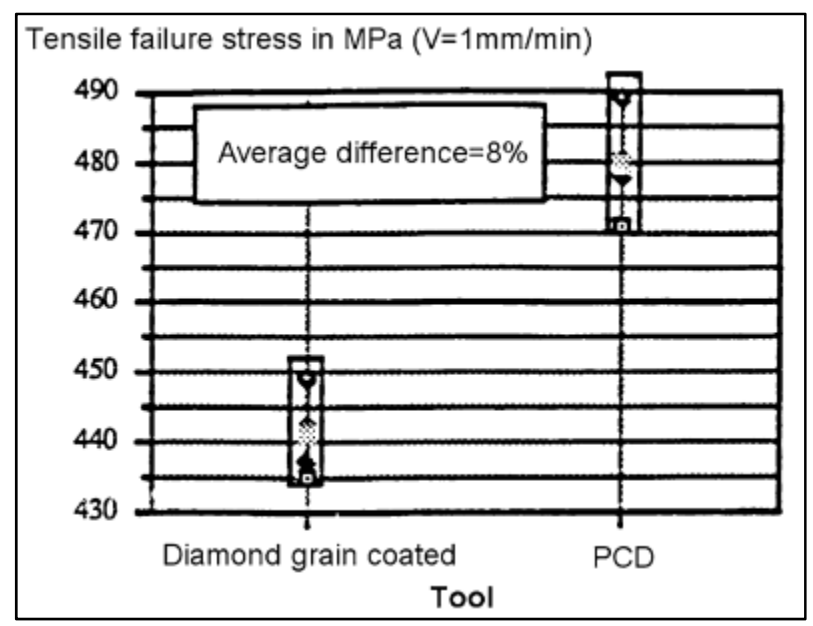

Figure 1.11 Effect of cutting tool material on tensile failure stress of machined coupons Drawn from Ghidossi et al. (2004, p. 992)

Ghidossi et al. (2004) carried out the experiments to verify the effect of cutting speed on failure strength; the results showed that cutting speed significantly affected the failure stresses. The lowest cutting speeds produced the highest failure stresses as shown in Figure 1.12. According to this research, they concluded that machining reduced the coupon strength but it was not possible to use an indicator such as roughness.

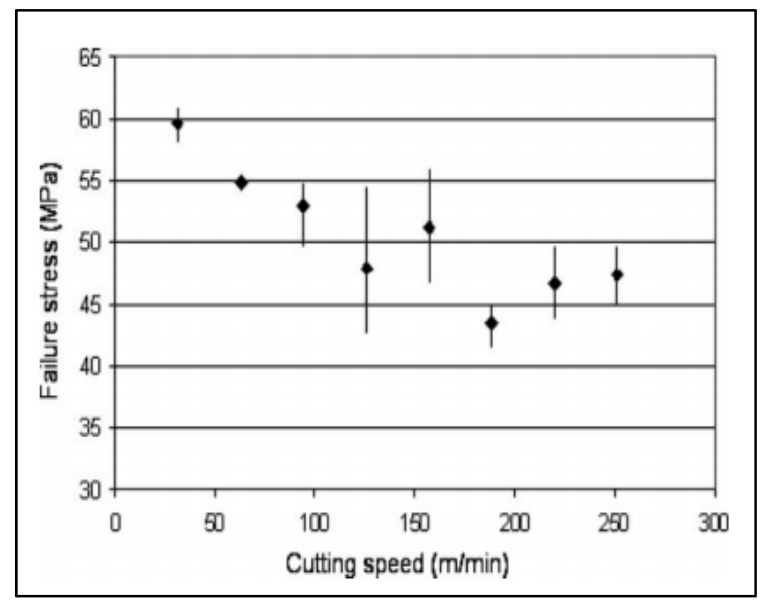

Figure 1.12 Effect of cutting speed on failure stress of machined coupons

Drawn from Ghidossi et al. (2004, p. 998) 


\subsubsection{Cutting Forces}

Due to inhomogeneous nature of FRPs, cutting forces are oscillating and periodic. They are periodic because during the milling of composites, the cutting tool cuts the fibers and matrix phases alternatively, so the cutting force has different magnitudes during machining. The periodic cutting forces are also affected by the periodic changes of fiber angles relative to the speed. The cutting forces generated during the machining processes are very important, especially when machining of CFRP. Controlling these cutting forces is one of the keys to decrease the quality issues or defects induced in CFRP machined components. The cutting forces are affected by many factors, such as material properties, cutting conditions and tool geometry.

J.F. Chatelain et al. (2012) studied the effect of tool geometry on the cutting forces during trimming of multilayered CFRP laminates. They carried out some experiments using crosscut tool with positive negative helix angle, grooved teeth tool and carbide standard end mill. The cross-cut and grooved teeth tools were compared to the carbide standard endmill in terms of the cutting forces. At first, some experiments were carried out using three tools at different cutting conditions in order to find stable conditions. For the obtained stable conditions, the force amplitude and profile were compared together. It was shown that the cross cut geometry was more sensitive to instability than standard and grooved geometries while the cross cut geometry produced a compressive thrust force which was the opposite of the standard geometry. Furthermore it was found that the special grooves decreased the axial force to almost a zero value. Also, they showed that the grooves considerably decreased the fluctuation of the feed and normal cutting forces.

Wang et al. (2011) verified the cutting performance of CFRPs using PCD tool during milling. They showed that the cutting force was the main factor affecting surface roughness during milling of CFRP. They observed that when the cutting forces increased up to $250 \mathrm{~N}$, roughness values increased while the cutting forces increased above $250 \mathrm{~N}$, roughness values decreased. 
Zaghbani et al. (2012) proposed a comprehensive analysis of cutting forces during trimming of multilayer CFRP laminates. It was shown that the cutting force profile didn't depend on the fiber orientation. They also found that fiber composite properties generated a non-linear variation of average cutting forces. They used the estimated average forces attained in experiments in order to obtain the average cutting force coefficients which were utilized in a predictive cutting force. Finally they showed that the predicted and the measured cutting forces had a good agreement at different speeds and feeds. This predicted cutting force model could be used to estimate the possible damage during trimming of CFRPs however it wasn't a fully predictive model.

Haiyan et al. (2013) analysed the cutting forces during drilling of carbon fiber-reinforced plastics. The effects of the machining parameters and tool wear on the cutting forces were analyzed. In order to model the cutting forces under different cutting conditions, a mechanistic modeling technique was proposed to predict cutting forces during drilling of CFRP. The cutting force coefficients were identified and corrected through a series of experiments. They showed that the predicted and the measured cutting forces had a good agreement (maximum error was 18\%). Moreover, according to the experimental results, it was found that the radial resultant and the axial cutting forces decreased with an increase in cutting speed and increased with an increase in the feed rate per tooth and axial feed rate. Finally, the influence of tool wear on the cutting force was also analyzed. The larger the tool wear led to the larger the cutting forces.

\subsubsection{Tool wear and tool life}

The main tool wear mechanism is abrasion in trimming of FRPs due to the interrupted nature of milling. When the cutting tool has insufficient toughness and weak cutting edges, microfracture and chipping are main problems. In milling of CFRPs, special tool material properties are important such as resistance to abrasive wear and high fracture toughness. For a cutting tool, it is also essential to have high thermal conductivity as well, because the heat generated in cutting zones is conducted to the cutting tool. The tool materials which meet these criteria are fine-grained cemented carbides, PCD and diamond-coated carbides. The 
cutting time required for reaching an amount of wear (tool-life criterion) is called tool life. A tool-life criterion is also defined by predetermined acceptable levels of cutting forces, surface quality, dimensional stability or production rate. In addition, the tool life could end with great cutting speed due to excessive chipping or breakage of the cutting edge. Unfortunately, there is no agreement on this criterion for machining FRPs. In this study, the tool life criterion (VBmax) was considered average overall teeth of $0.3 \mathrm{~mm}$ according to the first criterion of ISO 8688-2 standard.

Ferreira et al. (1999) studied the characteristics of carbon fiber composite during turning. They found that only diamond tools were suitable for use in finishing turning. For rough turning, the coated cemented carbide showed good results, and the higher feeds decreased the tool wear. They showed that with an increase in cutting speed, the tool wear increased as shown in Figure 1.13 1.13.

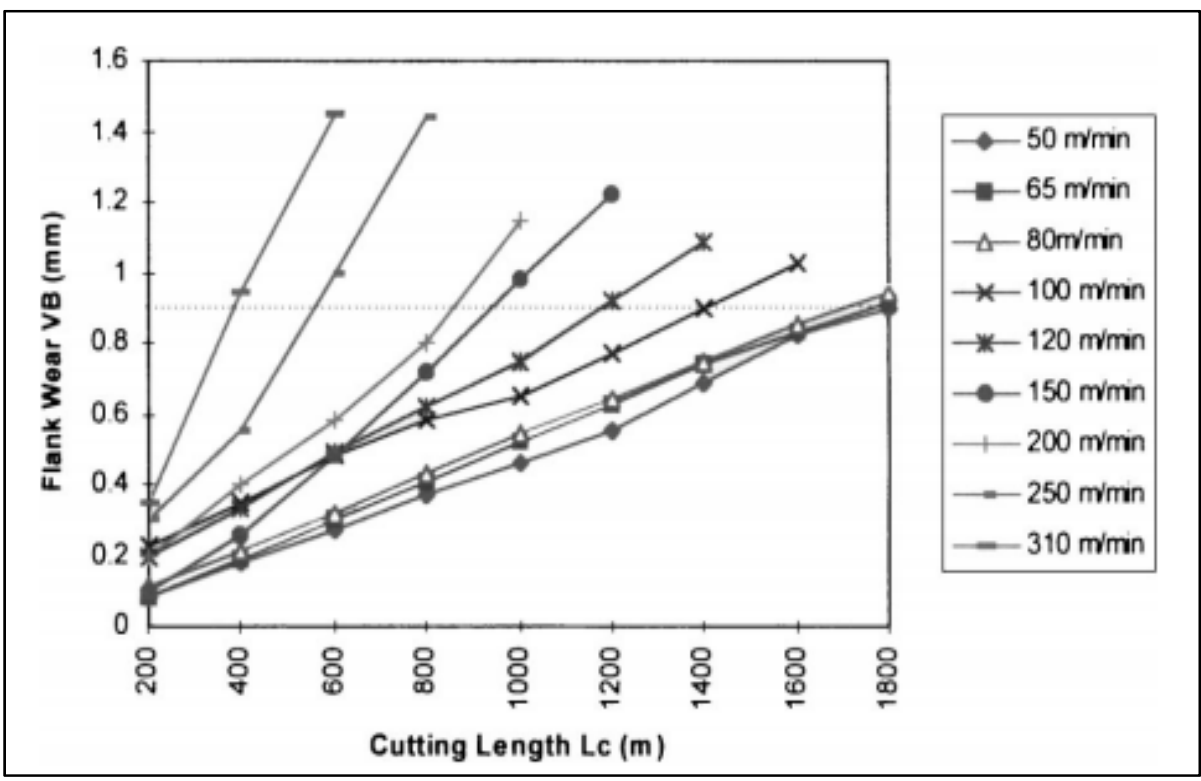

Figure 1.13 Effect of cutting speed on tool wear in turning of CFRPs Drawn from Ferreira et al. (1999, p. 139)

Ghidossi et al. (2004) verified edge machining effects on the failure of polymer matrix composite coupons. In terms of surface quality and delamination, they found that there was a big difference when specimens were machined with worn tools instead of new 
tools. Free Edge delamination was considerably high when the tool was worn out as shown in Figure 1.14Figure 1.14.

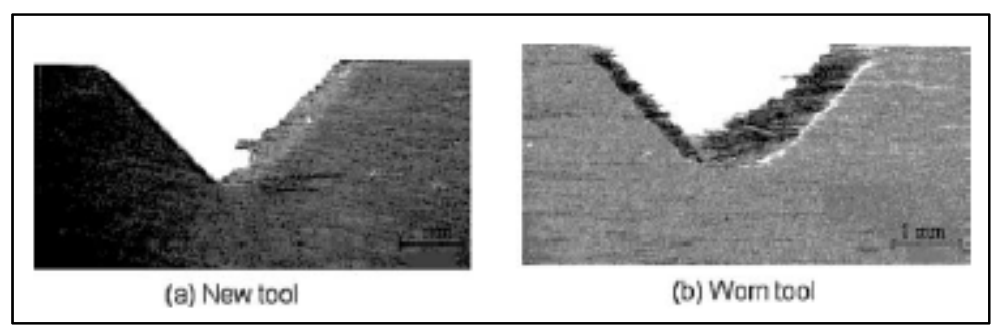

Figure 1.14 Effect of tool wear on delamination of CFRP laminate using a) new tool, b) worn tool Drawn from Ghidossi et al. (2004, p. 996)

D. Iliescu et al. (2010) proposed a model which related the thrust force, the drilling parameters and the tool wear. This model was verified by experimental tests. The experimental results showed that the feed rate, the cutting speed and the tool wear were the most significant factors influencing the thrust force. The obtained model could be used for tool-wear monitoring. Based on this model, the thrust force $(\mathrm{Fa})$ also depended on the feed rate (f) and the cutting speed $(\mathrm{Vc})$, the following model was proposed:

$$
\mathrm{Fa}=\mathrm{Kf}^{\alpha} \mathrm{Vc}^{\beta} \mathrm{g}(\mathrm{W})
$$

Where $\mathrm{g}(\mathrm{W})$ is a function of the tool wear. To determine the model coefficients, the limited experiments were carried out. After comparison of the experimental and analytical results, they concluded that the proposed model of axial load based on tool wear was in good agreement with experimental results. The small differences between the model and experiments could be related to a temperature deviation of the drill during the experiments, vibrations of laminates during drilling and the choice of the mathematical function that described the tool wear. In addition, they pointed out the presence of a diamond coating on the carbide drill increased tool life more than 10 times compared to the uncoated carbide drill at certain speeds. 
López de Lacalle et al. (2009) designed and tested a multitooth tool for CFRP milling. The multitooth milling tool made with micrograin carbide with $6 \%$ Co substrate, coated with a monolayer 4 um-thick of TiAlN, led to the best tool life, reaching 40 to 50 meters before bad quality of machining was observed. The tool wear mechanism was mainly abrasion, therefore the thicker the coating layer, the longer the tool life. They proposed $4 \mu \mathrm{m}$ coating value and more than this thickness could affect the sharpness of edges of cutting tool. New coatings based on nanostructures (TiAlN+SiC) didn't provide better results than AlTiN and the main cause would be their lack of adherence to the carbide substrate. It was shown that the pyramidal edges milling tools or multitooth milling tools didn't have force along the $\mathrm{z}$ direction. They also found that, in terms of machinability, carbon + kevlar fiber-reinforced composites were more difficult to machine than those reinforced only with carbon fibers. The specific cutting force could be an indicator of the machinability of each composite; while other parameters such as the type of fibers were also important. In addition, PCD tools didn't reach enough conditions to be economically feasible compared to their high price. In terms of influence of coating naCo on tool wear only a slight effect was observed as shown in Figure 1.15.

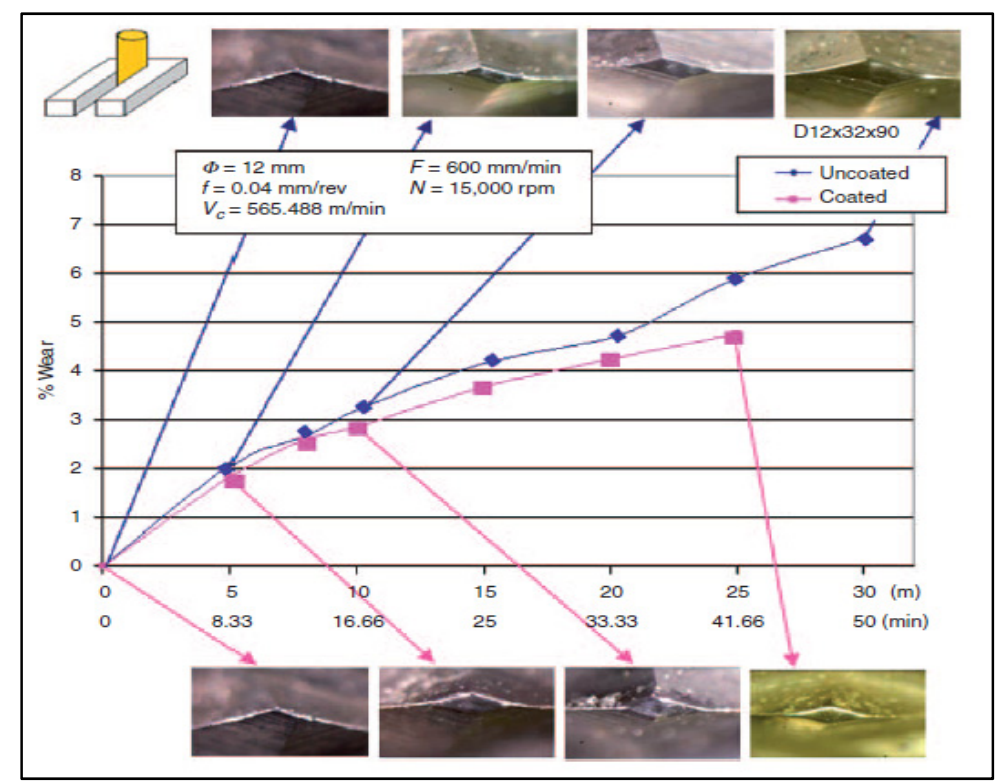

Figure 1.15 Tool wear diagram for the $6 \%$ Co micrograin (cutting tool material), coated and uncoated tools Drawn from López de Lacalle et al. (2009, p. 3282) 
They also carried out the tool life experiments using two tool geometries, one with 14 right hand helix and 12 left-hand helix (Z14-12), and the other with 14 right-hand helix and 11 left-hand (Z14-11), as shown in Figure 1.16. When both cutting tool were new, there was good finishing on the trimmed surfaces, and when cutting tool were worn (after $25 \mathrm{~m}$ of cutting length), delamination was observed in both cases, as shown in Figure 1.17.

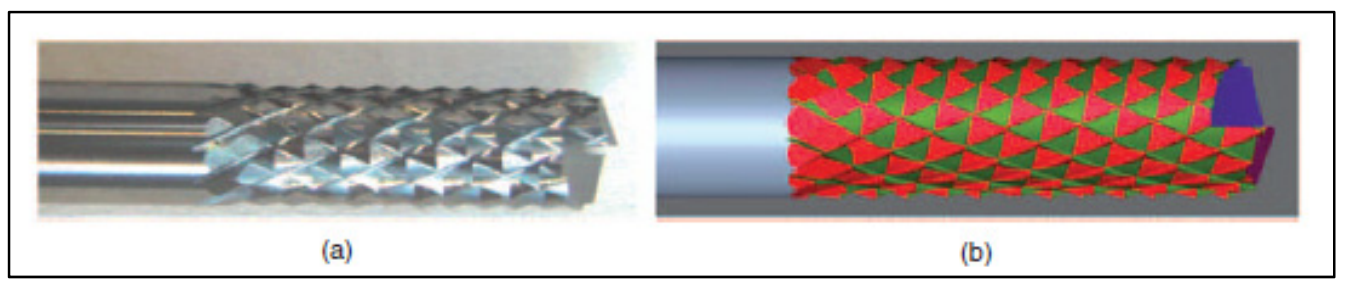

Figure 1.16 Milling tool (a) Z14-12 and (b) Z14-11

Drawn from López de Lacalle et al. (2012, p. 3286)

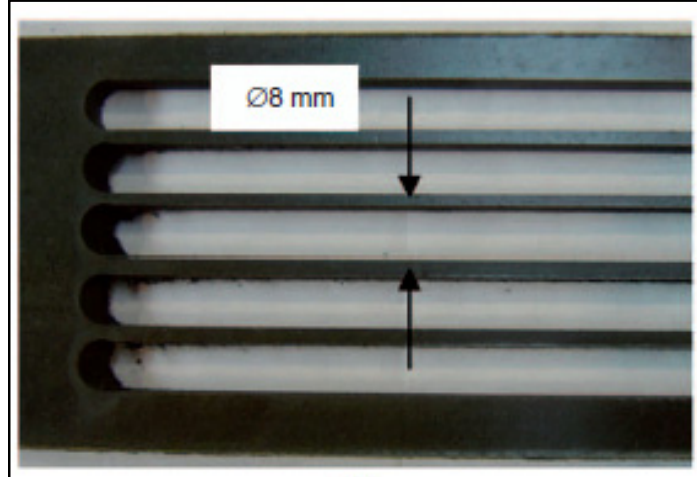

(a)

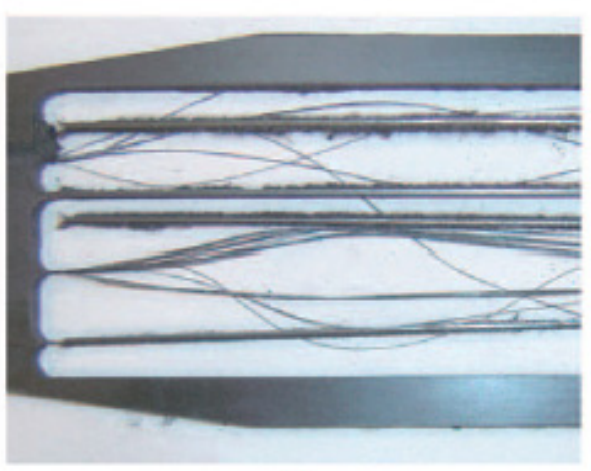

(b)

Figure 1.17 (a) The machined laminates using new tool; (b) using worn tool (after $30 \mathrm{~m}$ of cutting length)

Drawn from López de Lacalle et al. (2012, p. 3287)

Wang et al. (2013) investigated the tool wear of certain coated drills during drilling of CFRP. They carried out the experiments using three different drills: uncoated, diamond coated and AlTiN coated carbide (WC-Co) drills. They showed that the tool wear in machining of CFRP was considerably different from that in metal machining. In case of CFRP, the primary wear type was a dulling of the cutting edge. In metal cutting, the edge of a cutting tool was covered by the workpiece material (stagnation zone) which protected the cutting edge from 
the excessive tool wear. Due to the brittle nature of CFRP, the stagnation zone in front of the cutting edge, which typically occurred in metal machining, didn't exist in machining of CFRP. Moreover they pointed out that the diamond coating considerably decreased the edge rounding wear while AlTiN coated drills didn't show the considerable improvement due to its oxidation during machining.

Khairusshima et al. (2013) studied the effect of chilled air on tool wear and workpiece quality during milling of CFRP. Chilled air of $-10{ }^{\circ} \mathrm{C}$ was used to cool the cutting tool using a vortex tube as shown in Figure 1.18. Cutting speed was between 160 to $200 \mathrm{~m} / \mathrm{min}$ and feed rate was between 0.025 to $0.05 \mathrm{~mm} / \mathrm{rev}$. The end mill router was solid uncoated carbide. They found that under room temperature machining (RT), the tool wear was higher than that under chilled air machining (AC). They concluded that the chilled air used during the milling operation helped to decrease the heat generated which resulting in the increase of tool life. The surface roughness under AC machining was less than that under RT machining. The smoothest CFRP surface was obtained at lowest feed rate of $0.025 \mathrm{~mm} / \mathrm{rev}$ at a cutting speed of $179 \mathrm{~m} / \mathrm{min}$ under $\mathrm{AC}$ machining and the highest surface roughness was observed at cutting speed of $160 \mathrm{~m} / \mathrm{min}$ under RT machining. In addition, a better delamination factor was provided in $\mathrm{AC}$ machining compared to RT machining.

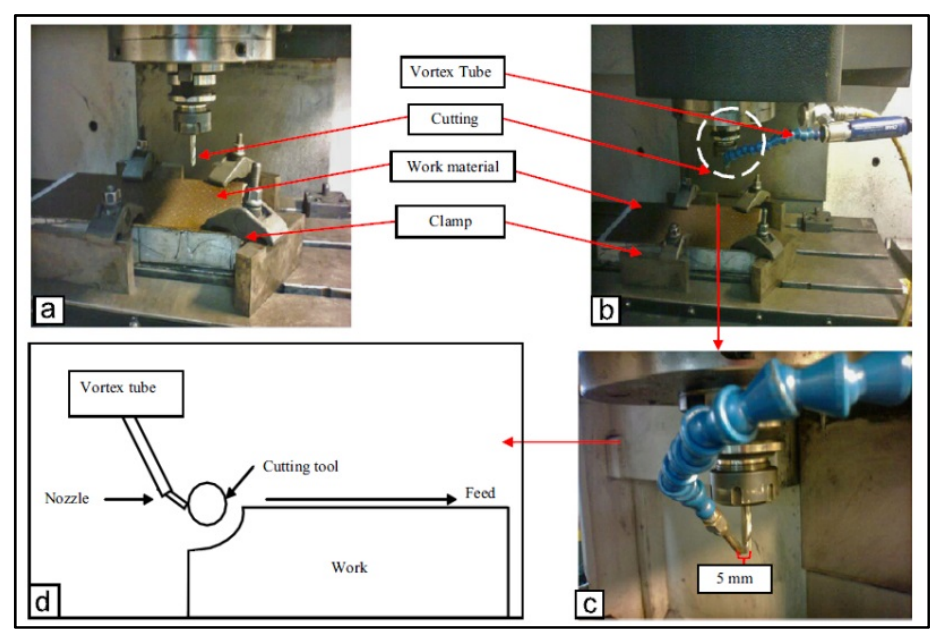

Figure 1.18 Machining in a) the room temperature (RT) and b) chilled air (AC)

Drawn from Khairusshima et al. (2013, p.4) 
Based on the tool wear section in this chapter, it can be concluded that tool condition plays a key role in surface quality. The tool may continue to machine the CFRP laminates and tool life may not be ended while the quality of machining can't meet the standard thresholds for edge delamination depth and surface roughness. Basically, few studies have been done in the field of the effect of tool wear on the surface quality during the milling of high performance composite laminates. Most of the researches have been limited to drilling of CFRPs. Moreover, unlike many research projects, which base their studies on unidirectional laminates machining, this research considers a multilayer quasi-isotropic material utilized in the aerospace industry. So, this work focuses mainly on the effect of tool wear on the resulting quality as well as on the effect of machining conditions on tool wear following the trimming operation of quasi-isotropic CFRP laminates used in aerospace. In terms of quality parameters, the study focuses on surface roughness and material integrity (uncut fibers, fiber pull-out, delamination or thermal damage of the matrix), which could jeopardize the mechanical performance of the components. 




\section{CHAPTER 2}

\section{METHODOLOGY}

\subsection{Introduction}

In this research, the main objective was to study the effect of tool wear on the resulting quality of CFRP during trimming. Therefore, it was necessary to carry out tool life experiments in order to verify this effect. In tool life test, tool wear was obtained as a function of cutting length. In this work, to properly relate the quality of the trimmed laminates as a function of the length of cut expressed in linear meters, two setups were used, one to generate tool wear of several meters and transform the laminate in "chips and dust", and the other to trim test coupons dedicated to full inspection and related to the length of wearing cut achieved at each step of an iterative process. Thus, in each tool life experiment, the cutting tool machined $100 \mathrm{~mm}$ using short cut set-up and then $900 \mathrm{~mm}$ using long cut setup. On the other hand, at first, each tool life experiment started by machining of short panel and then long panel was trimmed alternately. This process was repeated until the tool wear reached the flank wear criterion. This tool life limit indicates that a cutting tool, reaches the end of its useful life. In this work, the tool life criterion was considered an average maximum flank wear of $0.3 \mathrm{~mm}$ according to ISO 8688-2 standard. Figure 2.1 shows the cutting process in the tool life experiment. Figure 2.2 shows short cut and long cut experimental set-ups. In terms of tool life measurement, before each short cut, the tool wear was also measured using optical microscope.

In this study, the second objective was to verify the effect of cutting conditions on the cutting forces, tool life, surface integrity and surface roughness in tool life tests. To study this effect,

during each short cut, the cutting forces were measured using a dynamometer table. Before each short cut, the cutting tool was removed in order to measure the tool wear. Moreover, for each coupon (32 mm wide and $100 \mathrm{~mm}$ long) which was obtained from the short cut, the

surface finish was inspected using SEM micrograph in terms of surface integrity. In terms of surface roughness, the surface finish was evaluated using profilometer. 


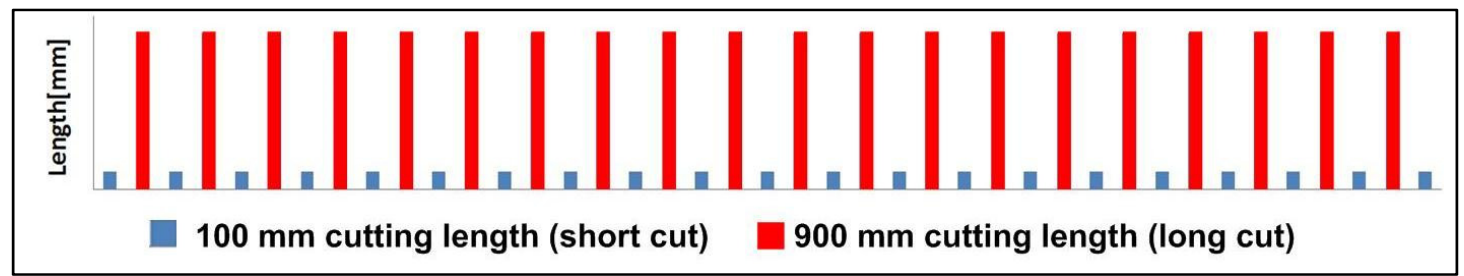

Figure 2.1 Cutting process in each tool life test

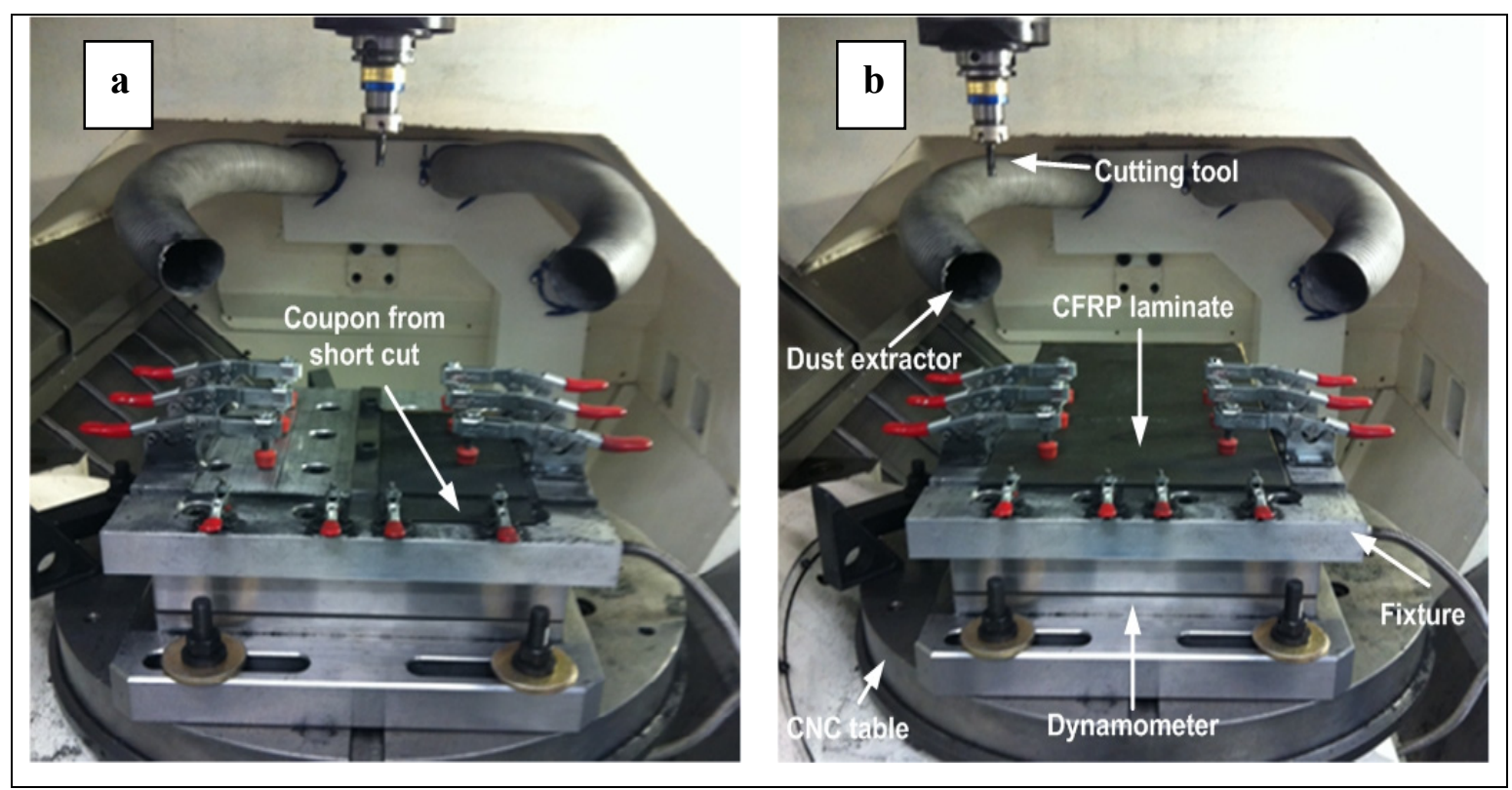

Figure 2.2 Experimental a) short cut set-up and b) long cut set-up

\subsection{Preliminary tests and tool life test conditions}

In this work, the preliminary cutting parameters were selected according to Bérubé (2012) who proposed the best operational conditions including feed rate and cutting speed ranges for similar tool type and composite materials. Three feed rates and three cutting speeds including minimum, intermediate and maximum values of feed rate and cutting speed were chosen from those ranges. Then nine preliminary tests were carried out according to Table 2.1. In each preliminary test, cutting forces in $\mathrm{x}, \mathrm{y}$ and $\mathrm{z}$ directions were recorded. All recorded signals were verified for the absence of distortion using Fast Fourier Transform (FFT) program. In all preliminary tests, the harmonics of the spindle speeds and the tooth passing frequency were not superposed and the recorded signals were harmonic in all directions; 
meaning that the cutting force FFT analysis didn't show the presence of amplification at measuring system resonance. Figure 2.3 shows FFT results in the ninth preliminary test in $\mathrm{x}$, $\mathrm{y}$ and $\mathrm{z}$ directions. In the next chapter, the results of these preliminary experiments are analysed and discussed in terms of effect of cutting parameters on the cutting force and the surface roughness.

Table 2.1 Cutting conditions of preliminary tests

\begin{tabular}{|c|c|c|c|}
\hline Test No. & $\begin{array}{c}\text { Cutting Speed } \\
(\mathbf{m} / \mathbf{m i n})\end{array}$ & \multicolumn{2}{|c|}{ Feed Rate (mm/rev) - (mm/min) } \\
\hline $\mathbf{1}$ & 200 & 0.3048 & 1524 \\
\hline $\mathbf{2}$ & 200 & 0.3556 & 2794 \\
\hline $\mathbf{3}$ & 200 & 0.4064 & 4064 \\
\hline $\mathbf{4}$ & 300 & 0.3048 & 1524 \\
\hline $\mathbf{5}$ & 300 & 0.3556 & 2794 \\
\hline $\mathbf{6}$ & 300 & 0.4064 & 4064 \\
\hline $\mathbf{7}$ & 400 & 0.3048 & 1524 \\
\hline $\mathbf{8}$ & 400 & 0.3556 & 2794 \\
\hline $\mathbf{9}$ & 400 & 0.4064 & 4064 \\
\hline
\end{tabular}

Based on the results of these preliminary tests, three tests were selected in order to carry out the tool life tests. The first test had the highest cutting speed and the lowest feed rate, the second test had the intermediate cutting speed and feed rate and finally the third test had the lowest cutting speed and highest feed rate for our feed rate and cutting speed ranges. Table 2.2 shows the parameters of tool life experiments. All the details of these experiments are presented in chapter 4 . 


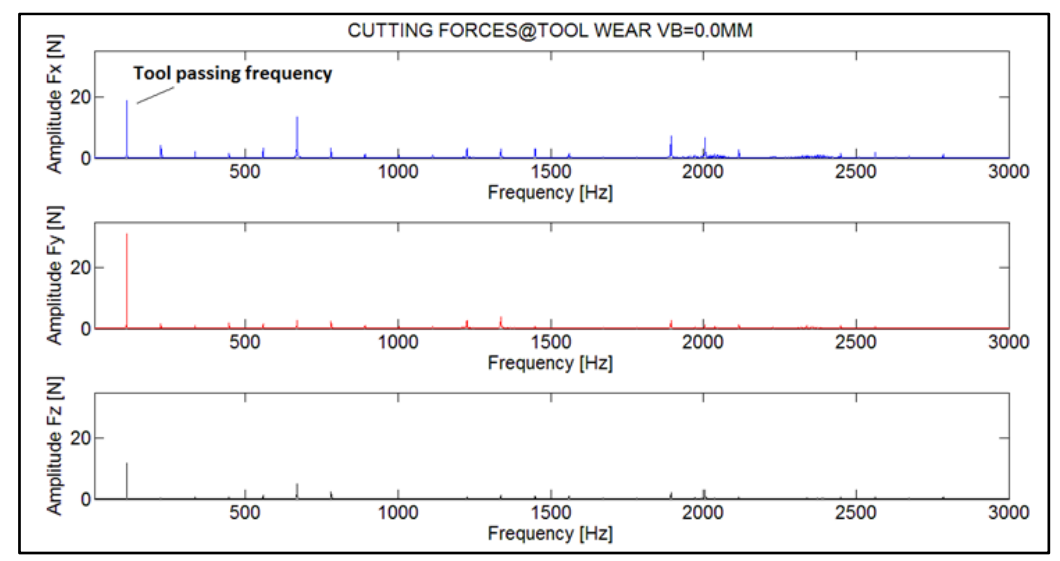

Figure 2.3 FFT results in the ninth preliminary test in $\mathrm{x}, \mathrm{y}$ and $\mathrm{z}$ directions

Table 2.2 Parameters of tool life experiments

\begin{tabular}{|c|c|c|c|}
\hline Test No. & \multicolumn{2}{|c|}{ Feed(mm/min) - (mm/rev) } & Speed(m/min) \\
\hline $\mathbf{1}$ & 1524 & 0.3048 & 400 \\
\hline $\mathbf{2}$ & 2794 & 0.3556 & 300 \\
\hline $\mathbf{3}$ & 4064 & 0.4064 & 200 \\
\hline
\end{tabular}

\subsection{Machining set-up and equipment for experiments}

\subsubsection{Cutting tool}

The end mill router was a 3/8 " CVD diamond coated carbide tool with six flutes. This type of cutting tool was selected according to Bérubé (2012) who proposed the best operational conditions for the same type of tool. The specifications of the cutting tool are shown in Table 2.3 and Figure 2.4 shows the CVD diamond coated carbide cutting tool.

Table 2.3 Cutting tool specifications

\begin{tabular}{|c|c|c|c|c|c|c|c|}
\hline $\begin{array}{c}\text { No. of } \\
\text { Teeth }\end{array}$ & Rake & Relief & Helix & Tool Type & Dia. & $\begin{array}{c}\text { Length } \\
\text { of Cut }\end{array}$ & $\begin{array}{c}\text { Overall } \\
\text { Length }\end{array}$ \\
\hline 6 & $8^{\circ}$ & $10^{\circ}$ & $10^{\circ}$ & Coated Carbide & $3 / 8^{\prime \prime}$ & $1^{\prime \prime}$ & $3^{\prime \prime}$ \\
\hline
\end{tabular}




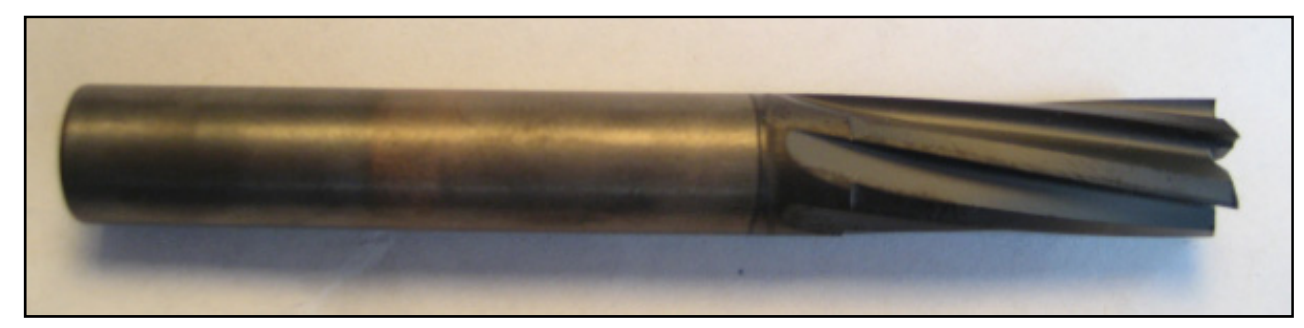

Figure 2.4 CVD coated cutting tool

\subsubsection{Workpiece material}

The workpiece material used in our experiments was an autoclave-cured 24-ply quasiisotropic aerospace CFRP (carbon fiber/ epoxy) laminate produced using pre-impregnated technology, with a fiber volume fraction of $64 \%$ and a stacking sequence [ $\left(90^{\circ}\right.$,$\left.\left.45^{\circ}, 45^{\circ}, 0^{\circ}, 45^{\circ},-45^{\circ}, 45^{\circ},-45^{\circ}, 0^{\circ},-45^{\circ}, 45^{\circ}, 90^{\circ}\right)\right] s$ as shown in Figure 2.5. This stacking sequence resulted in a laminate thickness of $4.44 \mathrm{~mm}$. CFRP laminates are shown in Figure 2.6.

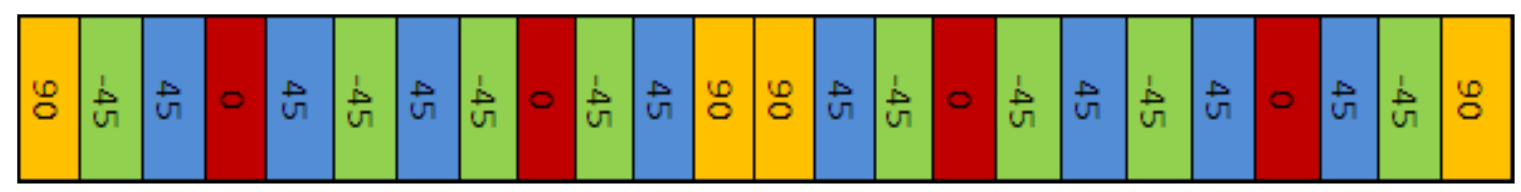

Figure 2.5 Stacking sequence of CFRP laminate

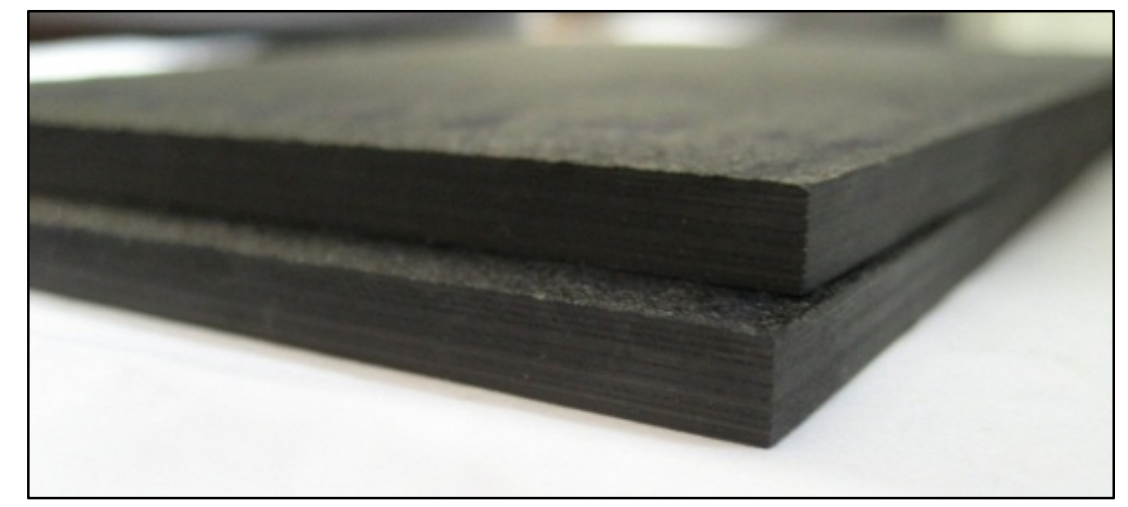

Figure 2.6 CFRP laminates 


\subsubsection{Experimental set-up}

An aluminium fixture was utilized to fix securely the CFRP laminate workpiece. In this fixture, five clamps were used to secure the CFRP panels for short cuts and ten clamps were used for long cuts. The fixture was attached to a 3-axis dynamometer table. The Kistler dynamometer table was mounted on the $\mathrm{CNC}$ table. The Figure 2.7 shows the experimental short cut and long cut set-ups including CFRP laminates, fixture, dynamometer table and $\mathrm{CNC}$ table.

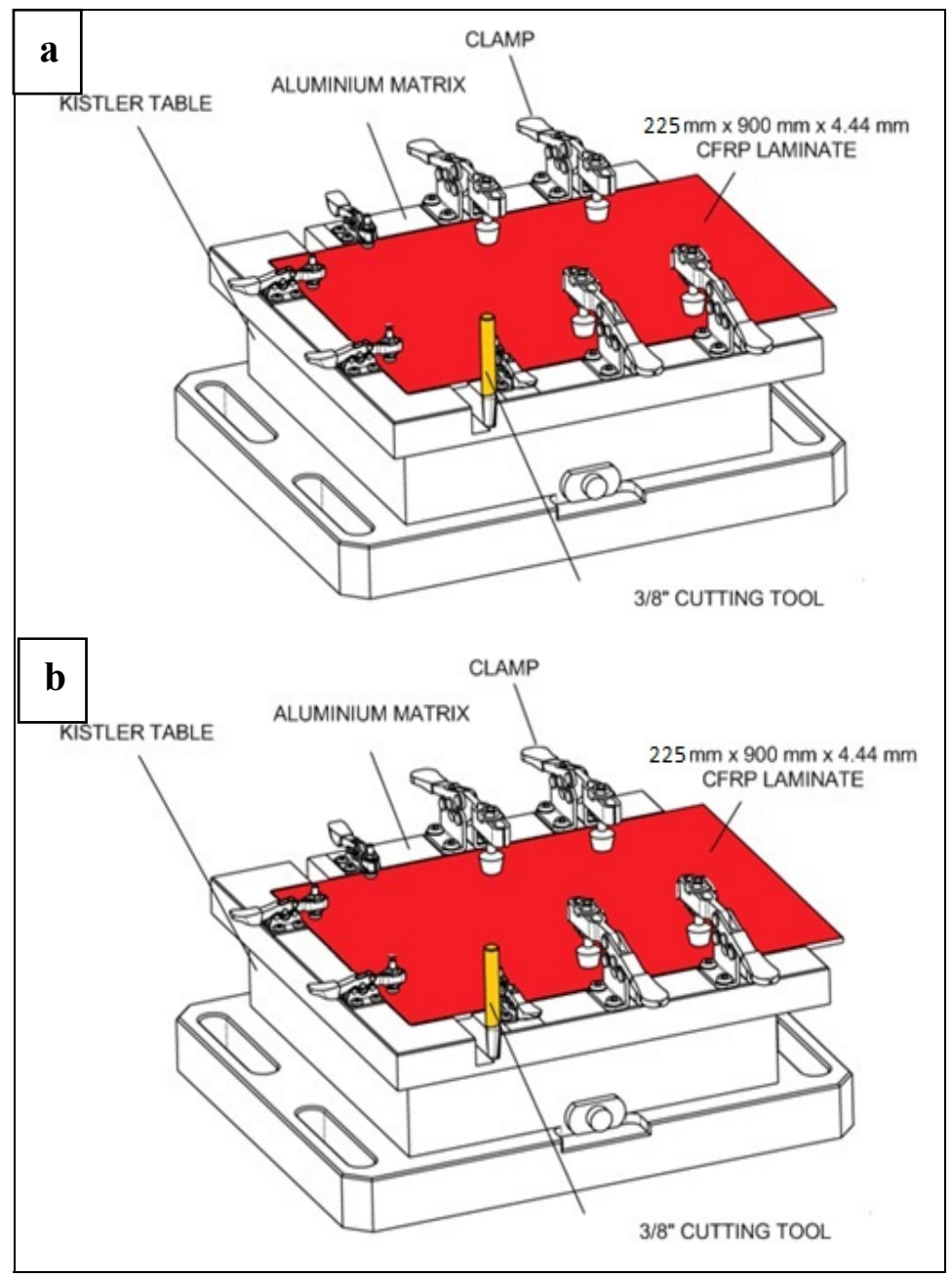

Figure 2.7 Experimental a) short cut set-up and b) long cut set-up 


\subsubsection{CNC cutting machine}

The CNC machine used for the experiments was a 3-axis high speed center HURON K2X8 with a maximum spindle speed of $24000 \mathrm{rpm}$ at $24 \mathrm{kw}$. The $\mathrm{CNC}$ machine is shown in Figure 2.8 and its specifications are presented in Table 2.4. This machine was equipped with a dust extraction system. During machining of CFRPs, it is necessary to utilize vacuum system in order to remove the generated dusts which are harmful for human health.

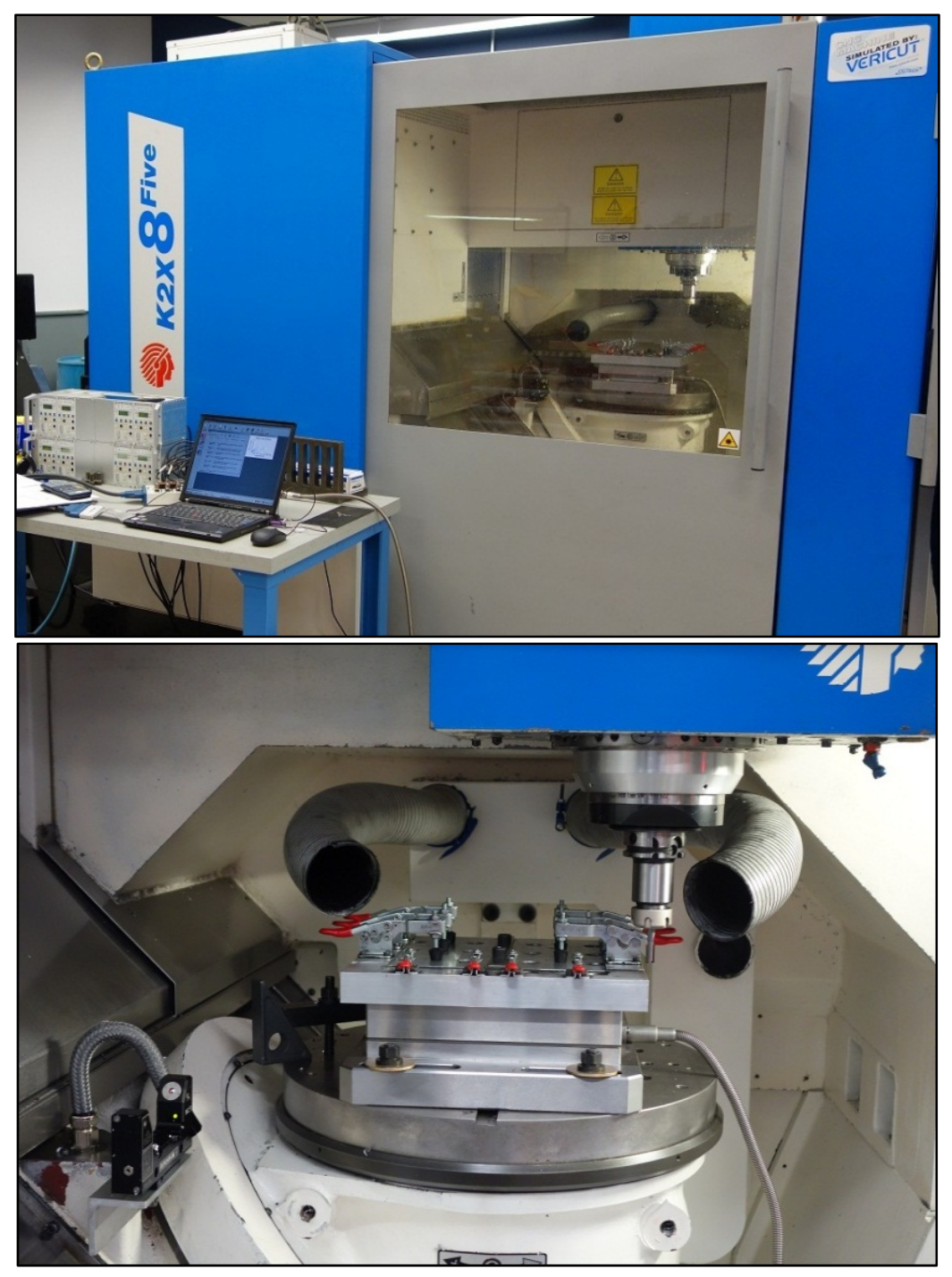

Figure 2.8 HURON K2X8 
Table 2.4 CNC machine specifications

\begin{tabular}{|c|c|}
\hline Machine type & HURON K2X8 five \\
\hline Power (kw) & 24 \\
\hline Minimum Spindle Speed (rpm) & 100 \\
\hline Maximum Spindle Speed (rpm) & 24000 \\
\hline Maximum Feed Rate (m/min) & 50 \\
\hline X Axis (mm) & 650 \\
\hline Y Axis (mm) & 700 \\
\hline Z Axis (mm) & 450 \\
\hline
\end{tabular}

\subsubsection{Force acquisition}

In this work, the cutting forces in $\mathrm{x}, \mathrm{y}$ and $\mathrm{z}$ directions were measured during short cut using Kistler table type $9255 \mathrm{~B}$. The data acquisition system of cutting forces was a table with four piezoelectric gauges to obtain the cutting forces. This system provided the amplitude of cutting force along the three axes. The Kistler table was connected to the charge amplifiers type Kistler 5010. The charge amplifiers produced five output signals which were transmitted to a data acquisition card. A USB communication protocol interpreted the output signals of the data acquisition card using a Matlab-based signal processing program. In this study, the sampling frequency was set at $24 \mathrm{kHz} /$ canal, for a recording time of 20 seconds. To detect the slightest chatter signals, no filter was used on the force signals. The analysis applied on the resulting force signals for different cutting conditions is presented in the chapter 4 . Figure 2.9 shows a three-axis dynamometer table type Kistler 9255B and Figure 2.10 illustrates the dimensions of Kistler table and its measuring coordinate system. 


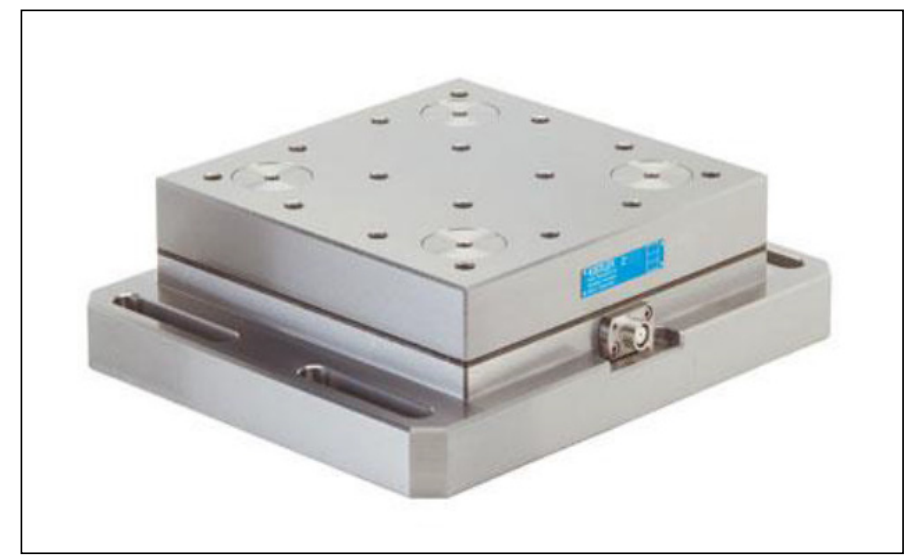

Figure 2.9 Kistler table type 9255 B

Drawn from Kistler catalogue (2013)

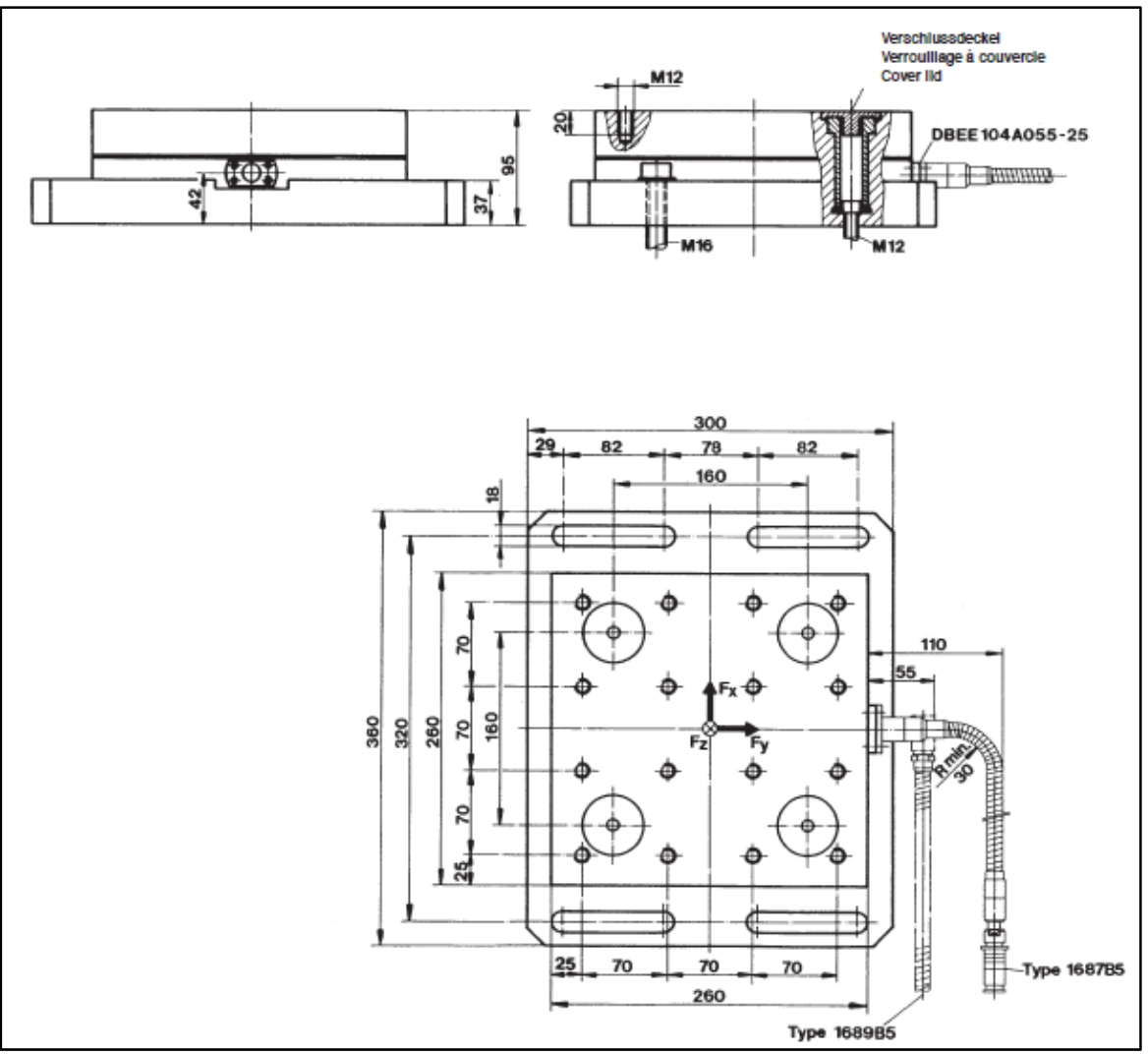

Figure 2.10 Kistler table type 9255 B dimensions and measuring coordinate system

Drawn from Kistler catalogue (2013) 


\subsection{Measurement set-up and equipment for quality evaluation}

\subsubsection{Roughness measurement}

The profilometer is an instrument to measure the surface roughness. In this research, the profilometer type was Mitutoyo SJ-400 SURFPAK with 2 micron tip radius. In order to evaluate the surface roughness, there are two methods. The first one is to verify the roughness profile and the second one is to measure surface roughness using roughness parameters. In terms of the roughness profile, Chatelain et al. (2012) conducted a research on the effect of ply orientation on roughness during trimming process of CFRP laminates. They found that the fiber angle is an important parameter affecting the roughness profile. They also showed that each ply orientation has its own "typical" roughness profile, regardless of machining conditions as shown in Figure 2.11. They concluded that characteristic roughness profiles were identified and found to only relate to the ply orientations of carbon fiber reinforced polymer laminates. Therefore, based on their research, for evaluating surface roughness in our study, we just focused on roughness parameters (for the plies with a specific fiber orientation).

In this work, three roughness parameters; Ra, Rt and Rv (Ra: Arithmetic average, Rt: Maximum Height of the Profile, Rv: maximum valley depth) were selected to evaluate surface roughness. All results were obtained from the $-45^{\circ}$ plies for the up-milling side of the coupons because according to Bérubé (2012), trimming operation generated the worst surface roughness on the $-45^{\circ}$ plies. He also showed that up milling mode obtained a better surface roughness. The surface roughness measurement was performed using the contact profilometer, one ply at a time, over a longitudinal length of $14 \mathrm{~mm}$ in the approximate middle of each ply. 


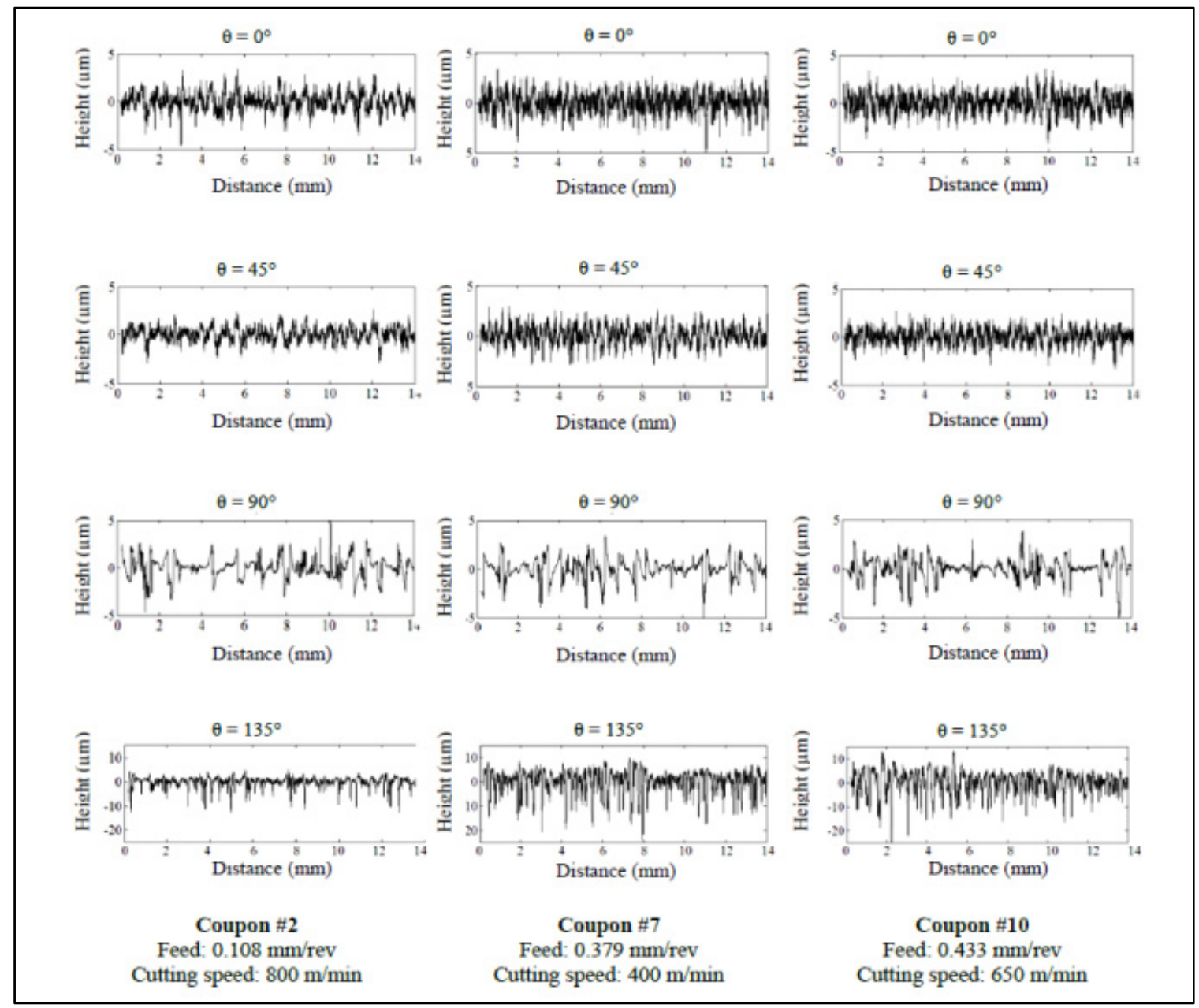

Figure 2.11 Comparison of 4 plies for 3 samples at different cutting conditions

Figure 2.12 illustrates the assembly used during roughness measurement on the surface of trimmed coupons. In our experiments, the longitudinal method was used to measure roughness because as mentioned before, the surface roughness in the transverse direction was mostly higher than that in the longitudinal direction and showed no clear trends with cutting parameters (cutting speed and feed rate). Moreover, the transverse method had very low repeatability. Figure 2.13 shows the longitudinal and transverse measurement directions and shows the parameters of roughness measurement. The cut-off value (the longest nominal wavelength) depends on the range of $\mathrm{Ra}$. In this study, Ra was varied between 1 and $11 \mu \mathrm{m}$, therefore, the value of Lc Cut-off should be chosen $2.5 \mathrm{~mm}$ according to the ANSI B46.1 standard. 


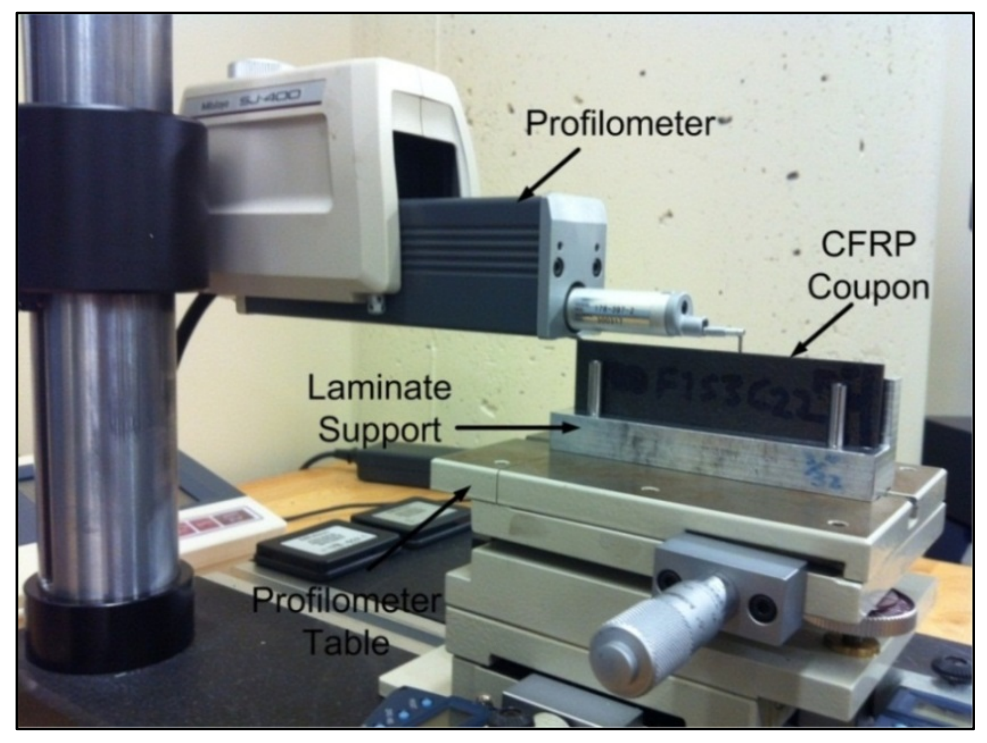

Figure 2.12 Profilometer Mitutoyo type SJ 400 SURFPAK used to measure surface roughness

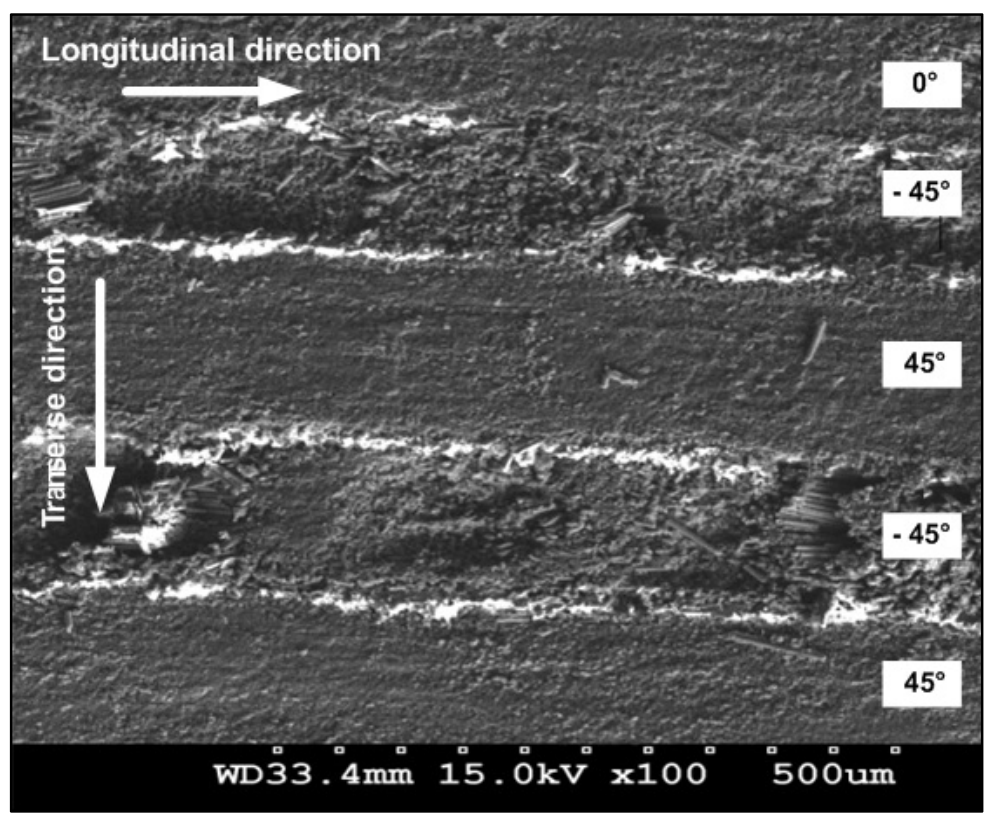

Figure 2.13 Longitudinal and transverse measurement directions 
Table 2.5 Parameters of roughness measurement

\begin{tabular}{|c|c|}
\hline Sampling Length & $\mathbf{1 4} \mathbf{~ m m}$ \\
\hline Cut-off & $2.5 \mathrm{~mm}(1 \mu \mathrm{m}<\mathrm{Ra}<11 \mu \mathrm{m})$ \\
\hline Criteria & $\mathrm{Ra}, \mathrm{Rt}, \mathrm{Rv}(\mu \mathrm{m})$ \\
\hline Evaluation Profile & $(12000$ points $)$ \\
\hline
\end{tabular}

\subsubsection{Tool wear measurement}

In this work, the optical microscope type Keyence VHX-600+500F was used to measure the tool wear. At the beginning of each tool life test, the teeth of cutting tool were marked in order to identify them during tool wear measurement. Before each short cut, the tool holder including cutting tool was removed from $\mathrm{CNC}$ tool magazine, and then the tool holder including cutting tool was mounted and fixed on magnetic clamp as shown in Figure 2.14. For each tooth, the maximum flank wear (VBmax) was measured using this optical microscope. VBmax is the maximum tool wear on the flank face of the cutting tool as shown in Figure 2.15. The cutting tool had six teeth. Tool wear of all six teeth were measured using this optical microscope. Finally, tool wear was calculated according to ISO 8688-2 standard. For the tool life criterion, ISO 8688-2 standard (Tool life testing milling Part2- End milling) recommended two criteria for certain width of flank wear (VB) in metal machining:

1- Uniform wear (average of Vbmax): $0.3 \mathrm{~mm}$ average overall teeth;

2- Localized wear (maximum of $\mathrm{Vbmax}$ ): $0.5 \mathrm{~mm}$ maximum on any individual teeth.

There is no agreement yet on similar criteria for machining FRPs, but a value of VB $=0.2$ $\mathrm{mm}$ has been frequently used (Sheikh-Ahmad, 2009). Khairusshima et al. (2013) also used ISO 8688-2 standard in their study of tool wear during milling of carbon fiber / epoxy. In this study, the tool life criterion (VBmax) was considered average overall teeth of $0.3 \mathrm{~mm}$ according to the first criterion of ISO 8688-2 standard. In addition, the $30 \mathrm{X}$ optical magnification was used for all tool life measurements. 


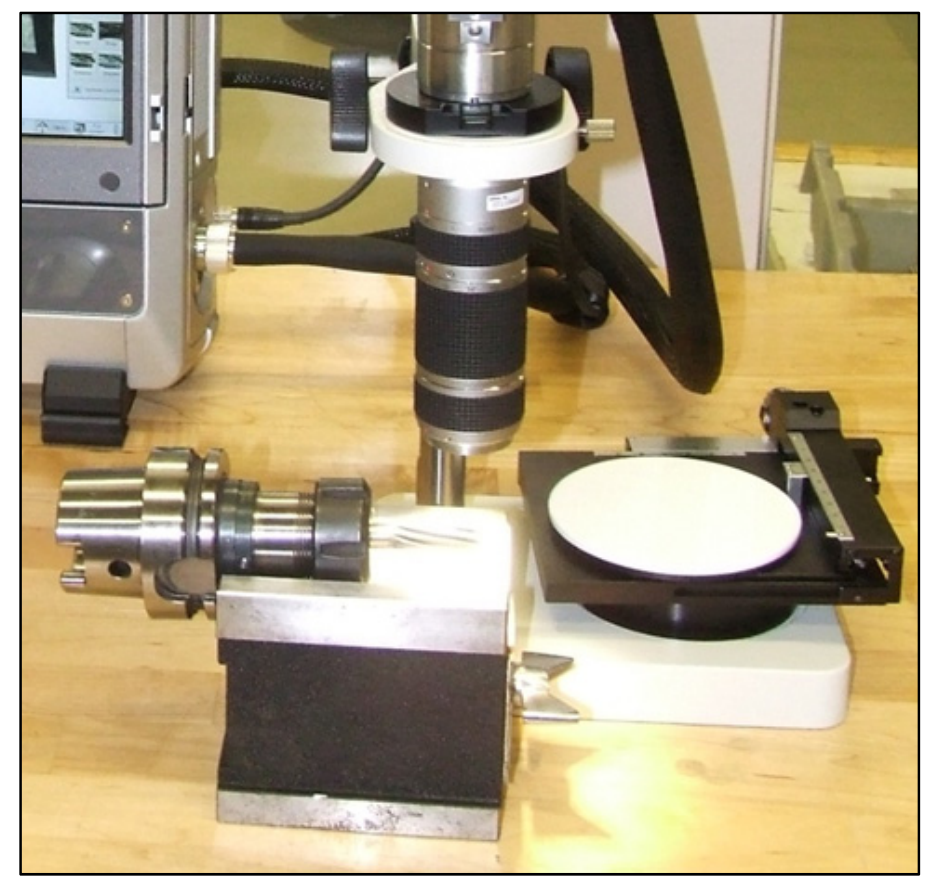

Figure 2.14 Tool holder including cutting tool mounted on magnetic clamp for tool wear measurement

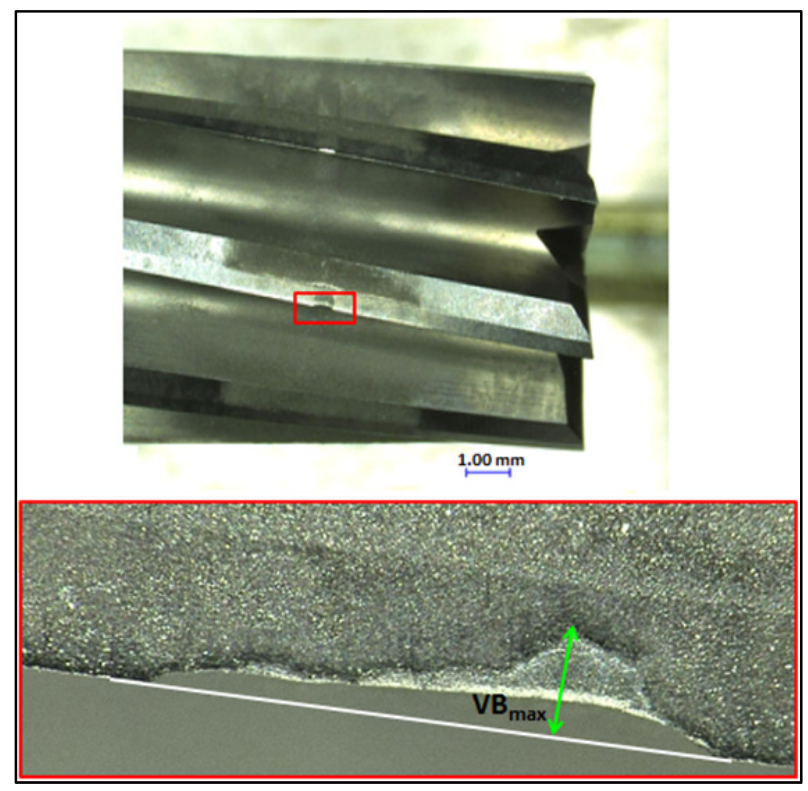

Figure 2.15 Measurement of tool wear (VBmax)

The optical microscope type Keyence VHX-600+500F focuses accurately on the cutting tool edge that could not be targeted on with conventional microscopes. This microscope obtains 
advanced functions that enable ultra-deep and high definition observations. It also provides a variety of user's requests for evaluation time reduction and quality improvement. Observation, recording and measurement can all be performed within this model. Figure 2.16 shows the optical microscope type Keyence VHX-600+500F. Its specifications are also attached in a table in Annex I.

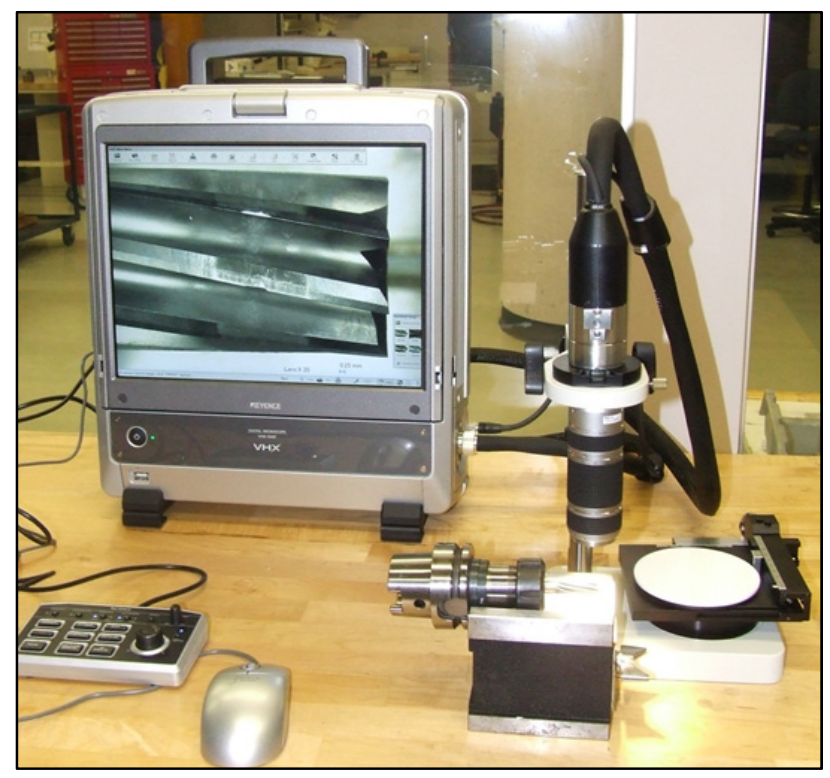

Figure 2.16 Optical microscope type Keyence VHX-600+500F

\subsubsection{Surface integrity evaluation}

In this research, the surface integrity of the trimmed CFRP laminate was verified using a scanning electron microscope type Hitachi S-3600N as shown in Figure2.17a. This scanning electron microscope provides a magnification range between $5 \mathrm{X}$ and $300,000 \mathrm{X}$. The $100 \mathrm{X}$ magnification was used in all measurements. Figure $2.17 \mathrm{~b}$ shows CFRP laminate in the vacuum chamber of scanning electron microscope and the microscope specifications are shown in Table 2.6.

Usually, a scanning electron microscope (SEM) provides images of a specimen using a focused beam of electrons. The electrons interact with electrons in the specimen, providing 
different signals that could be detected and that include information about the specimen's surface topography and its composition. The electron beam is scanned in a raster scan pattern, and the beam's position is mixed with the detected signal in order to provide an image.

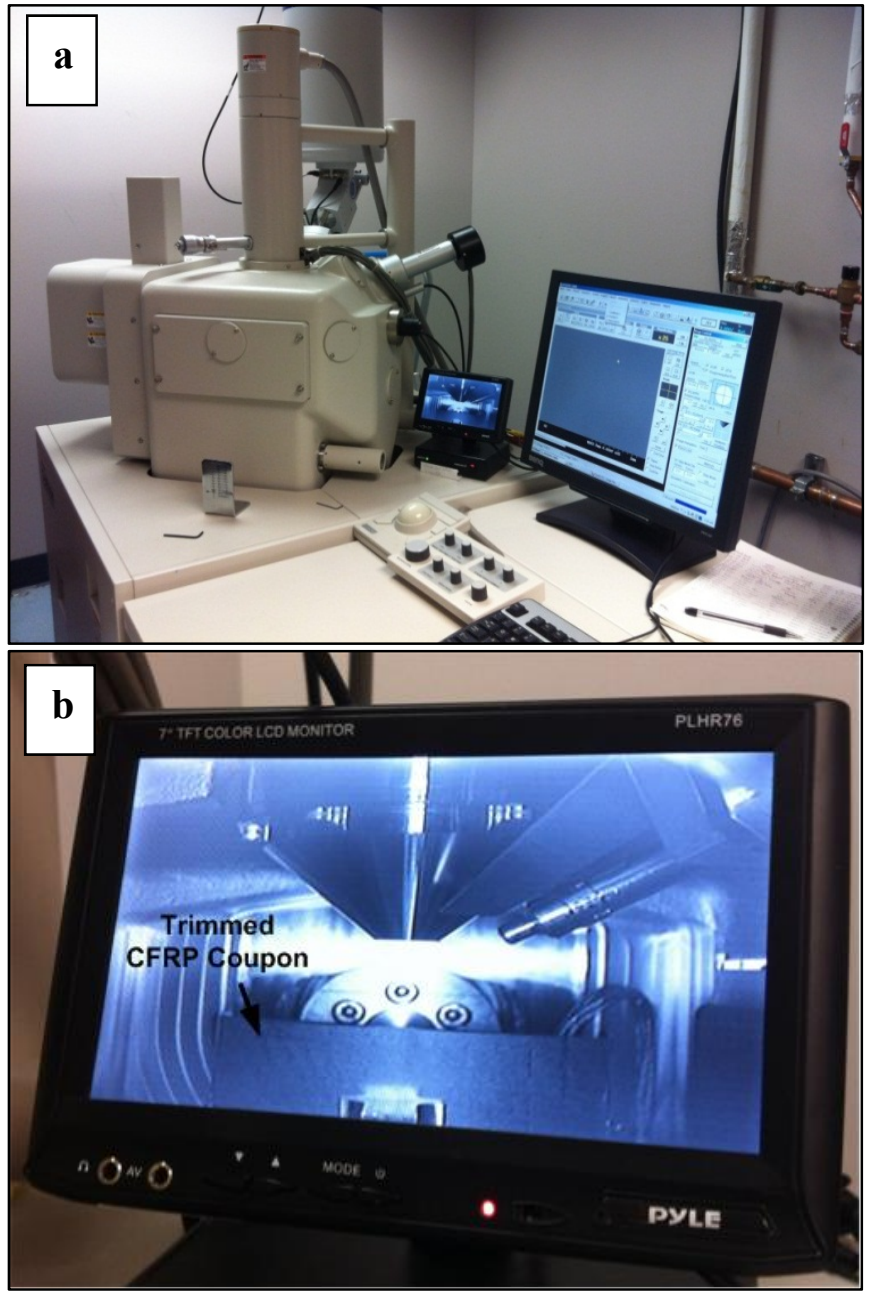

Figure 2.17 a) SEM - type Hitachi S-3600N, b) CFRP laminate in the vacuum chamber of scanning electron microscope 
Table 2.6 Scanning electron microscope specifications type Hitachi S-3600

\begin{tabular}{|c|c|}
\hline Type & Hitachi S-3600 \\
\hline Element & Tungsten \\
\hline Pressure (Pa) & $1-270$ \\
\hline Voltage (kV) & $15-20$ \\
\hline Ampere (mA) & $41-54$ \\
\hline Displacement & 5 axes $(\mathrm{c}=360 \mathrm{deg}, \mathrm{B}=52 \mathrm{deg})$ \\
\hline Zoom & $5 \mathrm{X}-300,000 \mathrm{X}$ \\
\hline
\end{tabular}





\section{CHAPTER 3}

\section{STUDY AND MODELING OF MACHINING PARAMETERS EFFECT ON CUTTING FORCES AND SURFACE ROUGHNESS (PRELIMINARY TESTS)}

\subsection{Introduction}

Validation of the experimental results is necessary in order to remove experimental errors and obtain a level of confidence for results. This validation is carried out by statistical analysis. There are many different types of software that help in order to analyse the results statistically, one of them is Statgraphics. Thanks to this software, it is possible to define the parameters as inputs and outputs and it is feasible to find the statistical relations between them. It also helps to understand the role of each input parameter. In Statgraphics, analysis of variance (ANOVA) finds the level of confidence between the parameters and provides the experimental equations between the parameters. In this study, the results of nine preliminary experiments were used for modeling and prediction of cutting forces and surface roughness during trimming of CFRP laminates using new tool (VBmax $=0 \mathrm{~mm}$ ). Independent variables were feed rate and cutting speed while dependent variables or responses were normal force $(\mathrm{Fx})$, feed force $(\mathrm{Fy})$, axial force $(\mathrm{Fz})$, total force and surface roughness $(\mathrm{Ra})$. In addition, in this modeling, full factorial method was selected. This prediction was developed based on experimental results for cutting forces and surface roughness ( $\mathrm{Ra}$ ) using the spindle speed and feed by multiple linear regressions. Furthermore, ANOVA was employed to verify the effects of various factors on cutting force components, total force and surface roughness (Ra). Finally, the regression equation was proposed for each responses based on independent variables. The objectives of this analysis were to establish a model using multiple regression analysis between feed rate and cutting speed with the cutting forces and the surface roughness during trimming of CFRP using a new tool (nine preliminary tests) and then identify 3 cutting parameters set to pursue the tool wear effect on quality of trimmed CFRP laminates ( 3 tool life tests). Table 3.1 shows the independent variables and Table 3.2 presents the dependent variables in this experimental design. Table 3.3 shows the values of cutting forces and $\mathrm{Ra}$ as a function of the cutting parameters. 
Table 3.1 Independent variables

\begin{tabular}{|c|c|c|c|}
\hline Test No. & \multicolumn{2}{|c|}{ Feed(mm/min) - (mm/rev) } & Speed(m/min) \\
\hline $\mathbf{1}$ & 1524 & 0.3048 & 400 \\
\hline $\mathbf{2}$ & 2794 & 0.3556 & 300 \\
\hline $\mathbf{3}$ & 4064 & 0.4064 & 200 \\
\hline
\end{tabular}

Table 3.2 Dependent variables

\begin{tabular}{|c|}
\hline Responses \\
\hline Fx (Normal Force) $(\mathrm{N})$ \\
\hline Fy (Feed Force) $(\mathrm{N})$ \\
\hline Fz $($ Axial Force) $(\mathrm{N})$ \\
\hline Ft (Total Force) $(\mathrm{N})$ \\
\hline Roughness $(\mathrm{Ra})$ \\
\hline
\end{tabular}

Table 3.3 Values of cutting forces and $\mathrm{Ra}$ as a function of the cutting parameters

\begin{tabular}{|c|c|c|c|c|c|c|c|}
\hline & $\begin{array}{c}\text { Input factor } \\
\mathbf{2}\end{array}$ & $\begin{array}{c}\text { Input factor } \\
\mathbf{1}\end{array}$ & $\begin{array}{c}\text { Response } \\
\mathbf{1}\end{array}$ & $\begin{array}{c}\text { Response } \\
\mathbf{2}\end{array}$ & $\begin{array}{c}\text { Response } \\
\mathbf{3}\end{array}$ & $\begin{array}{c}\text { Response } \\
\mathbf{4}\end{array}$ & $\begin{array}{c}\text { Response } \\
\mathbf{5}\end{array}$ \\
\hline Test No. & $\begin{array}{c}\text { Feed Rate } \\
(\mathrm{mm} / \mathrm{rev})\end{array}$ & $\begin{array}{c}\text { Speed } \\
(\mathrm{m} / \mathrm{min})\end{array}$ & $+\mathrm{Fx}(\mathrm{N})$ & $-\mathrm{Fy}(\mathrm{N})$ & $-\mathrm{Fz}(\mathrm{N})$ & $\mathrm{Ft}(\mathrm{N})$ & $\mathrm{Ra}(\mu \mathrm{m})$ \\
\hline $\mathbf{1}$ & 0.3048 & 200 & 140 & 123 & 23 & 188 & 5.124 \\
\hline $\mathbf{2}$ & 0.3556 & 200 & 222 & 135 & 38 & 263 & 6.184 \\
\hline $\mathbf{3}$ & 0.4064 & 200 & 303 & 139 & 55 & 338 & 7.148 \\
\hline $\mathbf{4}$ & 0.3048 & 300 & 102 & 128 & 13 & 164 & 8.879 \\
\hline $\mathbf{5}$ & 0.3556 & 300 & 166 & 165 & 23 & 235 & 9.923 \\
\hline $\mathbf{6}$ & 0.4064 & 300 & 236 & 180 & 38 & 299 & 13.076 \\
\hline $\mathbf{7}$ & 0.3048 & 400 & 79 & 92 & 11 & 121 & 8.801 \\
\hline $\mathbf{8}$ & 0.3556 & 400 & 139 & 146 & 17 & 203 & 9.933 \\
\hline $\mathbf{9}$ & 0.4064 & 400 & 193 & 202 & 27 & 281 & 13.378 \\
\hline
\end{tabular}




\subsection{Influence of cutting parameters on Fx (Normal force)}

Table 3.4 shows the results of the analysis of variance for Fx (Normal force). According to this table, feed rate and cutting speed both were statistically significant factors because they had P-values less than 0.05 at the $95.0 \%$ confidence level. In this case, the R-Squared statistic was $97.7979 \%$.

Table 3.4 Analysis of Variance for Fx

\begin{tabular}{|c|c|c|c|c|c|}
\hline Source & Sum of Squares & Df & Mean Square & F-Ratio & P-Value \\
\hline A:Feed & 28153.5 & 1 & 28153.5 & 192.82 & 0.0000 \\
\hline B:Speed & 10752.7 & 1 & 10752.7 & 73.64 & 0.0001 \\
\hline Total error & 876.056 & 6 & 146.009 & & \\
\hline Total (corr.) & 39782.2 & 8 & & & \\
\hline
\end{tabular}

R-squared $=97.7979$ percent

R-squared (adjusted for d.f.) $=97.0638$ percent

Standard Error of Est. $=12.0834$

Mean absolute error $=9.06173$

Lag 1 residual autocorrelation $=-0.0136062$

The regression equation of the fitted model for Fx (Normal force) is

$$
\mathrm{Fx}=-176.944+1348.43 * \text { Feed }-0.423333 * \text { Speed }
$$

Where Feed is expressed in $\mathrm{mm} / \mathrm{rev}$ and Speed in $\mathrm{m} / \mathrm{min}$, as expressed in table 3.3.

Figure 3.1 shows Pareto chart and Figure 3.2 displays the main effects plot for Fx. It indicates that Fx (Normal force) increased with an increase in feed rate but it decreased with an increase in cutting speed. 


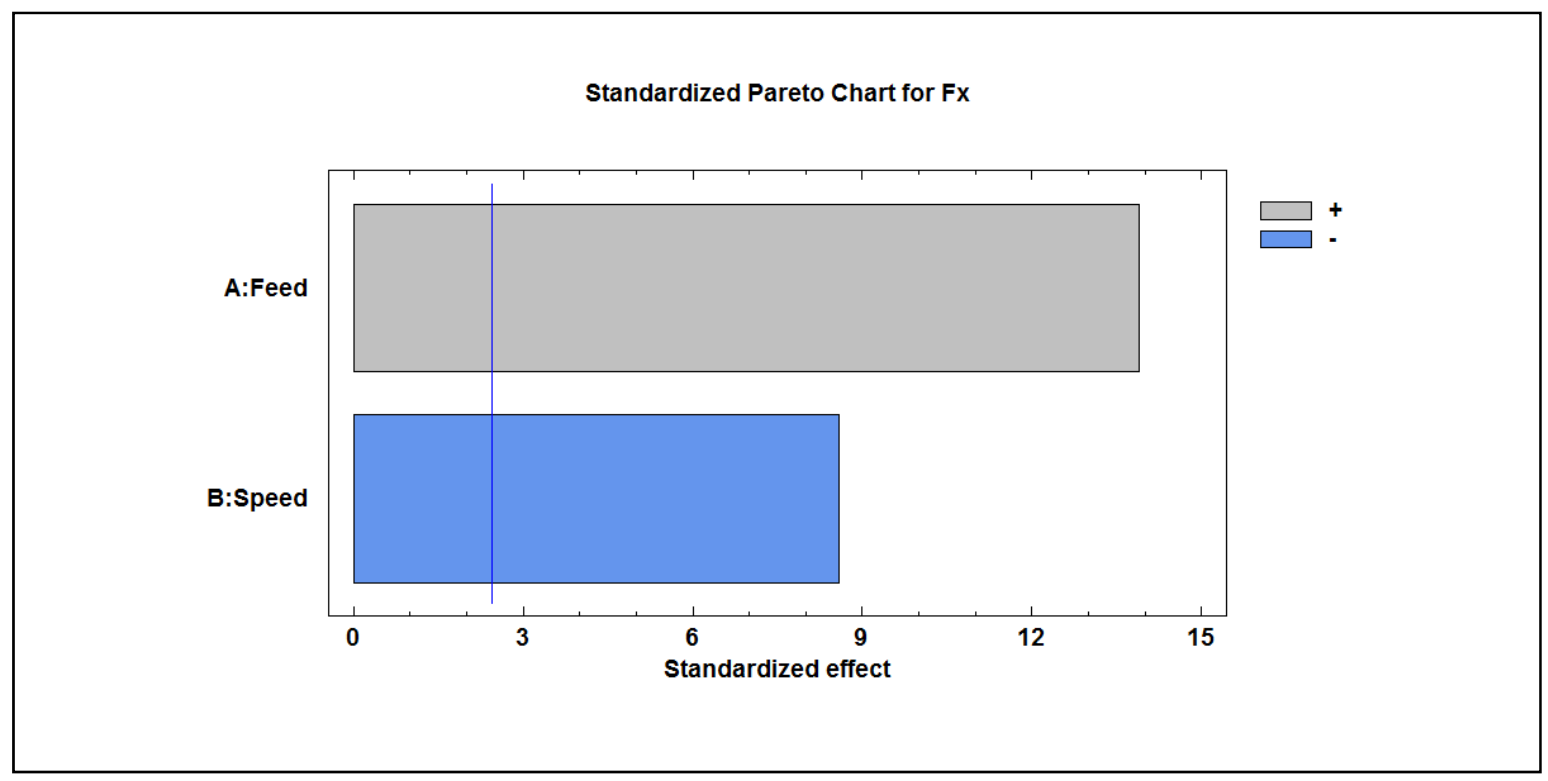

Figure 3.1 Pareto chart for Fx

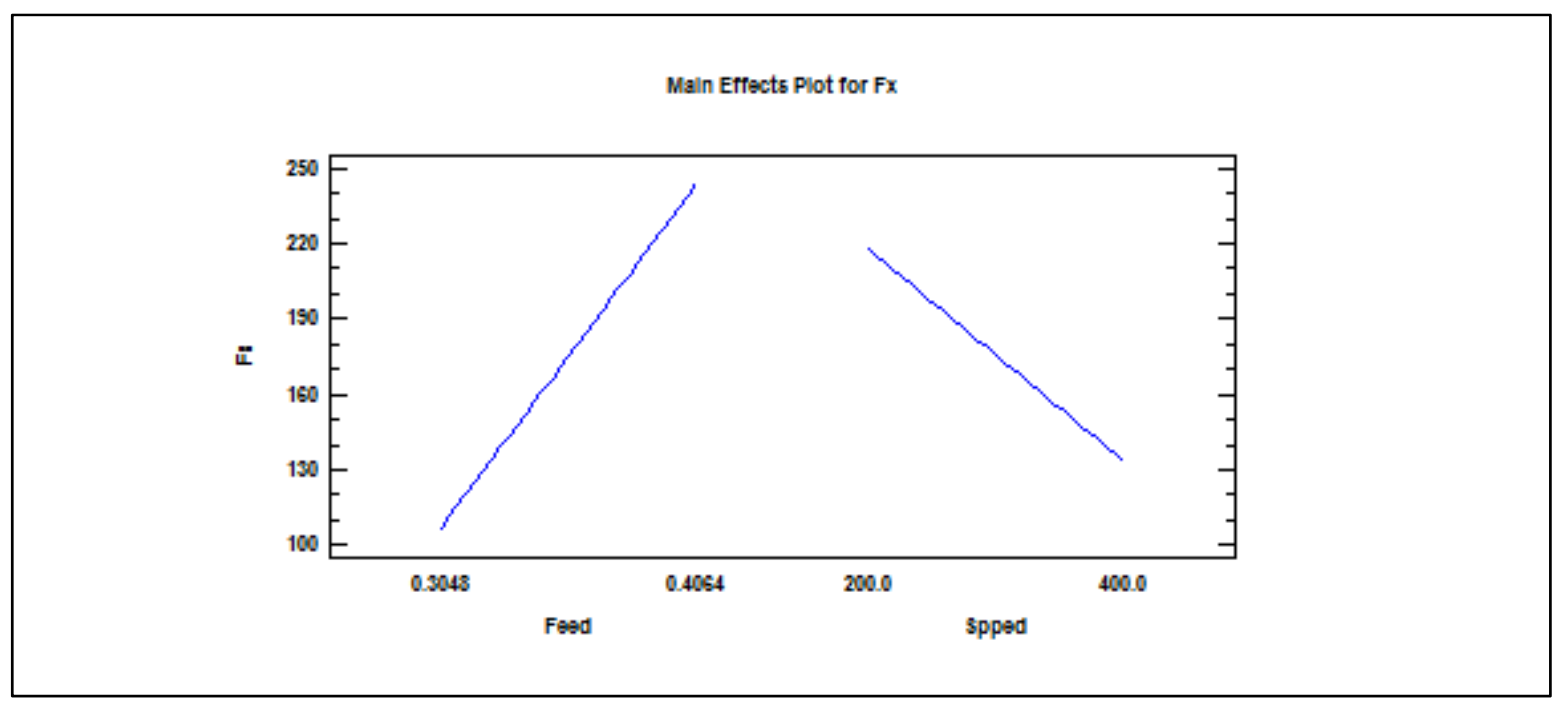

Figure 3.2 Main effects plot for Fx 


\subsection{Influence of cutting parameters on Fy (Feed force)}

Table 3.5 shows the results of the analysis of variance for Fy (Feed force). According to this table, feed rate was a significant factor while cutting speed was not a significant factor because feed rate had P-value less than 0.05 since cutting speed had P-value more than 0.05 at the $95.0 \%$ confidence level. In this case, the R-Squared statistic was $65.0604 \%$.

Table 3.5 Analysis of Variance for Fy

\begin{tabular}{|l|l|l|l|l|l|}
\hline Source & Sum of Squares & Df & Mean Square & F-Ratio & P-Value \\
\hline A:Feed & 5280.67 & 1 & 5280.67 & 10.56 & 0.0175 \\
\hline B:Speed & 308.167 & 1 & 308.167 & 0.62 & 0.4624 \\
\hline Total error & 3001.39 & 6 & 500.231 & & \\
\hline Total (corr.) & 8590.22 & 8 & & & \\
\hline
\end{tabular}

R-squared $=65.0604$ percent

R-squared (adjusted for d.f.) $=53.4139$ percent

Standard Error of Est. $=22.3659$

Mean absolute error $=15.6049$

Lag 1 residual autocorrelation $=-0.0149478$

The regression equation of the fitted model for Fy (Feed force) is

$$
\text { Fy }=-83.6111+583.99 * \text { Feed }+0.0716667 * \text { Speed }
$$

Figure 3.3 shows Pareto chart and Figure 3.4 displays the main effects plot for Fy. It indicates that Fy (Feed force) increased with an increase in feed rate. Fy (Feed force) also slightly increased with an increase in cutting speed but as mentioned before, the effect of cutting speed was not significant according to statistical analysis. 


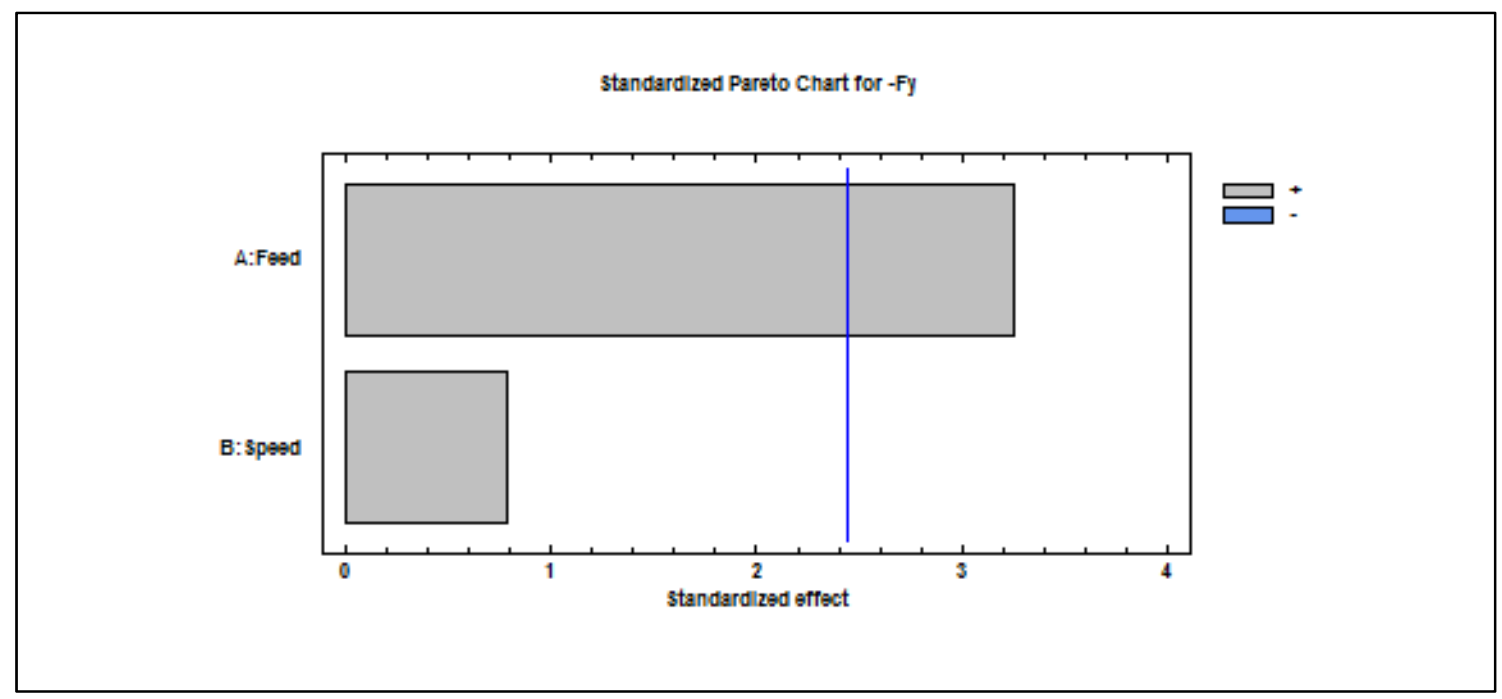

Figure 3.3 Pareto chart for Fy

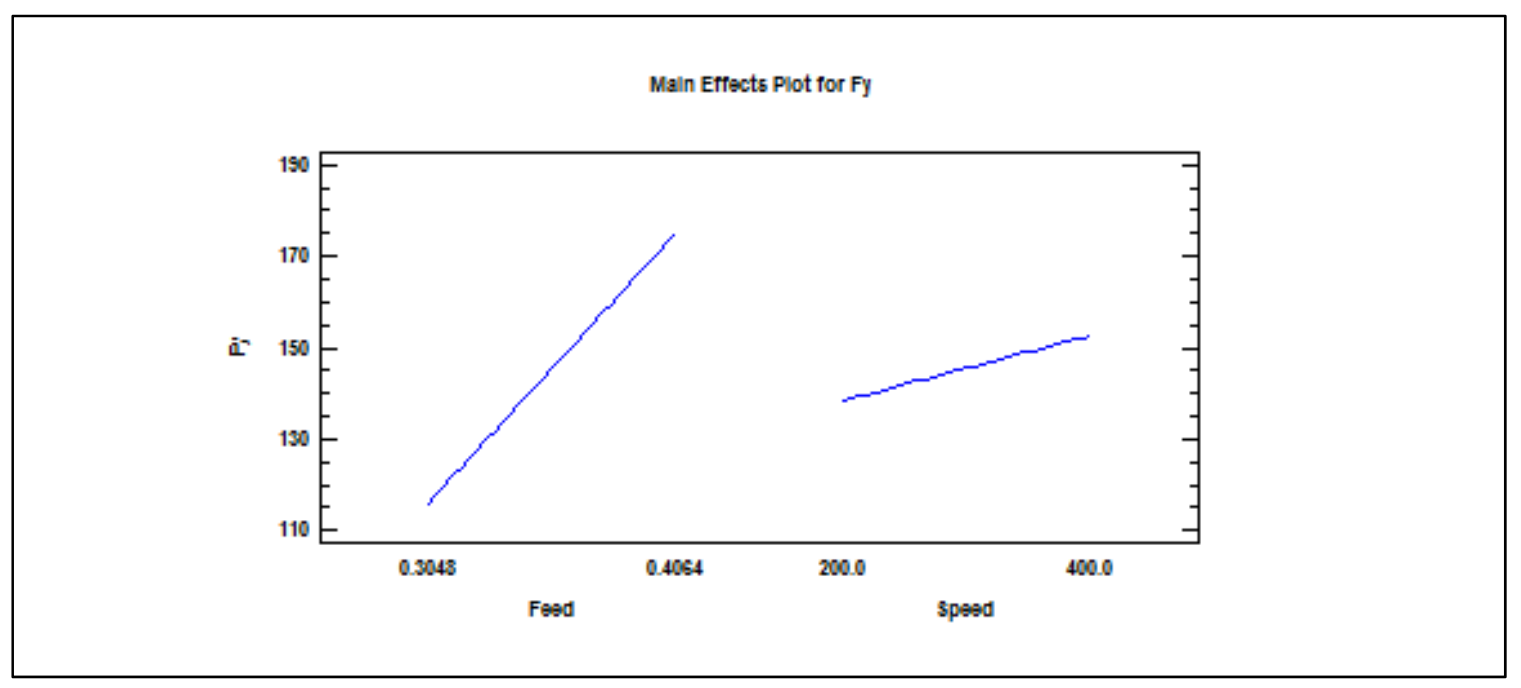

Figure 3.4 Main effects plot for Fy 


\subsection{Influence of cutting parameters on Fz (Axial force)}

Table 3.6 shows the results of the analysis of variance for $\mathrm{Fz}$ (Axial force). According to this table, feed rate and cutting speed both were statistically significant factors because they had P-values less than 0.05 at the $95.0 \%$ confidence level. In this case, the R-Squared statistic was $93.7112 \%$.

Table 3.6 Analysis of Variance for Fz

\begin{tabular}{|c|c|c|c|c|c|}
\hline Source & Sum of Squares & Df & Mean Square & F-Ratio & P-Value \\
\hline A:Feed & 888.167 & 1 & 888.167 & 52.65 & 0.0003 \\
\hline B:Speed & 620.167 & 1 & 620.167 & 36.76 & 0.0009 \\
\hline Total error & 101.222 & 6 & 16.8704 & & \\
\hline Total (corr.) & 1609.56 & 8 & & & \\
\hline
\end{tabular}

R-squared $=93.7112$ percent

R-squared (adjusted for d.f.) $=91.6149$ percent

Standard Error of Est. $=4.10736$

Mean absolute error $=2.7037$

Lag 1 residual autocorrelation $=-0.0334187$

The regression equation of the fitted model for Fz (Axial force) is

$$
\mathrm{Fz}=-27.4444+239.501 * \text { Feed }-0.101667 * \text { Speed }
$$

Figure 3.5 shows Pareto chart and Figure 3.6 displays the main effects plot for Fz. It indicates that $\mathrm{Fz}$ (Axial force) increased with an increase in feed rate but it decreased with an increase in cutting speed. 


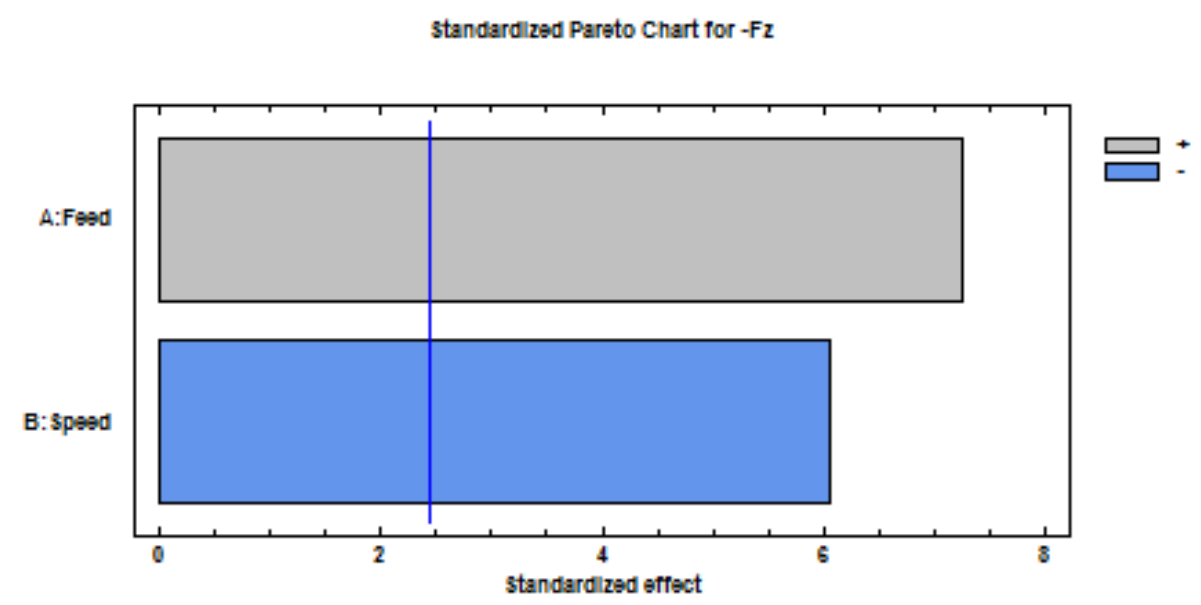

Figure 3.5 Pareto chart for $\mathrm{Fz}$

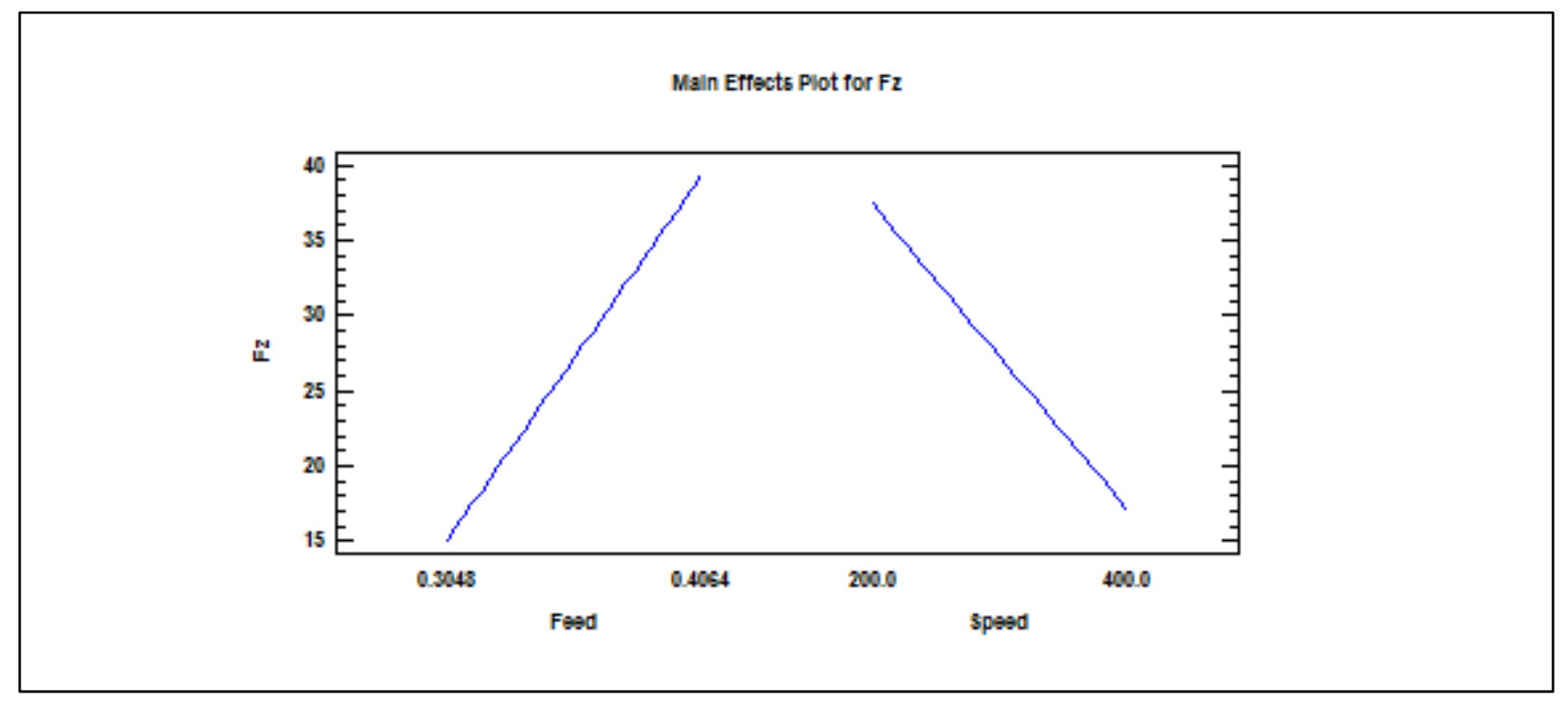

Figure 3.6 Main effects plot for $\mathrm{Fz}$ 


\subsection{Influence of cutting parameters on Ft (Total force)}

Table 3.7 shows the results of the analysis of variance for Ft (Total force). According to this table, feed rate and cutting speed both were statistically significant factors because they had P-values less than 0.05 at the $95.0 \%$ confidence level. In this case, the R-Squared statistic was $99.5636 \%$.

Table 3.7 Analysis of Variance for $\mathrm{Ft}$

\begin{tabular}{|c|c|c|c|c|c|}
\hline Source & Sum of Squares & Df & Mean Square & F-Ratio & P-Value \\
\hline A:Feed & 33004.2 & 1 & 33004.2 & 1169.06 & 0.0000 \\
\hline B:Speed & 5642.67 & 1 & 5642.67 & 199.87 & 0.0000 \\
\hline Total error & 169.389 & 6 & 28.2315 & & \\
\hline Total (corr.) & 38816.2 & 8 & & & \\
\hline
\end{tabular}

R-squared $=99.5636$ percent

R-squared (adjusted for d.f.) $=99.4182$ percent

Standard Error of Est. $=5.31333$

Mean absolute error $=3.39506$

Lag 1 residual autocorrelation $=0.281877$

The regression equation of the fitted model for Ft (Total force) is

$$
\mathrm{Ft}=-194.722+1459.97 * \text { Feed }-0.306667 * \text { Speed }
$$

Figure 3.7 shows Pareto chart and Figure 3.8 displays the main effects plot for Ft. It indicates that $\mathrm{Ft}$ (Total force) increased with an increase in feed rate but it decreased with an increase in cutting speed. 


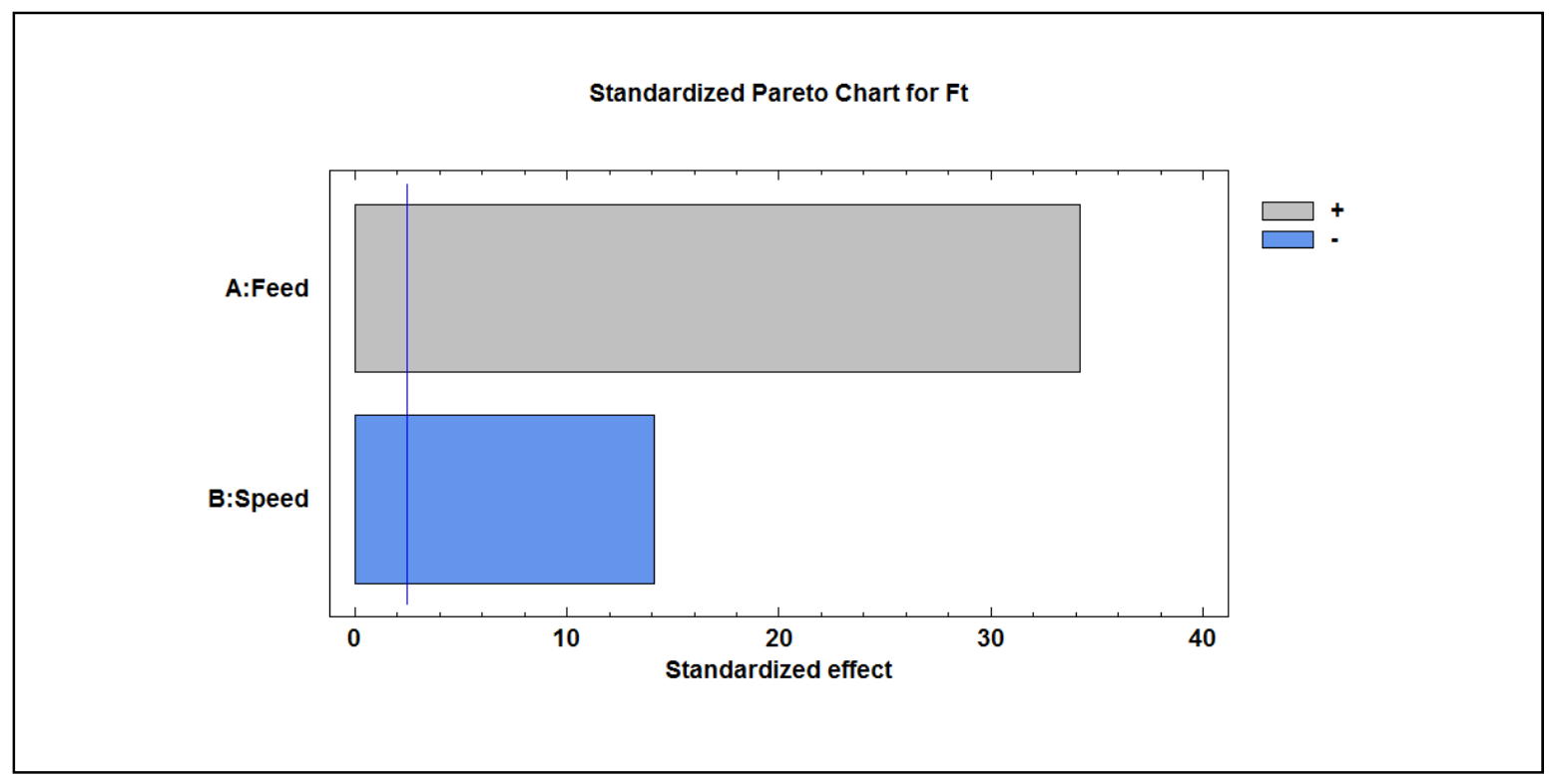

Figure 3.7 Pareto chart for F total

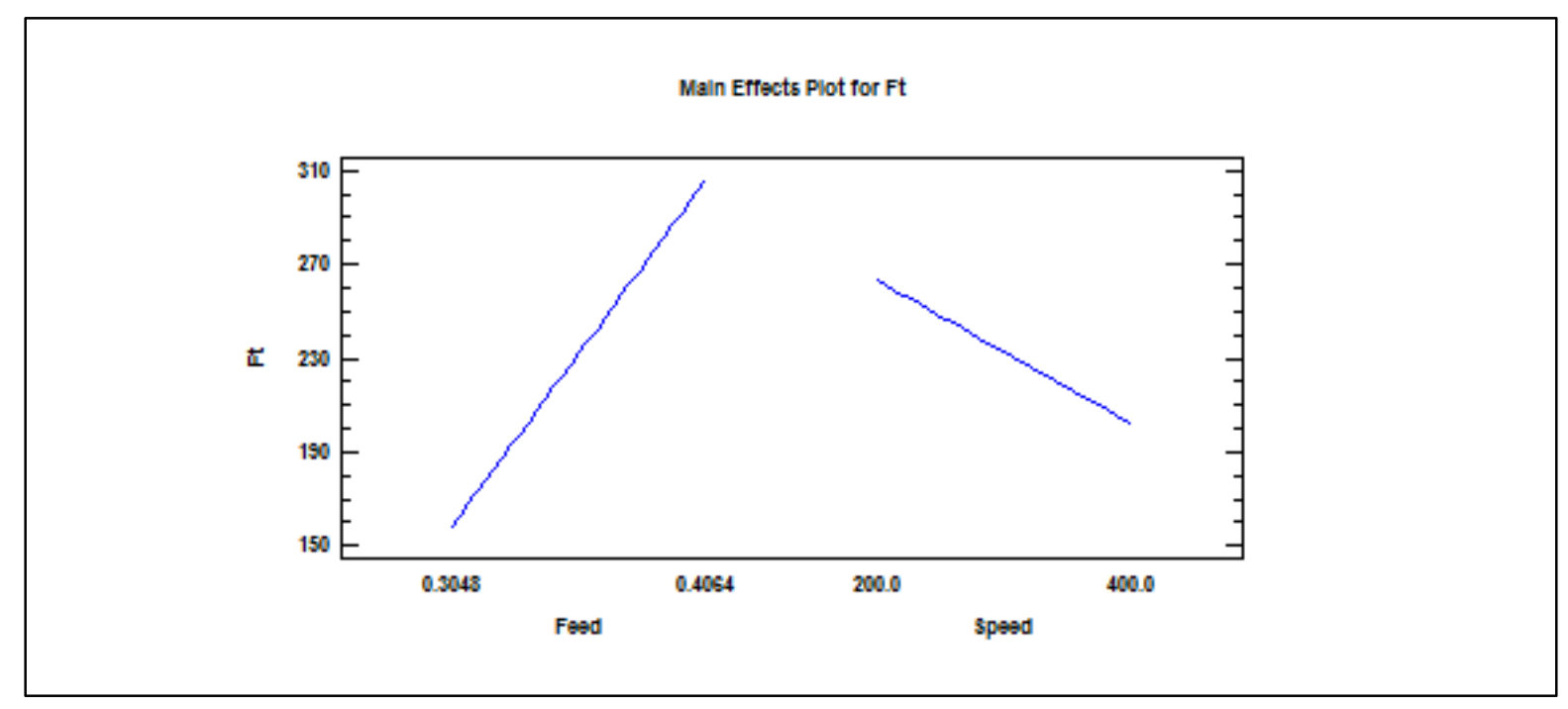

Figure 3.8 Main effects plot for F total 


\subsection{Influence of cutting parameters on Ra (Surface roughness)}

Table 3.8 shows the results of the analysis of variance for Ra (Surface roughness). According to this table, feed rate and cutting speed both were statistically significant factors because they had P-values less than 0.05 at the $95.0 \%$ confidence level. In this case, the R-Squared statistic was $72.2895 \%$.

Table 3.8 Analysis of Variance for Ra

\begin{tabular}{|c|c|c|c|c|c|}
\hline Source & Sum of Squares & Df & Mean Square & F-Ratio & P-Value \\
\hline A:Feed & 19.4328 & 1 & 19.4328 & 8.84 & 0.0249 \\
\hline B:Speed & 31.0811 & 1 & 31.0811 & 14.13 & 0.0094 \\
\hline Total error & 13.1943 & 6 & 2.19905 & & \\
\hline Total (corr.) & 63.7081 & 8 & & & \\
\hline
\end{tabular}

R-squared $=79.2895$ percent

R-squared (adjusted for d.f.) $=72.386$ percent

Standard Error of Est. $=1.48292$

Mean absolute error $=1.01704$

Lag 1 residual autocorrelation $=0.057782$

The regression equation of the fitted model for Ra (Surface roughness) is

$$
\mathrm{Ra}=-10.265+35.4265 * \text { Feed }+0.02276 * \text { Speed }
$$

Figure 3.9 shows Pareto chart and Figure 3.10 displays the main effects plot for Ra. It indicates that $\mathrm{Ra}$ (Surface roughness) increased with an increase in feed rate. It also increased with an increase in cutting speed. 


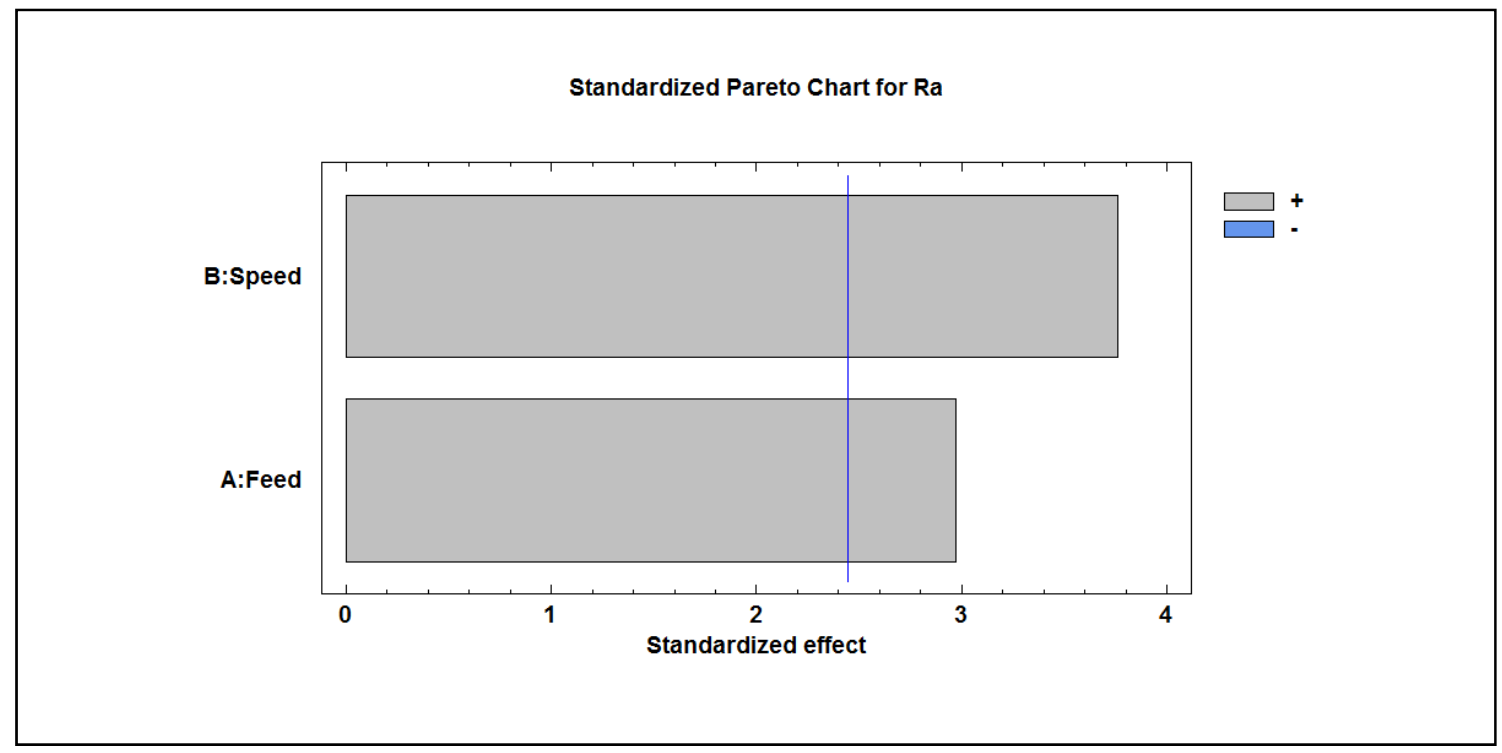

Figure 3.9 Pareto chart for $\mathrm{Ra}$

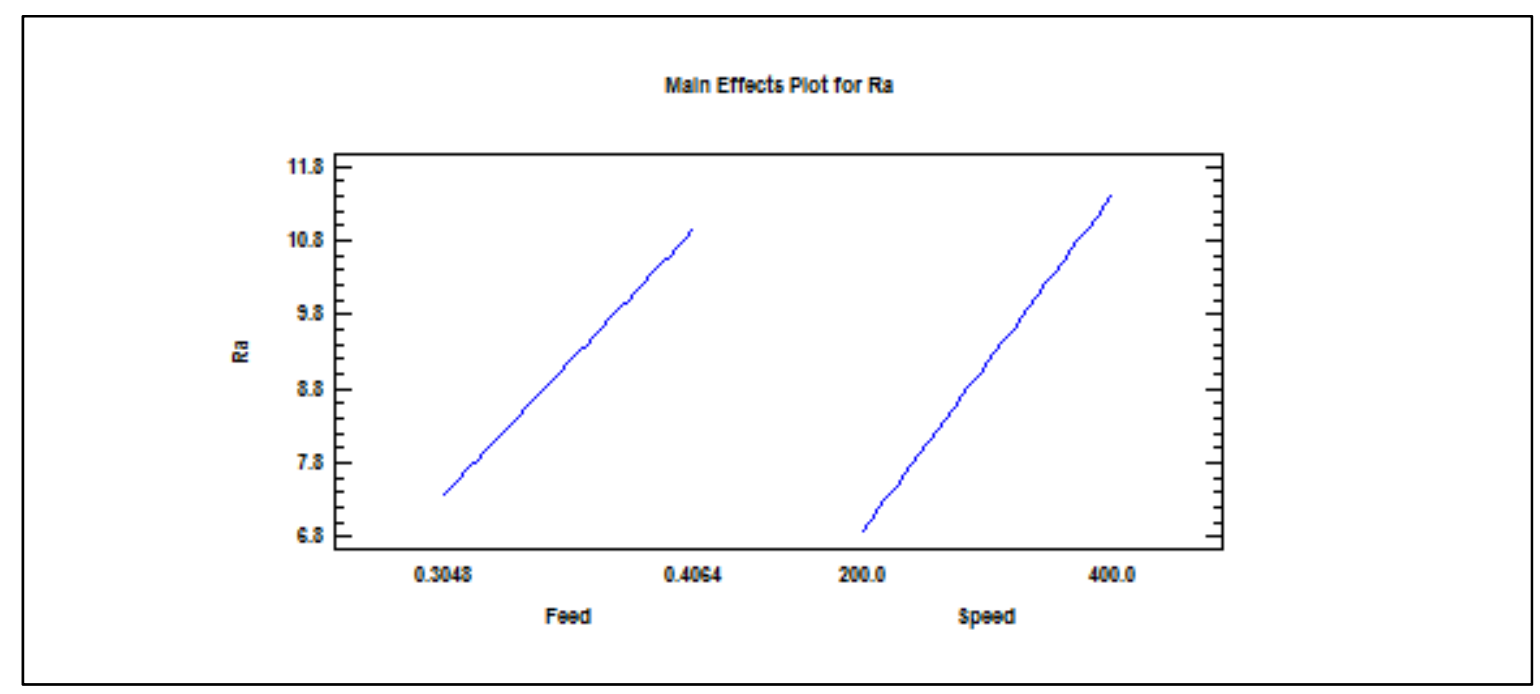

Figure 3.10 Main effects plot for Ra 


\subsection{Conclusion}

Based on these preliminary results, it was found that both, feed rate and cutting speed are significant factors on cutting forces and surface roughness response. For economical reason, since it is important to achieve the tool life for studying the effect of tool wear on quality of trimmed laminates, in next chapter, we propose a focus on three set of machining parameter to perform such a study. 



\section{CHAPTER 4}

\section{TOOL WEAR EFFECT ON QUALITY OF TRIMMED LAMINATES}

\subsection{Analysis of tool life tests}

As presented in chapter 2, three tool life tests are proposed to study the tool wear effect on quality of CFRP laminates. The first one relates to the highest cutting speed with the lowest feed rate, the second one relates to intermediate values of feed rate and cutting speed while the last one relates to the lowest cutting speed and the highest feed rate.

\subsubsection{Tool wear analysis}

Tool condition plays a key role in surface finish. A worn tool could affect surface quality, so tool wear evaluation and analysis are necessary to verify this effect. In all tool life tests (Test 1-3), before the beginning of each tool life test, the cutting tool's teeth were marked in order to identify them during tool wear measurement. Before each short cut, the tool wear (flank wear) was measured for each tooth using optical microscope, and then the average tool wear of six teeth were calculated. In this study, the tool life criterion was considered $0.3 \mathrm{~mm}$ of average VBmax (flank wear) according to ISO 8688-2 standard. Table 4.1-4.3 show the tool wear of each tooth, average tool wear, maximum VBmax and the related cutting length during Test 1-3. In these tables, the cutting length related to tool wear was considered and calculated before each small cut. Figure 4.1-4.3 show the progress of tool wear on the flank face of cutting tool for Teeth \#5 during Test 1-3 respectively. As shown in these figures, with an increase in cutting length, tool wear increased. It could be assumed that, the cutting tool edges (the flank face) deteriorated with an increase in cutting length in all three tool life tests (Test 1-3). 
Table 4.1 Average tool wear, tool wear of teeth, maximum VBmax and their related cutting lengths during Test 1 (Feed: $1524 \mathrm{~mm} / \mathrm{min}$, Speed: $400 \mathrm{~m} / \mathrm{min}$ )

\begin{tabular}{|c|c|c|c|c|c|c|c|c|}
\hline $\begin{array}{l}\text { Cutting } \\
\text { length } \\
\text { (m) }\end{array}$ & $\begin{array}{c}\text { Tool } \\
\text { wear } \\
\text { of } \\
\text { Teeth } \\
\# 1 \\
(\mathrm{~mm})\end{array}$ & $\begin{array}{c}\text { Tool } \\
\text { wear } \\
\text { of } \\
\text { Teeth } \\
\# 2 \\
(\mathrm{~mm})\end{array}$ & $\begin{array}{c}\text { Tool } \\
\text { wear } \\
\text { of } \\
\text { Teeth } \\
\# 3 \\
(\mathrm{~mm})\end{array}$ & $\begin{array}{c}\text { Tool } \\
\text { wear } \\
\text { of } \\
\text { Teeth } \\
\# 4 \\
(\mathrm{~mm})\end{array}$ & $\begin{array}{c}\text { Tool } \\
\text { wear } \\
\text { of } \\
\text { Teeth } \\
\# 5 \\
(\mathrm{~mm})\end{array}$ & $\begin{array}{c}\text { Tool } \\
\text { wear } \\
\text { of } \\
\text { Teeth } \\
\# 6 \\
(\mathrm{~mm})\end{array}$ & $\begin{array}{c}\text { Average } \\
\text { tool } \\
\text { wear } \\
(\mathrm{mm})\end{array}$ & $\begin{array}{c}\text { Maximum } \\
\text { VB max } \\
(\mathbf{m m})\end{array}$ \\
\hline 0 & 0 & 0 & 0 & 0 & 0 & 0 & 0 & 0 \\
\hline 1 & 0.025 & 0.026 & 0.026 & 0.023 & 0.024 & 0.027 & 0.026 & 0.027 \\
\hline 2 & 0.036 & 0.037 & 0.039 & 0.040 & 0.038 & 0.037 & 0.038 & 0.041 \\
\hline 3 & 0.046 & 0.044 & 0.047 & 0.047 & 0.046 & 0.046 & 0.046 & 0.047 \\
\hline 4 & 0.056 & 0.057 & 0.057 & 0.056 & 0.055 & 0.056 & 0.057 & 0.057 \\
\hline 5 & 0.061 & 0.064 & 0.059 & 0.066 & 0.059 & 0.063 & 0.063 & 0.067 \\
\hline 6 & 0.064 & 0.065 & 0.067 & 0.068 & 0.064 & 0.065 & 0.066 & 0.069 \\
\hline 7 & 0.067 & 0.070 & 0.069 & 0.072 & 0.068 & 0.067 & 0.069 & 0.072 \\
\hline 8 & 0.068 & 0.071 & 0.071 & 0.073 & 0.072 & 0.073 & 0.072 & 0.073 \\
\hline 9 & 0.072 & 0.073 & 0.073 & 0.073 & 0.073 & 0.074 & 0.073 & 0.074 \\
\hline 10 & 0.074 & 0.074 & 0.074 & 0.076 & 0.075 & 0.074 & 0.075 & 0.077 \\
\hline 11 & 0.077 & 0.075 & 0.077 & 0.079 & 0.076 & 0.075 & 0.077 & 0.079 \\
\hline 12 & 0.078 & 0.076 & 0.078 & 0.080 & 0.078 & 0.075 & 0.078 & 0.080 \\
\hline 13.9 & 0.079 & 0.076 & 0.078 & 0.080 & 0.078 & 0.075 & 0.078 & 0.080 \\
\hline 15.8 & 0.079 & 0.076 & 0.079 & 0.084 & 0.078 & 0.075 & 0.079 & 0.084 \\
\hline 17.7 & 0.090 & 0.076 & 0.080 & 0.103 & 0.078 & 0.075 & 0.084 & 0.103 \\
\hline 19.6 & 0.113 & 0.076 & 0.081 & 0.139 & 0.107 & 0.082 & 0.100 & 0.140 \\
\hline 21.5 & 0.115 & 0.076 & 0.081 & 0.140 & 0.107 & 0.135 & 0.109 & 0.140 \\
\hline 23.4 & 0.116 & 0.076 & 0.081 & 0.142 & 0.109 & 0.171 & 0.116 & 0.171 \\
\hline 25.3 & 0.139 & 0.078 & 0.157 & 0.267 & 0.245 & 0.212 & 0.183 & 0.267 \\
\hline 27.2 & 0.172 & 0.106 & 0.399 & 0.298 & 0.279 & 0.266 & 0.254 & 0.400 \\
\hline 28.2 & 0.388 & 0.485 & 0.459 & 0.328 & 0.408 & 0.447 & 0.420 & 0.485 \\
\hline
\end{tabular}


Table 4.2 Average tool wear, tool wear of teeth, maximum VBmax and their related cutting lengths during Test 2 (Feed: $2794 \mathrm{~mm} / \mathrm{min}$, Speed: $300 \mathrm{~m} / \mathrm{min}$ )

\begin{tabular}{|c|c|c|c|c|c|c|c|c|}
\hline $\begin{array}{l}\text { Cutting } \\
\text { length } \\
\text { (m) }\end{array}$ & $\begin{array}{c}\text { Tool } \\
\text { wear of } \\
\text { Teeth } \\
\# 1 \\
(\mathrm{~mm})\end{array}$ & $\begin{array}{c}\text { Tool } \\
\text { wear } \\
\text { of } \\
\text { Teeth } \\
\# 2 \\
(\mathrm{~mm})\end{array}$ & $\begin{array}{c}\text { Tool } \\
\text { wear of } \\
\text { Teeth } \\
\# 3 \\
(\mathrm{~mm})\end{array}$ & $\begin{array}{c}\text { Tool } \\
\text { wear of } \\
\text { Teeth } \\
\# 4 \\
(\mathrm{~mm})\end{array}$ & $\begin{array}{c}\text { Tool } \\
\text { wear of } \\
\text { Teeth } \\
\# 5 \\
(\mathrm{~mm})\end{array}$ & $\begin{array}{c}\text { Tool } \\
\text { wear of } \\
\text { Teeth } \\
\# 6 \\
(\mathrm{~mm})\end{array}$ & $\begin{array}{c}\text { Average } \\
\text { tool } \\
\text { wear } \\
(\mathrm{mm})\end{array}$ & $\begin{array}{c}\text { Maximum } \\
\text { VB max } \\
(\mathbf{m m})\end{array}$ \\
\hline 0 & 0 & 0 & 0 & 0 & 0 & 0 & 0 & 0 \\
\hline 1 & 0.032 & 0.035 & 0.037 & 0.032 & 0.035 & 0.036 & 0.035 & 0.038 \\
\hline 2 & 0.042 & 0.041 & 0.046 & 0.046 & 0.043 & 0.047 & 0.044 & 0.047 \\
\hline 3 & 0.055 & 0.051 & 0.094 & 0.059 & 0.064 & 0.055 & 0.063 & 0.095 \\
\hline 4 & 0.099 & 0.070 & 0.121 & 0.062 & 0.066 & 0.063 & 0.082 & 0.128 \\
\hline 5 & 0.144 & 0.071 & 0.154 & 0.064 & 0.067 & 0.064 & 0.094 & 0.155 \\
\hline 6 & 0.177 & 0.075 & 0.166 & 0.068 & 0.068 & 0.065 & 0.103 & 0.178 \\
\hline 7 & 0.180 & 0.075 & 0.186 & 0.069 & 0.070 & 0.067 & 0.108 & 0.186 \\
\hline 8 & 0.189 & 0.109 & 0.192 & 0.069 & 0.123 & 0.072 & 0.126 & 0.192 \\
\hline 9 & 0.216 & 0.162 & 0.195 & 0.072 & 0.171 & 0.073 & 0.149 & 0.217 \\
\hline 10 & 0.285 & 0.179 & 0.197 & 0.073 & 0.186 & 0.074 & 0.166 & 0.285 \\
\hline 11 & 0.288 & 0.179 & 0.198 & 0.073 & 0.294 & 0.187 & 0.204 & 0.295 \\
\hline 12 & 0.371 & 0.235 & 0.212 & 0.108 & 0.306 & 0.230 & 0.244 & 0.372 \\
\hline 13 & 0.386 & 0.236 & 0.241 & 0.202 & 0.330 & 0.231 & 0.271 & 0.387 \\
\hline 14 & 0.487 & 0.258 & 0.255 & 0.213 & 0.331 & 0.280 & 0.304 & 0.487 \\
\hline 15 & 0.534 & 0.532 & 0.329 & 0.296 & 0.400 & 0.442 & 0.423 & 0.534 \\
\hline
\end{tabular}


Table 4.3 Average tool wear, tool wear of teeth, maximum VBmax and their related cutting lengths during Test 3 (Feed: $4064 \mathrm{~mm} / \mathrm{min}$, Speed: $200 \mathrm{~m} / \mathrm{min}$ )

\begin{tabular}{|c|c|c|c|c|c|c|c|c|}
\hline $\begin{array}{l}\text { Cutting } \\
\text { length } \\
\text { (m) }\end{array}$ & $\begin{array}{c}\text { Tool } \\
\text { wear } \\
\text { of } \\
\text { Teeth } \\
\# 1 \\
(\mathrm{~mm}) \\
\end{array}$ & $\begin{array}{c}\text { Tool } \\
\text { wear } \\
\text { of } \\
\text { Teeth } \\
\# 2 \\
(\mathrm{~mm}) \\
\end{array}$ & $\begin{array}{c}\text { Tool } \\
\text { wear } \\
\text { of } \\
\text { Teeth } \\
\# 3 \\
(\mathrm{~mm}) \\
\end{array}$ & $\begin{array}{c}\text { Tool } \\
\text { wear } \\
\text { of } \\
\text { Teeth } \\
\# 4 \\
(\mathrm{~mm}) \\
\end{array}$ & $\begin{array}{c}\text { Tool } \\
\text { wear of } \\
\text { Teeth } \\
\# 5 \\
(\mathrm{~mm})\end{array}$ & $\begin{array}{c}\text { Tool } \\
\text { wear } \\
\text { of } \\
\text { Teeth } \\
\# 6 \\
(\mathrm{~mm}) \\
\end{array}$ & $\begin{array}{c}\text { Average } \\
\text { tool wear } \\
(\mathbf{m m})\end{array}$ & $\begin{array}{c}\text { Maximum } \\
\text { VBmax } \\
(\mathbf{m m})\end{array}$ \\
\hline $\mathbf{0}$ & 0 & 0 & 0 & 0 & 0 & 0 & 0 & 0 \\
\hline 1 & 0.037 & 0.035 & 0.034 & 0.036 & 0.036 & 0.035 & 0.036 & 0.038 \\
\hline 2 & 0.044 & 0.043 & 0.035 & 0.036 & 0.036 & 0.037 & 0.039 & 0.044 \\
\hline 3 & 0.046 & 0.045 & 0.045 & 0.048 & 0.048 & 0.046 & 0.047 & 0.049 \\
\hline 4 & 0.119 & 0.046 & 0.045 & 0.141 & 0.098 & 0.054 & 0.084 & 0.141 \\
\hline 5 & 0.163 & 0.462 & 0.106 & 0.142 & 0.150 & 0.133 & 0.124 & 0.163 \\
\hline 6 & 0.164 & 0.050 & 0.135 & 0.143 & 0.151 & 0.134 & 0.130 & 0.164 \\
\hline 7 & 0.166 & 0.051 & 0.144 & 0.144 & 0.155 & 0.148 & 0.135 & 0.166 \\
\hline 8 & 0.170 & 0.055 & 0.164 & 0.156 & 0.171 & 0.155 & 0.145 & 0.172 \\
\hline 9 & 0.172 & 0.055 & 0.165 & 0.174 & 0.177 & 0.159 & 0.151 & 0.177 \\
\hline 10 & 0.178 & 0.055 & 0.175 & 0.181 & 0.208 & 0.166 & 0.161 & 0.209 \\
\hline 11 & 0.199 & 0.058 & 0.190 & 0.257 & 0.219 & 0.166 & 0.182 & 0.257 \\
\hline 12 & 0.207 & 0.061 & 0.196 & 0.257 & 0.222 & 0.182 & 0.188 & 0.257 \\
\hline 13 & 0.205 & 0.061 & 0.207 & 0.258 & 0.226 & 0.183 & 0.190 & 0.258 \\
\hline 14 & 0.212 & 0.066 & 0.322 & 0.259 & 0.298 & 0.191 & 0.225 & 0.323 \\
\hline 15 & 0.224 & 0.119 & 0.336 & 0.262 & 0.312 & 0.212 & 0.245 & 0.336 \\
\hline 16 & 0.252 & 0.170 & 0.340 & 0.267 & 0.315 & 0.239 & 0.265 & 0.341 \\
\hline 17 & 0.255 & 0.173 & 0.340 & 0.268 & 0.318 & 0.240 & 0.266 & 0.340 \\
\hline 18 & 0.259 & 0.173 & 0.341 & 0.269 & 0.319 & 0.241 & 0.267 & 0.341 \\
\hline 19 & 0.260 & 0.178 & 0.342 & 0.270 & 0.320 & 0.241 & 0.269 & 0.343 \\
\hline 20 & 0.261 & 0.182 & 0.343 & 0.271 & 0.321 & 0.242 & 0.270 & 0.343 \\
\hline
\end{tabular}




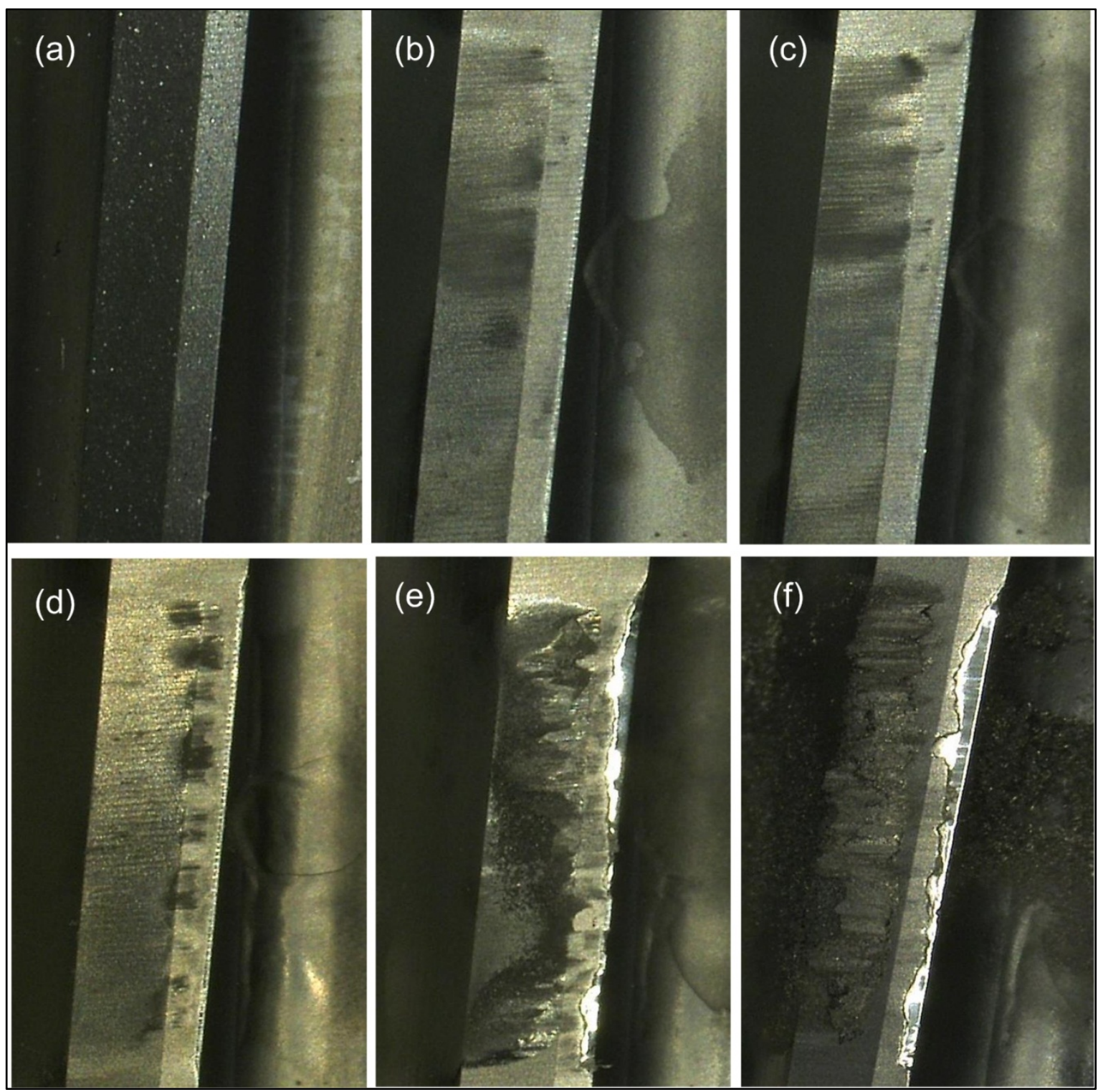

Figure 4.1Tool wear at a) 0, b) 4, c) 9, d) 15.8, e) 27.2 and f) 28.2 meters of cut for Tooth \#5 in Test 1 (Feed: $1524 \mathrm{~mm} / \mathrm{min}$, Speed: $400 \mathrm{~m} / \mathrm{min}$ ) 


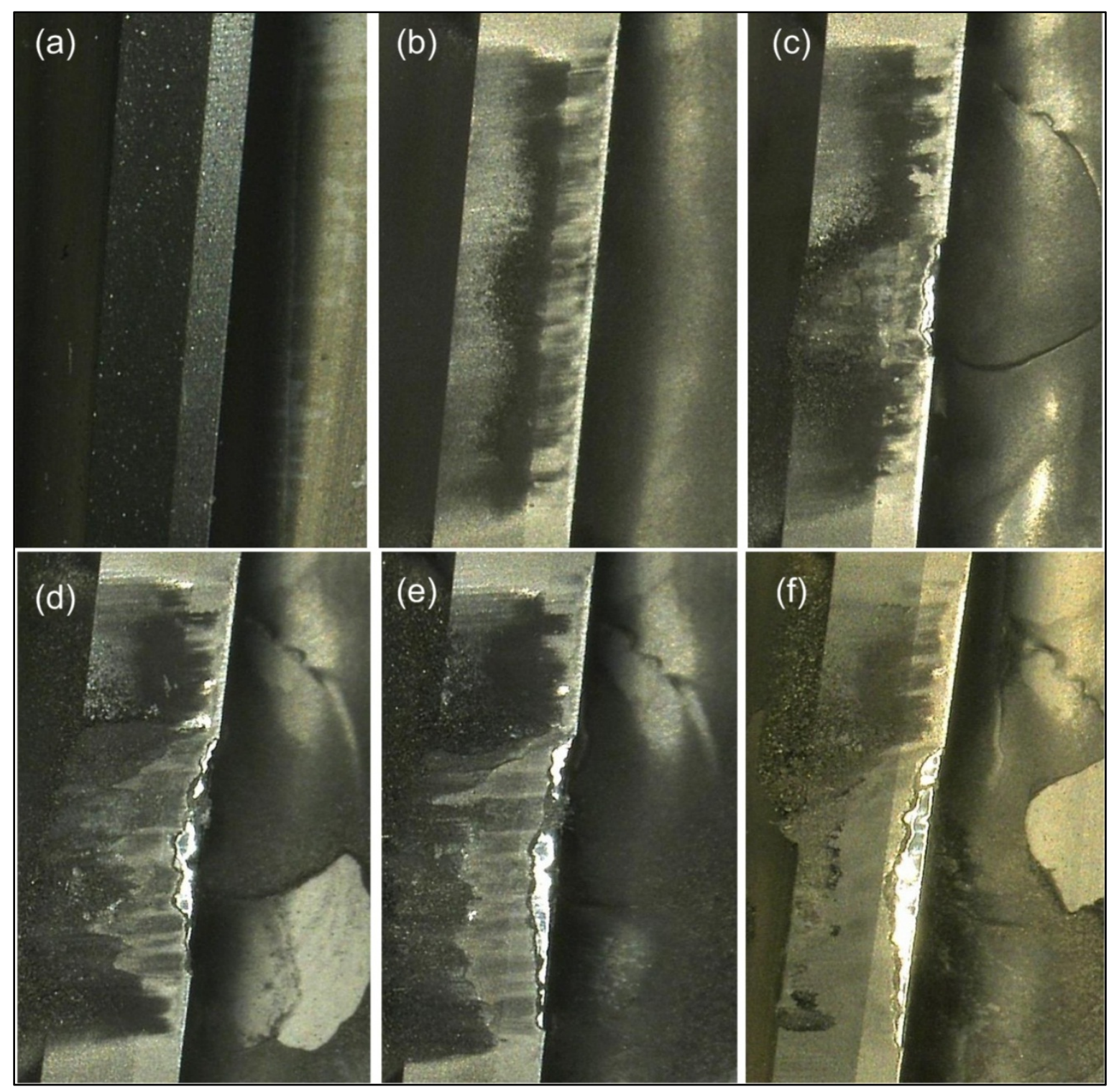

Figure 4.2 Tool wear at a) 0, b) 4, c) 9, d) 12, e) 14 and f) 15 meters of cut for Tooth \#5 in Test 2 (Feed: $2794 \mathrm{~mm} / \mathrm{min}$, Speed: $300 \mathrm{~m} / \mathrm{min}$ ) 


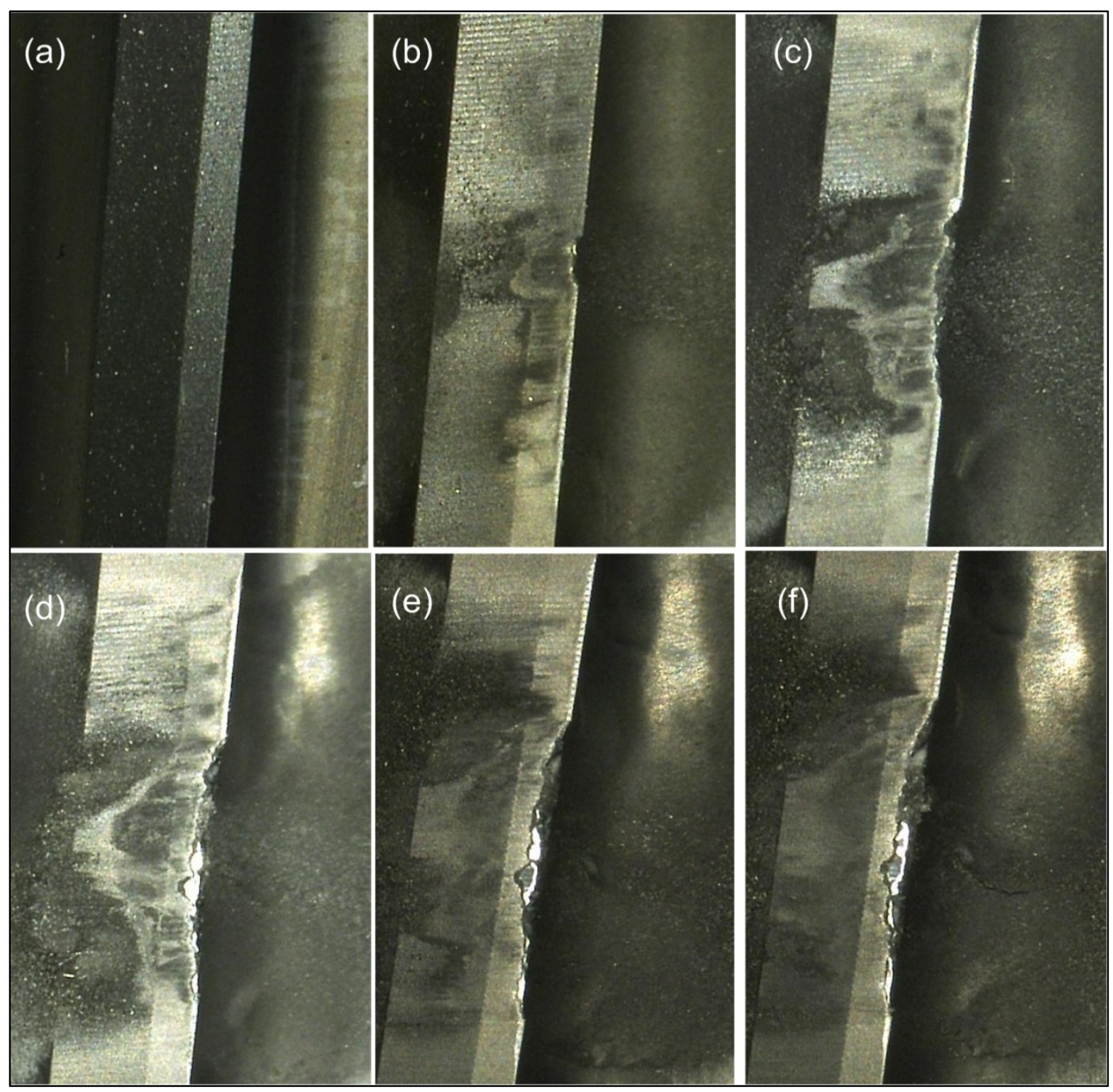

Figure 4.3 Tool wear at a) 0, b) 4, c) 9, d) 14, e) 19 and f) 20 meters of cut for Tooth \#5 in Test 3 (Feed: $4064 \mathrm{~mm} / \mathrm{min}$, Speed: $200 \mathrm{~m} / \mathrm{min}$ )

Figure 4.4 shows average tool wear (average VBmax) as a function of cutting length for Test 1-3. It was seen that the tool wear on the flank face of end mill router increased with an increase in time and cutting length. Based on the tool life criterion of $0.3 \mathrm{~mm}$ of average VBmax (flank wear), we achieved the end of tool life after 27 meters of cut for Test 1 (minimum feed and maximum speed). In Test 2 (intermediate feed and speed), the end of tool life was obtained after 14 meters of cut. Finally, for Test 3 (maximum feed and 
minimum speed), we approximately achieved the end of tool life after 20 meters of cut as shown in Figure 4.4.

In terms of tool wear, for the comparable cutting lengths, a lower tool wear was observed at lower feed rate and higher cutting speed (Test 1), while a higher tool wear rate was observed at intermediate values of our feed rate and cutting speed (Test 2). On the other hand, a higher tool life was observed at lower feed rate and higher cutting speed (Test 1), while a lower tool life was observed at intermediate values of our feed rate and cutting speed ranges (Test 2). Figure 4.5 shows maximum Vbmax as a function of cutting length for Test 1-3. By comparing Figure 4.4 and Figure 4.5, it indicates that two figures are almost similar.

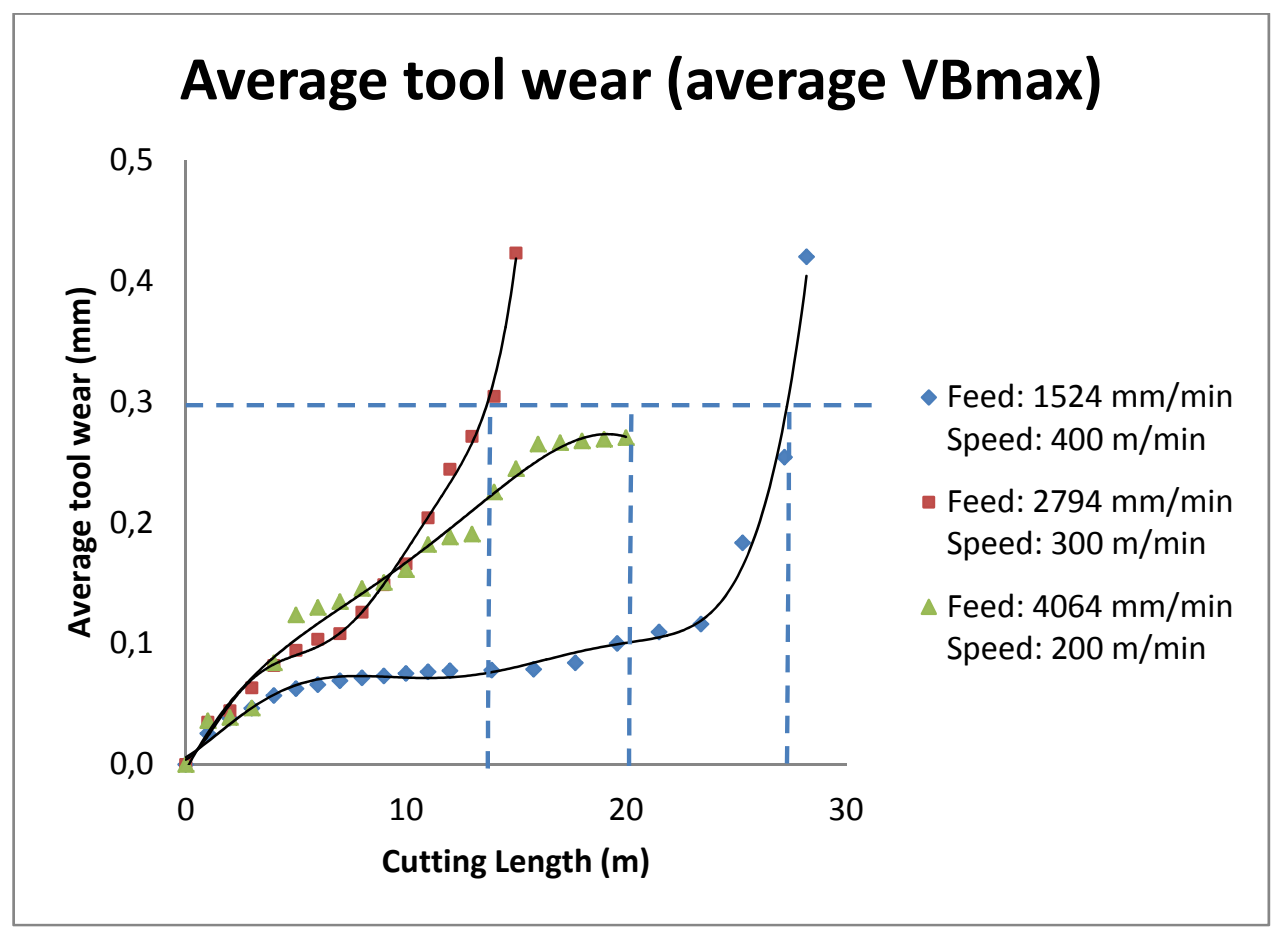

Figure 4.4 Average tool wear as a function of cutting length for Test 1-3 


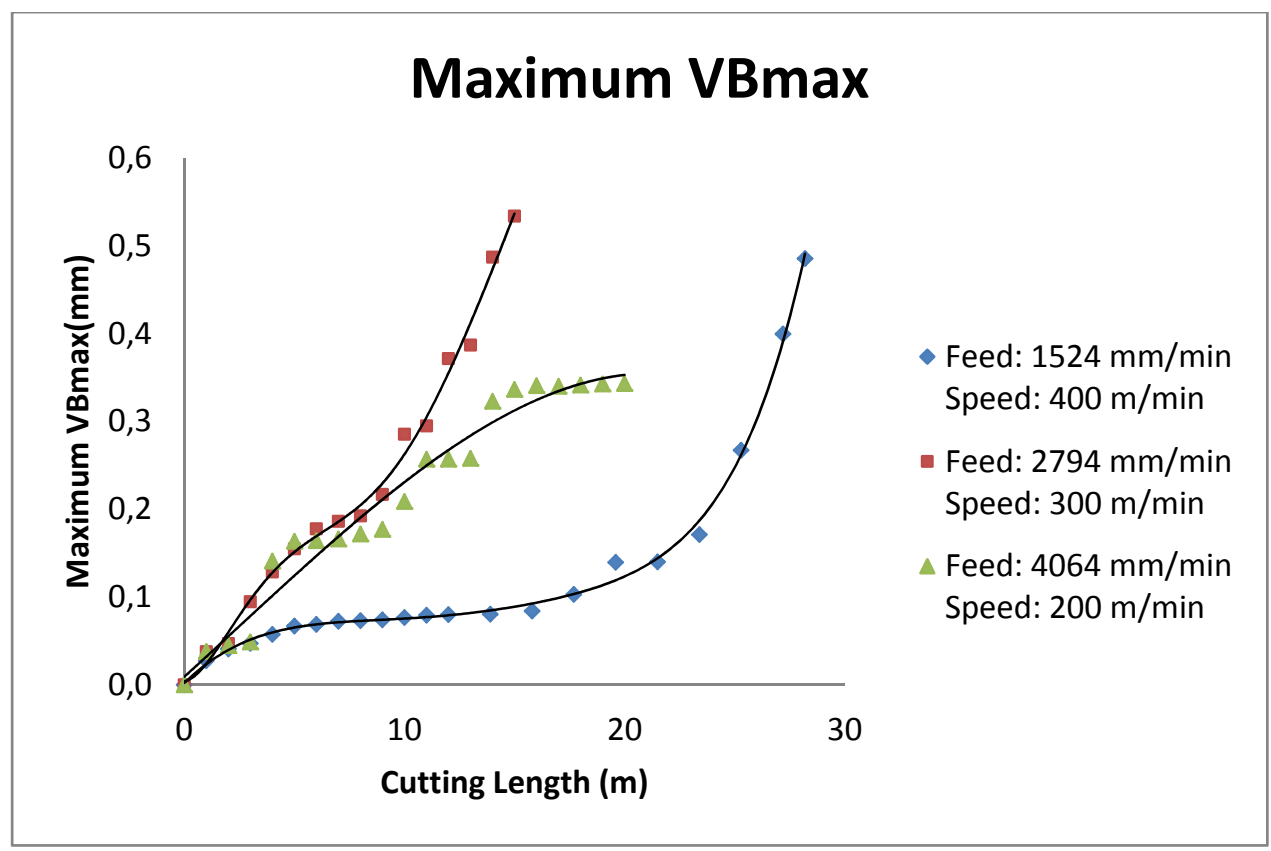

Figure 4.5 Maximum VBmax as a function of cutting length for Test 1-3

\subsubsection{Effect of fiber orientation on tool wear profile}

In our study, the workpiece material was an autoclave-cured 24-ply quasi-isotropic aerospace CFRP (carbon fiber/ epoxy) laminate with a stacking sequence $\left[\left(90^{\circ},-45^{\circ}, 45^{\circ}, 0^{\circ}, 45^{\circ},-45^{\circ}, 45^{\circ},-45^{\circ}, 0^{\circ},-45^{\circ}, 45^{\circ}, 90^{\circ}\right)\right] \mathrm{s}$. In our tool life experiments (Test 1-3), at the end of tool life, the profiles of tool wear in Test 1 was different from those for Tests 2-3 while the profiles of tool wear for Test 2-3 were similar. According to our results, the $0^{\circ}$ ply orientation played an important role on tool wear profile as shown in Figure 4.6. For example, in both Tests $2-3$, the $16^{\text {th }}$ ply ( $0^{\circ}$ ply orientation) produced the maximum Vbmax (Maximum tool wear) while in Test 1 , the $9^{\text {th }}$ ply $\left(0^{\circ}\right.$ ply orientation) generated the maximum Vbmax (Maximum tool wear). In case of $0^{\circ}$ ply orientation, the direction of feed rate and fiber orientation were the same. It could be assume that in this case, the tool-chip contact length increased. This increase most probably caused more tool wear. 

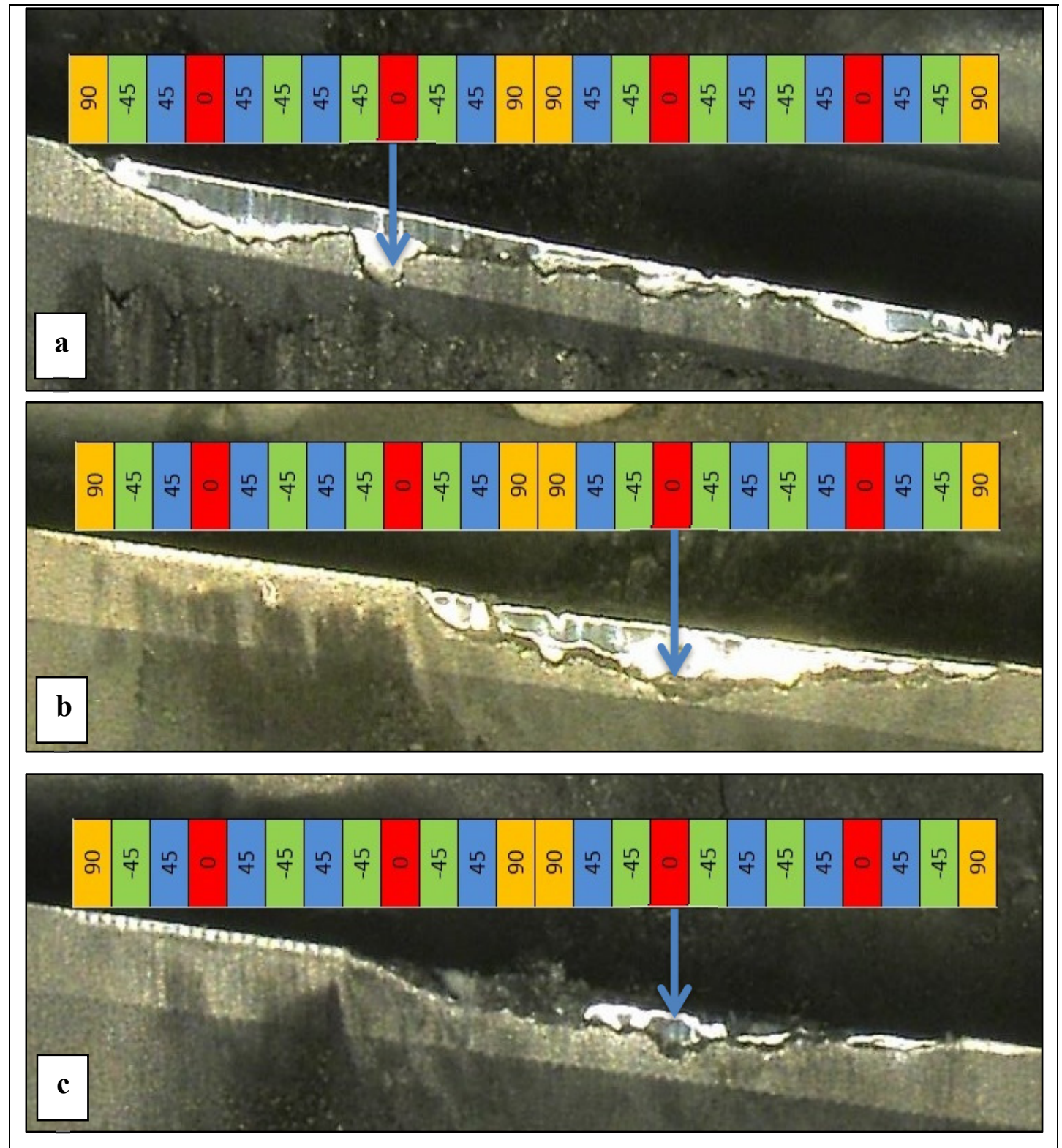

Figure 4.6 Effect of fiber orientation on tool wear for:

a) Test 1 (Feed: $1524 \mathrm{~mm} / \mathrm{min}$, Speed: $400 \mathrm{~m} / \mathrm{min}$ ),

b) Test 2 (Feed: $2794 \mathrm{~mm} / \mathrm{min}$, Speed: $300 \mathrm{~m} / \mathrm{min}$ ),

c) Test 3 (Feed: $4064 \mathrm{~mm} / \mathrm{min}$, Speed: $200 \mathrm{~m} / \mathrm{min}$ ) 


\subsubsection{Cutting forces analysis}

In this study, a 3/8 inch diameter CVD diamond coated carbide tool with six flutes was used to trim 24-ply carbon fiber laminates. During machining with the six teeth end mill, each tooth engaged and removed material while the chip thickness wasn't constant. The six flutes in one tool revolution produced six peaks during one revolution of the end mill cutter as shown in Figure 4.7. In this figure, each peak indicated the passage of one tooth. These six peaks didn't have identical amplitude. The differences between their amplitudes were most probably due to tool run-out.

Generally, the profiles of the cutting forces in $\mathrm{x}, \mathrm{y}$ and $\mathrm{z}$ directions for different cutting conditions are similar. This similarity presents three different zones in tool engagement process. Zone I corresponds to the engagement of the tool in the workpiece. The cutting force starts to increase from zero value in this zone. The cutter engagement brings high energy to the CFRP laminate, and this energy is at once dissipated in the laminate. During Zone I, the end mill cutter feeds into workpiece and when the end mill tool is fully engaged, the tool enters to next zone (Zone II). Zone II is the steady state condition, which is categorized by a cyclical cutting force profile from one revolution to another with almost constant force amplitude. In Zone III, the cutting forces start to change and attain their peak values. In this zone, the tool is disengaging from the workpice, so the chip thickness decreases. It causes high vibration which increases the cutting force. When the unsupported final part of the CFRP laminate is removed, the cutting force decreases smoothly. This decrease is most likely due to the decrease in chip thickness. The cutting force finally decreases to zero value when there is no CFRP laminate left to remove (Zaghbani et al., 2012). The tool engagement process for the six flutes cutting tool is shown in Figure 4.8.

In terms of quality, the cutting forces produced during the machining operations are very important, especially during machining of CFRP. Controlling these cutting forces is one of the main keys to decrease the quality issues or defects induced in CFRP machined components. To control the cutting forces, it is necessary to study the cutting force components. 


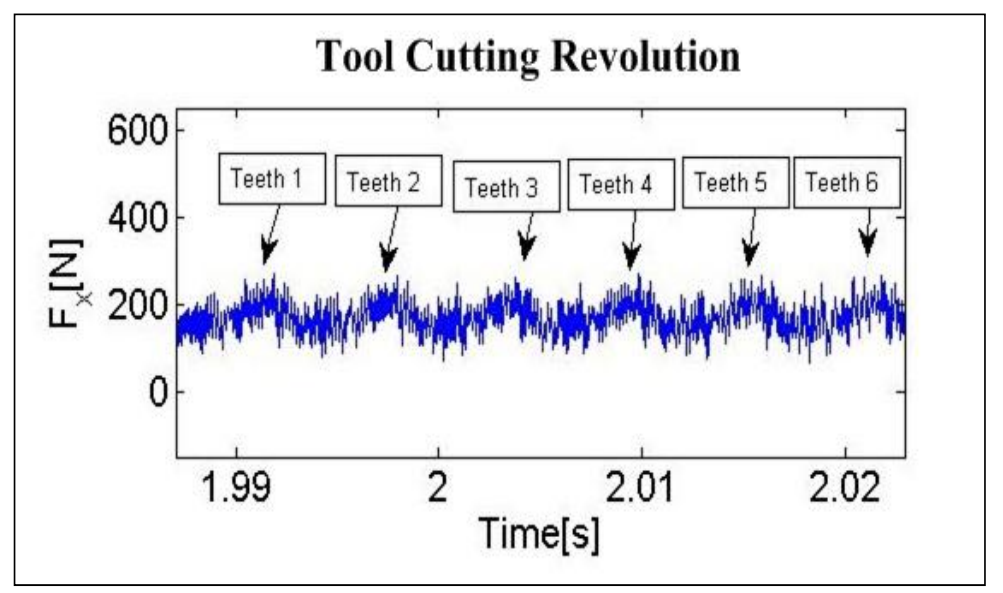

Figure 4.7 One tool cutting revolution for new six teeth end mill in Test 1 (Feed: $1524 \mathrm{~mm} / \mathrm{min}$, Speed: $400 \mathrm{~m} / \mathrm{min}$ )

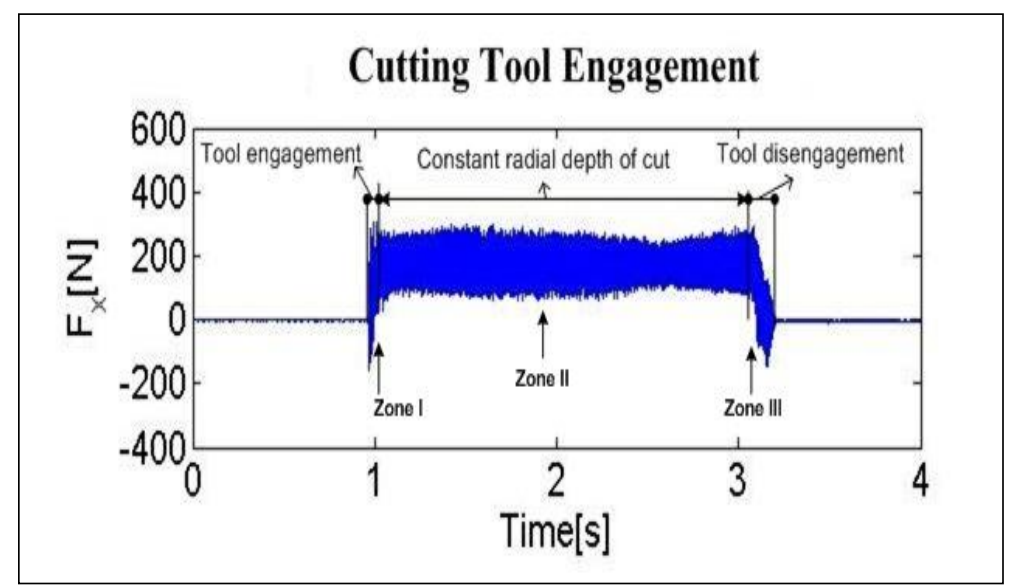

Figure 4.8 Tool engagement process for new six teeth end mill in Test 1

(Feed: $1524 \mathrm{~mm} / \mathrm{min}$, Speed: $400 \mathrm{~m} / \mathrm{min}$ )

In this study, for each tool life experiment, the average cutting forces in $\mathrm{x}, \mathrm{y}$ and $\mathrm{z}$ directions were obtained, and then the average total forces for each small cut are calculated from this equation:

$$
\left(F t=\sqrt{F x^{2}+F y^{2+} F z^{2}}\right)
$$


Table 4.4-4.6 show the average cutting forces in $\mathrm{x}, \mathrm{y}$ and $\mathrm{z}$ directions, the average total forces and their related cutting lengths during tool life experiments (Test 1-3). In this study, total cutting force is Ft. In addition, the components of cutting force are Fx (normal force), Fy (feed force) and $\mathrm{Fz}$ (axial force).

Table 4.4 Average cutting forces and their related cutting lengths in Test 1 (Feed: $1524 \mathrm{~mm} / \mathrm{min}$, Speed: $400 \mathrm{~m} / \mathrm{min}$ )

\begin{tabular}{|c|c|c|c|c|}
\hline Cutting length (m) & +Fx (N) & -Fy (N) & - Fz (N) & F total (N) \\
\hline $\mathbf{0 . 1}$ & 79 & 95 & 15 & 124 \\
\hline $\mathbf{1 . 1}$ & 75 & 93 & 10 & 120 \\
\hline $\mathbf{2 . 1}$ & 77 & 96 & 9 & 124 \\
\hline $\mathbf{3 . 1}$ & 77 & 98 & 8 & 125 \\
\hline $\mathbf{4 . 1}$ & 74 & 100 & 9 & 125 \\
\hline $\mathbf{5 . 1}$ & 76 & 107 & 7 & 131 \\
\hline $\mathbf{6 . 1}$ & 79 & 107 & 9 & 134 \\
\hline $\mathbf{7 . 1}$ & 78 & 111 & 9 & 136 \\
\hline $\mathbf{8 . 1}$ & 77 & 116 & 8 & 139 \\
\hline $\mathbf{9 . 1}$ & 78 & 123 & 9 & 146 \\
\hline $\mathbf{1 0 . 1}$ & 79 & 122 & 7 & 145 \\
\hline $\mathbf{1 1 . 1}$ & 79 & 121 & 15 & 145 \\
\hline $\mathbf{1 2 . 1}$ & 79 & 123 & 13 & 147 \\
\hline $\mathbf{1 4 . 0}$ & 79 & 128 & 8 & 151 \\
\hline $\mathbf{1 5 . 9}$ & 81 & 136 & 12 & 159 \\
\hline $\mathbf{1 7 . 8}$ & 75 & 134 & 7 & 153 \\
\hline $\mathbf{1 9 . 7}$ & 75 & 139 & 13 & 159 \\
\hline $\mathbf{2 1 . 6}$ & 75 & 144 & 10 & 163 \\
\hline $\mathbf{2 3 . 5}$ & 77 & 166 & 9 & 183 \\
\hline $\mathbf{2 5 . 4}$ & 79 & 215 & 11 & 229 \\
\hline $\mathbf{2 7 . 3}$ & 68 & 279 & 12 & 287 \\
\hline $\mathbf{2 8 . 3}$ & 113 & 519 & 19 & 532 \\
\hline
\end{tabular}


Table 4.5 Average cutting forces and their related cutting lengths in Test 2 (Feed: $2794 \mathrm{~mm} / \mathrm{min}$, Speed: $300 \mathrm{~m} / \mathrm{min}$ )

\begin{tabular}{|c|c|c|c|c|}
\hline $\begin{array}{c}\text { Cutting length } \\
(\mathbf{m})\end{array}$ & $+\mathbf{F x}(\mathbf{N})$ & $\mathbf{- F y}(\mathbf{N})$ & $\mathbf{- F z}(\mathbf{N})$ & F total (N) \\
\hline $\mathbf{0 . 1}$ & 173 & 155 & 25 & 234 \\
\hline $\mathbf{1 . 1}$ & 165 & 149 & 24 & 223 \\
\hline $\mathbf{2 . 1}$ & 162 & 149 & 23 & 221 \\
\hline $\mathbf{3 . 1}$ & 162 & 158 & 24 & 227 \\
\hline $\mathbf{4 . 1}$ & 164 & 185 & 23 & 248 \\
\hline $\mathbf{5 . 1}$ & 164 & 201 & 22 & 260 \\
\hline $\mathbf{6 . 1}$ & 161 & 209 & 22 & 265 \\
\hline $\mathbf{7 . 1}$ & 161 & 207 & 22 & 263 \\
\hline $\mathbf{8 . 1}$ & 170 & 240 & 24 & 295 \\
\hline $\mathbf{9 . 1}$ & 168 & 283 & 22 & 330 \\
\hline $\mathbf{1 0 . 1}$ & 176 & 333 & 22 & 377 \\
\hline $\mathbf{1 1 . 1}$ & 187 & 425 & 21 & 465 \\
\hline $\mathbf{1 2 . 1}$ & 197 & 502 & 26 & 540 \\
\hline $\mathbf{1 3 . 1}$ & 206 & 616 & 30 & 651 \\
\hline $\mathbf{1 4 . 1}$ & 205 & 727 & 33 & 756 \\
\hline $\mathbf{1 5 . 1}$ & 212 & 704 & 39 & 737 \\
\hline
\end{tabular}


Table 4.6 Average cutting forces and their related cutting lengths in Test 3

(Feed: $4064 \mathrm{~mm} / \mathrm{min}$, Speed: $200 \mathrm{~m} / \mathrm{min}$ )

\begin{tabular}{|c|c|c|c|c|}
\hline Cutting length (m) & $+\operatorname{Fx}(\mathrm{N})$ & $-F y(N)$ & $-\mathrm{Fz}(\mathrm{N})$ & F total $(\mathrm{N})$ \\
\hline 0.1 & 308 & 145 & 58 & 346 \\
\hline 1.1 & 297 & 143 & 58 & 335 \\
\hline 2.1 & 296 & 141 & 57 & 332 \\
\hline 3.1 & 293 & 142 & 56 & 331 \\
\hline 4.1 & 309 & 171 & 58 & 358 \\
\hline 5.1 & 325 & 223 & 60 & 399 \\
\hline 6.1 & 328 & 256 & 59 & 420 \\
\hline 7.1 & 331 & 314 & 62 & 461 \\
\hline 8.1 & 333 & 364 & 60 & 497 \\
\hline 9.1 & 336 & 403 & 60 & 529 \\
\hline 10.1 & 336 & 443 & 60 & 560 \\
\hline 11.1 & 339 & 479 & 61 & 590 \\
\hline 12.1 & 339 & 524 & 62 & 627 \\
\hline 13.1 & 341 & 556 & 63 & 655 \\
\hline 14.1 & 343 & 596 & 64 & 691 \\
\hline 15.1 & 318 & 585 & 62 & 669 \\
\hline 16.1 & 331 & 627 & 61 & 712 \\
\hline 17.1 & 328 & 659 & 62 & 739 \\
\hline 18.1 & 334 & 678 & 65 & 759 \\
\hline 19.1 & 343 & 722 & 67 & 802 \\
\hline 20.1 & 332 & 740 & 65 & 814 \\
\hline
\end{tabular}

Figure 4.9-4.11 show the normal, feed, axial and the average total forces as a function of cutting length for three tool life experiments (Test 1-3). As shown in these figures, in all three tool life experiments, the normal forces were higher than the axial forces and the feed forces were higher than two other cutting force components in Test 1-3 (for Test 3 after 8 meters of cut). The feed forces increased rapidly with an increase in cutting length in all three tests. In case of normal and axial forces, they were almost constant during each tool life test. This fact indicates that the feed force was the main cutting force component which influenced significantly the total cutting force during tool life test. Figure 4.12-4.14 compare the normal, feed and axial forces in Test 1-3 respectively. According to these figures, in Test 3 (maximum feed rate and minimum cutting speed), the highest level of normal, feed and axial forces were produced while in Test 1 (minimum feed and maximum cutting speed), the lowest level of normal, feed and axial forces were obtained. 
In case of total cutting forces, the total cutting forces increased with an increase in cutting length in all tool life tests as shown in Figure 4.15. In addition, it was seen that, again in Test 3 (maximum feed rate and minimum cutting speed), the total cutting forces were greater than the total cutting forces in Test 1 (minimum feed and maximum cutting speed). This fact indicates that with an increase in feed rate and a decrease in cutting speed, the total cutting forces increased. On the other hand, with a decrease in feed rate and an increase in cutting speed, the total cutting forces decreased. This observation could explain the rule of the thumb when machining of CFRP: high cutting speed and low feed rate. Tounsi et al., (2002) found similar results and they showed that under this condition (minimum feed and maximum cutting speed), it was much easier to soften low quantities of CFRP with the generated heat due to friction. In terms of energy consumption, Test 3 (maximum feed rate and minimum cutting speed) had the highest level of cutting forces and the CNC machine consumed more energy while Test 1 (minimum feed and maximum cutting speed) had the lowest level of cutting forces and the $\mathrm{CNC}$ machine consumed less energy during tool life experiments.

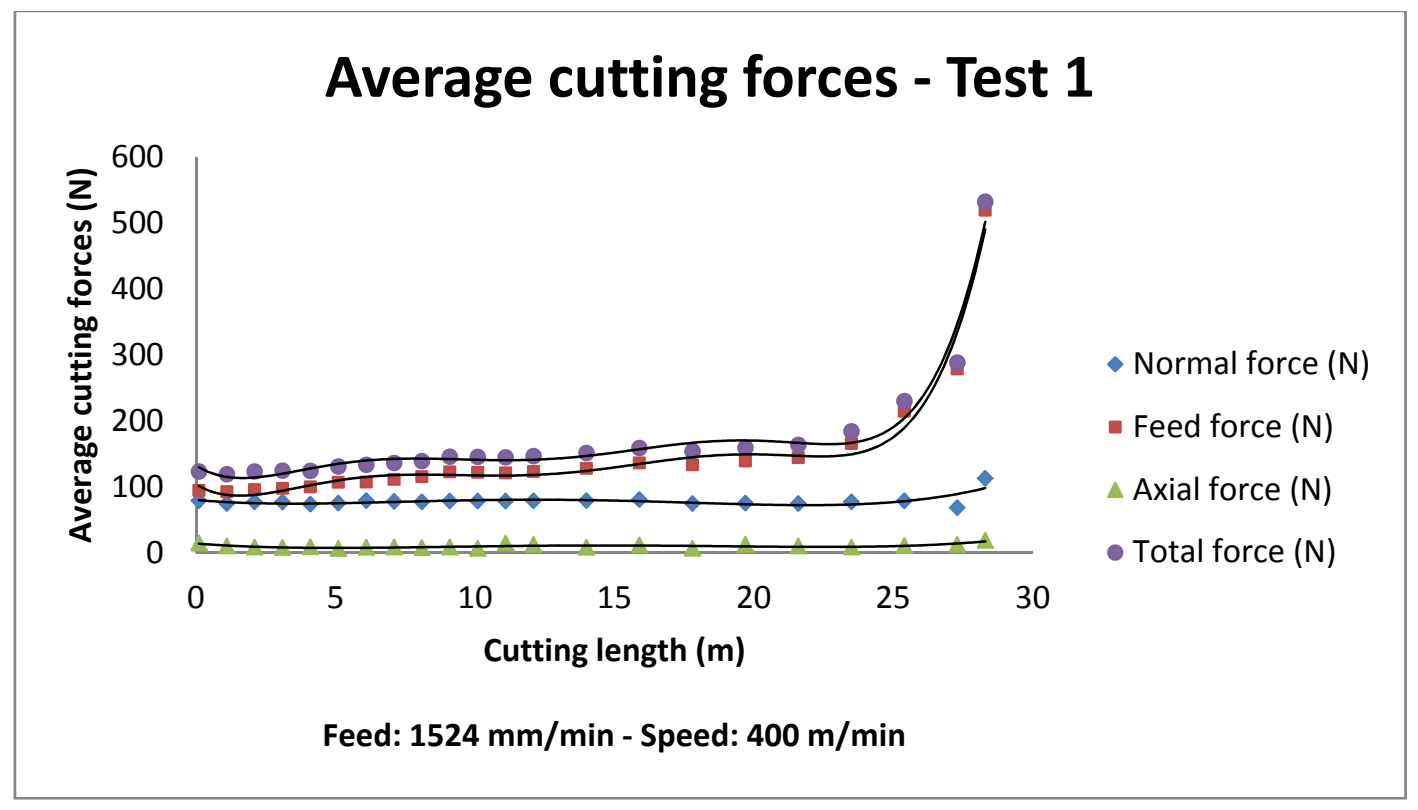

Figure 4.9 Average forces in $\mathrm{x}, \mathrm{y}$ and $\mathrm{z}$ directions and average total forces as a function of cutting length in Test 1 


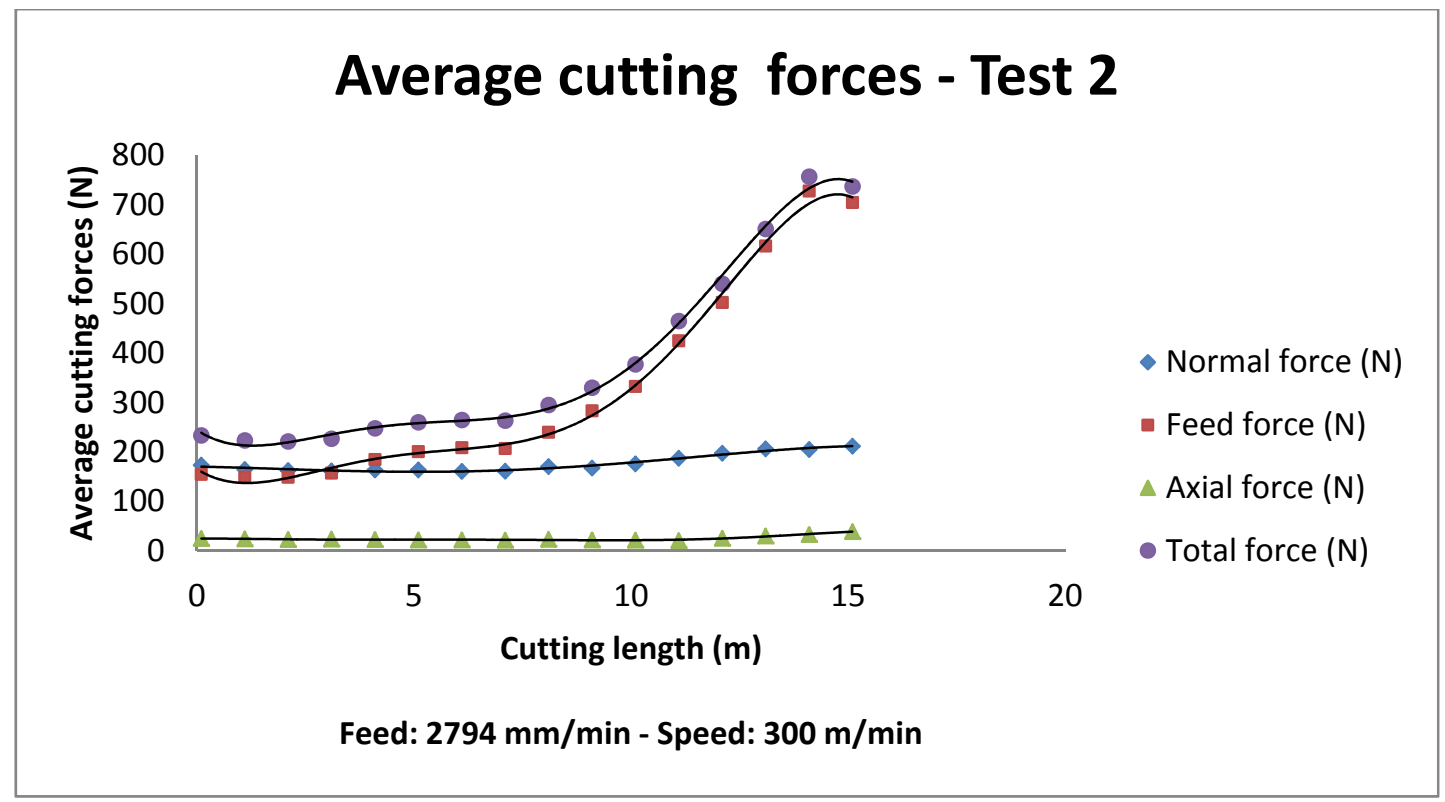

Figure 4.10 Average forces in $\mathrm{x}, \mathrm{y}$ and $\mathrm{z}$ directions and average total forces as a function of cutting length in Test 2

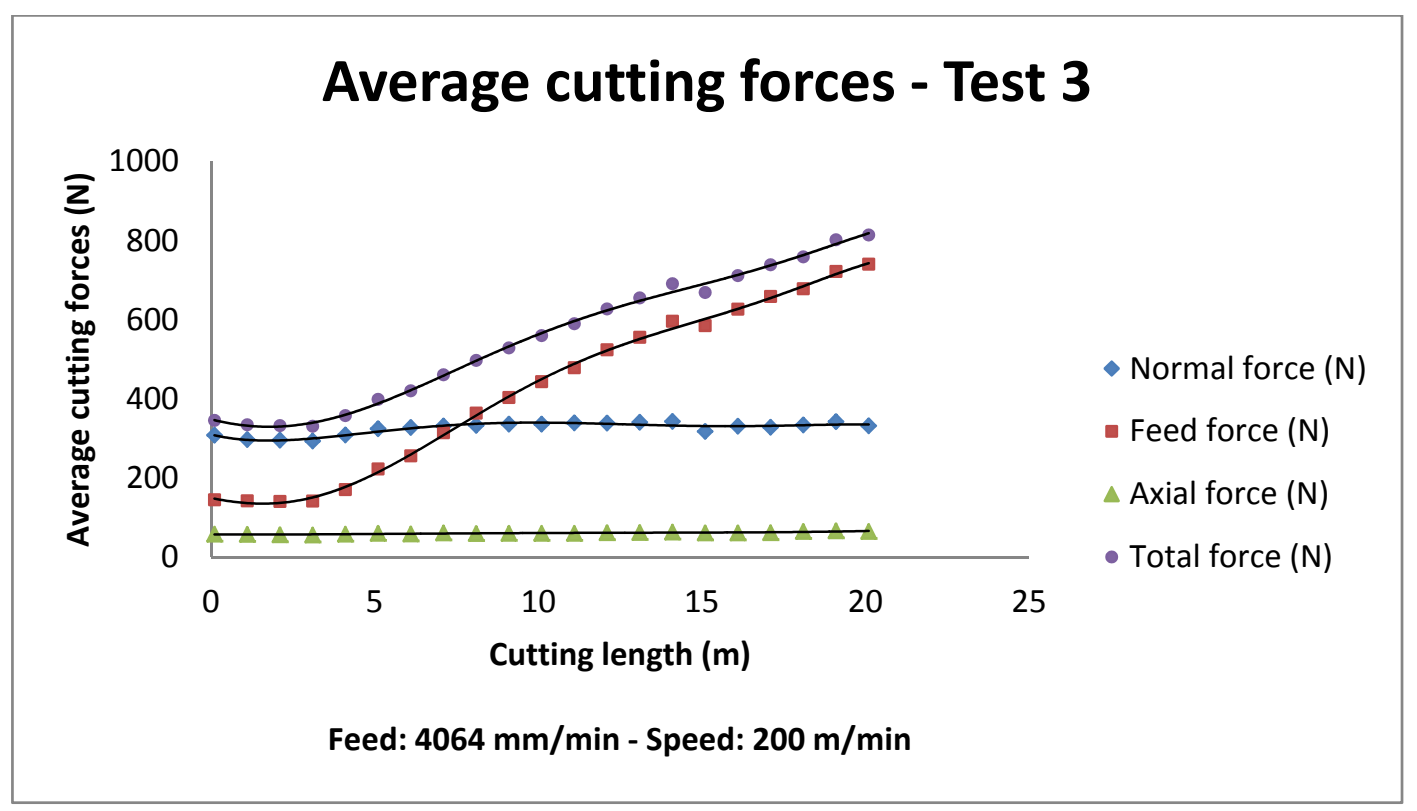

Figure 4.11 Average forces in $\mathrm{x}, \mathrm{y}$ and $\mathrm{z}$ directions and average total forces as a function of cutting length in Test 3 


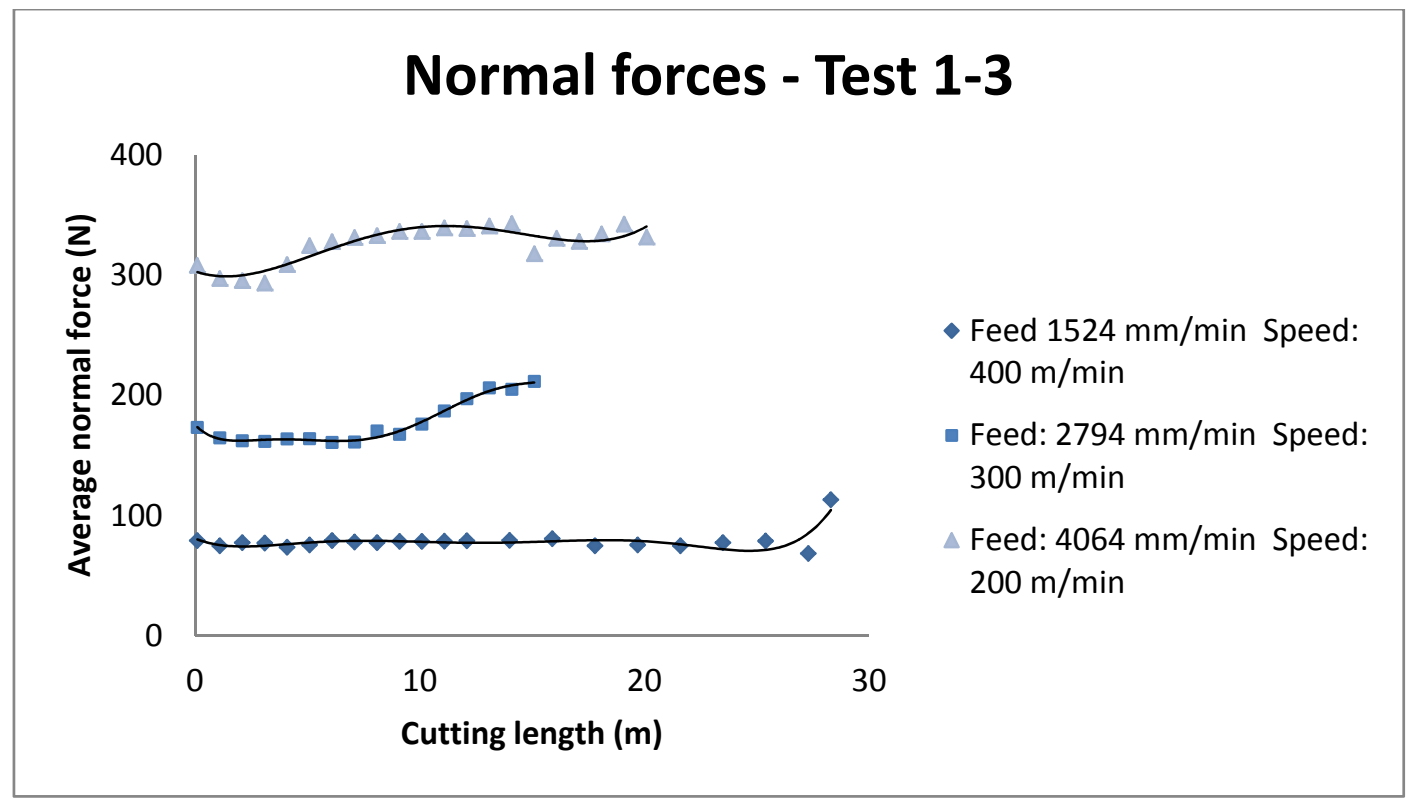

Figure 4.12 Average normal forces as a function of cutting length in Test 1-3

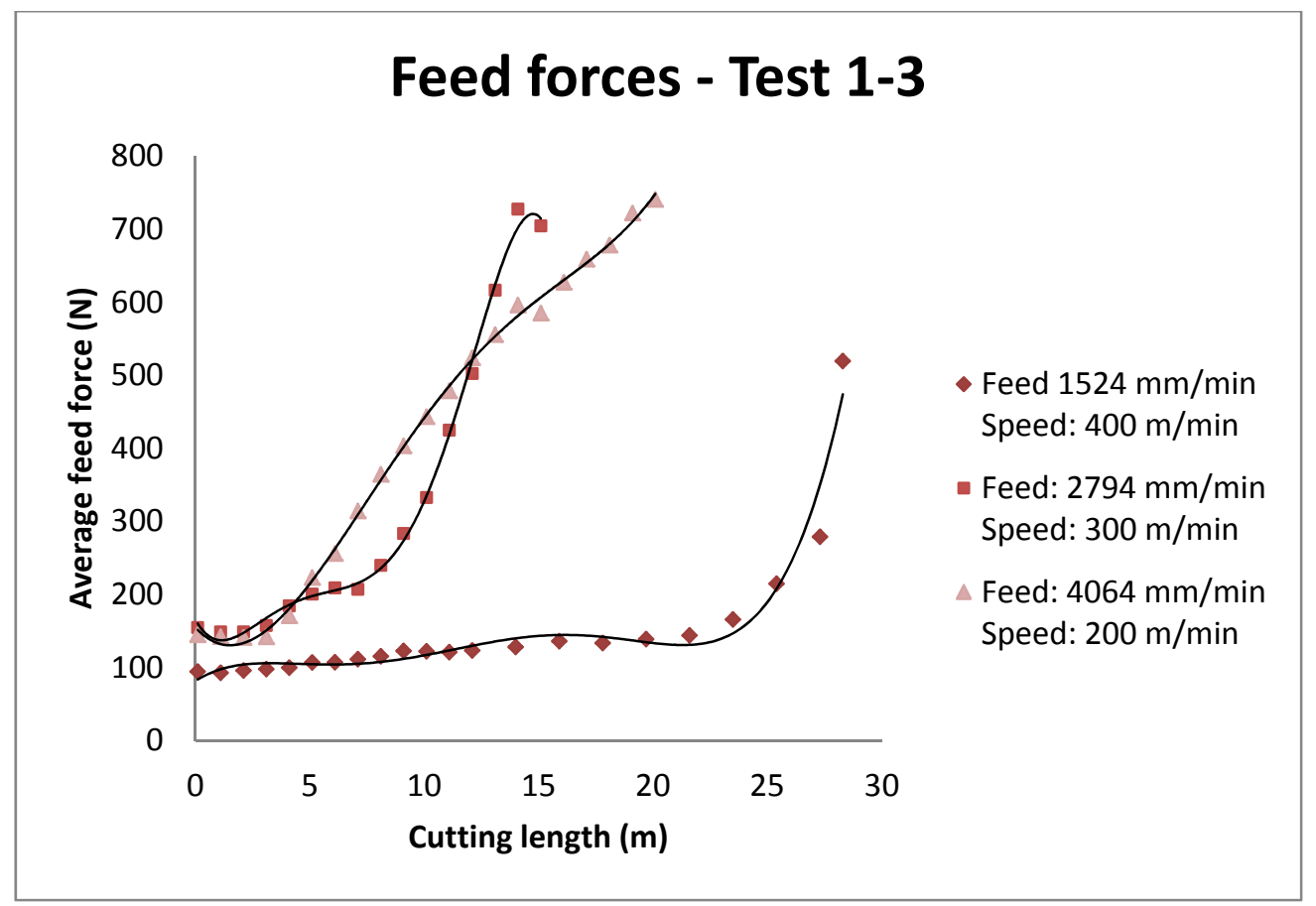

Figure 4.13 Average feed forces as a function of cutting length in Test 1-3 


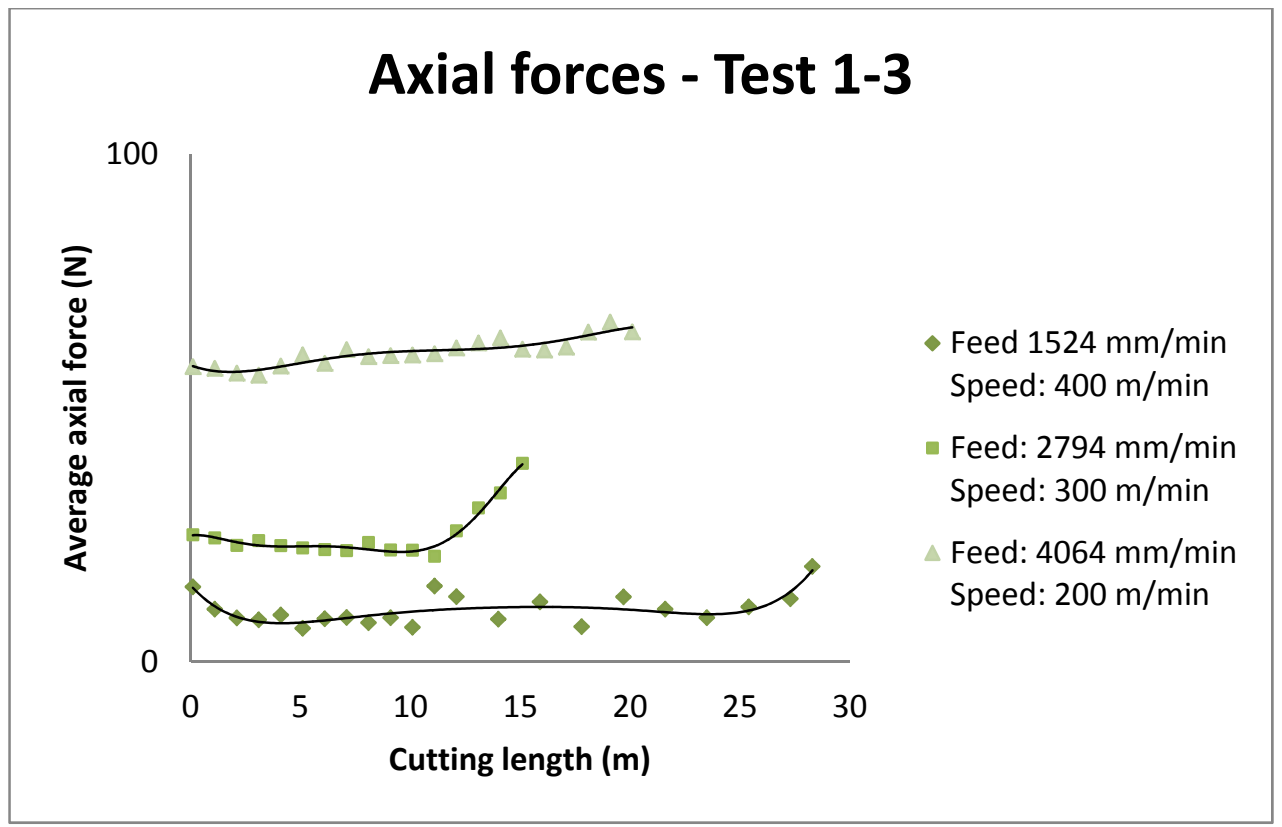

Figure 4.14 Average axial forces as a function of cutting length in Test 1-3

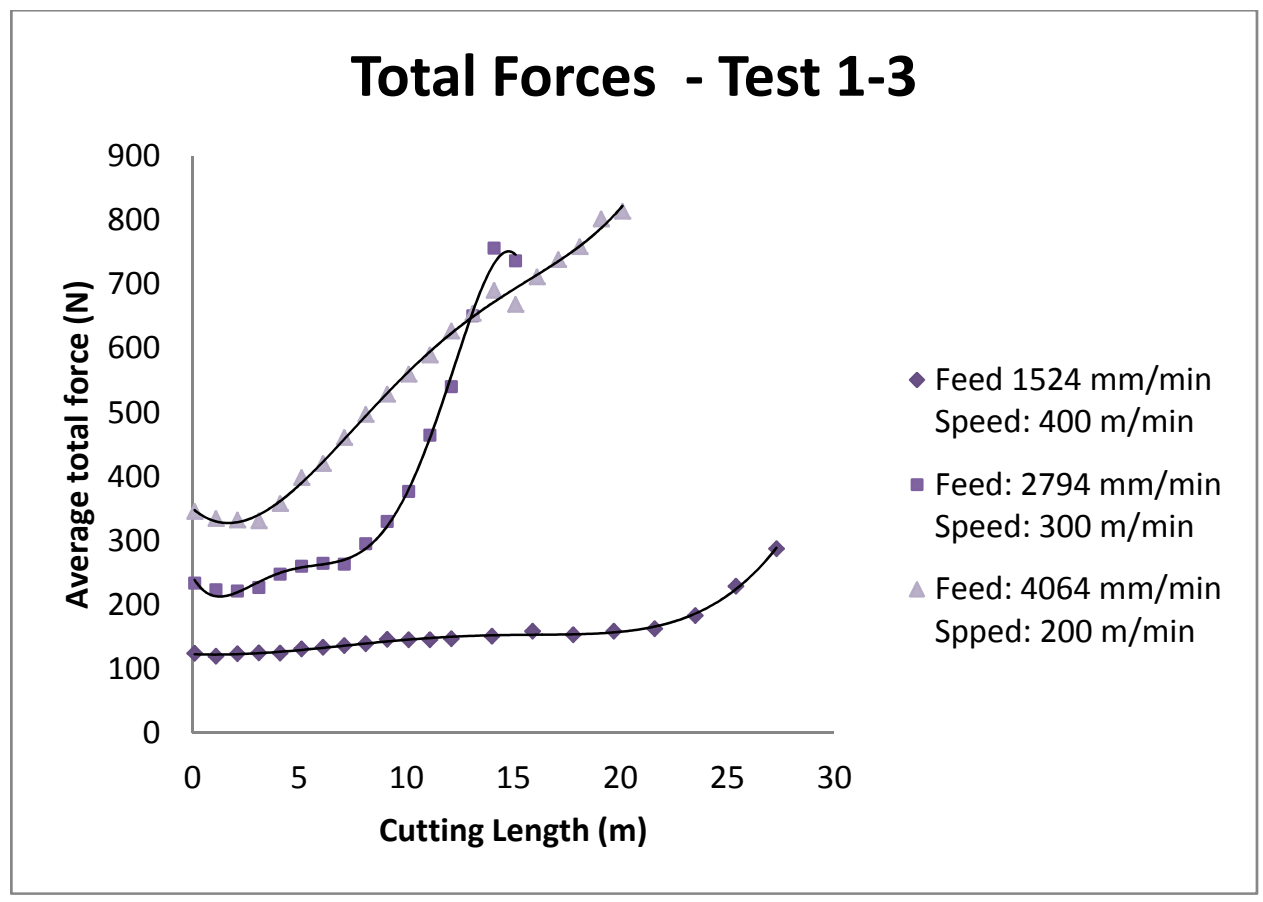

Figure 4.15 Average total forces as a function of cutting length in Test 1-3 
In terms of the effect of tool wear on the cutting forces, the cutting forces in $\mathrm{x}, \mathrm{y}$ and $\mathrm{z}$ directions were compared together at the beginning and at the end of each tool life test. Figure 4.16-4.18 illustrate the recorded cutting forces in $\mathrm{x}, \mathrm{y}$ and $\mathrm{z}$ directions during trimming of CFRP laminate using new tool and worn tool. Based on these figures, the feed forces (Fy), at the end of the tool life (using worn tool) were greatly higher than the feed forces at the beginning of tool life test (using new tool) in all three tool life tests. For example in Test 1, when the average tool wear was zero (new tool), the average feed force was $95 \mathrm{~N}$ while at the end of the tool life, when average tool wear was $0.42 \mathrm{~mm}$, the feed force was $519 \mathrm{~N}$. This fact indicates that the feed forces increased due to the chipping of the cutting tool (worn tool). In case of normal and axial forces (Fx and Fz), they didn't increase greatly with an increase in tool wear and they were almost constant. On the other hand, the effect of the tool wear increase was obvious on the y component of the cutting forces (feed force). For the Fx (normal force) and Fz (axial force) components, the effect of the tool wear was not very significant.

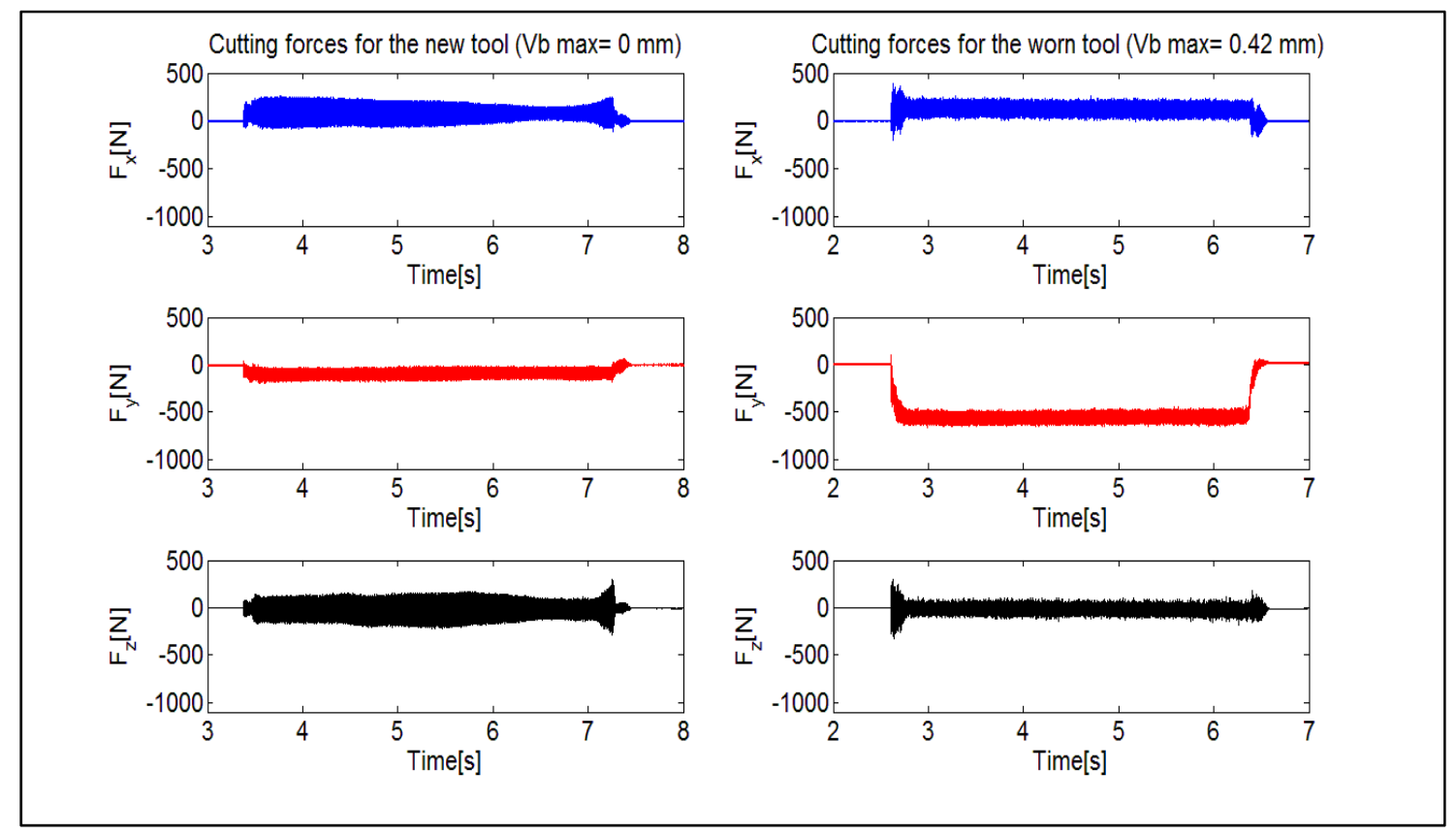

Figure 4.16 Recorded forces in $\mathrm{x}-$, $\mathrm{y}$ - and z-directions using new and worn tools in Test 1 (Feed: $1524 \mathrm{~mm} / \mathrm{min}$, Speed: $400 \mathrm{~m} / \mathrm{min}$ ) 


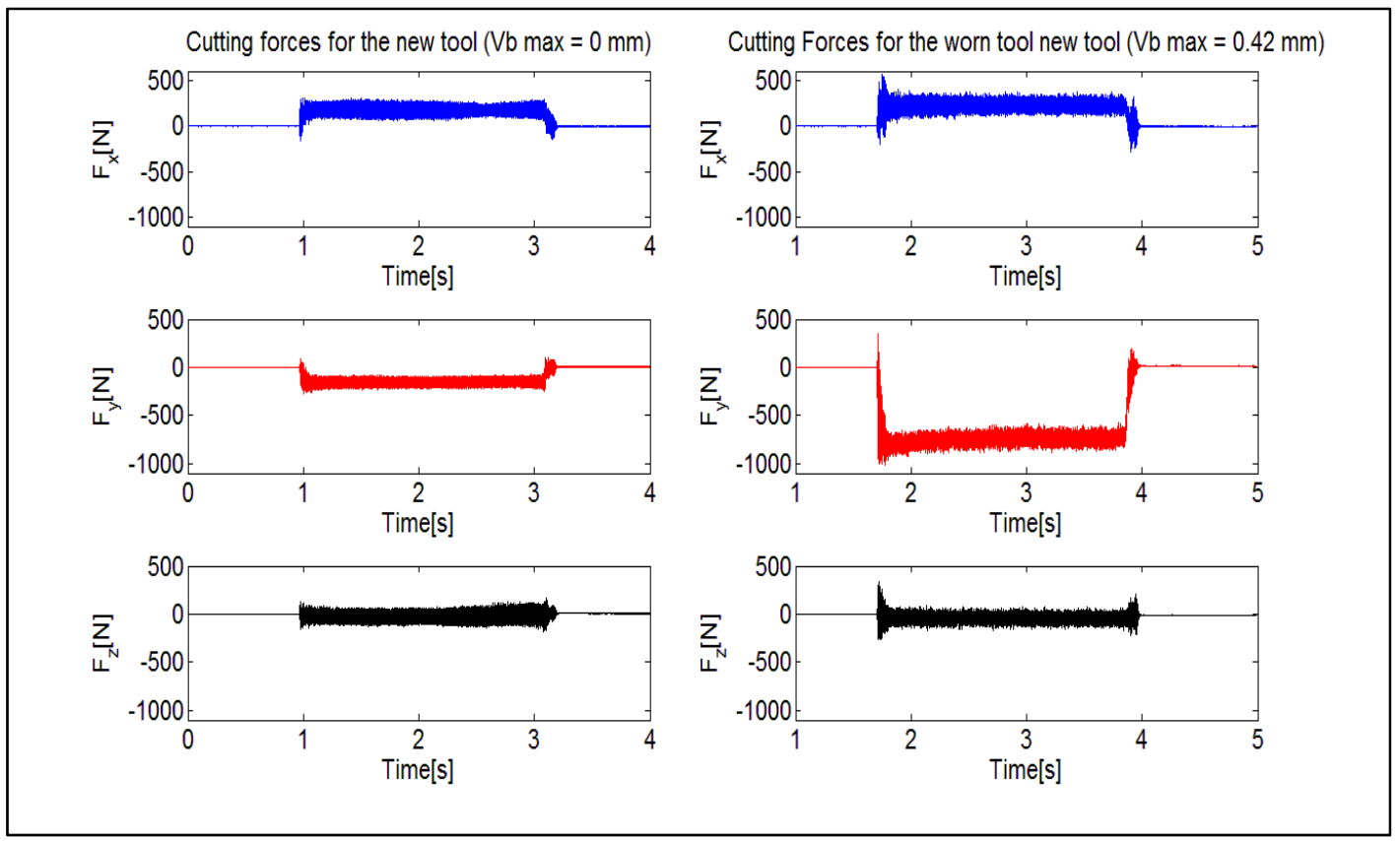

Figure 4.17 Recorded forces in $\mathrm{x}-\mathrm{y}, \mathrm{y}$ - and $\mathrm{z}$-directions using new and worn tools in Test 2 (Feed: $2794 \mathrm{~mm} / \mathrm{min}$, Speed: $300 \mathrm{~m} / \mathrm{min}$ )
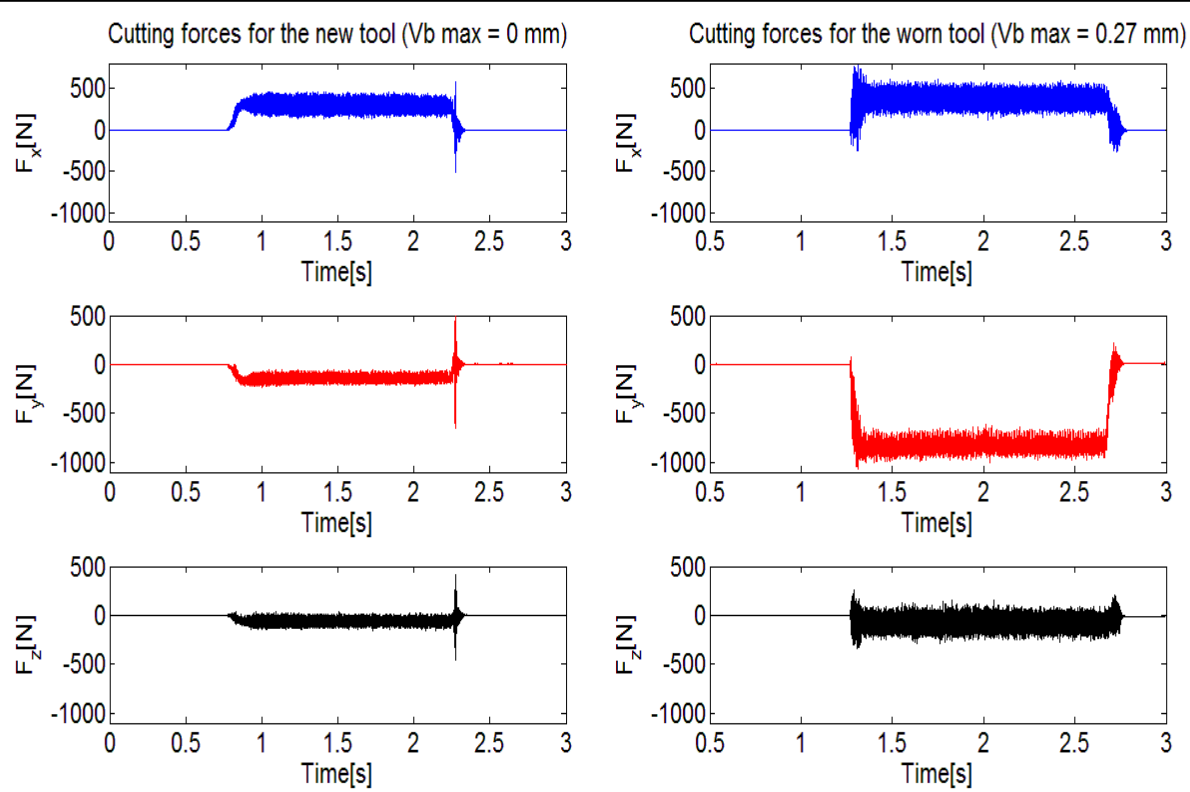

Figure 4.18 Recorded forces in $\mathrm{x}-, \mathrm{y}$ - and z-directions using new and worn tools in Test 3 (Feed: $4064 \mathrm{~mm} / \mathrm{min}$, Speed: $200 \mathrm{~m} / \mathrm{min}$ ) 


\subsubsection{Effect of tool wear on cutting force}

Figure 4.19 shows the total forces as a function of tool wear for three tool life tests. Generally, in all tool life experiments, with an increase in tool wear, the average total cutting force increased. Among three tool life tests, the highest value of cutting force was produced in Test 3 (maximum feed and minimum speed) while the lowest value of cutting force was generated in Test1 (minimum feed and maximum speed).To clarify the discussion concerning the effect of tool wear on cutting forces, this example is given. For example, according to the obtained results, the cutting tool with $0.080 \mathrm{~mm}$ of average VBmax, produced $125 \mathrm{~N}, 248 \mathrm{~N}$ and $358 \mathrm{~N}$ of total forces in Test 1-3 respectively. This fact indicates that with the similar value of tool wear; Test 1 (minimum feed and maximum speed) produced more cutting force while Test 3 (maximum feed and minimum speed) generated less cutting force.

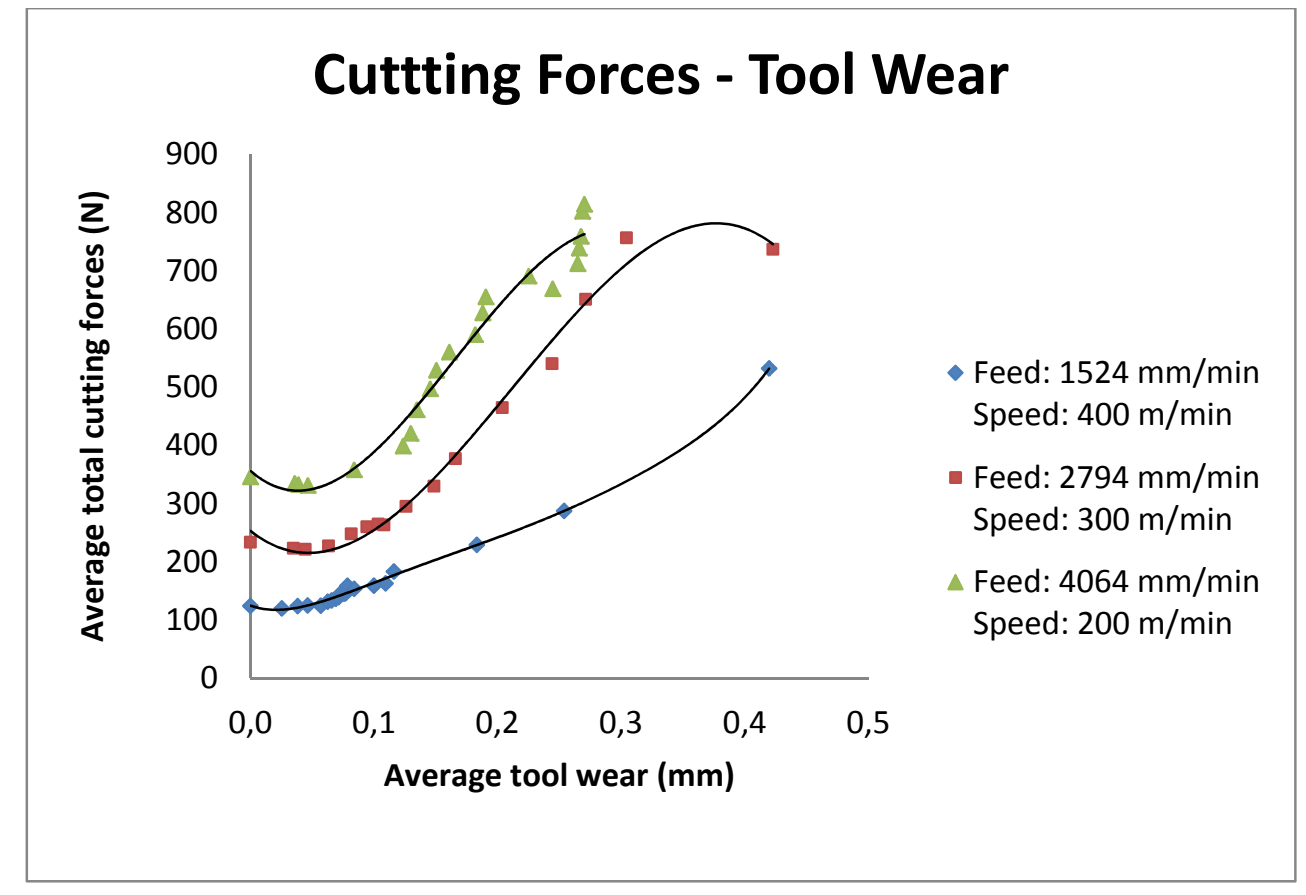

Figure 4.19 Total cutting forces as a function of tool wear in Test 1-3

\subsubsection{Machined surface integrity}

As mentioned in Chapter 2, there are four types of delamination. In this work, it wasn't seen any type of delamination or fiber pull-out on the trimmed surface of all coupons for the three 
tool life tests (Test 1-3) using CVD coated carbide tool. This fact indicates that the high fixture rigidity, high quality of CFRP laminates, the suitable cutting tool and the stable operational conditions could decrease the fiber pull-out and delamination.

As mentioned before, the cutting forces increased with an increase in tool wear as shown in Figure 4.19. High cutting forces could increase the cutting temperature, which consequently could cause poor surface integrity, including the softening and burning of the matrix material. The thermally affected matrix could facilitate flexible fibers to escape from the cutting edge and stick to the trimmed surface. It could cause some sort of "spreading and sticking" of the material which could improve the surface finish in these cases. For example, in Test 2 (intermediate feed and speed), when average tool wear was $0.30 \mathrm{~mm}$ (after $14.1 \mathrm{~m}$ of cutting length), the cutting force was $756 \mathrm{~N}$, compared to $234 \mathrm{~N}$ for the new tool. It could be assumed that the high cutting forces might cause the softening and burning of the resin, which led to the fibers being spread over different machined plies. The fibers were also broken at locations beneath the machined surface. In Test 2 (intermediate feed and speed), the first short cut (test coupon 1) using a new tool caused the production of empty grooves as a result of fiber pull-out in $-45^{\circ}$ plies, as shown in Figure $4.20 \mathrm{a}$, but at the end of the tool life (test coupon 15), poor surface integrity, including matrix cracking, fiber pull-out and empty holes, were seen for $-45^{\circ}$ plies, as shown in Figure $4.20 \mathrm{~b}$.

To clarify the effect of cutting force (Tool wear) on surface integrity, Figure 4.21 shows three specimens compared together, all produced after $14.1 \mathrm{~m}$ of cutting length, using different cutting conditions (Tests 1-3). The first specimen was trimmed using a tool with an average maximum flank wear of $0.080 \mathrm{~mm}$ (cutting force was $152 \mathrm{~N}$ ); the second was trimmed using a tool with an average maximum flank wear of $0.300 \mathrm{~mm}$ (cutting force was $757 \mathrm{~N}$ ), and the third was trimmed using a tool with an average maximum flank wear of $0.230 \mathrm{~mm}$ (cutting force was $691 \mathrm{~N}$ ). As shown in Figure 4.21, a burning of the matrix was observed on the trimmed surface of the second one in Test 2 and third specimens in Test 3 (Figure 4.21b and Figure 4.21c), and they had the worst surface integrities, compared to the 
first one (Figure 4.21a) in Test 1 (low feed and high speed), which had the best surface integrities. According to these results, it might be assumed that the surface integrity decreased with an increase in cutting force (increase in tool wear).

Figure 4.22-4.24 show SEM micrograph of the trimmed surfaces at different cutting length for Test 1-3. If we take a deepest look at material surface integrity of the trimmed coupons, with an increase in tool wear, the surface integrity decreased, meaning that matrix was burnt using worn tool due to excessive tool wear and thermal effect. On the machined surfaces which were produced using worn tool, different surface integrity problems were seen such as matrix cracking, loose fibers, empty holes from fiber pull out, matrix burning/sticking and the breaking of the carbon fibers beneath the trimmed surface.

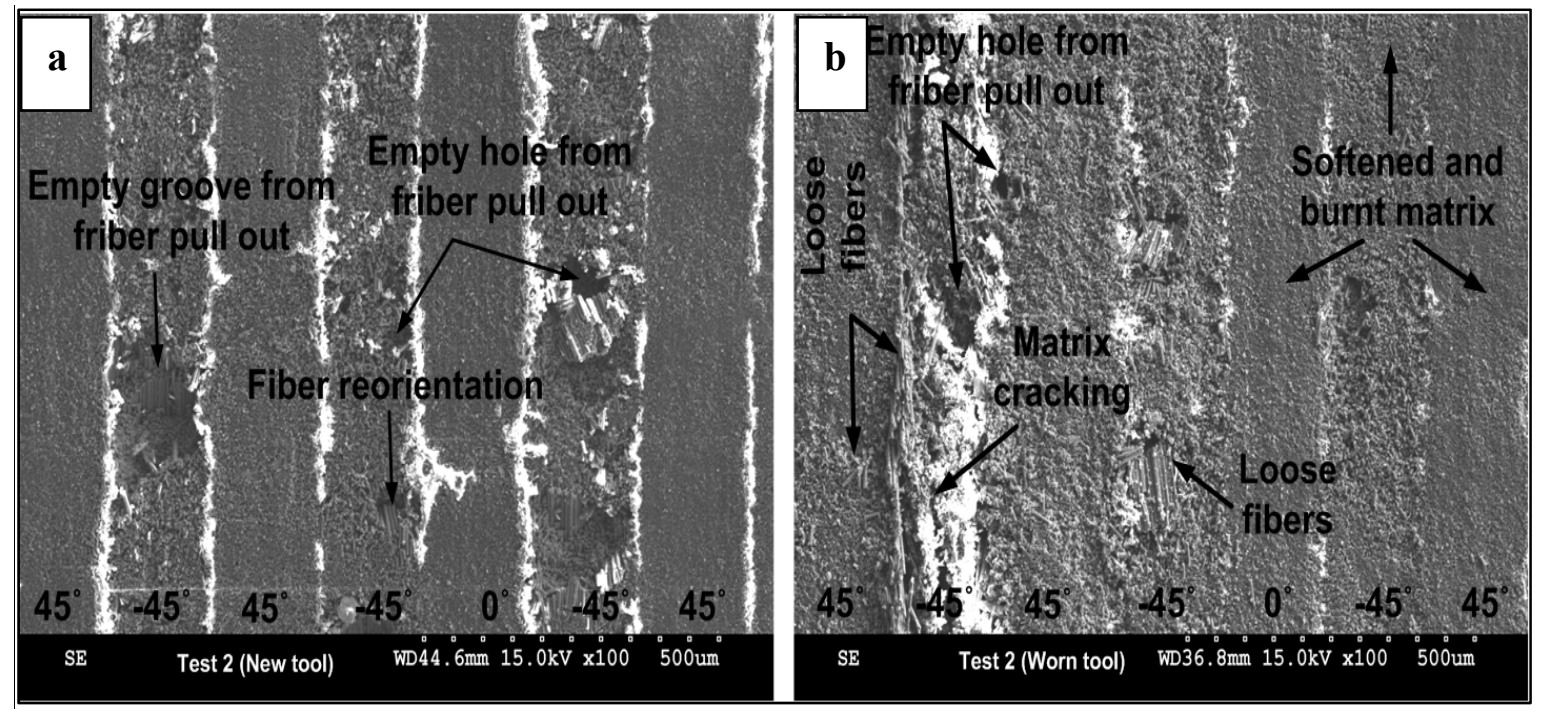

Figure 4.20 a) New tool, b) Worn tool $(14100 \mathrm{~mm})$ in Test 2 (Feed: $2794 \mathrm{~mm} / \mathrm{min}$, Speed: $300 \mathrm{~m} / \mathrm{min}$ ) 


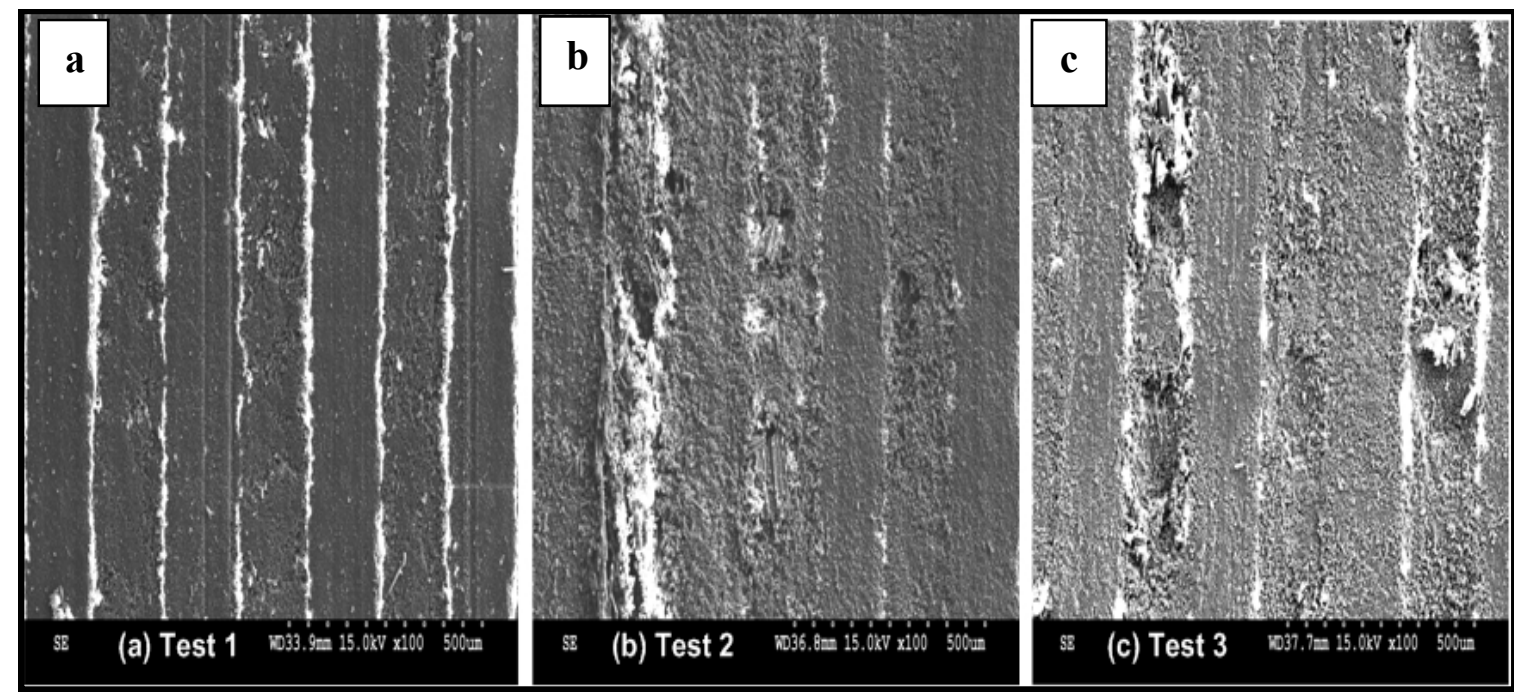

Figure 4.21 Trimmed surface after 14.1 meters of cutting length in a) Test 1 (Feed: 1524 $\mathrm{mm} / \mathrm{min}$, Speed: $400 \mathrm{~m} / \mathrm{min}$ ), b) Test 2 (Feed: $2794 \mathrm{~mm} / \mathrm{min}$, Speed: $300 \mathrm{~m} / \mathrm{min}$ ), c) Test 3 (Feed: $4064 \mathrm{~mm} / \mathrm{min}$, Speed: $200 \mathrm{~m} / \mathrm{min}$ ) 


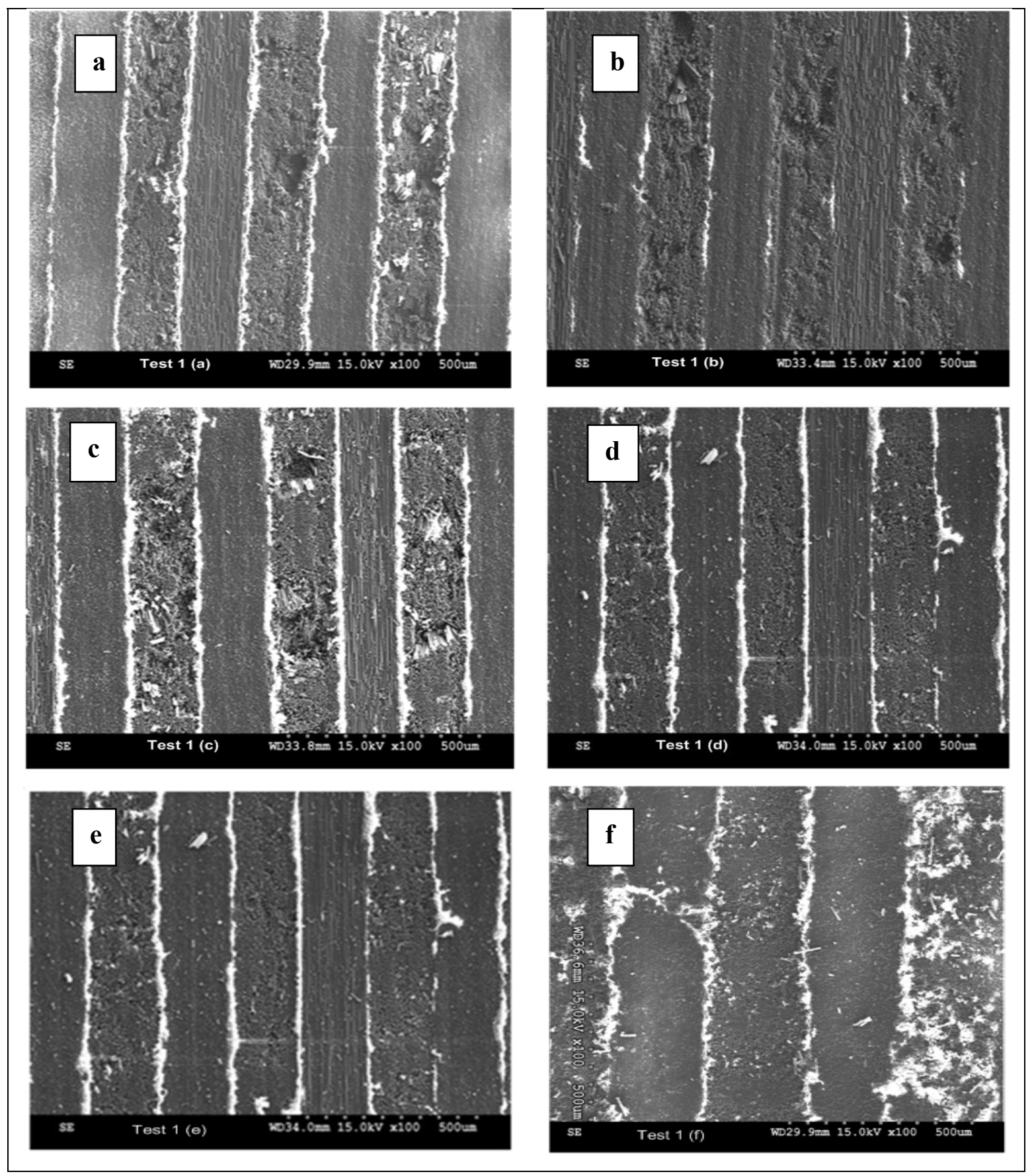

Figure 4.22 SEM micrographs of trimmed surface after a) 0.1, b) 4.1, c) 9.1, d) 15.9, e) 27.3 and f) 28.3 meters of cutting length in Test 1 


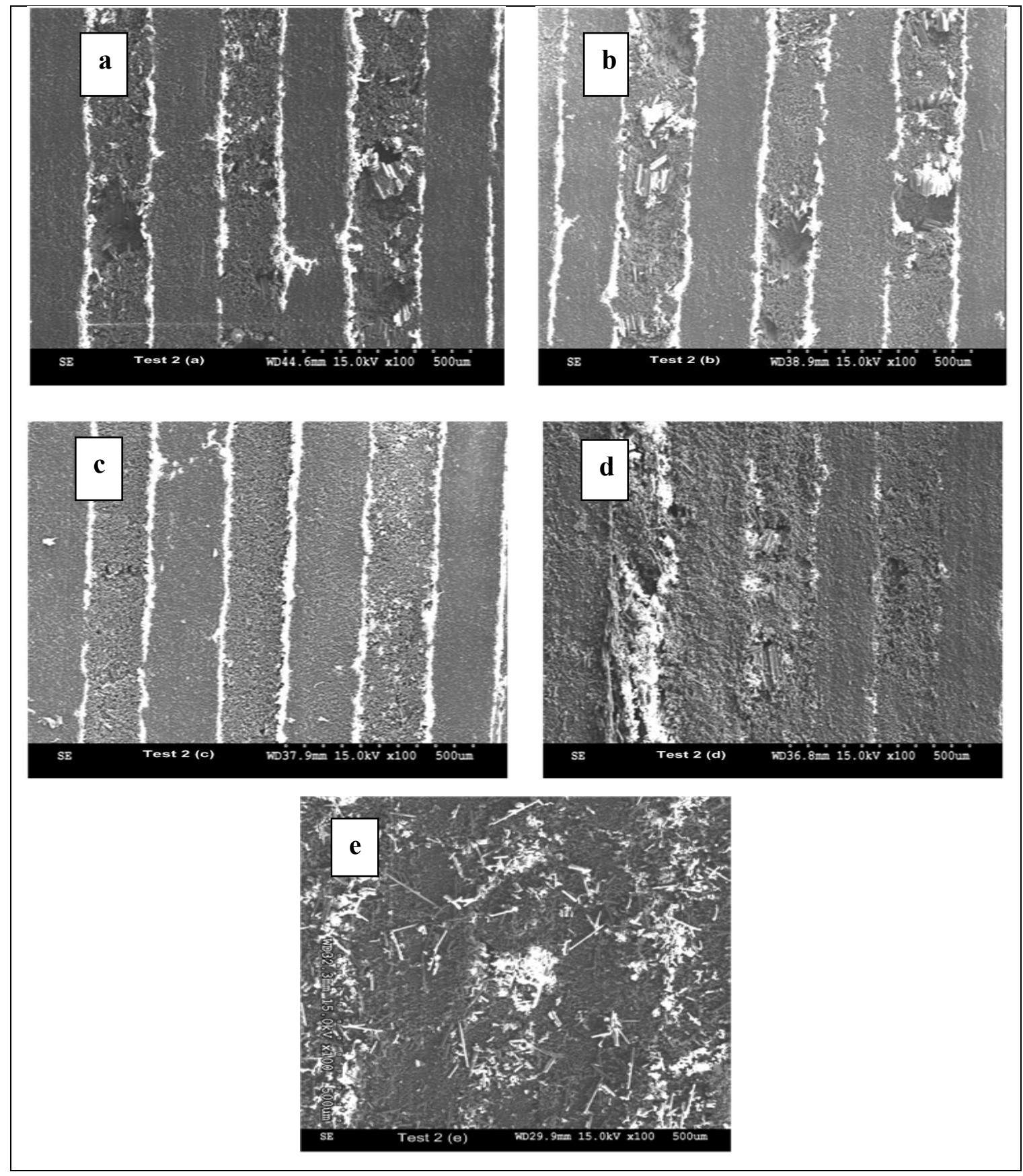

Figure 4.23 SEM micrographs of Trimmed surface after a) 0.1, b) 4.1, c) 9.1, d) 14.1 and e) 15.1 meters of cutting length in test 2 


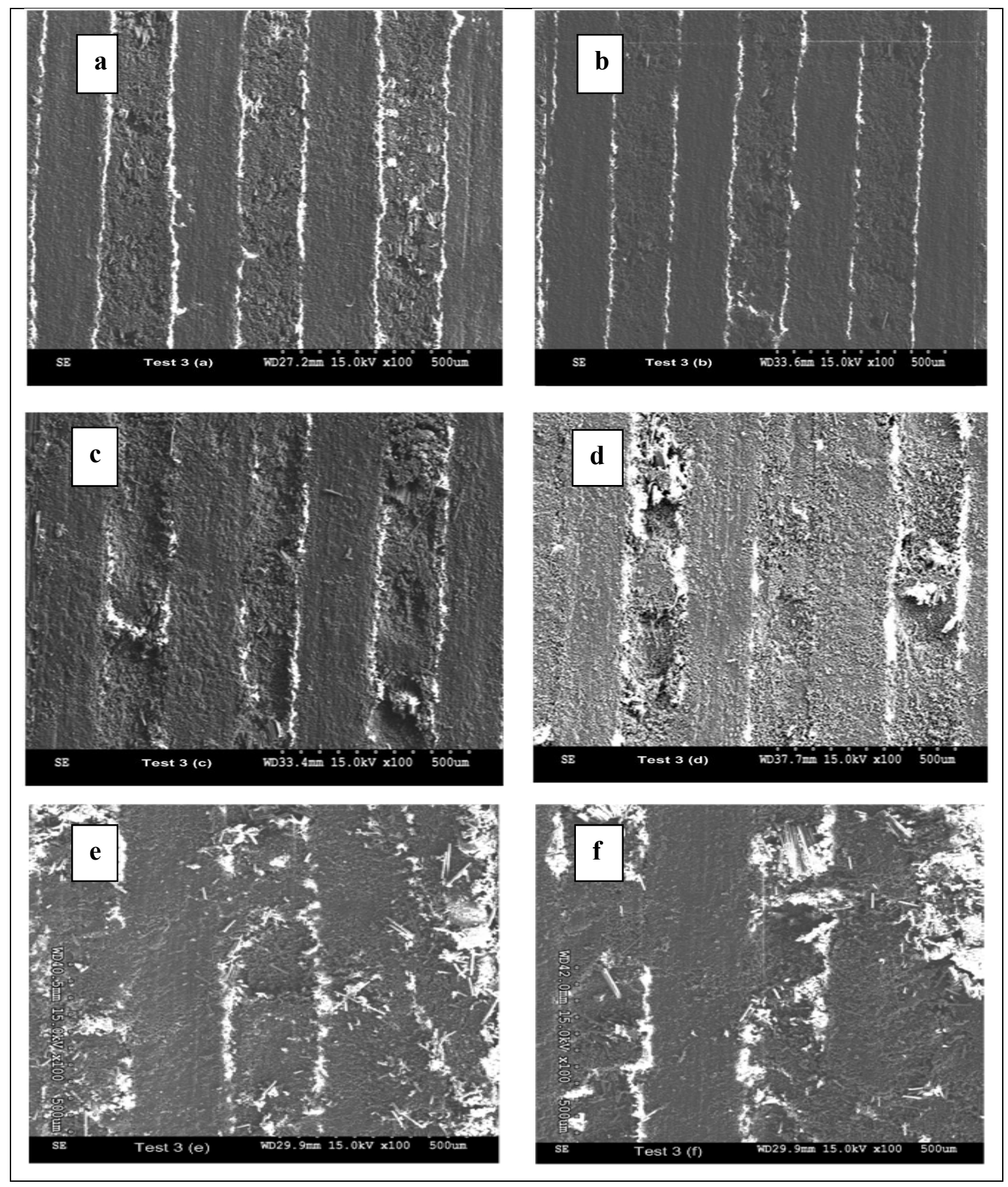

Figure 4.24 SEM micrographs of trimmed surface after a) 0.1, b) 4.1, c) 9.1, d) 14.1, e)19.1 and f) 20.1 meters of cutting length in Test 3 


\subsubsection{Excessive tool wear and material integrity}

At the end of tool life tests, the excessive tool wear led to the incidence of matrix burning which was associated with smoke and acrid odour during machining. On the trimmed edges, the resin epoxy matrix was burned due to the high tool wear and high cutting forces at the end of the tool life, especially in Test 1 (minimum feed and maximum speed) and Test 2 (intermediate feed and speed). Figure 4.25a shows smoke during machining using worn tool. Figure 4.25b shows the burnt matrix debris at the end of the tool life in Test 2 (Feed: 2794 $\mathrm{mm} / \mathrm{min}$, Speed: $300 \mathrm{~m} / \mathrm{min})$. It can be assumed that excessive tool wear and high cutting forces increased the cutting temperature. This temperature exceeded the glass transition temperature of the resin $\left(180^{\circ} \mathrm{C}\right)$ and consequently, it caused matrix burning/sticking and generated the acrid odour and the smoke. Figure 4.26 shows the trimmed surface after 15.1 metres of cutting length in Test 2 . In this figure, it was seen that the fibers were spread and stuck over different machined plies. The matrix was burned due to high cutting force $(737 \mathrm{~N})$ and high average tool wear $(0.423 \mathrm{~mm})$ and it was difficult to distinguish the machined plies. For all tool life tests, same results were observed. As a solution, El-Hofy et al. (2011) showed that the use of chilled air facilitated the removal of dust particles from the slot and decreased the incidence of matrix burning/sticking.

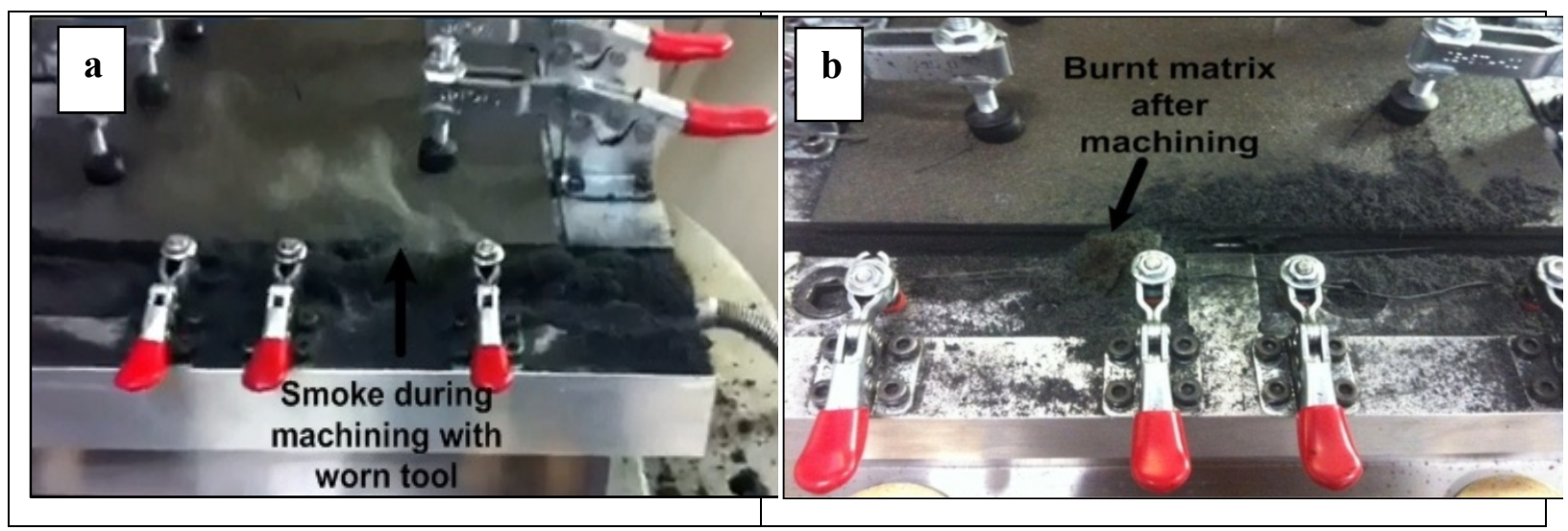

Figure 4.25 a) Smoke from burnt matrix, b) Burnt matrix in Test 2 (Feed: $2794 \mathrm{~mm} / \mathrm{min}$, Speed: $300 \mathrm{~m} / \mathrm{min}$ ) 


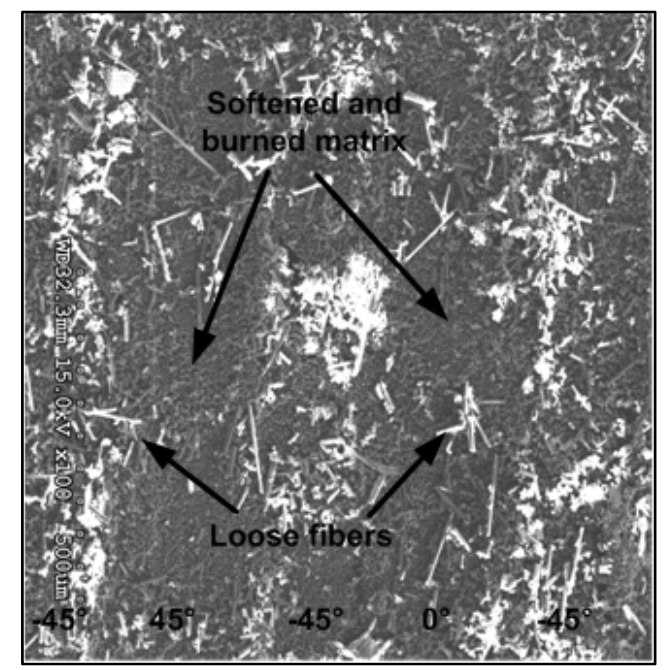

Figure 4.26 Trimmed surface after 15.1 meters of cutting length (Average VBmax: $0.42 \mathrm{~mm}$ ) in Test 2

\subsubsection{Surface Roughness}

In this study, surface roughness was measured using a profilometer Mitutoyo SJ-400 SURFPAK. The surface roughness measurement criteria were Ra, Rt and Rv (profile roughness parameters). All results were obtained and analysed from the $-45^{\circ}$ plies for the upmilling side of the coupons, using a longitudinal method over a distance of $14 \mathrm{~mm}$. The roughness measurement was repeated three times on $-45^{\circ}$ ply. The average values of $\mathrm{Ra}, \mathrm{Rt}$ and Rv were calculated separately. The up milling and down milling sides of the coupons for many cases were analysed and compared together. For example, Figure 4.27 shows the machined surfaces of two coupons (up milling and down milling sides). In this figure, the bottom surface was generated using the up milling mode ( $\mathrm{Ra}$ is $1.73 \mu \mathrm{m}$ ) while the top surface was produced using the down milling mode ( $\mathrm{Ra}$ is $10.76 \mu \mathrm{m})$. It indicates that in terms of surface roughness, up milling side was better than down milling side. So in this work, we decided to measure and analyse, the up milling side of the coupons. In addition, for the up-milling side of the coupons, all measurement results were obtained from the $-45^{\circ}$ plies because the trimming operation generated the worst surface roughness on the $-45^{\circ}$ plies according to Bérubé (2012). 


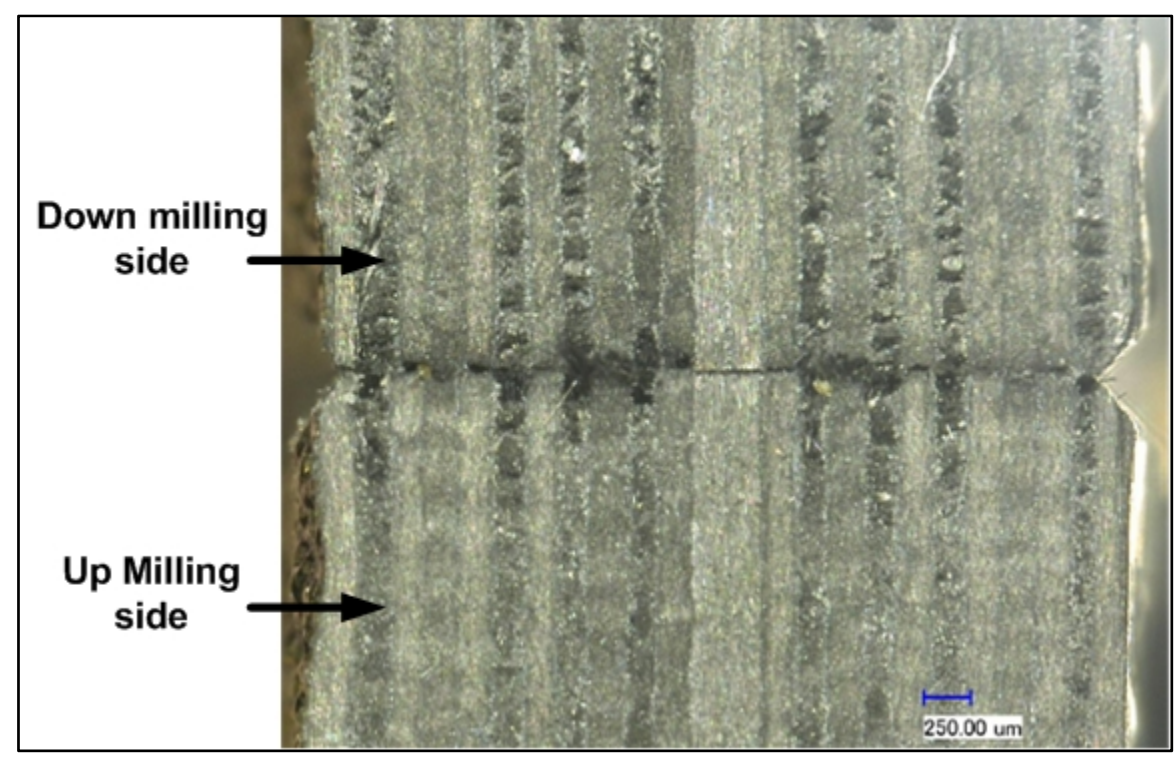

Figure 4.27 The machined surfaces of two coupons (up milling and down milling sides) Roughness (Ra) for up milling side: $1.73 \mu \mathrm{m}$, down milling side: $10.76 \mu \mathrm{m}$

Table 4.7-4.9 show the average values of $\mathrm{Ra}$, Rt and $\mathrm{Rv}$ for each short cut and the their related cutting lengths for Test 1-3 respectively. Figure 4.28-4.30 also show the average surface roughness and the calculated error bars (based on standard deviation) as a function of cutting length in Test 1-3 respectively. Figure 4.31 compares surface roughness (Ra) as a function of cutting length in Test 1-3. In all tool life tests, the surface roughness decreased with an increase in cutting length, especially after 10 meters of cutting length for Test 1-3 ( $\mathrm{Ra} \sim 2 \mu \mathrm{m})$. There is a contradiction between this result (surface roughness improvement) and those SEM micrograph results for the machined surface integrity. So, this indicates that the roughness parameter itself may not be an appropriate indicator for evaluating the cutting surface quality of CFRP composites and it could cause a false interpretation of good surface quality. It could be assumed that the surface roughness was improved due to the matrix burning/sticking and the breaking of the carbon fibers beneath the trimmed surface (using worn tool). Ghidossi et al. (2004) also carried out some experiments and they showed that machining reduced the coupon strength but it was not possible to use roughness as an indicator. 
Table 4.7 Average roughness Ra, Rt, Rv and their related cutting lengths in Test 1

(Feed: $1524 \mathrm{~mm} / \mathrm{min}$, Speed: $400 \mathrm{~m} / \mathrm{min}$ )

\begin{tabular}{|c|c|c|c|}
\hline Cutting Length (m) & $\mathbf{R a}(\boldsymbol{\mu m})$ & $\mathrm{Rt}(\boldsymbol{\mu m})$ & $\mathrm{Rv}(\mu \mathrm{m})$ \\
\hline 0.1 & 5.633 & 41.335 & 16.228 \\
\hline 1.1 & 4.780 & 39.106 & 19.199 \\
\hline 2.1 & 6.254 & 43.315 & 19.737 \\
\hline 3.1 & 2.813 & 30.356 & 13.088 \\
\hline 4.1 & 2.800 & 31.656 & 13.394 \\
\hline 5.1 & 1.793 & 10.858 & 4.306 \\
\hline 6.1 & 2.748 & 27.002 & 11.416 \\
\hline 7.1 & 3.279 & 23.978 & 10.305 \\
\hline 8.1 & 2.962 & 27.722 & 11.362 \\
\hline 9.1 & 2.622 & 24.098 & 10.835 \\
\hline 10.1 & 2.180 & 19.722 & 10.159 \\
\hline 11.1 & 2.540 & 21.161 & 10.011 \\
\hline 12.1 & 1.586 & 15.003 & 7.282 \\
\hline 14 & 1.354 & 11.476 & 5.833 \\
\hline 15.9 & 1.516 & 14.853 & 6.628 \\
\hline $\mathbf{1 7 . 8}$ & 1.385 & 14.265 & 6.125 \\
\hline 19.7 & 2.090 & 17.601 & 8.741 \\
\hline 21.6 & 1.740 & 16.368 & 7.507 \\
\hline 23.5 & 1.550 & 14.742 & 6.381 \\
\hline 25.4 & 1.201 & 12.330 & 6.094 \\
\hline 27.3 & 2.588 & 21.412 & 9.129 \\
\hline 28.3 & 2.696 & 25.993 & 10.984 \\
\hline
\end{tabular}


Table 4.8 Average roughness Ra, Rt, Rv and their related cutting lengths in Test 2

(Feed: $2794 \mathrm{~mm} / \mathrm{min}$, Speed: $300 \mathrm{~m} / \mathrm{min}$ )

\begin{tabular}{|c|c|c|c|}
\hline Cutting length $(\mathbf{m})$ & Ra $(\boldsymbol{\mu m})$ & Rt $(\boldsymbol{\mu m})$ & Rv $(\boldsymbol{\mu m})$ \\
\hline $\mathbf{0 . 1}$ & 11.424 & 69.445 & 29.621 \\
\hline $\mathbf{1 . 1}$ & 7.958 & 58.047 & 24.694 \\
\hline $\mathbf{2 . 1}$ & 5.712 & 43.160 & 20.147 \\
\hline $\mathbf{3 . 1}$ & 5.748 & 49.198 & 27.112 \\
\hline $\mathbf{4 . 1}$ & 6.738 & 52.200 & 23.183 \\
\hline $\mathbf{5 . 1}$ & 4.970 & 36.353 & 16.913 \\
\hline $\mathbf{6 . 1}$ & 4.373 & 30.998 & 14.320 \\
\hline $\mathbf{7 . 1}$ & 3.856 & 35.703 & 13.660 \\
\hline $\mathbf{8 . 1}$ & 2.128 & 17.524 & 7.338 \\
\hline $\mathbf{9 . 1}$ & 3.015 & 26.478 & 12.465 \\
\hline $\mathbf{1 0 . 1}$ & 1.671 & 13.594 & 5.543 \\
\hline $\mathbf{1 1 . 1}$ & 1.591 & 15.670 & 5.321 \\
\hline $\mathbf{1 2 . 1}$ & 1.654 & 15.308 & 5.595 \\
\hline $\mathbf{1 3 . 1}$ & 1.384 & 12.188 & 4.715 \\
\hline $\mathbf{1 4 . 1}$ & 1.730 & 15.066 & 5.133 \\
\hline $\mathbf{1 5 . 1}$ & 2.542 & 27.031 & 11.261 \\
\hline
\end{tabular}


Table 4.9 Average roughness Ra, Rt, Rv and their related cutting lengths in Test 3

(Feed: $4064 \mathrm{~mm} / \mathrm{min}$, Speed: $200 \mathrm{~m} / \mathrm{min}$ )

\begin{tabular}{|c|c|c|c|}
\hline Cutting Length (m) & $\mathbf{R a}(\boldsymbol{\mu m})$ & Rt ( $\mu \mathrm{m})$ & $\mathbf{R v}(\mu \mathrm{m})$ \\
\hline 0.1 & 3.353 & 25.538 & 12.507 \\
\hline 1.1 & 2.990 & 25.167 & 11.820 \\
\hline 2.1 & 3.545 & 33.216 & 15.367 \\
\hline 3.1 & 3.161 & 26.573 & 13.208 \\
\hline 4.1 & 3.221 & 25.821 & 12.847 \\
\hline 5.1 & 2.736 & 22.736 & 10.230 \\
\hline 6.1 & 2.775 & 30.165 & 10.244 \\
\hline 7.1 & 2.368 & 26.532 & 9.350 \\
\hline 8.1 & 3.725 & 32.007 & 13.861 \\
\hline 9.1 & 2.743 & 26.235 & 9.459 \\
\hline 10.1 & 2.949 & 27.451 & 10.309 \\
\hline 11.1 & 2.839 & 24.842 & 10.407 \\
\hline 12.1 & 2.901 & 21.601 & 9.992 \\
\hline 13.1 & 2.080 & 15.477 & 7.150 \\
\hline 14.1 & 3.499 & 30.803 & 11.792 \\
\hline 15.1 & 3.378 & 37.321 & 12.622 \\
\hline 16.1 & 3.818 & 33.369 & 12.721 \\
\hline 17.1 & 2.409 & 22.933 & 7.656 \\
\hline 18.1 & 2.137 & 16.544 & 6.919 \\
\hline 19.1 & 2.332 & 19.653 & 7.746 \\
\hline 20.1 & 1.234 & 10.395 & 4.115 \\
\hline
\end{tabular}




\section{a) Rt and Rv}

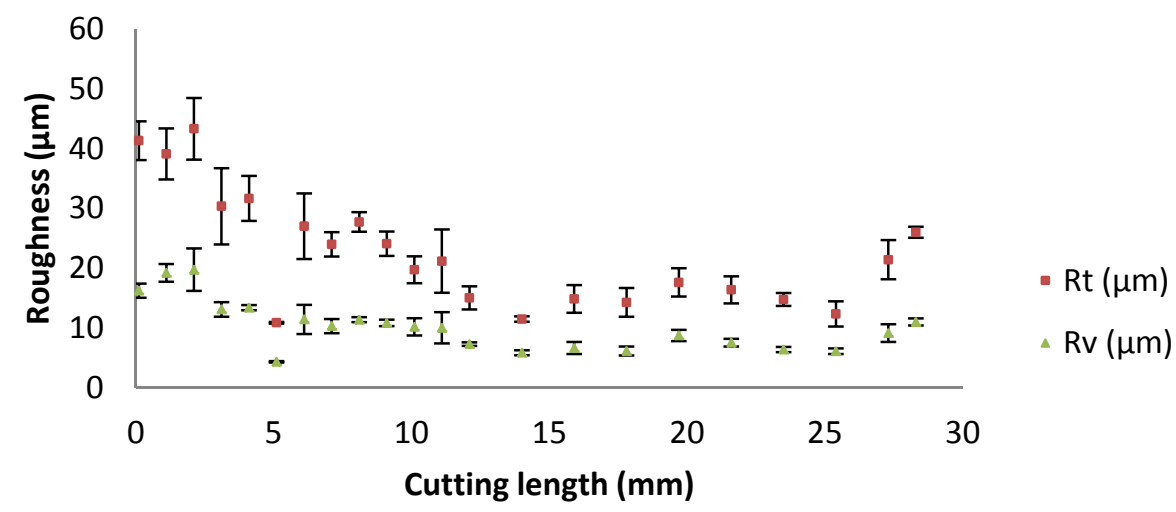

Feed $1524 \mathrm{~mm} / \mathrm{min}$ - Speed: $400 \mathrm{~m} / \mathrm{min}$

\section{b) $\mathrm{Ra}$}

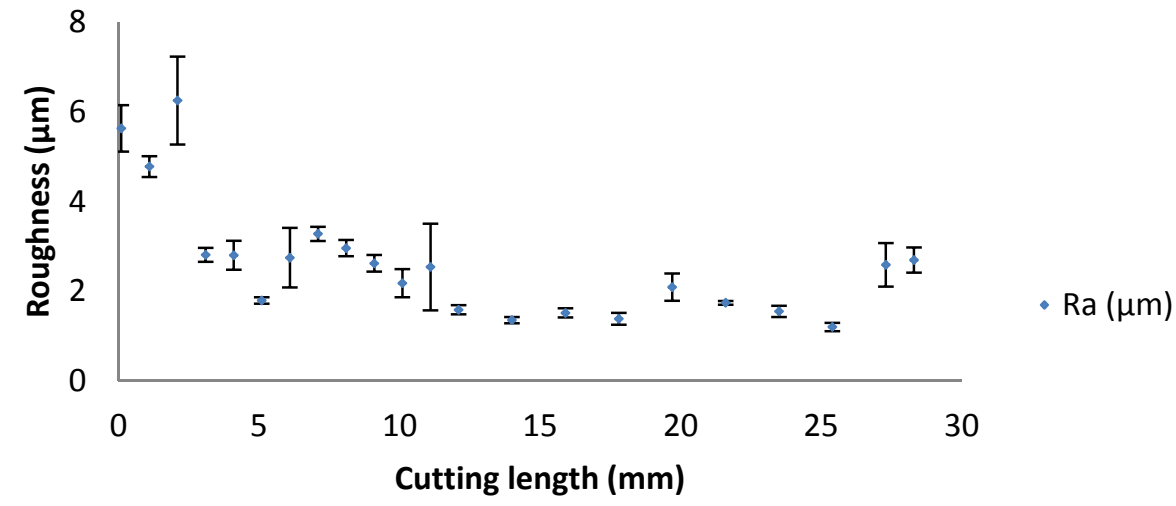

Feed $1524 \mathrm{~mm} / \mathrm{min}$ - Speed: $400 \mathrm{~m} / \mathrm{min}$

Figure 4.28 Surface roughness a) Rt and Rv, b) Ra as a function of cutting in Test 1 


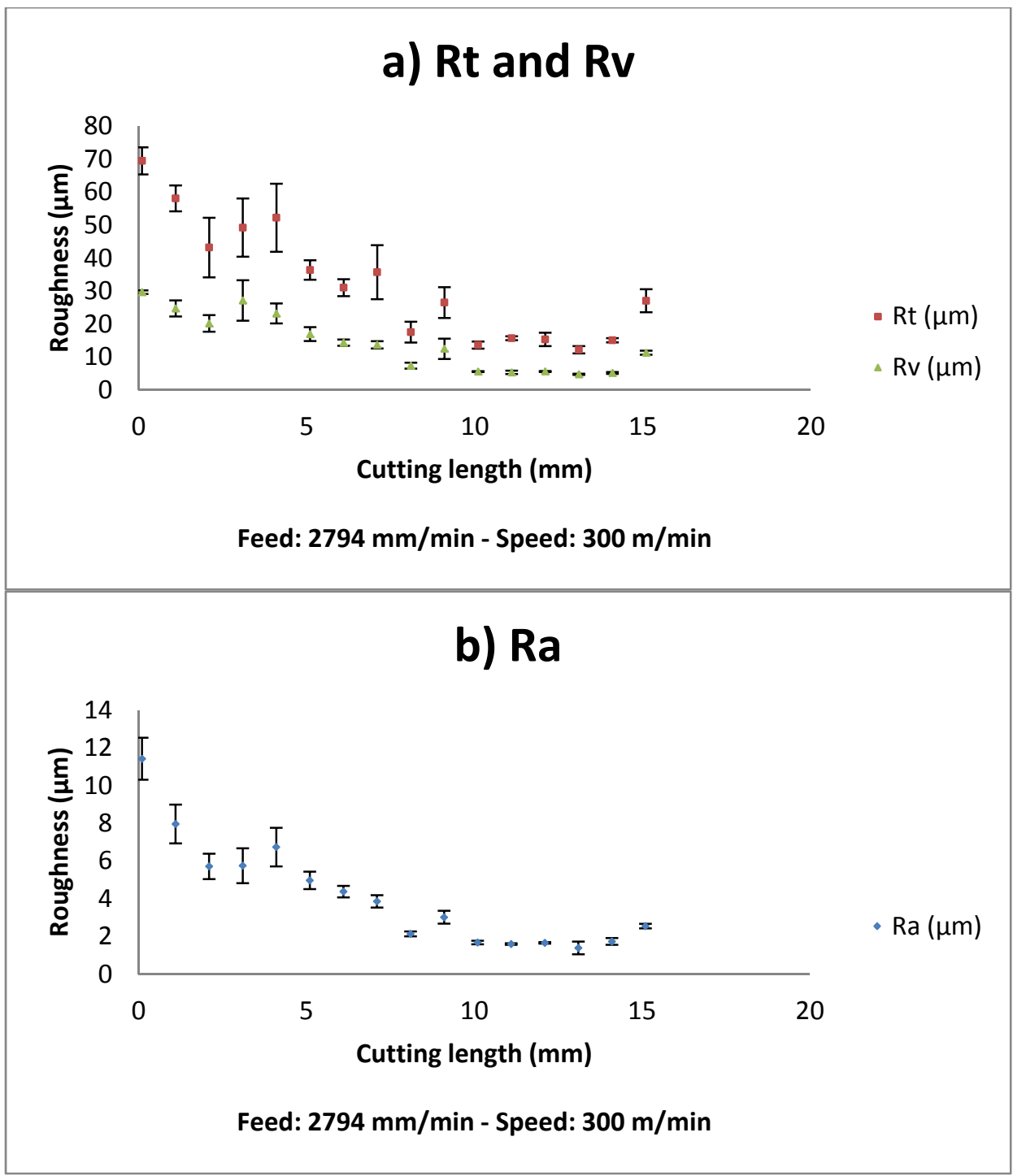

Figure 4.29 Surface roughness a) Rt and Rv, b) Ra as a function of cutting in Test 2 


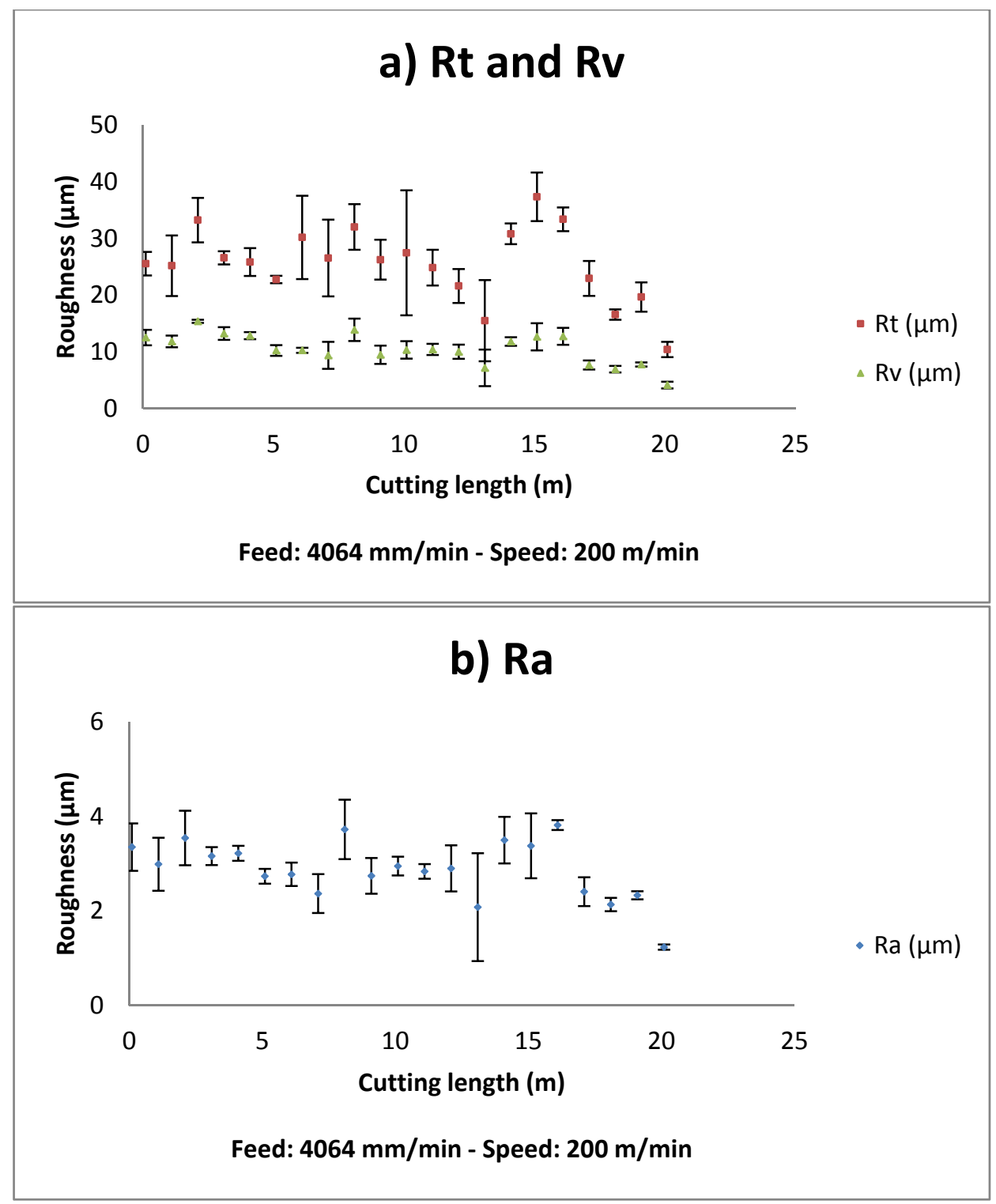

Figure 4.30 Surface roughness a) Rt and Rv, b) Ra as a function of cutting in Test 3 


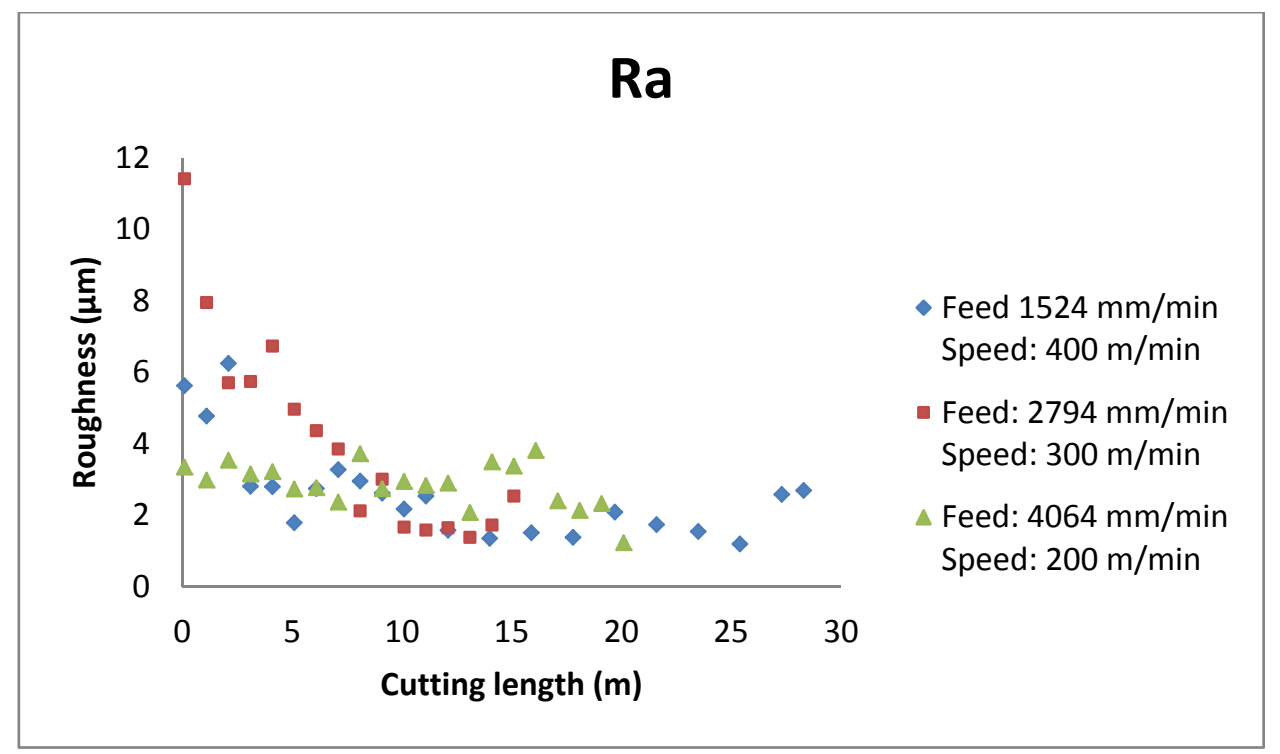

Figure 4.31 Surface roughness, $\mathrm{Ra}$ as a function of cutting in Test 1-3

\subsubsection{Effect of tool wear on roughness}

Figure 4.32-4.34 show the roughness as a function of tool wear. In all tool life tests, with an increase in tool wear, surface roughness $(\mathrm{Ra})$ decreased. This surface roughness improvement indicates that machining using new tool, increased surface roughness while machining using worn tool, decreased surface roughness ( $\mathrm{Ra}$ ). It could be assumed that due to the matrix burning/sticking and the breaking of the carbon fibers beneath the trimmed surface (using worn tool), the machined surface was improved in terms of surface roughness. 


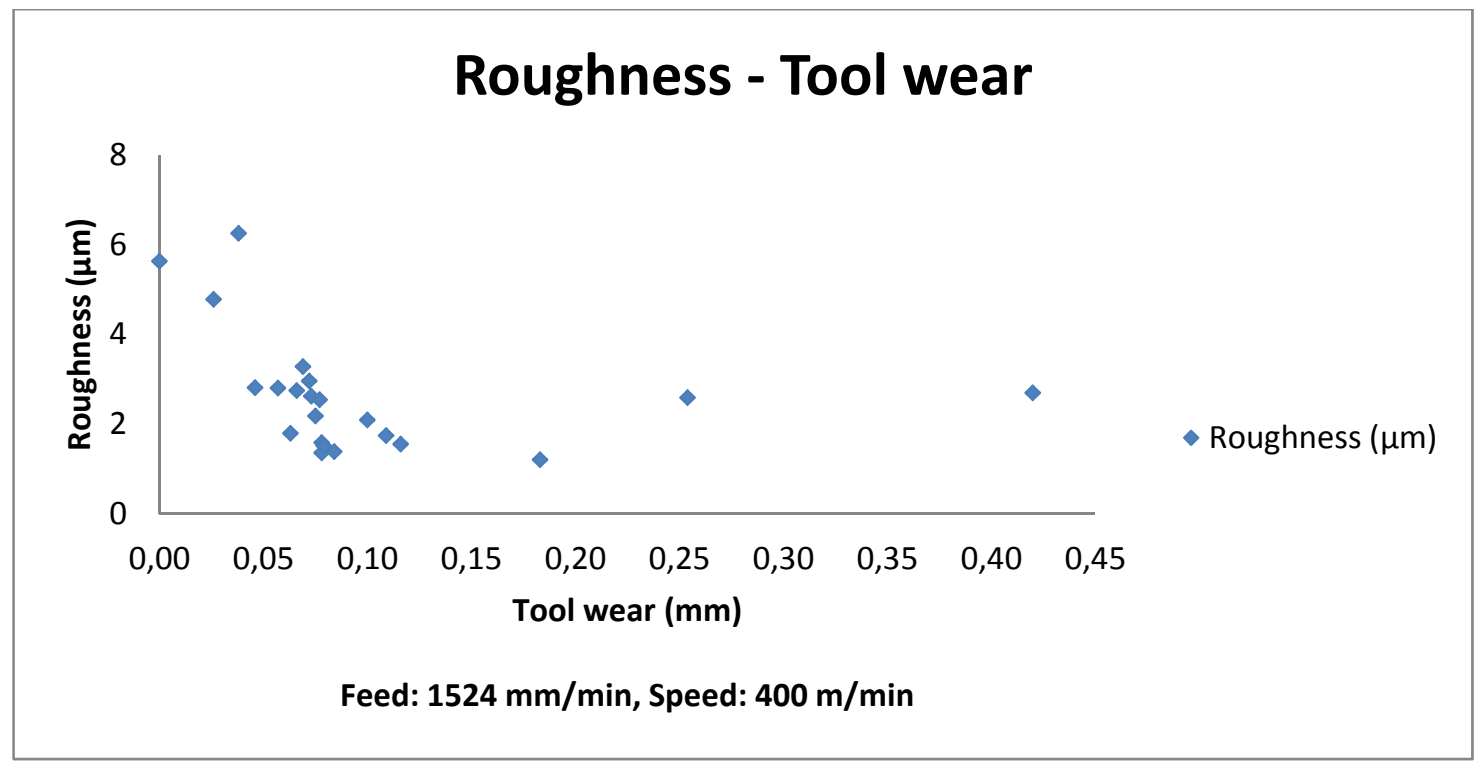

Figure 4.32 Effect of Tool Wear on Roughness in Test 1

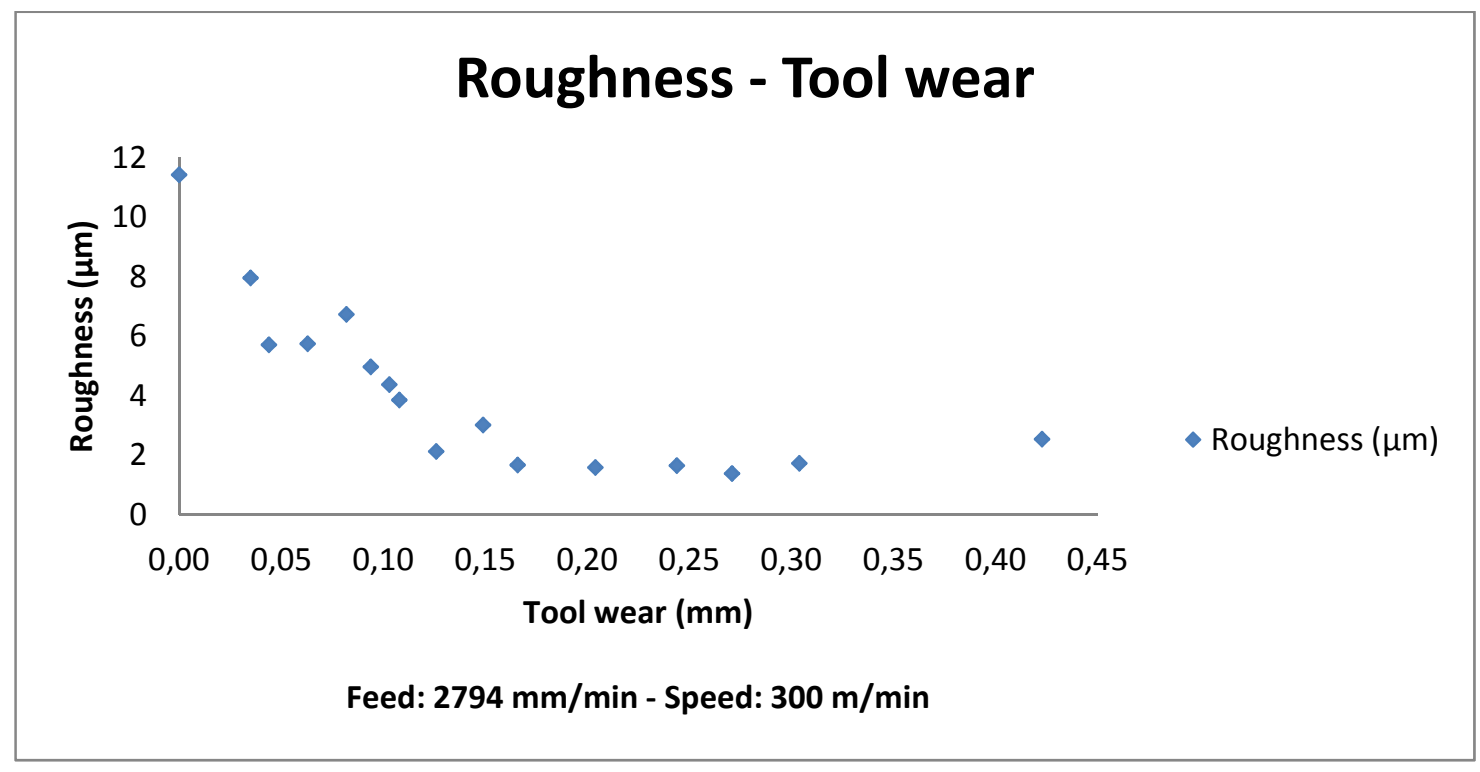

Figure 4.33 Effect of Tool Wear on Roughness in Test 2 


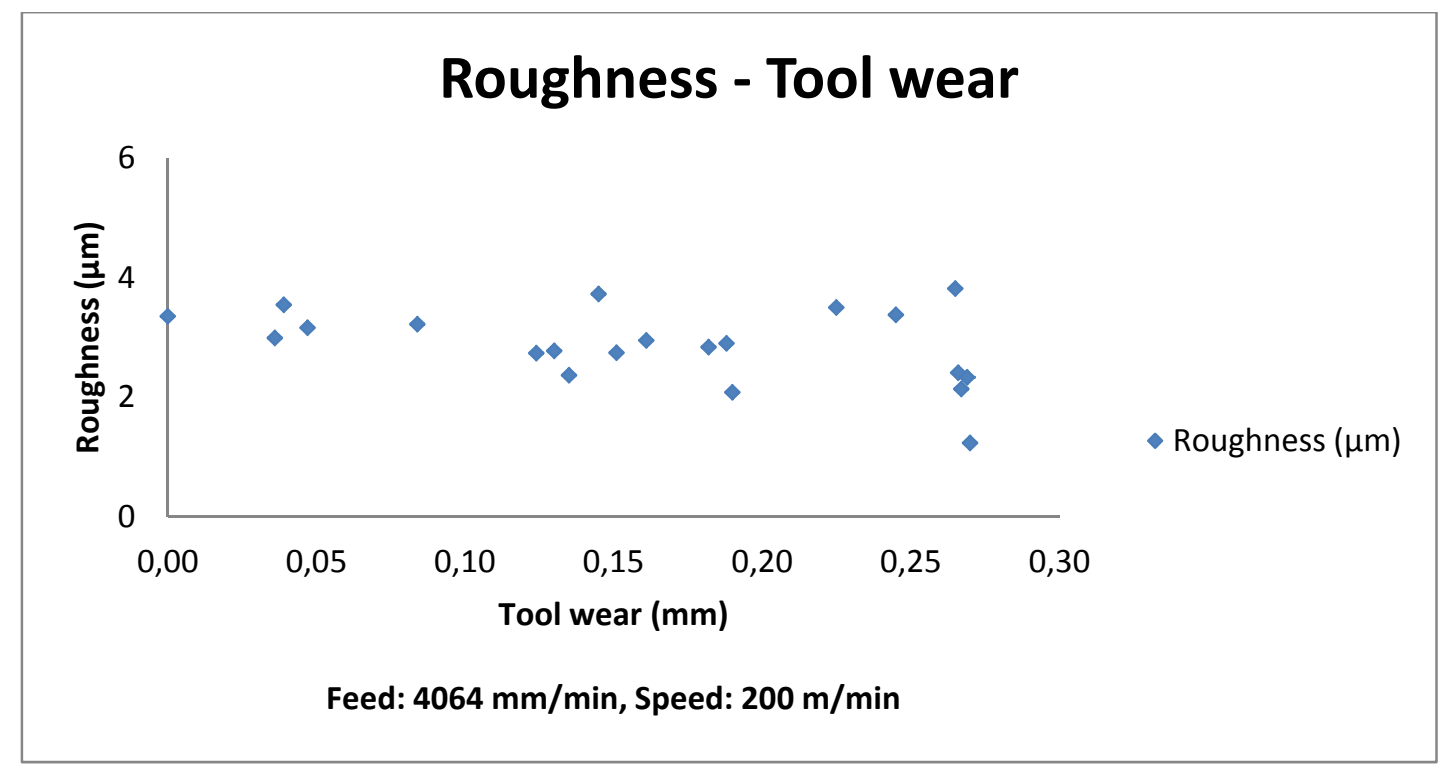

Figure 4.34 Effect of Tool Wear on Roughness in Test 3

\subsection{Analysis of preliminary tests}

\subsubsection{Effect of cutting conditions on cutting forces during trimming using new tool}

According to the results of nine preliminary tests as shown in Table 4.10, it was found that with an increase in feed rate, cutting forces increased while with an increase in cutting speed, cutting forces decreased as shown in Figure 4.35. The cutting condition of $7^{\text {th }}$ preliminary test was same as tool life Test 1 and the cutting condition of $3^{\text {rd }}$ preliminary test was same as tool life Test 3 . The preliminary results confirmed the tool life test results meaning that in $7^{\text {th }}$ preliminary test (low feed and high speed), low cutting force was produced while in $3^{\text {rd }}$ preliminary test (high feed and low speed), high cutting forces was generated. Zaghbani et al. (2012) also found the similar results and they also showed that the feed rate has a more significant effect on the average cutting forces than does the cutting speed. 
Table 4.10 Total cutting forces for different cutting speeds and feed rates (nine preliminary tests)

\begin{tabular}{|c|c|c|c|c|}
\hline Test No. & $\begin{array}{c}\text { Cutting } \\
\text { Speed } \\
(\mathbf{m} / \mathbf{m i n})\end{array}$ & \multicolumn{2}{|c|}{ Feed Rate $(\mathbf{m m} / \mathbf{r e v})-(\mathbf{m m} / \mathbf{m i n})$} & $\begin{array}{c}\text { F total } \\
\mathbf{( N )}\end{array}$ \\
\hline $\mathbf{1}$ & 200 & 0.3048 & 1524 & 188 \\
\hline $\mathbf{2}$ & 200 & 0.3556 & 2794 & 263 \\
\hline $\mathbf{3}$ & 200 & 0.4064 & 4064 & 338 \\
\hline $\mathbf{4}$ & 300 & 0.3048 & 1524 & 164 \\
\hline $\mathbf{5}$ & 300 & 0.3556 & 2794 & 235 \\
\hline $\mathbf{6}$ & 300 & 0.4064 & 4064 & 299 \\
\hline $\mathbf{7}$ & 400 & 0.3048 & 1524 & 121 \\
\hline $\mathbf{8}$ & 400 & 0.3556 & 2794 & 203 \\
\hline $\mathbf{9}$ & 400 & 0.4064 & 4064 & 281 \\
\hline
\end{tabular}

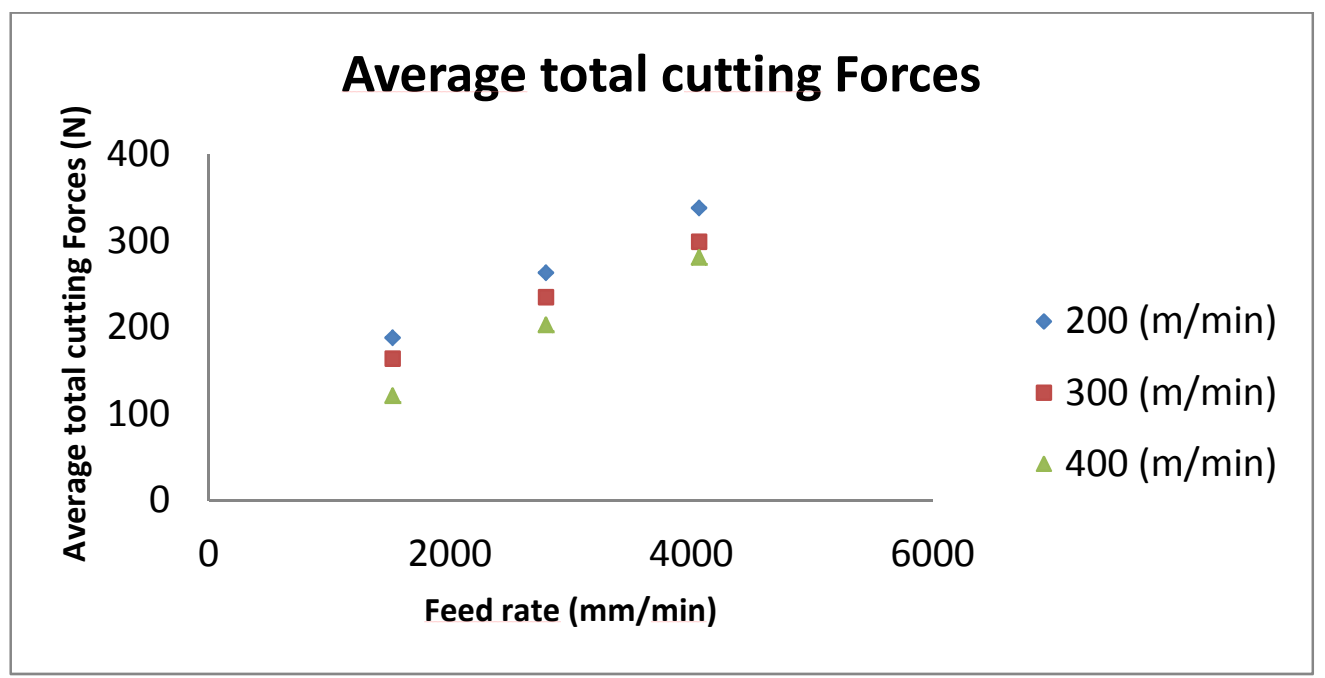

Figure 4.35 Effect of cutting speed and feed rate on average cutting forces in preliminary tests

\subsubsection{Effect of cutting conditions on surface roughness during trimming using new tool}

According to the results of nine preliminary tests as shown in Table 4.11, it was found that with an increase in feed rate, surface roughness $(\mathrm{Ra})$ increased while with an increase in cutting speed from $200 \mathrm{~m} / \mathrm{min}$ to 300 or $400 \mathrm{~m} / \mathrm{min}$, surface roughness (Ra) increased as 
shown in Figure 4.36. The increase in cutting speed from 300 to $400 \mathrm{~m} / \mathrm{min}$ didn't affect surface roughness $(\mathrm{Ra})$. Chatelain et al. (2012) found the similar results and they showed that low feed rates led to better surface finish. They also found that the cutting speed effect was not as significant as the feed rate effect on the surface roughness.

Table 4.11 Roughness for different cutting speeds and feed rates (nine preliminary tests)

\begin{tabular}{|c|c|c|c|c|}
\hline $\begin{array}{c}\text { Test } \\
\text { No. }\end{array}$ & $\begin{array}{c}\text { Cutting Speed } \\
(\mathbf{m} / \mathbf{m i n})\end{array}$ & \multicolumn{2}{|c|}{ Feed Rate $(\mathbf{m m} / \mathbf{r e v})-(\mathbf{m m} / \mathbf{m i n})$} & Ra $(\boldsymbol{\mu m})$ \\
\hline $\mathbf{1}$ & 200 & 0.3048 & 1524 & 5.124 \\
\hline $\mathbf{2}$ & 200 & 0.3556 & 2794 & 6.184 \\
\hline $\mathbf{3}$ & 200 & 0.4064 & 4064 & 7.148 \\
\hline $\mathbf{4}$ & 300 & 0.3048 & 1524 & 8.879 \\
\hline $\mathbf{5}$ & 300 & 0.3556 & 2794 & 9.923 \\
\hline $\mathbf{6}$ & 300 & 0.4064 & 4064 & 13.076 \\
\hline $\mathbf{7}$ & 400 & 0.3048 & 1524 & 8.801 \\
\hline $\mathbf{8}$ & 400 & 0.3556 & 2794 & 9.933 \\
\hline $\mathbf{9}$ & 400 & 0.4064 & 4064 & 13.378 \\
\hline
\end{tabular}

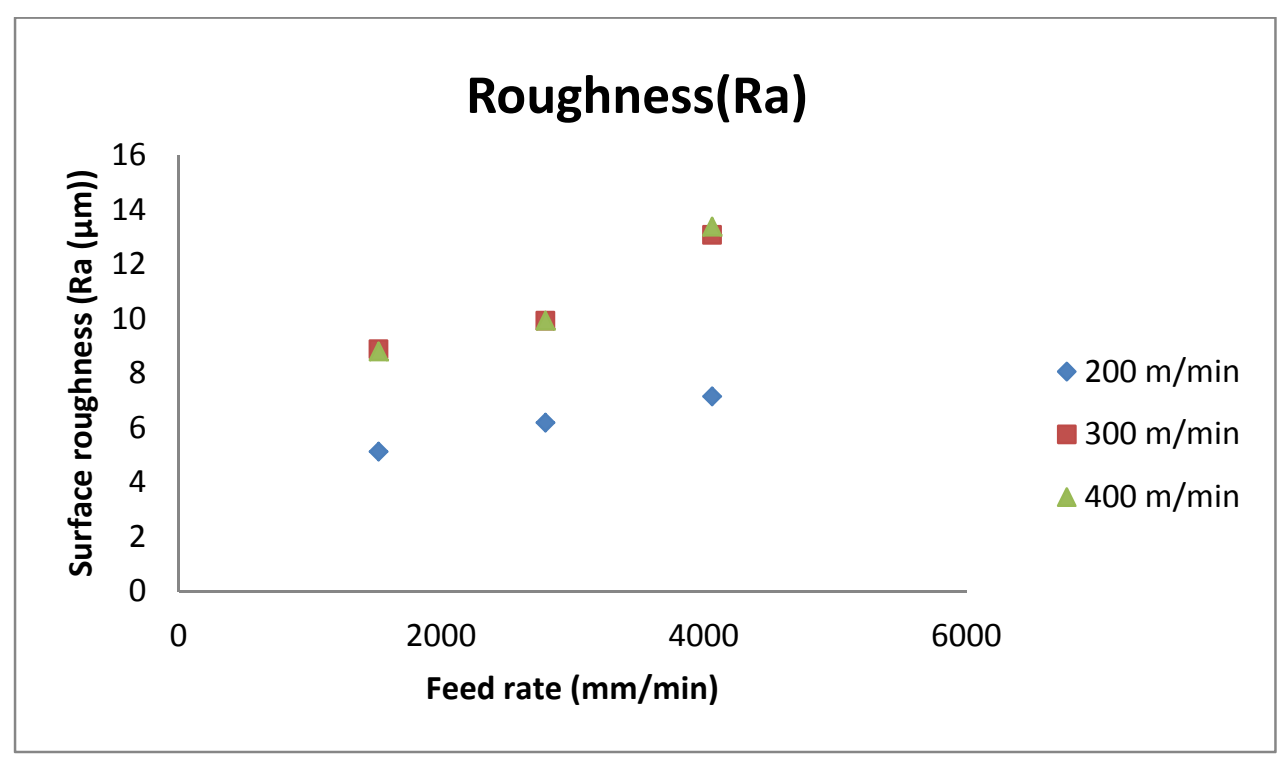

Figure 4.36 Effect of cutting speed and feed rate on roughness in preliminary tests 


\section{CONCLUSION}

The tool condition is one of the essential factors affecting machining quality. This paper studies primarily, the effect of tool wear on laminate integrity and surface roughness during the trimming operation of CFRP laminates used in aerospace. In this research, the effect of machining parameters on tool wear was verified as well. A 3/8 inch diameter CVD diamond coated carbide tool with six flutes was used to detour 24-ply carbon fiber laminates. The surface integrity was verified using a scanning electron microscope and the surface roughness was measured across the laminate for different fiber orientations. Several conclusions can be pointed out:

- It was found that a worn tool caused high cutting forces and lower surface quality in terms of surface integrity. Poor surface integrity, including matrix cracking, fiber pull-out and empty holes were seen, particularly for the $-45^{\circ}$ plies;

- The relation between tool wear and surface roughness showed an increase in tool wear improved the surface finish, with lower values of Ra, Rt and Rv parameters. There is a contradiction between this result (surface roughness improvement) and those SEM micrograph results for the machined surface integrity. It could be assumed that the surface roughness was improved due to the matrix burning/sticking and the breaking of the carbon fibers beneath the trimmed surface (using worn tool). Thus, surface roughness, itself without other quality parameters, is not an appropriate indicator to evaluate cutting surface quality;

- Concerning the effect of cutting conditions on tool wear, it was found that a lower tool wear was obtained at lower feed rates and higher cutting speeds, since a higher tool wear was obtained at intermediate feed rate and cutting speed values;

- In terms of fiber pull-out and delamination, it wasn't seen any fiber pull-out or delamination on the surface of all trimmed coupons for three tool life tests;

- At the end of tool life tests, the excessive tool wear caused the incidence of matrix burning which was associated with smoke and acrid odour during machining. On the 
trimmed edges, the resin epoxy matrix was burned due to the high tool wear and high cutting forces.

These conclusions are meaningful important regarding the industrial production for aerospace. The inspection of surface roughness must be appropriate for composite laminates as the interpretation of results largely differs than for the metallic materials. Improvement of surface finish may indicate that matrix degradation due to thermal effects. This can severely impact the mechanical properties of the composite. This research also proposes efficient machining parameters for typically utilized CVD coated cutting tools as expected tool life for such ones.

Based on the results of tool life experiments, a scientific paper has been published in Applied Mechanics and Materials journal (annex II). Another paper regarding the modeling of cutting forces and tool wear prediction has also been recently submitted to International Journal of Advanced Manufacturing Technology (annex III). 


\section{RECOMMENDATIONS}

As future work, it would be interesting to study the effect of tool wear on the mechanical properties. To verify this effect, the fatigue tests in tension and bending could be carried out on the coupons which are obtained from short cut by correlating the impact of tool wear on the mechanical properties of laminates. It could be also interesting to perform stability test in order to find stable cutting conditions. It means that a suitable model for quasi-isotropic laminates of stability lobes could be developed in order to find dynamically stable conditions. In our study, the rigidity of fixture was too high. So, it could be possible to study the effect of rigidity on the surface quality. The different fixture rigidity could change the quality of trimmed CFRP laminate. To reduce the effect of cutting temperature on the resulting quality, it might be interesting to study the effect of chilled air on the quality of machining. Moreover, different tool geometry and different cutting tool coating could be used in order to study the effect of tool geometry and tool coating on surface quality during tool life tests.

In our experiments, the traditional (2D) evaluation method was used in order to evaluate surface roughness. Based on the (2D) evaluation results, with an increase in tool wear, surface roughness (Ra, Rt and Rv parameters) decreased. It could be assumed that the surface roughness was improved due to the matrix burning/sticking. In order to better evaluate the surface roughness, it could be also interesting to perform (3D) evaluation and fractal methods even though (3D) evaluation standard hasn't been established internationally until now. 



\section{ANNEX I}

\section{OPTICAL MICROSCOPE TYPE VHX-600+500F SPECIFICATIONS}

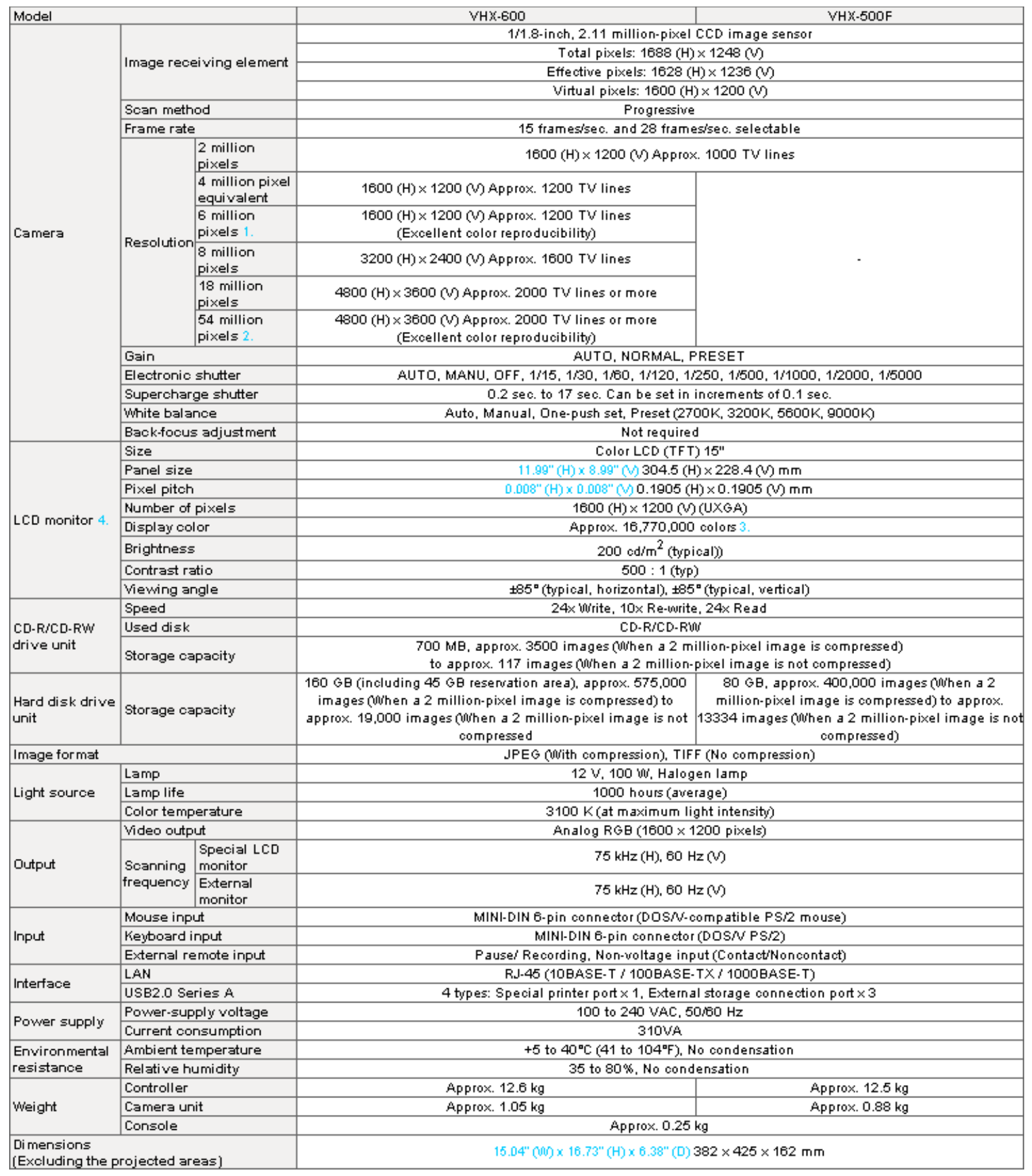





\title{
ANNEX II
}

\section{PUBLISHED JOURNAL I}

Effect of Tool Wear on Quality of Carbon Fiber Reinforced Polymer Laminate during Edge Trimming

Hossein Hamedanianpour, Jean-François Chatelain

Mechanical Engineering Department, École de technologie supérieure, Montréal, Québec, Canada

hossein.hamedanianpour.1@ens.etsmtl.ca, jfchatelain@mec.etsmtl.ca

Keywords: Composite, CFRP, Trimming, Milling, Tool Wear, Surface quality

Publication: Applied Mechanics and Materials Vols. 325-326 (2013), pp 34-39

\begin{abstract}
Polymer matrix composites, particularly carbon fiber reinforced polymers (CFRPs) are widely used in various high technology industries, including aerospace, automotive and wind energy. Normally, when CFRPs are cured to near net shape, finishing operations such as trimming, milling or drilling are used to remove excess materials. The quality of these finishing operations is highly crucial at the level of final assembly. The present research aims to study the effect of cutting tool wear on the resulting quality for the trimming process of high performance CFRP laminates, in the aerospace field. In terms of quality parameters, the study focuses on surface roughness and material integrity (uncut fibers, fiber pull-out, delamination or thermal damage of the matrix), which could jeopardize the mechanical performance of the components. In this study, a 3/8 inch diameter CVD diamond coated carbide tool with six flutes was used to trim 24-ply carbon fiber laminates. Cutting speeds ranging from $200 \mathrm{~m} / \mathrm{min}$ to $400 \mathrm{~m} / \mathrm{min}$ and feed rates ranging from $1524 \mathrm{~mm} / \mathrm{min}$ to $4064 \mathrm{~mm} / \mathrm{min}$ were used in the experiments. The results obtained using a scanning electron microscope (SEM) showed increasing defect rates with increased tool wear. The worst
\end{abstract}


surface integrity, including matrix cracking, fiber pull-out and empty holes, was also observed for plies oriented at $-45^{\circ}$ degrees. For the surface finish, it was observed that for the studied cutting length ranges, an increase in tool wear resulted in a decrease in surface roughness. Regarding tool wear, a lower rate was observed at lower feed rates and higher cutting speeds, while a higher tool wear rate was observed at intermediate values of our feed rate and cutting speed ranges.

\section{Introduction}

The use of CFRPs has greatly risen dramatically in high technology industries because it offers many advantages, including high fatigue strength, high specific strength, high specific modulus, corrosion resistance, as well as lighter weight, which provides energy savings. The machining of CFRPs is different from that of conventional metals and their alloys. Due to the heterogeneous nature of CFRPs, their machining is associated with different kinds of damages, including matrix cracking or thermal damage, fiber fracture, fiber pull-out and delamination (Iliescu et al., 2010).

Generally, relatively little research has been carried out on the machining of CFRP, as compared to metals and their alloys. Koplev et al. (1983) was one of the first researchers who studied CFRP orthogonal cutting. He found that chip formation was strongly affected by fiber orientation, and occurred during a series of successive ruptures. He also concluded that surface quality and the delamination factor were strongly influenced by cutting forces and the tool geometry. Ramulu et al. (1994) observed that an increase in the cutting speed led to a better surface finish during edge trimming and drilling processes. Arola et al. (1996) studied the effect of the tool geometry and fiber orientation on the cutting forces and surface roughness during the edge trimming process. They concluded that chip formation firstly depends on the fiber orientation, and secondly, is affected by tool geometry and cutting conditions. Palanikumar et al. (2007) studied the effect of feed rate on surface finish during the machining of glass fiber reinforced plastic composite. They showed that chatter increased with an increase in the feed rate. Further, it led to a higher tool flank wear and worse surface 
finish. Wang et al. (2011) found that the cutting force was a main factor affecting surface roughness, and observed that when these forces increase up to $250 \mathrm{~N}$, an increase in roughness values was seen, and that when the forces increase above $250 \mathrm{~N}$, roughness values would decrease for the milling of CFRP. Chatelain et al. (2012) found that the fiber angle is an important parameter affecting the roughness profile. They also showed that each ply orientation has its own "typical" roughness profile, regardless of machining conditions. In addition, they showed that the cutting speed effect was not as significant as the feed rate effect on surface roughness, but that a higher cutting speed leads to better surface finishes in most cases. Few studies discuss the effect of machining conditions on tool wear during the machining of high performance aerospace composite laminates. This paper focuses mainly on this influence as well as on the effect of tool wear on laminate integrity and surface roughness following the trimming operation of quasi-isotropic CFRP laminates used in aerospace.

\section{Methodology}

The workpiece material used in our experiments was an autoclave-cured 24-ply CFRP laminate produced using pre-impregnated technology, with a fiber volume fraction of $64 \%$ and a stacking sequence $\left[\left(90^{\circ},-45^{\circ}, 45^{\circ}, 0^{\circ}, 45^{\circ},-45^{\circ}, 45^{\circ},-45^{\circ}, 0^{\circ},-45^{\circ}, 45^{\circ}, 90^{\circ}\right)\right] \mathrm{s}$. This resulted in a laminate thickness of $4.44 \mathrm{~mm}$. The end mill router was a CVD diamond coated carbide tool with six flutes. The specifications of the cutting tool are shown in table 1 . The experiments were carried out with the cutting parameters, as specified in table 2. The parameters were selected according to Bérubé (2012) who proposed the best operational conditions for similar tool and composite materials. In order to properly relate the quality of the trimmed laminates as a function of the length of cut expressed in linear meters, two setups were used, one to generate tool wear of several meters and transform the laminate in "chips and dust", and the other to trim test coupons dedicated to full inspection and related to the length of wearing cut achieved at each step of an iterative process. Thus, each experiment contained short cuts $100 \mathrm{~mm}$ in length and long cuts $900 \mathrm{~mm}$ in length. All experiments for each new tool started with a short cut and then a long cut, with repetitions performed until an 
end of tool life criterion was reached. The test coupons trimmed with the short cuts setup were $32 \mathrm{~mm}$ wide and $100 \mathrm{~mm}$ long, and were analyzed in terms of the cutting forces, the surface finish and material/surface integrity. Before each short cut, the cutting tool was removed in order to measure the tool wear with an optical microscope, type Keyence VHX$600+500 \mathrm{~F}$. The tool life criterion was an average maximum flank wear of $0.3 \mathrm{~mm}$. The CNC machine used for the experiments was a 3-axis high speed center HURON K2X10 with a maximum spindle speed of $24000 \mathrm{RPM}$ at $24 \mathrm{~kW}$. The machine was equipped with a dust extraction system. A total of ten clamps were used to secure the panels for long cuts and seven clamps for short cuts. The fixtures were attached to a 3-axis dynamometer table (type Kistler 9255B), as shown in Figure 1. Surface integrity was verified using a scanning electron microscope (type Hitachi S-3600N) and C-scan for a few coupons. Surface roughness was measured using a profilometer (type Mitutoyo SURFPAK SJ-400).

Table 1 Cutting tool specifications

\begin{tabular}{|c|c|c|c|c|c|c|}
\hline No. of Teeth & Rake & Relief & Helix & LOC & Tool type & Diameter \\
\hline 6 & $8^{\circ}$ & $10^{\circ}$ & $10^{\circ}$ & $1 "$ & Coated Carbide & $3 / 8^{\prime \prime}$ \\
\hline
\end{tabular}

Table 2 Cutting parameters

\begin{tabular}{|c|c|c|}
\hline Test No. & Feed(mm/min) & Speed(m/min) \\
\hline $\mathbf{1}$ & 1524 & 400 \\
\hline $\mathbf{2}$ & 2794 & 300 \\
\hline $\mathbf{3}$ & 4064 & 200 \\
\hline
\end{tabular}




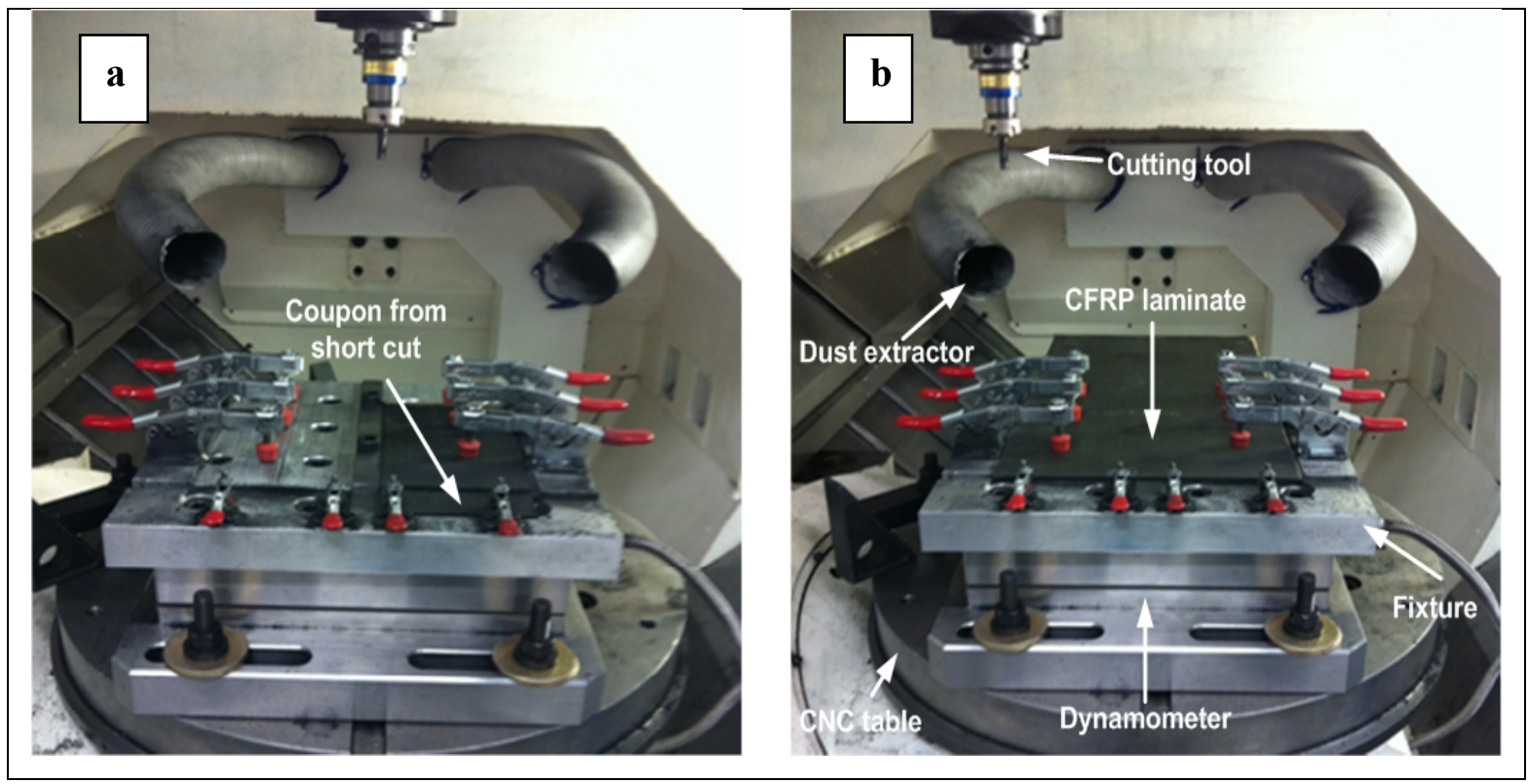

Fig.1 Experimental set-up: a) short cut and b) long cut

\section{Results and Discussions}

\section{Cutting force and tool wear}

One important factor affecting the quality of machining is the tool condition. In all three tests, the cutting forces and tool wear both increased with an increase in the cutting length, as shown in Figure 2Fig. a and 2b. A longer tool life was observed at lower feed rates and higher cutting speeds, while a shorter tool life was obtained with intermediate feed rate and cutting speed values. 


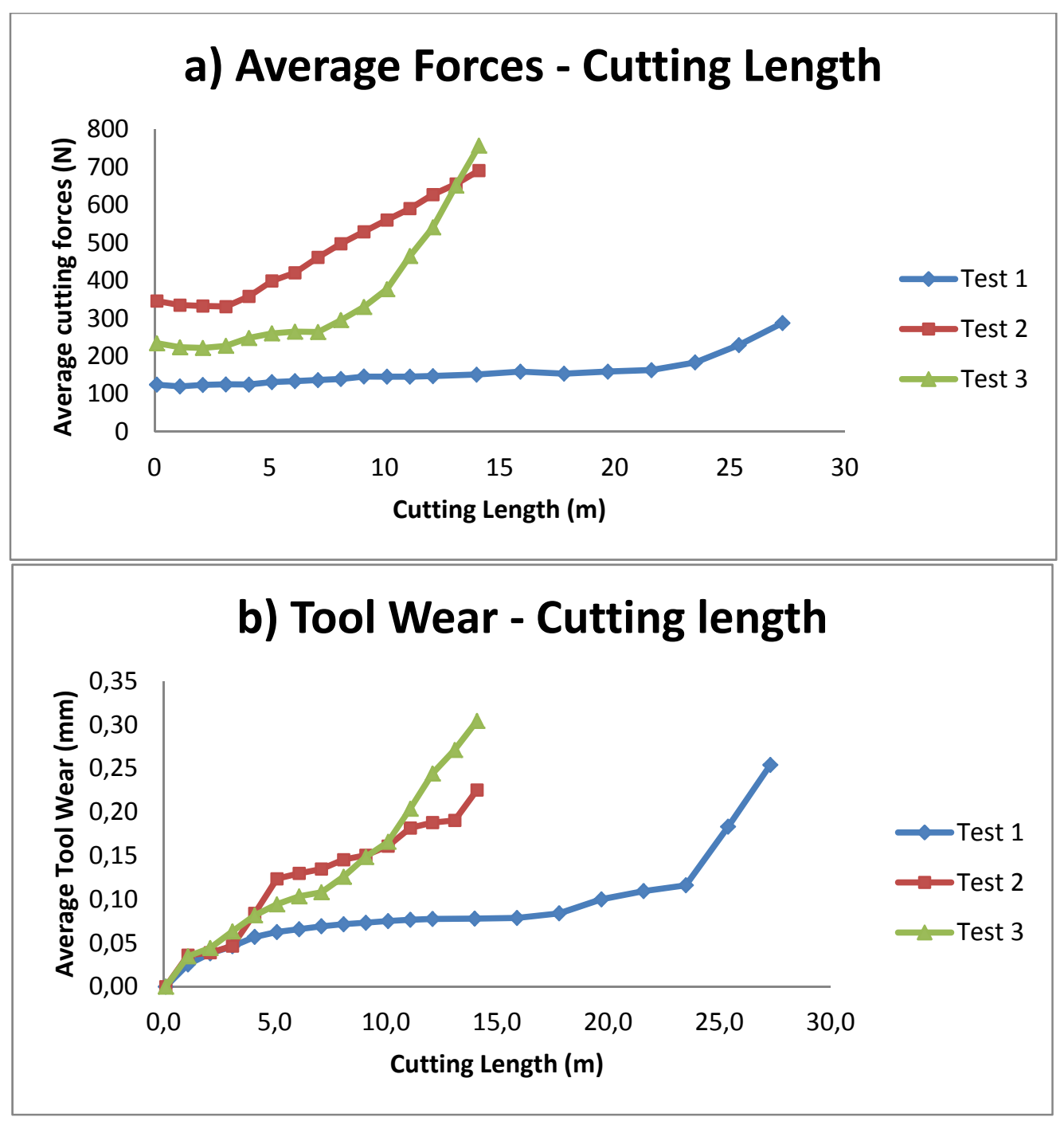

Fig. 2 a) Cutting forces and b) tool wear as a function of cutting length

\section{Surface Integrity}

Due to the low thermal conductivity of the epoxy resin matrix, the heat is retained in the cutting zone. This could cause the softening, degradation and burning of the matrix material due to the low glass transition temperature of the resin. (Jahanmir, 1999) In this study, based on the results obtained, cutting forces increased with an increase in tool wear. High cutting forces could increase the cutting temperature, which consequently could cause poor surface integrity, including the softening and burning of the matrix material. The thermally affected 
matrix may help flexible fibers to escape from the cutting edge and adhere to the trimmed surface. As a result, this may explain how some sort of "spreading and sticking" of the material could improve the surface finish in these cases. For example, for Test 2, when tool wear was $0.30 \mathrm{~mm}$ (after $14.1 \mathrm{~m}$ of cutting length), the cutting force was $756 \mathrm{~N}$, compared to $234 \mathrm{~N}$ for the new tool. It could be assumed that the high cutting forces could cause the softening and burning of the resin, which led to the fibers being spread over different, machined plies. The fibers were also broken at locations beneath the machined surface. The first short cut (test coupon 1) using a new tool resulted in the production of empty grooves as a result of fiber pull-out in $-45^{\circ}$ plies, as shown in Figure 3Fia, but at the end of the tool life (test coupon 15), poor surface integrity, including matrix cracking, fiber pull-out and empty holes, were seen in $-45^{\circ}$ plies, as shown in Figure 3Fib.

In Figure 4, three specimens are compared together, with all three produced after $14.1 \mathrm{~m}$ of cutting length, using different cutting conditions (Tests 1-3). The first specimen was trimmed using a tool with an average maximum flank wear of $0.08 \mathrm{~mm}$ (cutting force was $152 \mathrm{~N}$ ); the second was trimmed using a tool with an average maximum flank wear of $0.30 \mathrm{~mm}$ (cutting force was $757 \mathrm{~N}$ ) and the third was trimmed using a tool with an average maximum flank wear of $0.23 \mathrm{~mm}$ (cutting force was $691 \mathrm{~N}$ ). As shown in Figure 4a burning of the matrix was observed on the trimmed surface of the second and third specimens (Figure 4Fib and Figure 4Fic), and they had the worst surface integrities, compared to the first one (Figure 4Fia), which had the best. Based on these results, it could be assumed that the surface integrity decreases with an increase in cutting force (increase in tool wear). 


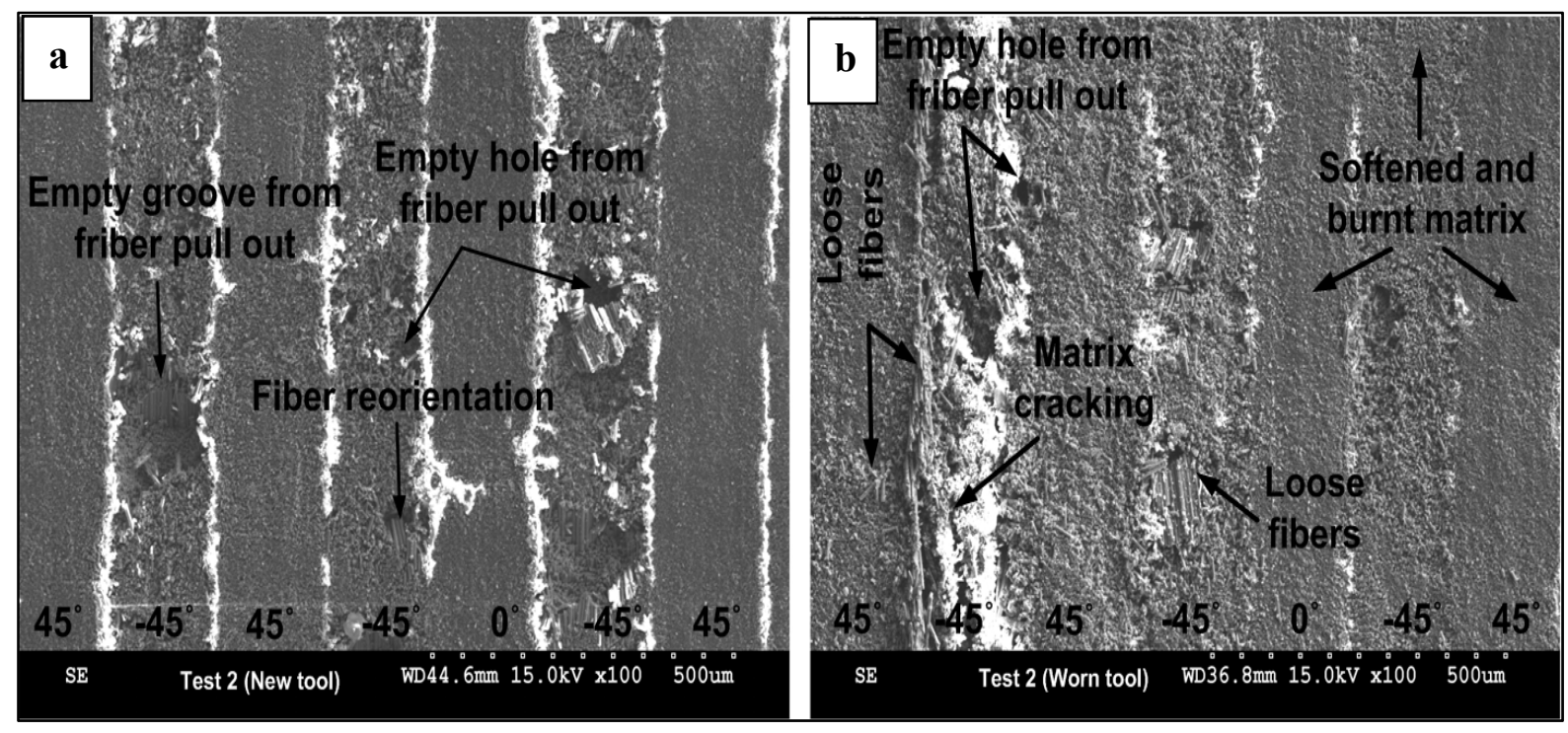

Fig. 3 a) New tool and b) Worn tool (14100 mm) in Test 2

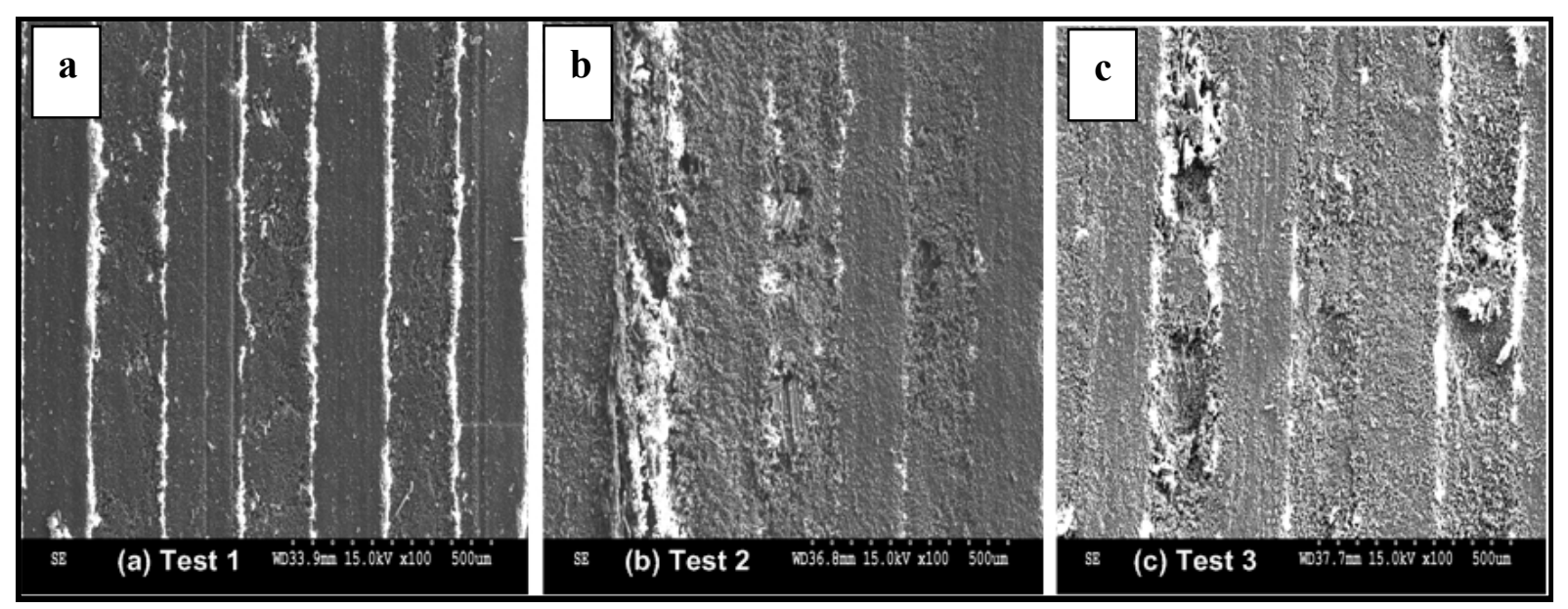

Fig. 4 Trimmed surface after 14.1 meters of cutting length a) Test 1, b) Test 2 and c) Test 3

\section{Surface Roughness}

Surface roughness was measured, and the parameters Ra, Rt and Rv were considered for the study. All results were obtained from the $-45^{\circ}$ plies for the up-milling side of the coupons, using a longitudinal method over a distance of $14 \mathrm{~mm}$, as specified in Bérubé (2012). Figure 5 shows that roughness decreased with an increase in cutting length (increase in tool wear). This result likely contradicts those obtained from the SEM micrographs used to evaluate 
material surface integrity. This fact, confirmed through exhaustive measurements, indicates that the roughness parameter itself may not be a suitable indicator for evaluating the cutting surface quality for composites. It could lead to a false good quality cut surface interpretation, while the mechanical properties of the material for the trimmed area may decrease due to thermal damage of the matrix and the breaking of the carbon fibers beneath the trimmed surface, as shown in Figure 3b. This is a hypothesis that may explain this result.

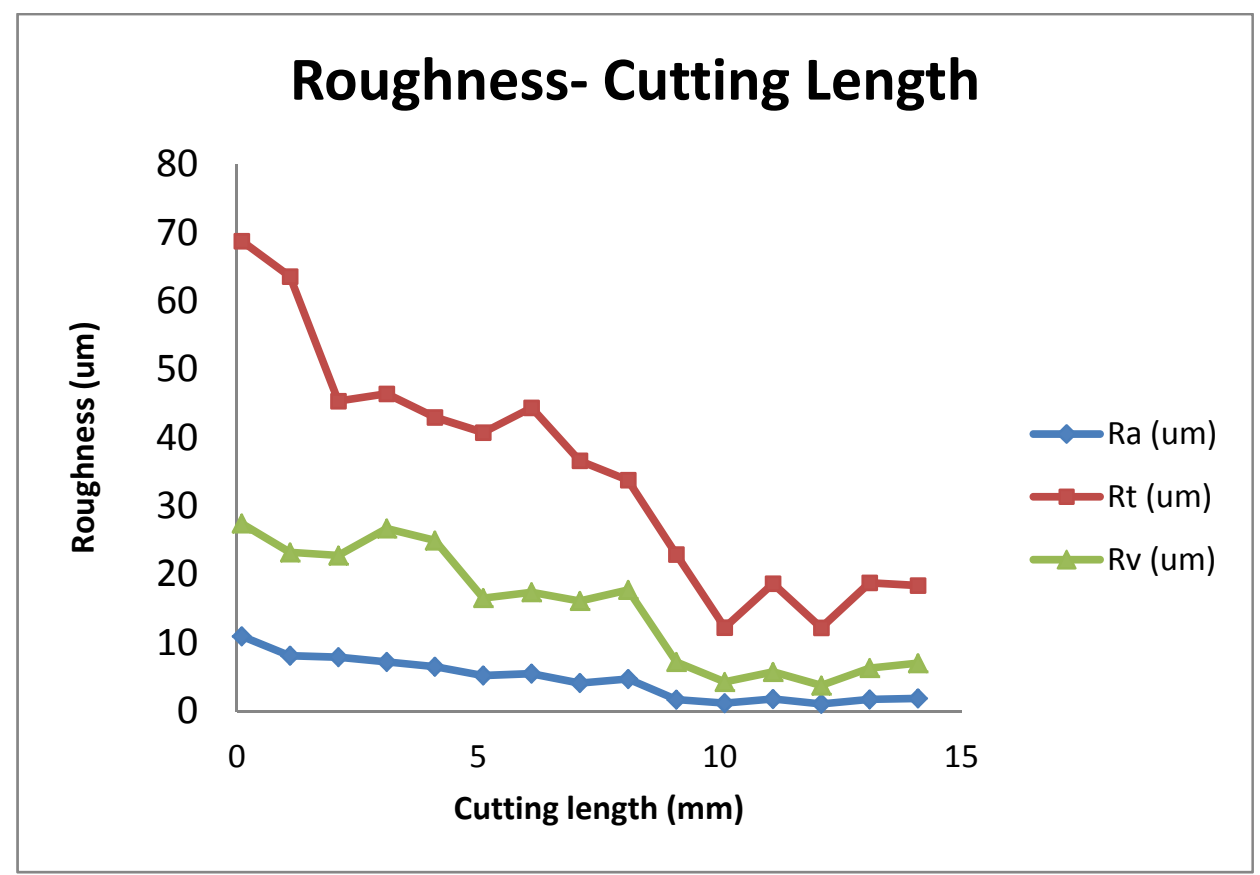

Fig. 5 Surface roughness as a function of cutting length in Test 2 (in up-milling in $-45^{\circ}$ ply)

\section{Conclusions}

One of the important factors affecting machining quality is the tool condition. This paper focuses mainly on the effect of tool wear on laminate integrity and surface roughness following the trimming operation of quasi-isotropic CFRP laminates used in aerospace. It also focuses on the effect of machining parameters on tool wear during the machining of high performance aerospace composite laminates. A 3/8 inch diameter CVD diamond coated carbide tool with six flutes was used to trim 24-ply carbon fiber laminates. The 
surface integrity was verified using a scanning electron microscope and the surface roughness was measured across the laminate for different fiber orientations. Several conclusions can be pointed out:

It was found that a worn tool led to high cutting forces and lower quality in terms of surface integrity. Poor surface integrity, including matrix cracking, fiber pull-out and empty holes were seen, particularly for the $-45^{\circ}$ plies. The relation between tool wear and surface roughness was demonstrated. An increase in wear improved the surface finish, with lower values of Ra, Rt and Rv parameters. This may be due to matrix burning, which initiates material spreading and the breaking of the carbon fibers beneath the surface. Thus, we may conclude that surface roughness, taken by itself, without other quality parameters, is not a suitable indicator for evaluating cutting surface quality. Regarding the effect of cutting parameters on tool wear, it was found that a lower tool wear was measured at lower feed rates and higher cutting speeds, while a higher tool wear was measured at intermediate feed rate and cutting speed values.

\section{Acknowledgment}

This work was funded by the Consortium for Research and Innovation in Aerospace in Québec (CRIAQ) and its partners, the Natural Sciences and Engineering Research Council of Canada (NSERC), MITACS, Bombardier Aerospace, Avior Integrated Products, Delastek and AV\&R Vision \& Robotics. 
ANNEX III

SUBMITTED JOURNAL II

\title{
Modeling and prediction of tool wear and cutting force during high speed trimming of Carbon-fibre reinforced polymers
}

Mohamed Slamani, Jean-François Chatelain, Hossein Hamedanianpour

\begin{abstract}
Because of the low thermal conductivity of Carbon Fibre Reinforced Polymers (CFRPs) during high speed-trimming, cutting forces and tool wear significantly increase the temperature at the contact zone, which is then completely transferred to the cutting tool and exceeds the permitted thermal stability limit of the cutting material. This then leads to a drastic reduction of the tool life, thermal damage, poor quality, and in some cases, rejection of machined parts. This paper presents the development of tool wear and cutting force prediction models in the trimming of CFRPs. A 3/8 inch diameter CVD diamond coated carbide tool with six straight flutes was used to trim 24-ply carbon fibre laminates. The results obtained using a scanning electron microscope (SEM) showed increasing defect rates with increased tool wear. Two models were adjusted to predict tool wear and cutting force for different values of cutting speed, feed and cutting length. One of them is a multiplicative statistical model, and the other, an exponential model. Outcomes from the two models were analysed and compared. The ANOVA approach was also used to test the overall significance of the models by applying F-tests. The results obtained show that the exponential model is better capable of accurately predicting the cutting force and tool wear under the conditions studied. To enhance the prediction accuracy of the tool wear model, the cutting force was added as a variable in the tool wear model. Results show that the enhanced multiplicative model provided higher predictive capabilities than the exponential model.
\end{abstract}

Keywords: Composite, CFRP, Trimming, Tool Wear, Cutting Force, Modeling 


\section{Introduction}

The advent of Carbon Fibre Reinforced Polymers (CFRPs) has led to significant breakthroughs in the manufacturing industry, thanks to their desirable mechanical and physical properties, including high strength, high stiffness, low weight, durability, and extreme corrosion resistance. CFRP parts are usually produced by moulding or near net shape; moreover, in some applications, trimming, milling, drilling, turning and grinding are still required in order to bring CFRP parts to their final shapes and sizes. However, CFRPs are naturally inhomogeneous, and are anisotropic in every layer. As a result of their anisotropic and highly abrasive nature, numerous machining problems, such as rapid tool wear, matrix cracking or thermal damage, fibre pull-out, fibre fracture, and delamination are encountered (Davim, 2010). Koplev et al. (1983) was one of the first researchers who studied CFRP orthogonal cutting. He found that chip formation was strongly affected by fibre orientation, and occurred during a series of successive ruptures. He also concluded that surface quality and the delamination factor were strongly influenced by cutting forces and tool geometry. The development of process control schemes for avoiding delamination by controlling and regulating the cutting process parameters require an accurate prediction of the cutting forces (Kalla et al., (2010)). Cutting forces represent an important factor of machinability evaluation, and their size will directly influence the quality of machined parts. They are related to many factors, such as cutting parameters, workpiece materials and tools. Haiyan et al (2013) used an analytical cutting force model based on mechanistic modeling techniques to simulate cutting forces in the helical milling of CFRP. In addition, the cutting force coefficients were corrected according to the experimental data, and the established model was tested through cutting experiments. They found that the resultant radial and axial cutting forces decrease with an increase in the cutting speed and increase with an increase in the feed rate per tooth and axial feed rate. Kalla et al. (2010) developed a methodology that combines the mechanistic modeling techniques from metal machining and neural network approximation in order to obtain a predictive cutting force model for helical end milling of carbon fibre reinforced polymers (CFRP). They concluded that the mechanistic modeling approaches from metal cutting are valid for machining FRPs. Furthermore, model predictions were compared with experimental data and were found to be in good agreement in cutting 
unidirectional laminate, but in lesser agreement in the case of a multidirectional laminate. More recently, Karpat et al. (2013) proposed a mechanistic model for the milling of multidirectional CFRP laminates using double helix milling tools. In the model, cutting and edge coefficients are calculated based on the laminate fibre direction. Issues related to surface quality and tool wear were also investigated. Zaghbani et al. (2012) presented a comprehensive analysis of the instantaneous cutting forces at play during the trimming process of unidirectional laminates. They developed an empirical model for cutting forces, using a high mechanistic order model. They found that for machined laminates, the fibre orientation does not significantly influence the profile of the tangential and radial forces; however, it influences their amplitude.

In addition to delamination, machining precision and surface quality are directly related to tool wear. The high mechanical resistance of carbon fibres is most responsible for excessive tool wear. Furthermore, the cutting tools are loaded with heavy forces and friction resulting from the interactions between the tool and workpiece, which cause the increased milling temperature. Because the thermal conductivity of the CFRP is very low, most of the heat produced during the milling process can only transfer to the cutting tool. Consequently, the temperature at the tool-chip interface rises, causing tool wear, and then lower tool life, as well as quality issues such as delamination, matrix degradation and lower dimensional or geometrical accuracies. Haiyan et al (2013) analyzed the effects of the cutting parameters and tool wear on the cutting forces during helical milling of carbon fibre reinforced plastic, and found a direct proportional relationship between tool wear and cutting forces. They report that in all, the wear is smooth, and is uniformly distributed along the entire cutting edge. Unfortunately, no model was developed to predict the tool wear. Wang et al. (2012) studied the effect of low temperature on the performance of drilling Carbon Fibre Reinforced Polymer and Ti Stack Materials. They showed that low temperature air can reduce tool wear and thrust force effectively. A similar approach was used by Khairusshima et al. (2011) to study the effect of tool wear and surface roughness on the milling of carbon fibre-reinforced plastic using chilled air. They showed experimentally that there is demonstrably less tool wear at lower feed rates and higher cutting speeds. They observed that the wear is shiny and 
polished at the cutting edge because of excessive wear during machining; they also showed that the life of the carbide tool shortens as the feed rate and the cutting speed increase. They state that the suitable temperature for machining CFRP in their study is approximately $91.5^{\circ} \mathrm{C}$.

Based on the literature reviews above, machining precision, surface quality, cost price, and productivity are directly related to the cutting force and tool wear. Therefore, it is very important that priority be given to the modelling and prediction of cutting forces and tool wear during high speed machining of Carbon fibre reinforced polymers. This paper presents the development of statistical predictive models for cutting forces and tool wear during high speed trimming of Carbon fibre reinforced polymers, using machining variables such as cutting speed, feed rate and length of cut. The experimental results are given, along with a comparison between two selected models. Furthermore, ANOVA is used to test the significance of the fit by applying F-tests on the ratio of variances.

\section{Methodology}

The workpiece material used in our experiments was an autoclave-cured 24-ply CFRP laminate produced using pre-impregnated technology, with a fibre volume fraction of $64 \%$ and a stacking sequence $\left[\left(90^{\circ},-45^{\circ}, 45^{\circ}, 0^{\circ}, 45^{\circ},-45^{\circ}, 45^{\circ},-45^{\circ}, 0^{\circ},-45^{\circ}, 45^{\circ}, 90^{\circ}\right)\right] \mathrm{s}$. This resulted in a laminate thickness of $4.44 \mathrm{~mm}$. The end mill router was a CVD diamond coated carbide tool with six straight flutes. The specifications of the cutting tool are shown in Table 1 . The experiments were carried out with the cutting parameters, as specified in Table 2. The parameters were selected according to Berube (2012), who proposed the best operational conditions for similar tool and composite materials. To properly relate the quality of the trimmed laminates as a function of the length of cut expressed in linear meters, two set-ups were used, one to generate tool wear of several meters and transform the laminate into "chips and dust", and the other, to trim test coupons dedicated to full inspection and related to the length of wear cut achieved at each step of an iterative process. Thus, each experiment contained short cuts $100 \mathrm{~mm}$ in length and long cuts $900 \mathrm{~mm}$ in length. All experiments for each new tool started with a short cut, followed by a long cut, with repetitions performed 
until an end-of-tool-life criterion was met. Before each short cut, the cutting tool was removed in order to measure its wear with an optical type Keyence VHC-600+500F microscope.

The tool-life criterion was an average maximum flank wear of $0.3 \mathrm{~mm}$, as per ISO $8688-2$ standard. The CNC machine used for the experiments was a 3-axis high speed center HURON K2X10, with a maximum spindle speed of $28000 \mathrm{RPM}$ at $30 \mathrm{~kW}$. The machine was equipped with a dust extraction system. A total of ten clamps were used to secure the panels for long cuts and seven clamps for short cuts. The fixtures were attached to a 3-axis dynamometer table (type Kistler 9255B), as shown in Fig. 1.

Table 1 Cutting tool specifications

\begin{tabular}{|c|c|c|c|c|c|c|}
\hline No. of Teeth & Rake & Relief & Helix & LOC & Tool type & Diameter \\
\hline 6 & $8^{\circ}$ & $10^{\circ}$ & $10^{\circ}$ & $1^{\prime \prime}$ & Coated Carbide & $3 / 8^{\prime \prime}$ \\
\hline
\end{tabular}

Table 2 Cutting parameters

\begin{tabular}{|c|c|c|}
\hline Test No. & Feed(mm/min) & Speed(m/min) \\
\hline $\mathbf{1}$ & 1524 & 400 \\
\hline $\mathbf{2}$ & 2794 & 300 \\
\hline $\mathbf{3}$ & 4064 & 200 \\
\hline
\end{tabular}




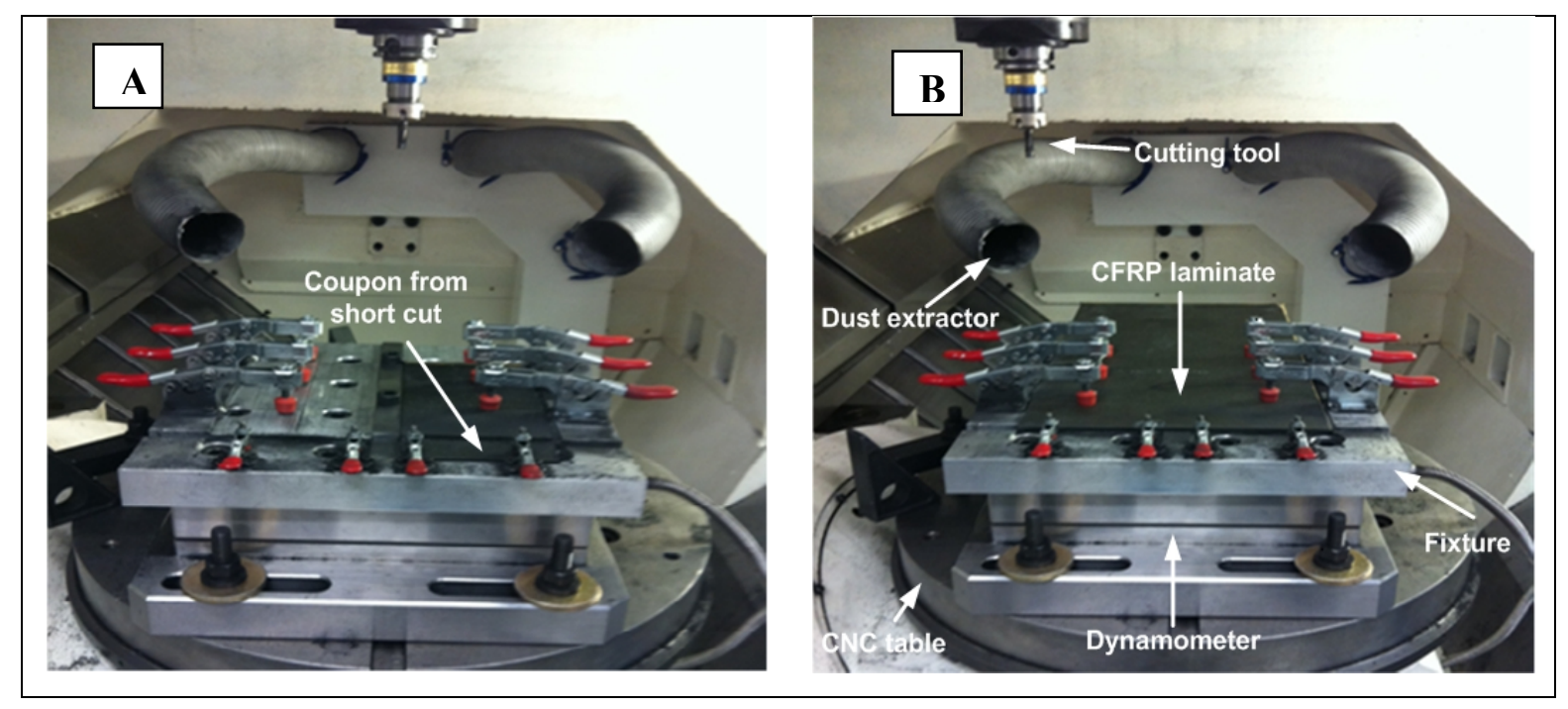

Fig. 1 Experimental set-up: short cut (A), long cut (B)

\section{Results and discussion}

To obtain cutting force and tool wear models, specimens were trimmed under different cutting conditions, and the cutting forces were measured in the $\mathrm{x}, \mathrm{y}$, and $\mathrm{z}$ directions with a 3axis dynamometer table. The cutting force data were then recorded for further analysis and evaluation. After completing one meter trimming, the tool was removed from the chuck for observation of the cutter flutes under the optical microscope and to measure the amount of tool wear; the latter was measured on all six flutes and the average value was calculated. When tool wear evaluation was completed, other $100 \mathrm{~mm}$ long specimens were machined after the tool being worn, with long cuts $900 \mathrm{~mm}$ in length. Again, the cutting force and the average tool wear value were calculated for each specimen. This iterative process lasted until the tool-life criterion was met.

Results show that in all three cutting conditions, the cutting forces and tool wear both increased with an increase in the cutting length. Figure 2 indicates a strong correlation between cutting force and the ratio of cutting speed to federate. The lower the ratio, the higher the cutting force. Furthermore, as shown in Figure 3, a longer tool life was observed at lower feed rates and higher cutting speeds, while a shorter tool life was obtained with 
intermediate feed rate and cutting speed values. Photomicrographs in Figure 4 show the condition of all six flutes of the cutting tool at and after $27 \mathrm{~m}$ of trimming as the tool wear reaches the allowable limit. A closer look at these photomicrographs reveals the presence of a non-uniform type of flank wear for all of the six flutes. Figure 4 also shows that the cutting tool is very contaminated with the adhered chips.

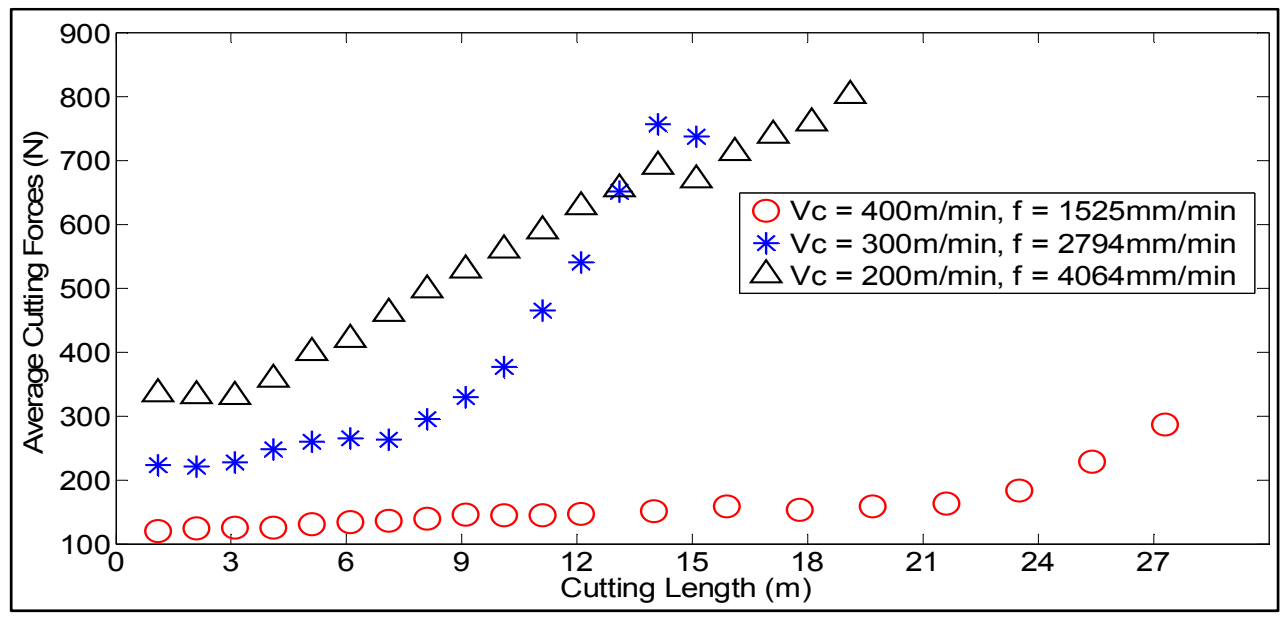

Fig. 2 Average cutting force as a function of cutting length

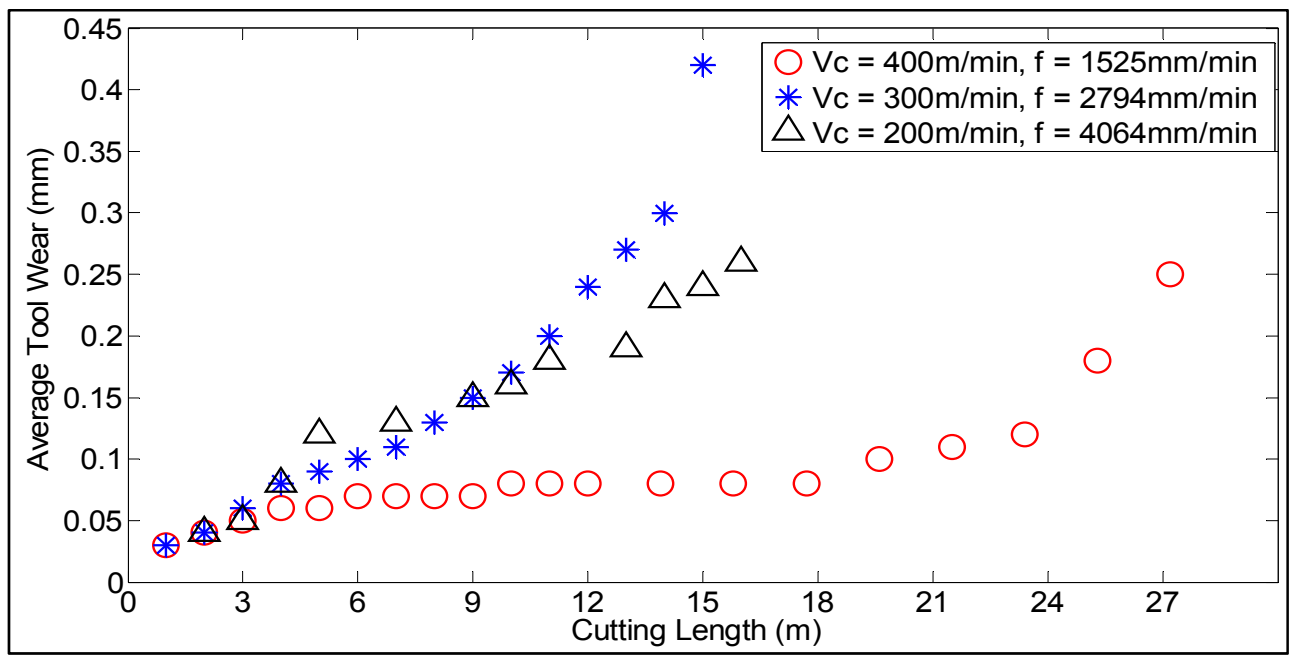

Fig. 3 Average tool wear as a function of cutting length 


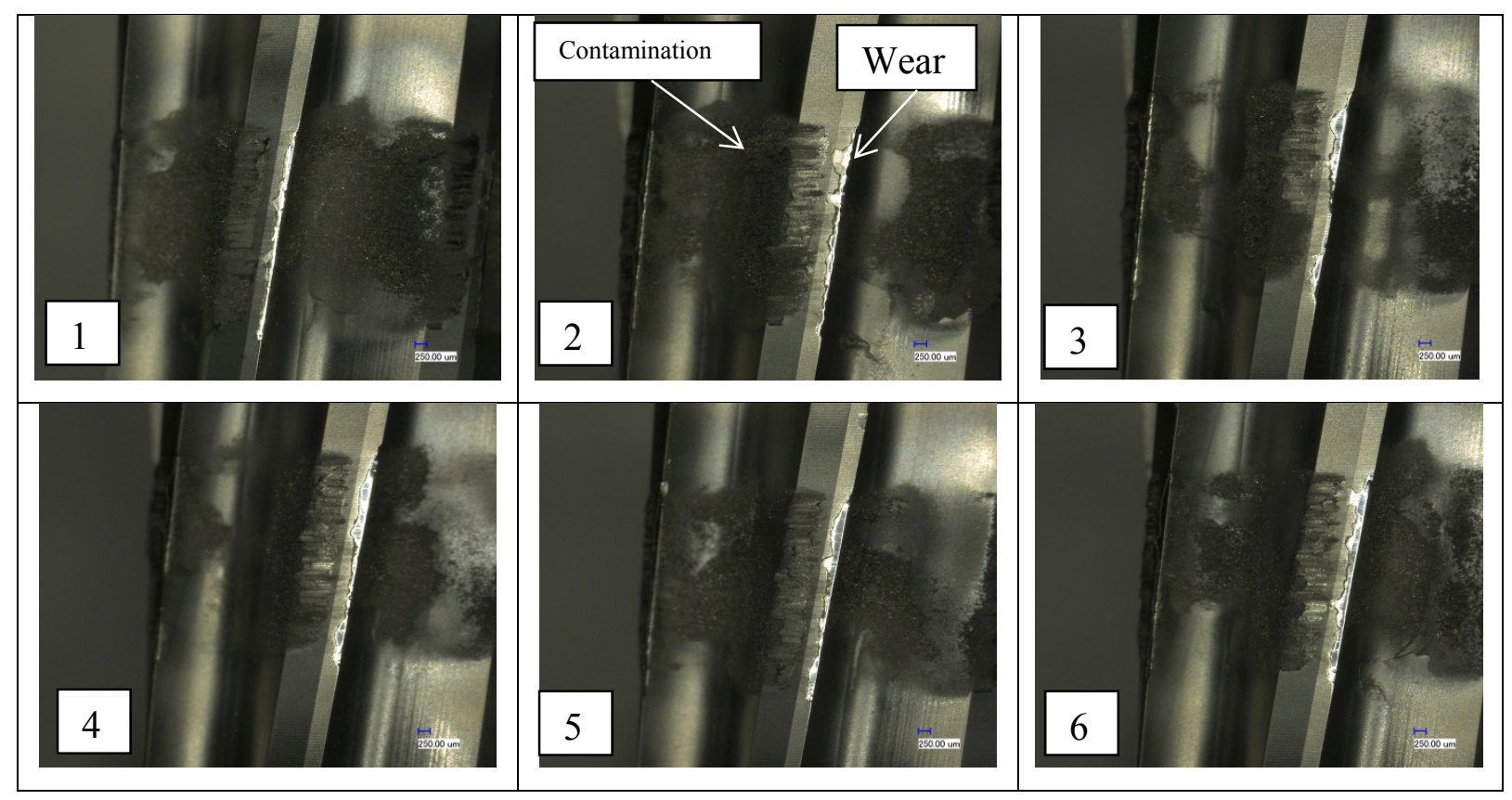

Figure 4. Micrographs of adhered chips and tool wear for all six flutes after $27 \mathrm{~m}$ of machining at $V_{C}=400 \mathrm{~m} / \mathrm{min}$ and $\mathrm{f}=1525 \mathrm{~mm} / \mathrm{min}$

\section{Tool Wear Models}

In this modelling, two models and three variables are proposed, namely, cutting speed, feed rate and cutting length.

\section{1- Multiplicative model}

The proposed relationship between the tool wear and the independent machining variables, speed, feed and cutting length can be represented by the following equation:

$$
T_{w}=b_{0}\left(V_{C}\right)^{b_{1}}(f)^{b_{2}}(L)^{b_{3}} \mathcal{E}
$$

Where $T_{w}$ is the response variable tool wear in mm, $V_{C}, f$ and $L$ are the cutting speed $(\mathrm{m} / \mathrm{min})$, feed $(\mathrm{mm} / \mathrm{min})$ and cutting length $(\mathrm{mm}) . \mathrm{b}_{0}, \ldots, \mathrm{b} 3$ are constants and $\varepsilon$ is a random error having normal distribution with mean zero. 
Multiple linear regression models for tool wear can be obtained by applying a logarithmic transformation that converts non-linear form of Eq. (1) into following linear mathematical form:

$\log \left(T_{w}\right)=\log \left(b_{0}\right)+b_{1} \log \left(V_{C}\right)+b_{2} \log (f)+b_{3} \log (L)+\log (\varepsilon)$

This linear model can be written as:

$y=\beta_{0}+\beta_{1} x_{1}+\beta_{2} x_{2}+\beta_{3} x_{3}+\varepsilon^{\prime}$

Where $\mathrm{y}$ is the logarithmic value of the measured tool wear, $\beta_{0}, \beta_{0}, \beta_{2}$ and $\beta_{3}$ are regression coefficients to be estimated, $x_{1}, x_{2}$ and $x_{3}$ are the logarithmic values of cutting speed, feed and cutting length, $\mathcal{E}^{\prime}$ is the random error.

To write down the least squares estimator for the linear regression model of Eq. (3), it should be fitting to use matrix notation. The above equation in matrix form becomes:

$Y=X \beta+\epsilon$

If the data matrix X of Eq. (4) has full column rank, then no column in X can be written as a linear combination of the other columns. In this case, coefficients of Eq (4) can be obtained by the least squares estimation.

The fitted regression model is

$\hat{y}=X \hat{\beta}$

After parameters estimation, Eq. (1) becomes

$\hat{T}_{w}=e^{-25.745}\left(V_{C}\right)^{1.47}(f)^{1.75}(L)^{0.68}$

The adequacy of the model was tested by using ANOVA technique at a $95 \%$ confidence level (Mason et al. (2003)). Table 3 shows the ANOVA analysis for the proposed model.

The total and error sum of squares presented in ANOVA Table can be expressed as (Mason et al. (2003)). 
$T S S=\sum_{i=1}^{n}\left(y_{i}-\bar{y}\right)^{2}$

$S S E=\sum_{i=1}^{n}\left(y_{i}-\widehat{y_{l}}\right)^{2}$

The regression sum of squares is

$\operatorname{SSR}=\sum_{i=1}^{n}\left(\widehat{y}_{l}-\bar{y}\right)^{2}$

The test of measuring of model adequacy consists in calculating the variance ratio or F-ratio between the mean square due to regression (MSR) and the mean square error (MSE). The usual procedure is then to compare the ratio $F=\frac{M S R}{M S E}$ with the $F_{\alpha, p, n-p-1}$. Where $F_{\alpha, p, n-p-1}$ is the critical value of Fisher given by the Fisher table at threshold $\propto=0.05$.

$M S R=\frac{S S R}{p}$

$M S E=\frac{S S E}{n-p-1}$

In multiple regression models there are p degrees of freedom for the sum of squares due to regression, because $\mathrm{p}$ coefficients, namely $\beta_{1}, \beta_{2} \ldots \ldots \beta_{p}$ must be estimated to obtain the regression sum of squares.

After statistical analysis, it was found that the model presented in Eq. (6) is adequate since $F=\frac{5.3698}{0.0641}=83.77$ is bigger than $F_{0.05,3,43}=2.83$ at a significant level of $5 \%$, which means that the model has a significant meaning.

Table 3: ANOVA Table for the multiplicative model for the tool wear

\begin{tabular}{|c|c|c|c|c|}
\hline Effect & Sum of squares & D.F & Mean squares & F-level \\
\hline Regression $(\boldsymbol{S S R})$ & 16.1093 & 3 & 5.3698 & 83.77 \\
\hline Residual $(\boldsymbol{S S} \boldsymbol{E})$ & 2.7554 & 43 & 0.0641 & \\
\hline Total $(\boldsymbol{T S S})$ & 18.8647 & 46 & & \\
\hline
\end{tabular}


Figure. 5 shows a comparison between measured and predicted tool wear at different cutting speed and feed rates. The residual is also plotted in this figure.

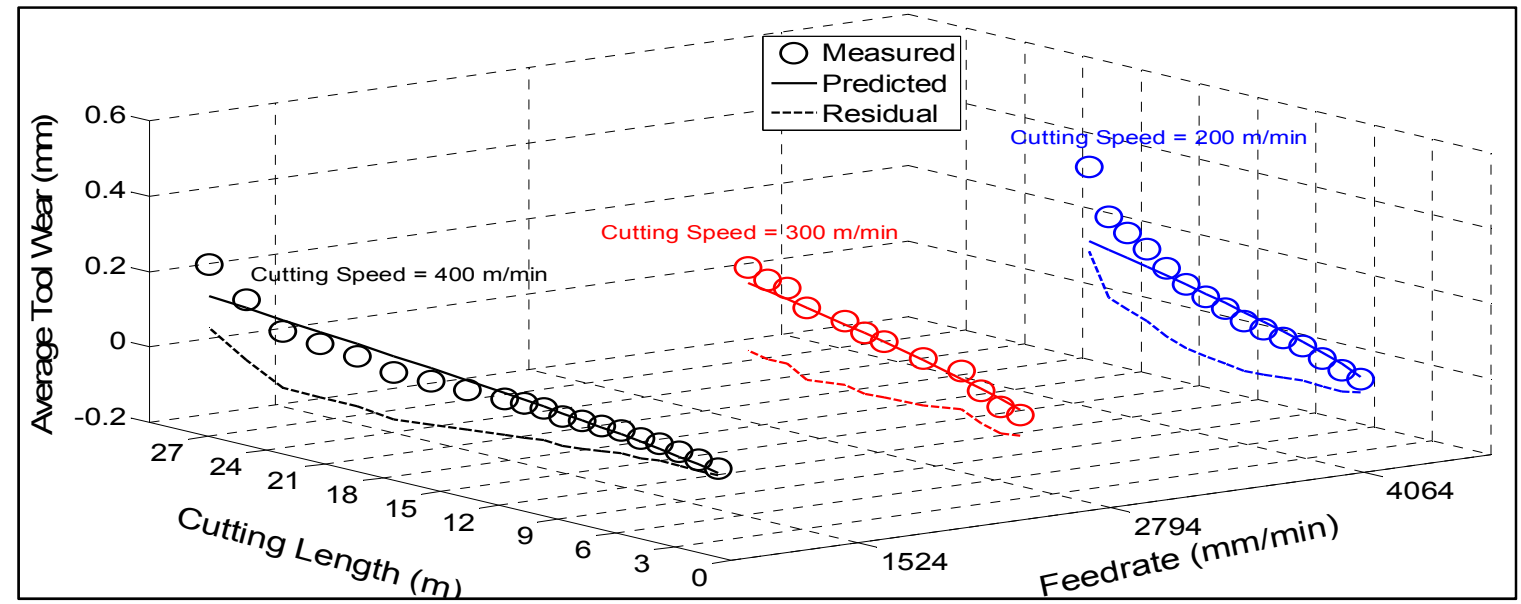

Fig. 5. Residual, measured and predicted tool wear as a function of cutting speed, feed rate and cutting length for the multiplicative model

\section{2- Exponential model}

By introducing interaction between independent variables, the exponential model can be represented by the following equation:

$$
T_{w}=e^{b_{0}+b_{1} V_{C}+b_{2} f+b_{3} L+b_{4} V_{C} \times f+b_{5} V_{C} \times L+b_{6} f \times l} \varepsilon
$$

Similarly, the exponential model can also transformed to one of linear form by tacking logarithms of the both sides of the equation as follows

$\mathrm{y}=\beta_{0}+\beta_{1} x_{1}+\beta_{2} x_{2}+\beta_{3} x_{3}+\beta_{4} x_{4}+\beta_{5} x_{5}+\beta_{6} x_{6}+\epsilon^{\prime}$

Where, $y=\log \left(T_{w}\right)$, equation (13) in matrix form becomes

$Y=X \beta+\varepsilon$

In least-squares estimation, the sum of the squares of the residual vector elements is minimised. The minimisation is equivalent to:

$\hat{\beta}=\left(X^{\prime} X\right)^{-1} X^{\prime} Y=X^{+} Y$ 
Provided that the inverse of $\left(X^{\prime} X\right)^{-1}$ exists. The matrix $X^{+}=\left(X^{\prime} X\right)^{-1} X^{\prime}$ is the MoorePenrose pseudoinverse of $X$ (some-times just called the pseudoinverse).

Redundancies exist amongst the coefficients of the model (13), and as a result, the X matrix is ill-conditioned (very high condition number). It was therefore necessary to remove redundant coefficients from the analysis to lower the condition number and obtain more reliable estimates of the unknowns. Using an analysis of singular values, the columns of weakly contributing coefficients or redundant ones are removed.

Coefficients $\beta_{0}$ and $\beta_{5}$ of Eq. (13) are found redundant and then removed from the model. The size and the rank of the $X$ matrix become 5 .

In order to improve the conditioning of matrix $X$, it was preferable to normalize the variables $x_{i}$ by subtracting from these values their average $\bar{x}_{i}$ and dividing the result by its standard deviation $S$.

$x_{n r, i}=\frac{\left(x_{i}-\bar{x}\right)}{s}$

After normalisation the condition number is reduced to 64 .

The obtained statistical model is

$T_{W}=e^{-0.0079 V_{C}-0.00089 f+0.282 L+0.000002 V_{C} \times f-0.00057 f \times l}$

The ANOVA analysis in Table 4 shows that the model is adequate since $F=\frac{3.5044}{0.032}=$ 109.51 is bigger than $F_{0.05,5,41}=2.45$ at a significant level of $5 \%$.

Table 4: ANOVA Table for the exponential model for the tool wear

\begin{tabular}{|c|c|c|c|c|}
\hline Effect & Sum of squares & D.F & Mean squares & F-level \\
\hline Regression $(\boldsymbol{S S R})$ & 17.5222 & 5 & 3.5044 & 109.51 \\
\hline Residual $(\boldsymbol{S S E})$ & 1.3425 & 41 & 0.032 & \\
\hline Total $(\boldsymbol{T S S})$ & 18.8647 & 46 & & \\
\hline
\end{tabular}




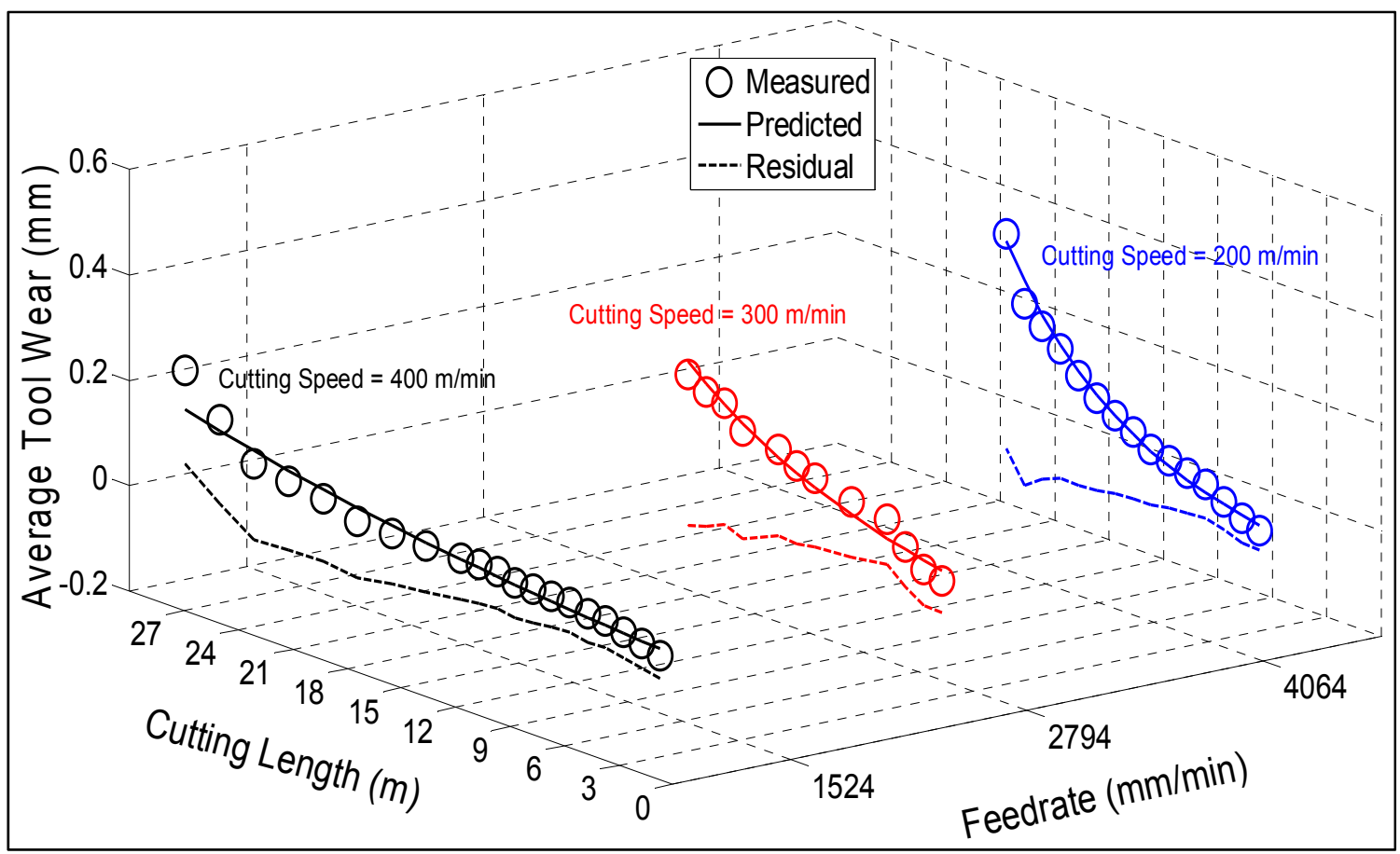

Fig. 6. Residual, measured and predicted tool wear as a function of cutting speed, feed rate and cutting length for the exponential model.

One useful measure of the adequacy of the fitted model is the coefficient of determination $R^{2}$. A preferred choice for calculating $R^{2}$ is as follows:

$R^{2}=1-\frac{S S E}{T S S}$

For least-squares estimates of the model parameters, the value of $R^{2}$ lies between 0 and 1 ; the closer it is to 1 , the closer the predicted responses are to the observed responses. Results show that the exponential model has a higher coefficient of determination $R^{2}=0.93$ than the multiplicative model, $R^{2}=0.85$. That means that the exponential model is better capable of accurately predicting of tool wear under the conditions studied (Figures 5 and 6).

\section{3- Enhanced tool wear models}

It is known that a clear relationship exists between tool wear and cutting forces. Lower cutting forces lead to low tool wear and low cutting forces provide good dimensional accuracy for the work material, including low surface roughness. Exploring the relationship 
between tool wear propagation and cutting force variation is of great importance in developing an effective tool wear predictive model. In this section, the importance of including the cutting force as a variable in the tool wear model is investigated.

By adding the cutting force $(F)$ to the multiplicative model, Eq. (1) becomes:

$$
T_{w}=b_{0}\left(V_{C}\right)^{b_{1}}(f)^{b_{2}}(L)^{b_{3}}(F)^{b_{4}} \mathcal{E}
$$

The estimated model is

$$
\hat{T}_{w}=e^{18.95}\left(V_{C}\right)^{-2.287}(f)^{-1.8557}(L)^{0.3899}(F)^{0.9865}
$$

From ANOVA test presented in Table 5 we can conclude that this model is adequate since $F=150.106$ is bigger than $F_{0.05,5,41}=2.45$ at a significant level of $5 \%$.

As shown in Fig. 7, an excellent fitting was obtained after including the cutting force in the multiplicative model. Furthermore, the coefficient of determination is lifted from $R^{2}=0.85$ to $R^{2}=0.95$.

Table 5: ANOVA Table for the enhanced multiplicative model for the tool wear

\begin{tabular}{|c|c|c|c|c|}
\hline Effect & Sum of squares & D.F & Mean squares & F-level \\
\hline Regression $($ SSR) & 17.8650 & 5 & 3.5730 & 150.106 \\
\hline Residual $(\boldsymbol{S S E})$ & 0.9997 & 41 & 0.0238 & \\
\hline Total $(\boldsymbol{T S S})$ & 18.8647 & 46 & & \\
\hline
\end{tabular}

On the other hand, results show also that statistically no significant improvement was observed after adding the cutting force to the exponential model. The coefficient of determination remained $R^{2}=0.93$. 


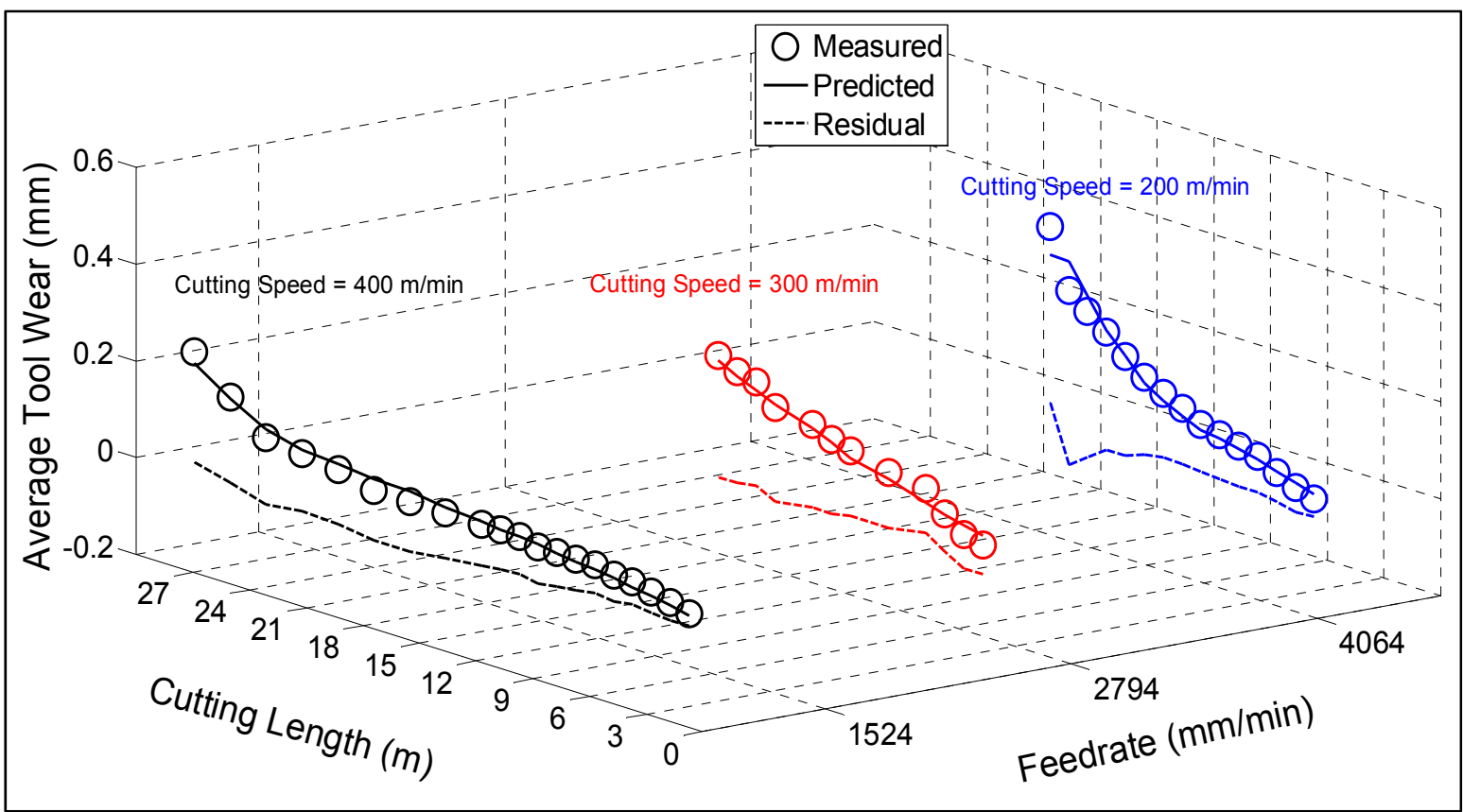

Fig. 7. Residual, measured and predicted tool wear as a function of cutting speed, feed rate and cutting length for the enhanced multiplicative model.

\section{Cutting Force Models}

As in the previous section, we would like to determine an empirical model for predicting the cutting force with three independent variables.

\section{1- Multiplicative model}

Statistical analysis shows that the estimated multiplicative model for the resultant cutting force is

$$
\widehat{F}=e^{-58.416}\left(V_{c}\right)^{4.98}(f)^{4.490}(L)^{0.317}
$$

The summery of the ANOVA test is presented in Table 6

Despite the lack-of-fit observed in Fig. 8 for the test when $\mathrm{Vc}=200 \mathrm{~m} / \mathrm{min}$ and $\mathrm{f}=4064$ $\mathrm{mm} / \mathrm{min}$, Table 4 shows that in overall, the model is adequate since $\mathrm{F}=124.9351$ is bigger than $F_{0.05,4,49}=2.57$ at a significant level of $5 \%$. 
Table 6: ANOVA Table for the multiplicative model for the cutting force

\begin{tabular}{|c|c|c|c|c|}
\hline Effect & Sum of squares & D.F & Mean squares & F-level \\
\hline Regression & 19.2399 & 4 & 4.81 & 124.9351 \\
\hline Residual & 1.9264 & 49 & 0.0385 & \\
\hline Total & 21.1663 & 53 & & \\
\hline
\end{tabular}

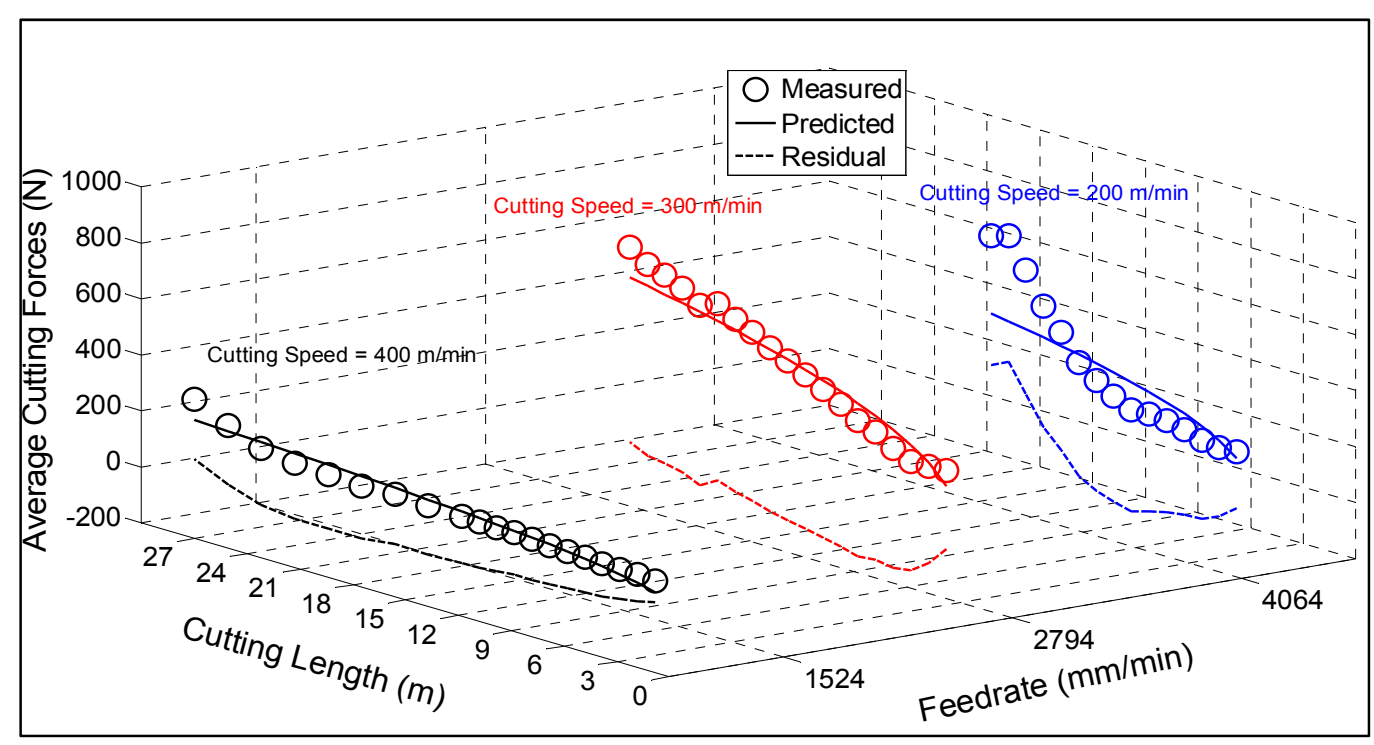

Fig. 8. Residual, measured and predicted cutting force as a function of cutting speed, feed rate and cutting length for the multiplicative model

\section{2- Exponential model}

After parameter estimation, the cutting force exponential model obtained was

$$
\hat{F}=e^{0.0031 V_{c}-0.00008 f+0.16078 L+0.0000059 V_{c} \times f-0.000345 f \times L}
$$

Table 7: ANOVA Table for the exponential model for the cutting force

\begin{tabular}{|c|c|c|c|c|}
\hline Effect & Sum of squares & D.F & Mean squares & F-level \\
\hline Regression & 20.7024 & 5 & 4.1405 & 435.8421 \\
\hline Residual & 0.4639 & 48 & 0.0095 & \\
\hline Total & 21.1663 & 53 & & \\
\hline
\end{tabular}


Table 7 shows that the model is adequate since $\mathrm{F}=435.8421$ is bigger than $F_{0.05,5,48}=2.41$ at a significant level of $5 \%$.

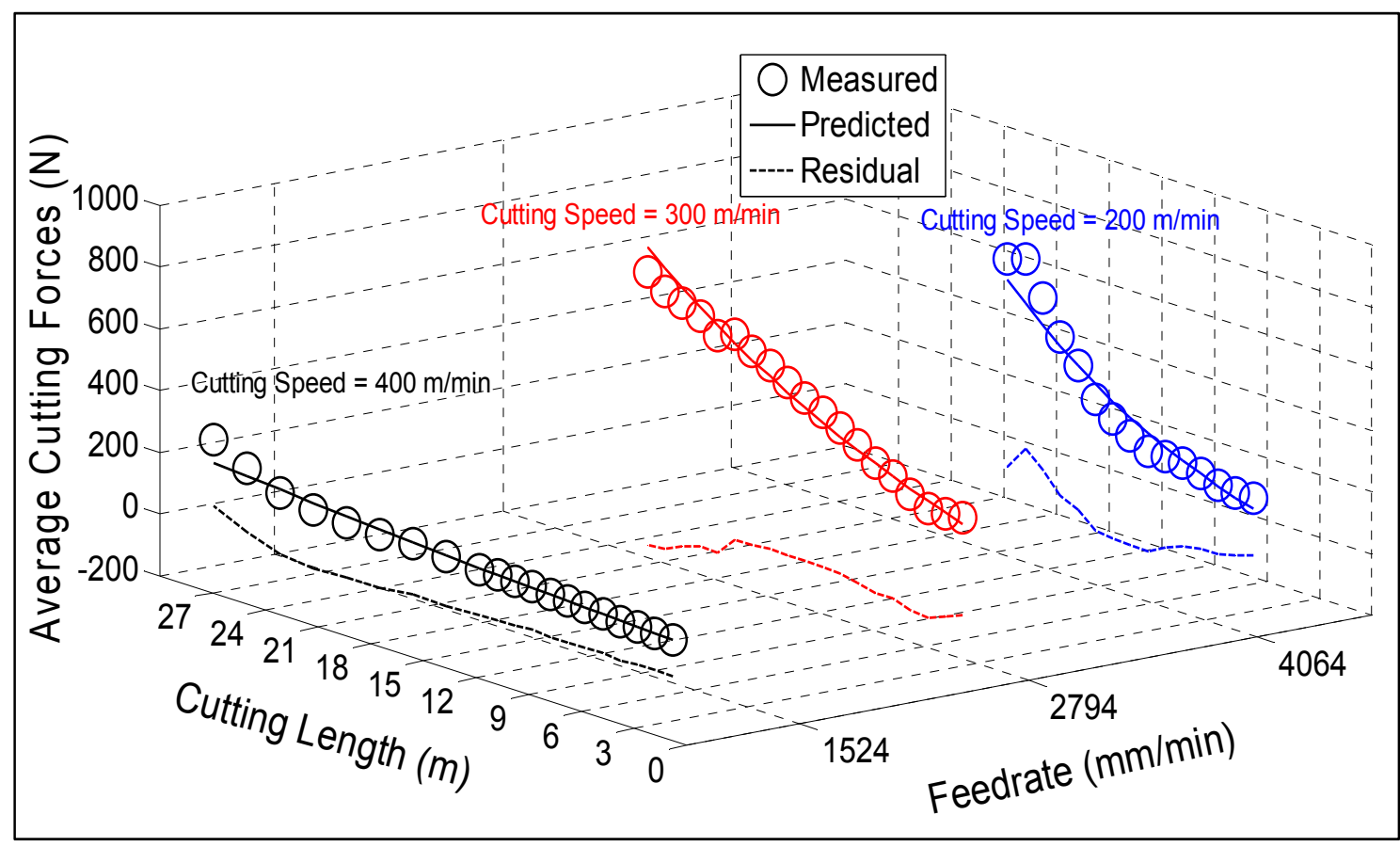

Fig. 9. Residual, measured and predicted cutting force as a function of cutting speed, feed rate and cutting length for the exponential model

As shown in Figures 8 and 9, a comparison between the two proposed models reveals that the exponential model is better and has a higher coefficient of determination $R^{2}=0.98$ than the multiplicative model, $R^{2}=0.91$.

\section{Conclusion}

During the trimming of Carbon Fibre Reinforced Polymers, the quality of the machined part, cost price, and productivity are directly related to cutting tool conditions. It was found in this study that a worn tool leads to high cutting forces and lower quality. Regarding the effect of cutting parameters on tool wear, it was found that a lower tool wear was measured at lower feed rates and higher cutting speeds, while a higher tool wear was measured at intermediate 
feed rates and cutting speed values. Furthermore, adhered chips and non-uniform types of flank wears were observed for all six flutes of the cutting tool. This paper also presented models developed to predict tool wear and cutting forces in high speed trimming. Various statistical tests and analyses were performed to select the best models. By taking cutting speed, feed and cutting length as independent variables in the model, results show that exponential models demonstrate better capacity to accurately predict tool wear and cutting force under the conditions studied. The exponential models present the highest coefficients of determination reached ( $98 \%$ and $93 \%$ ) for the cutting force and tool wear models, respectively, whereas they were only $91 \%$ and $85 \%$ in the case of the multiplicative models. After adding the cutting force as an independent variable in the tool wear model, results show that the enhanced multiplicative model is significantly improved and its prediction capacity exceeds that of the enhanced exponential model. The coefficient of determination of the multiplicative model is lifted from $85 \%$ to $95 \%$, whereas it remains for the exponential model.

\section{Acknowledgment}

This work was funded by the Natural Sciences and Engineering Research Council of Canada (NSERC) and the Consortium for Research and Innovation in Aerospace in Québec (CRIAQ) and its partners, MITACS, Bombardier Aerospace, Avior Integrated Products, Delastek and Av\&R Vision \& Robotics. 


\section{LIST OF BIBLIOGRAPHICAL REFERENCES}

Arola, D., M. Ramulu and D. H. Wang. 1996. " Chip formation in orthogonal trimming of graphite/epoxy composite ». Composites Part A: Applied Science and Manufacturing, vol. $27, \mathrm{n}^{\mathrm{o}} 2$, p. 121-133.

Bérubé, S., 2012. "Évaluation de la performance d'outils de coupe dédiés au détourage de structures composites carbone/époxy ». Mémoire de maîtrise. École de technologie supérieure.

Campbell, F. C. 2010. Structural composite materials. Materials Park, Ohio: ASM International.

Chatelain J-F. and I. Zaghbani. 2012. « A Comparison of Special Helical Cutter Geometries Based on Cutting Forces for the Trimming of CFRP Laminates ». NAUN International Journal of Mechanics, Vol. 6, No. 1, pp. 52-59.

Chatelain J-F., I. Zaghbani and J. Monier. 2012. «Effect of Ply Orientation on Roughness for the Trimming Process of CFRP Laminates ». World Academy of Science, Engineering and Technology, vol. 68, p. 1204-1210.

Colligan K. and M. Ramulu. 1992. «The Effect of Edge Trimming on Composite Surface Plies ». Manufacturing Review, vol. 5, nº 4, p. 274-283.

Davim, J.P. 2010. « Machining Composite Materials ». John Wiley \& Sons Inc., London, England.

Davim, J. P. and P. Reis. 2005. « Damage and dimensional precision on milling carbon fiberreinforced plastics using design experiments ». Journal of Materials Processing Technology, vol. $160, \mathrm{n}^{\circ} 2$, p. 160-167.

El-Hofy, M. H., S. L. Soo, D. K. Aspinwall, W. M. Sim, D. Pearson and P. Harden. 2011. « Factors Affecting Workpiece Surface Integrity in Slotting of CFRP ». Procedia Engineering, vol. 19, $\mathrm{n}^{\circ}$ 0, p. 94-99.

Ferreira, J. R., N. L. Coppini and G. W. A. Miranda. 1999. " Machining optimisation in carbon fibre reinforced composite materials ». Journal of Materials Processing Technology, vol. 92-93, nº, p. 135-140. 
Ghidossi, P., M. El Mansori and F. Pierron. 2004. « Edge machining effects on the failure of polymer matrix composite coupons ». Composites Part A: Applied Science and Manufacturing, vol. 35, n ${ }^{0} 7-8$, p. 989-999.

Gordon, S. and M. T. Hillery. 2003. "A review of the cutting of composite materials ». Proceedings of the Institution of Mechanical Engineers, vol. 217, ${ }^{\mathrm{o}}$ 1, p. 35-45.

Guégan, P., 1994. « Contribution à la qualification de l'usinage de matériaux composites à matrice organique ». Mémoire de doctorat. Université de Nantes.

Haiyan W., Q. Xuda, L. Hao and R. Chengzu. 2013. " Analysis of cutting forces in helical milling of carbon fiber-reinforced plastics ». Part B: Journal of Engineering Manufacture, vol.227, $\mathrm{n}^{\mathrm{o}} 1, \mathrm{p} .62-74$.

Hintze, W., D. Hartmann and C. Schütte. 2011. " Occurrence and propagation of delamination during the machining of carbon fibre reinforced plastics (CFRPs) - An experimental study ». Composites Science and Technology, vol. 71, no 15, p. 17191726.

Iliescu, D., D. Gehin, M. E. Gutierrez and F. Girot. 2010. " Modeling and tool wear in drilling of CFRP ». International Journal of Machine Tools and Manufacture, vol.50, no 2, p. 204-213.

ISO Standard 8688-2, 1989, International Standard for Tool Life Testing in End Milling, Part-2, First Edition, 1989-05-01.

Jahanmir, S. 1999. Machining of Ceramics and Composites. Marcel Dekker.

Janardhan, P., J. Sheikh-Ahmad and H. Cheraghi. 2006. « Edge trimming of CFRP with diamond interlocking tools ». Materials and Manufacturing Processes, vol. 27, no 7, p. $802-808$.

Kalla, D., J. Sheikh-Ahmad and J. Twomey. 2010. « Prediction of Cutting Forces in Helical End Milling Fiber Reinforced Polymers ». International Journal of Machine Tools \& Manufacture, vol. 50, p. 882-891.

Karpat, Y. and N. Polat. 2013. " Mechanistic force modeling for milling of carbon fiber reinforced polymers with double helix tools ». CIRP Annals - Manufacturing Technology, http://dx.doi.org/10.1016/j.cirp.2013.03.105. 
Keyence 2013. « Keyence type VHX-600+500F ».

$<$ http://www.keyence.eu/products/microscope/microscope/vhx500f/vhx500f.php>. Consulted on 8 March 2013.

Khairusshima, N., Ch. Hassan, A. Jaharah and N. Amin. 2011. « Tool wear and surface roughness on milling carbon fiber-reinforced plastic using chilled air ». Journal of Asian Scientific Research, vol. 11, n 2, p. 593-598.

Khairusshima, N., M. K., C. H. Che Hassan, A. G. Jaharah, A. K. M. Amin and A. N. Md Idriss. 2013. «Effect of chilled air on tool wear and workpiece quality during milling of carbon fibre-reinforced plastic ». In Press, Available online, Elsevier.

Kistler 2013. «Kistler type 9255b».

$<$ http://www.helmar.com.pl/helmar/biblioteka/pdf/9255b.pdf > . Consulted on 8 March 2013.

Koplev, A. 1980. "Cutting of CFRP with single edge tools ». Proceedings of the third international conference on composite materials, vol. 2, p. 1597-1605.

Koplev, A., Aa Lystrup and T. Vorm. 1983. " The cutting process, chips, and cutting forces in machining CFRP ». Composites, vol. 14, n 4, p. 371-376.

Lasri, L., M. Nouari and M. El Mansori. 2009. « Modelling of chip separation in machining unidirectional FRP composites by stiffness degradation concept ». Composites Science and Technology, vol. 69, n ${ }^{\circ}$ 5, p. 684-692.

López de Lacalle, L. N., A. Lamikiz, A. Lamikiz, F. J. Campa, A. Fdz. Valdivielso and I. Etxeberria. 2009. «Desing and Test of a Multitooth Tool for CFRP Milling ». Journal of Composite Materials, vol. 43, p. 3275-3290.

Mason, R. L., R. F. Gunst and J. L. Hess. 2003. "Statistical Design and Analysis of Experiments ». Applications to Engineering and Science, John Wiley \& Sons, Inc.

OLYMPUS 2013. « OLYMPUS».

$<$ http://www.olympus-ims.com/en/knowledge/metrology/roughness/3d_parameter/>. Consulted on 3 October 2013.

Palanikumar, K. 2007. "Modeling and analysis for surface roughness in machining glass fibre reinforced plastics using response surface methodology ». Materials \& Design, vol. $28, \mathrm{n}^{\mathrm{o}} 10$, p. $2611-2618$. 
Palanikumar, K., and J. Paulo Davim. 2007. « Mathematical model to predict tool wear on the machining of glass fibre reinforced plastic composites ». Materials \& Design, vol. $28, \mathrm{n}^{\mathrm{0}} 7$, p. 2008-2014.

Pecat, O., R. Rentsch and E. Brinksmeier. 2012. «Influence of Milling Process Parameters on the Surface Integrity of CFRP ». Procedia CIRP, vol. 1, p. 466-470.

Rajasekaran T., B. K. Vinayagam, K. Palanikumar and S. Prakash. 2010. "Influence of machining parameters on surface roughness and material removal rate in machining carbon fiber reinforced polymer material ». Frontiers in Automobile and Mechanical Engineering (FAME), vol. 1, p.75-80.

Ramulu M., Arola D. and Colligan K. (1994). «Preliminary investigation of effects on the surface integrity of fiber reinforced plastics». Engineering Systems Design and Analysis, ASME 2, vol. 64, n ${ }^{\circ}$ 2, p. 93-101.

Ramulu, M. 1999. "Characterization of surface quality in machining of composites ». Marcel Dekker, New York, NY, 1999, p. 575-648.

Sarma P., L. Karunamoorthy and K. Palanikumar. 2009. « Surface roughness parameters evaluation in machining GFRP composites by PCD tool using digital image processing ». Journal of Reinforced Plastics and Composites, vol. 1, p. 1567-1585.

Sheikh-Ahmad, J. Y. 2009. Machining of polymer composites. Springer.

Sheikh-Ahmad, J. Y., N. Urban and H. Cheraghi. 2012. " Machining Damage in Edge Trimming of CFRP ». Materials and Manufacturing Processes, vol. 27, $\mathrm{n}^{\mathrm{o}}$ 7, p. 802808.

Tounsi, N., J. Vincenti, A. Otho and M. Elbestawi. 2002. " The basic mechanics of orthogonal metal cutting toward the identification of the constitutive equation $\gg$. International Journal of Machine Tools andManufacture, vol. 42, no 12, p.13731383.

Wang, D. H., 1993. " Machining characteristics of graphite/epoxy composite ». PhD dissertation, University of Washington.

Wang, D., M. Ramulu and D. Arola. 1995. " Orthogonal cutting mechanisms of graphite/epoxy composite. Part 1: Unidirectional laminate ». Part 1: Unidirectional laminate. Int. J. Mach. Tools and Mf, vol. 35, n 12 , p. 1639-1648. 
Wang, X. Ch. Wang, R. Shi, Y. Song and Y. Hu. 2012. "Research on the Effect of Low Temperature on the Performance of Drilling Carbon Fibre Reinforced Polymer and Ti Stack Materials ». Materials Science Forum, vol. 723, n 7, p. 30-34.

Wang, X. M. and L. C. Zhang. 2003. « An experimental investigation into the orthogonal cutting of unidirectional fibre reinforced plastics ». International Journal of Machine Tools and Manufacture, vol. 43, no 10, p. 1015-1022.

Wang, X., P. Y. Kwon, C. Sturtevant, D. Kim and J. Lantrip. 2013. « Tool wear of coated drills in drilling CFRP ». Journal of Manufacturing Processes, vol. 15, $\mathrm{n}^{\mathrm{0}} 1$, p. 127135.

Wang, Y. G., X. P. Yan, X. G. Chen, C. Y. Sun and G. Liu. 2011. « Cutting Performance of Carbon Fiber Reinforced Plastics Using PCD Tool». Advanced Materials Research, vol. 215, p. 14-18.

Zaghbani I., J.F Chatelain, V. Songmene, S., Bérubé. and A. Atarsia. 2012. «A comprehensive analysis of cutting forces during detouring of multilayer CFRP laminates». Journal of composite materials, vol. 46, nº 16, p. 1955-1971. 

